\title{
High Exposure Facility Technical Description
}

\author{
GL Carter MK Murphy \\ AR Stithem AK Smith
}

February 2008 


\title{
DISCLAIMER
}

This report was prepared as an account of work sponsored by an agency of the United States Government. Neither the United States Government nor any agency thereof, nor Battelle Memorial Institute, nor any of their employees, makes any warranty, express or implied, or assumes any legal liability or responsibility for the accuracy, completeness, or usefulness of any information, apparatus, product, or process disclosed, or represents that its use would not infringe privately owned rights. Reference herein to any specific commercial product, process, or service by trade name, trademark, manufacturer, or otherwise does not necessarily constitute or imply its endorsement, recommendation, or favoring by the United States Government or any agency thereof, or Battelle Memorial Institute. The views and opinions of authors expressed herein do not necessarily state or reflect those of the United States Government or any agency thereof.

\author{
PACIFIC NORTHWEST NATIONAL LABORATORY \\ operated by \\ BATTELLE \\ for the \\ UNITED STATES DEPARTMENT OF ENERGY \\ under Contract DE-AC05-76RL01830
}

Printed in the United States of America

Available to DOE and DOE contractors from the

Office of Scientific and Technical Information,

P.O. Box 62, Oak Ridge, TN 37831-0062;

ph: (865) 576-8401

fax: (865) 576-5728

email: reports@adonis.osti.gov

\footnotetext{
Available to the public from the National Technical Information Service, U.S. Department of Commerce, 5285 Port Royal Rd., Springfield, VA 22161 ph: (800) 553-6847 fax: (703) 605-6900 email: orders@ntis.fedworld.gov

online ordering: http://www.ntis.gov/ordering.htm
} 
PNNL-17320

\title{
High Exposure Facility Technical Description
}

\author{
G. L. Carter \\ A. R. Stithem \\ M. K. Murphy \\ A. K. Smith
}

February 2008

Prepared for

the U.S. Department of Energy

under Contract DE-AC05-76RL01830

Pacific Northwest National Laboratory

Richland, Washington 99352 



\section{Executive Summary}

This report documents the methodology behind the design of the High Exposure Facility collimated gamma irradiator, located in Building 318 of the 300 Area on the Hanford Site. The report is intended for personnel with the appropriate technical background for the purpose of maintaining the facility. Details of this report are focused upon the mechanical, electrical and software design aspects. 



\section{Contents}

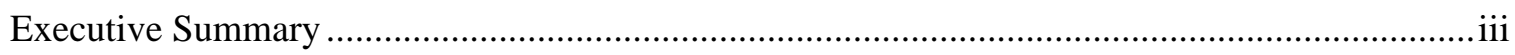

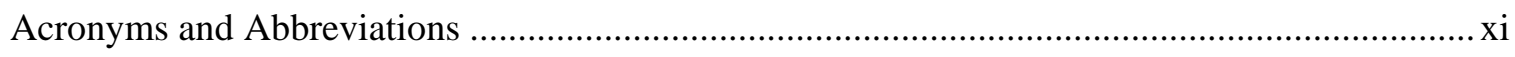

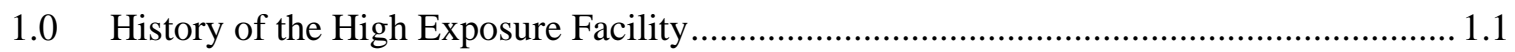

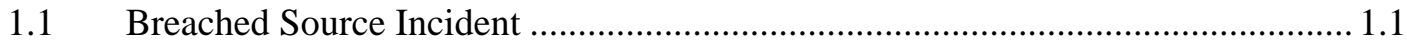

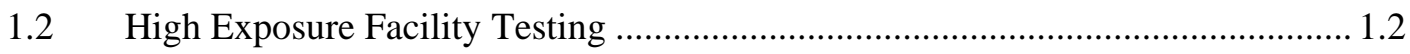

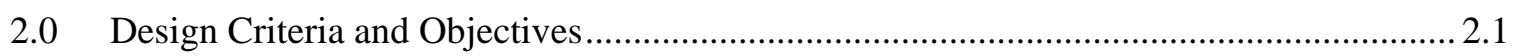

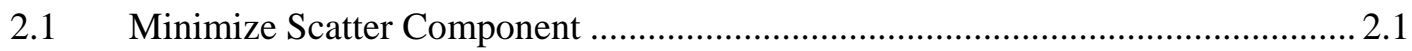

2.2 Minimize Exposure to Control Room and X-Ray Facilities ................................. 2.1

2.3 Minimize Background When Sources Are Stored ................................................ 2.1

2.4 Minimize Radiation Damage to Components ................................................... 2.1

2.5 Desired Exposure Rate Range........................................................................... 2.1

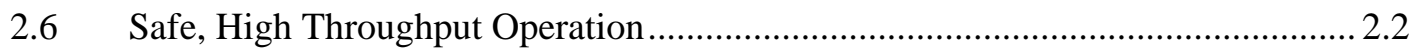

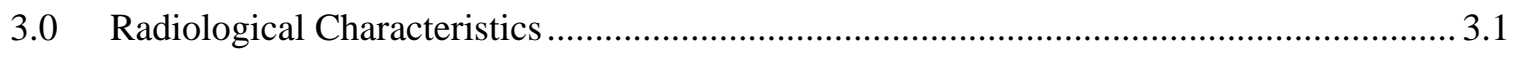

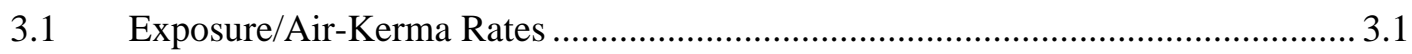

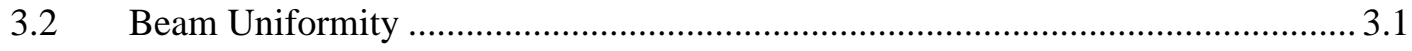

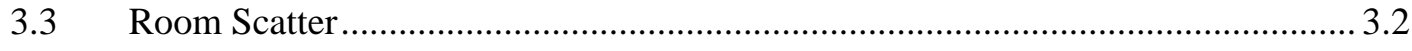

3.4 Establishing Charged-Particle Equilibrium Conditions ........................................ 3.2

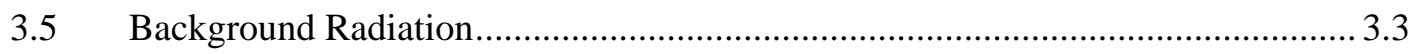

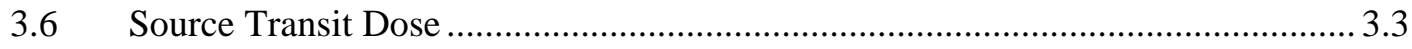

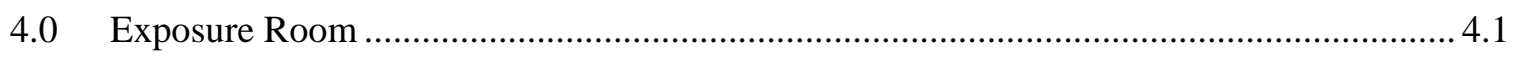

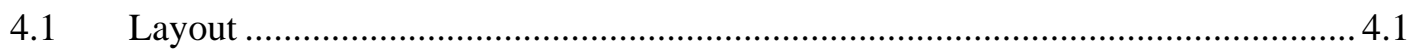

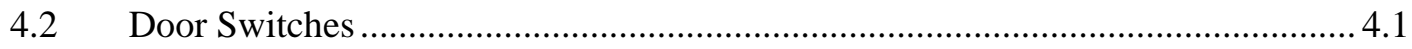

$4.3 \quad$ Emergency Stop Buttons............................................................................... 4.1

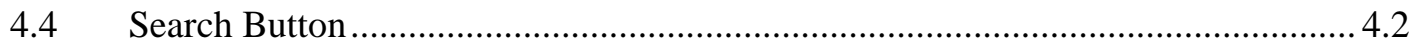

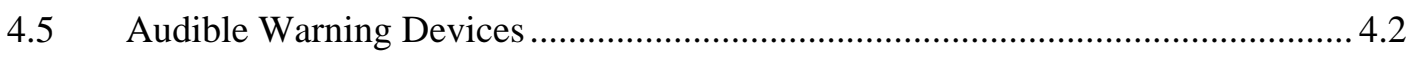

4.6 Radiation Warning Lights .............................................................................. 4.2

4.7 Area Radiation Monitor Detector and Remote Indicator ..................................... 4.2

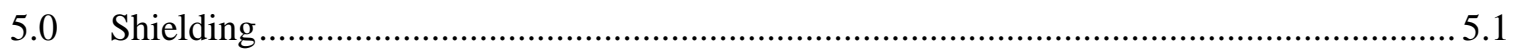

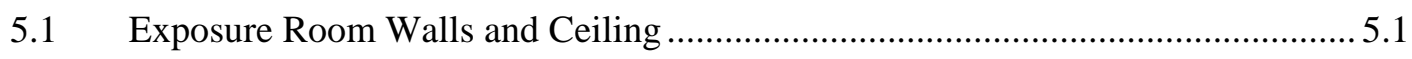

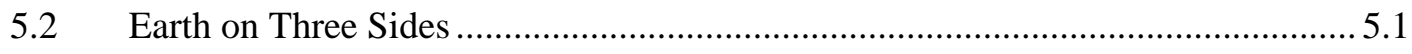

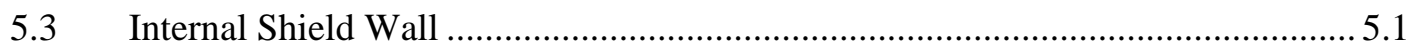

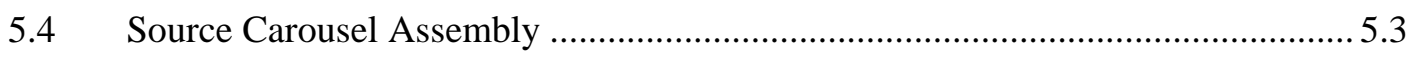

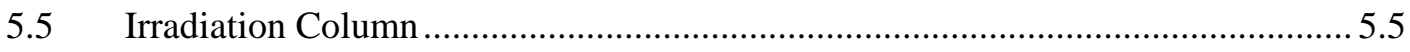

5.6 Irradiation Column Shield Plug ……................................................................ 5.6

5.7 Effect of Lead Cold Flow.................................................................................. 5.6 


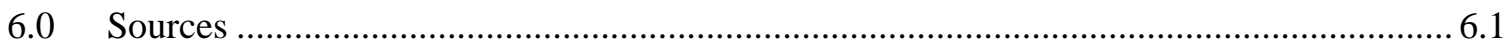

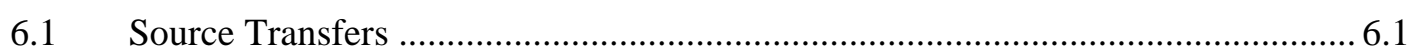

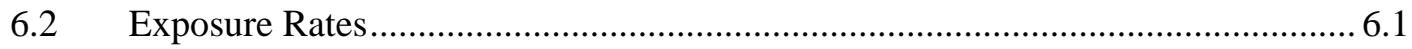

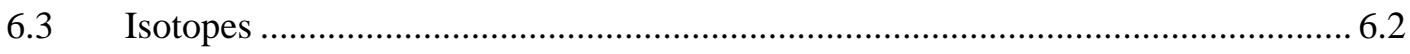

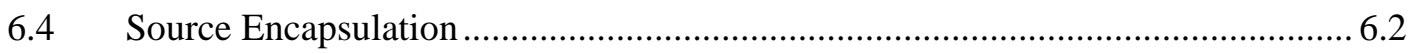

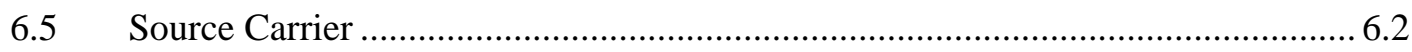

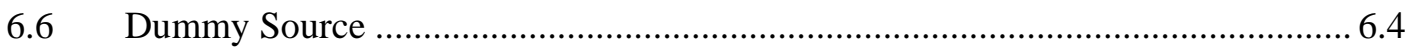

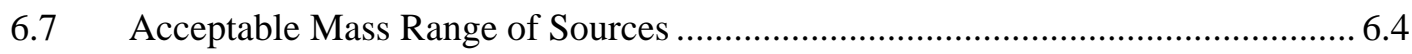

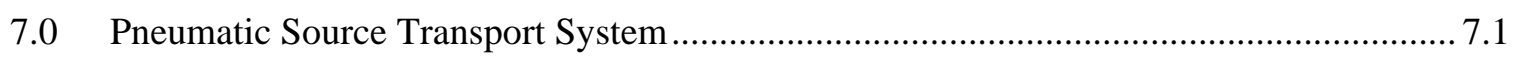

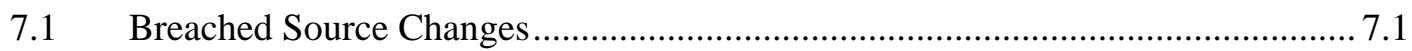

7.2 Pneumatic System Sequence of Operation........................................................ 7.2

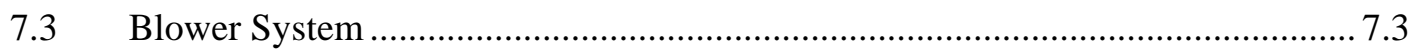

7.3.1 Regenerative Blower.......................................................................... 7.4

7.3.2 Blower Variable Frequency Drive ................................................... 7.4

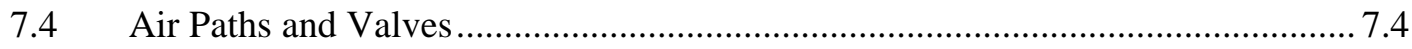

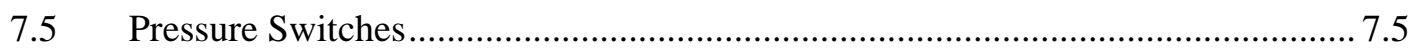

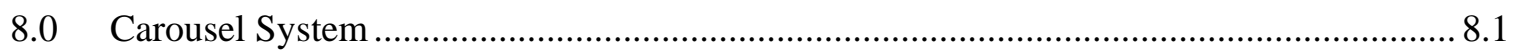

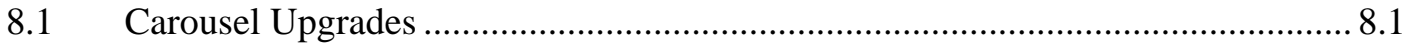

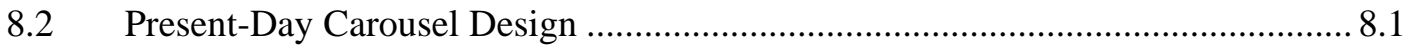

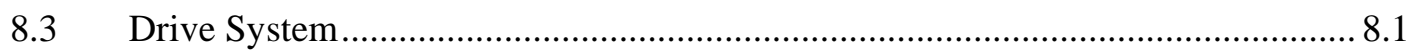

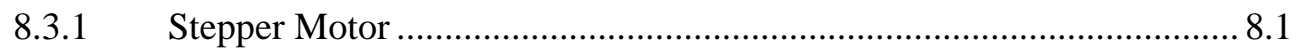

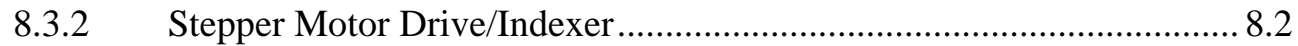

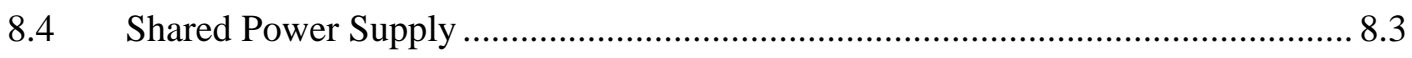

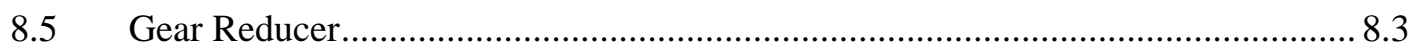

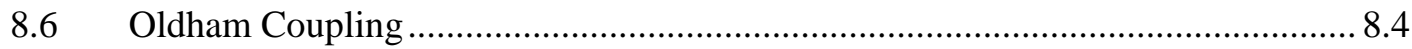

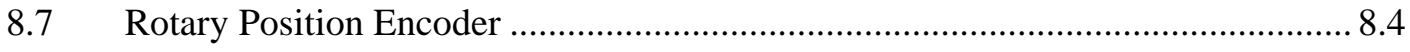

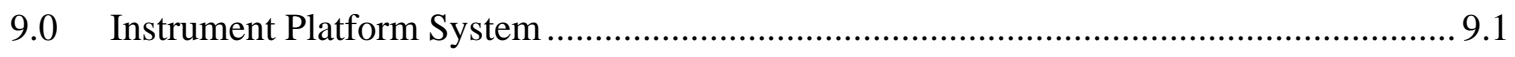

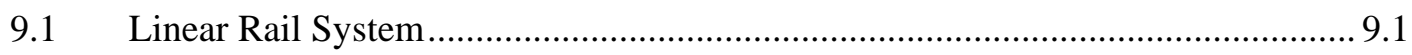

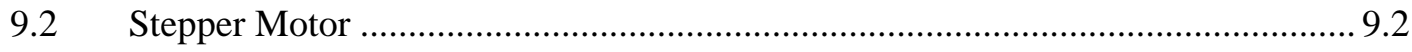

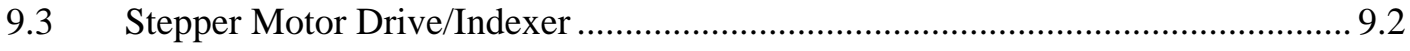

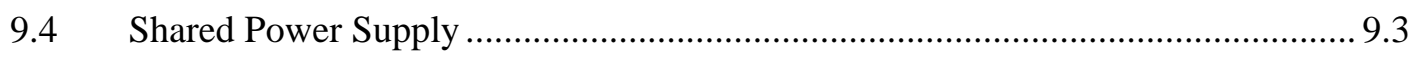

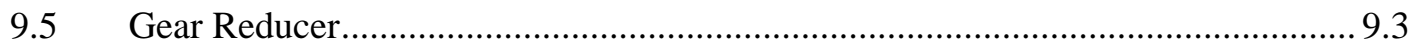

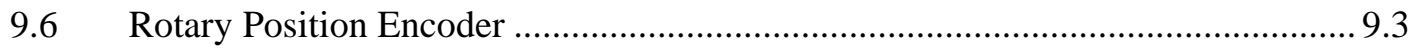

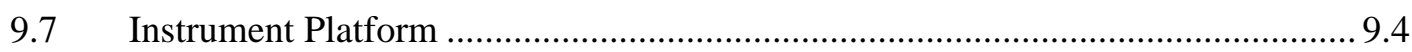

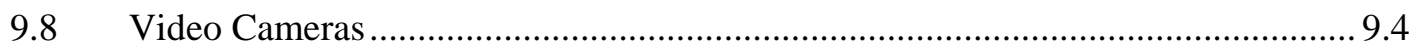

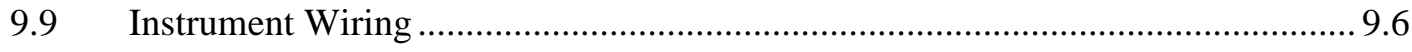

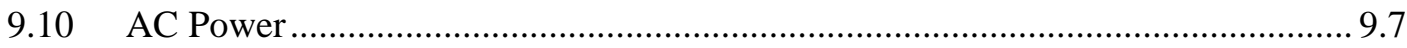

10.0 Supplementary Physical Components of the HEF...................................................... 10.1 


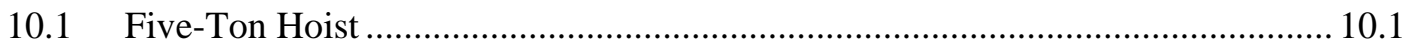

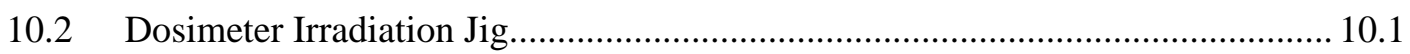

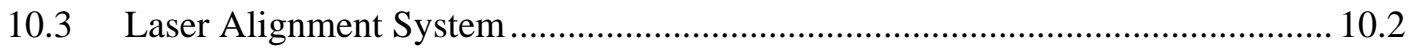

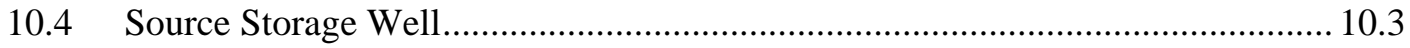

10.5 Quality Control Measurement Systems............................................................ 10.6

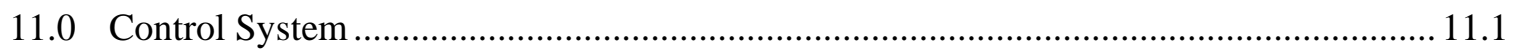

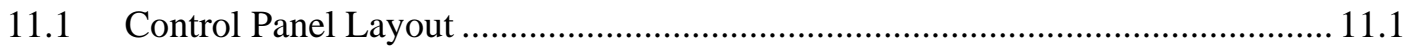

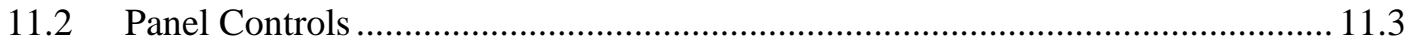

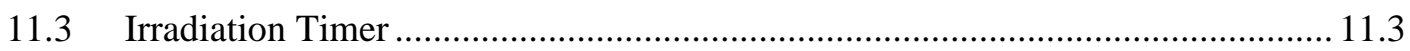

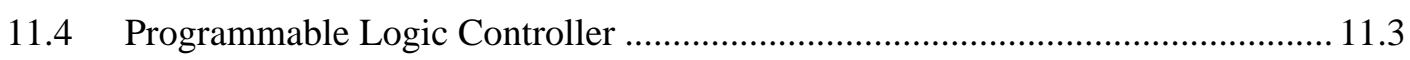

11.4.1 Central Processing Unit Module ........................................................ 11.4

11.4.2 Input/Output Modules.............................................................. 11.4

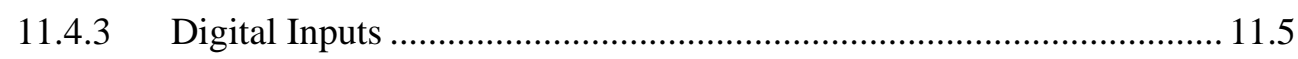

11.4.4 Digital Outputs......................................................................... 11.5

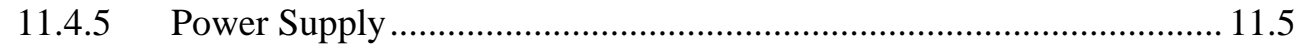

11.4.6 Program Development System .................................................... 11.5

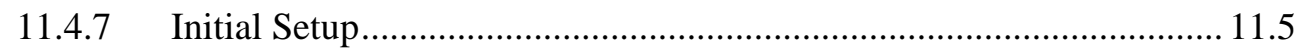

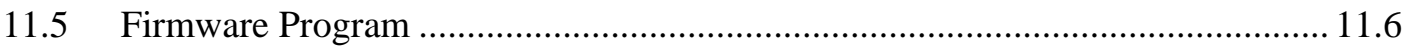

11.5.1 Design Objectives ....................................................................... 11.7

11.5.2 Program Block Descriptions...................................................... 11.7

11.5.3 Relay Ladder Logic Programming................................................... 11.8

11.6 Radiation Warning Light Control Circuit ...................................................... 11.14

11.7 Radiation Warning Light Monitor Circuit ................................................... 11.14

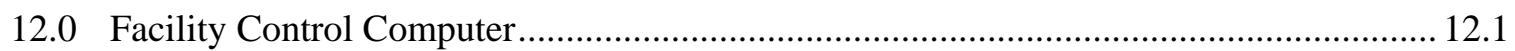

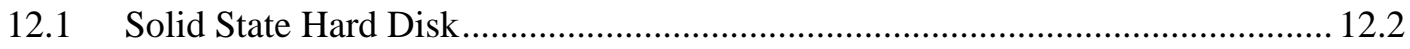

12.2 Facility Control Computer and Programmable Logic Control Interface .............. 12.3

12.3 Instrument Platform Control Interface .............................................................. 12.3

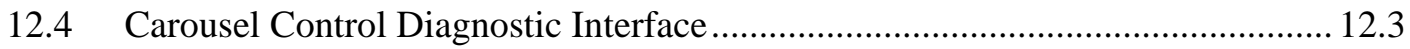

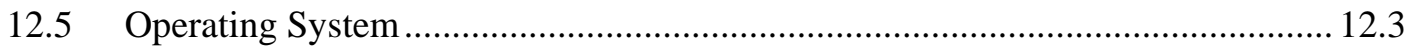

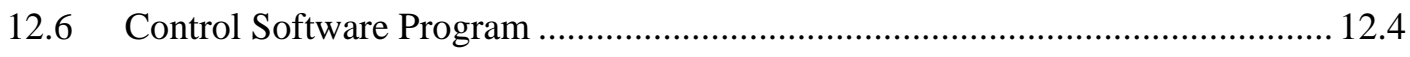

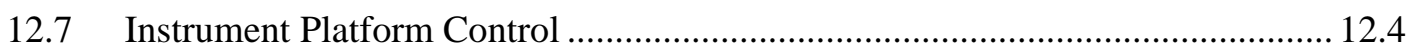

12.8 Manipulating the Programmable Logic Controller ............................................. 12.4

12.9 Exposure Rate Versus Distance Algorithms ..................................................... 12.5

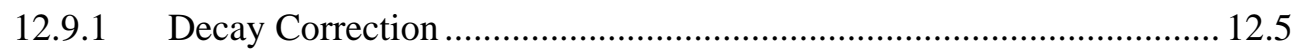

12.9.2 Temperature and Pressure Correction................................................. 12.6

12.10 Automated Instrument Calibration Routines...................................................... 12.6

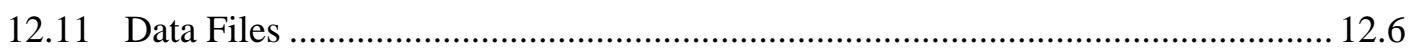

12.12 Diagnostic Software Programs....................................................................... 12.6 


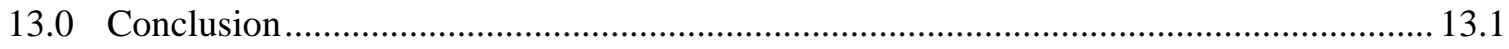

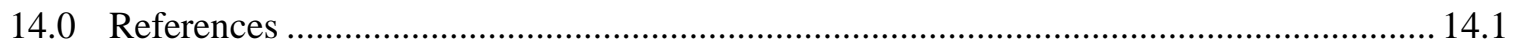

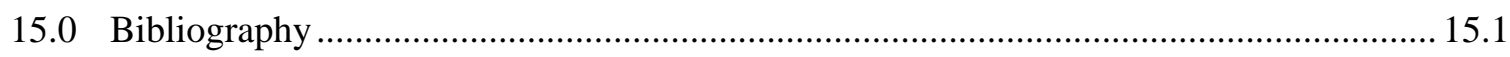

Appendix A - Firmware Programming ............................................................................. A.1

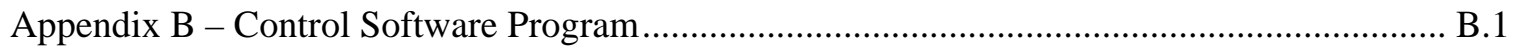

Appendix C - Diagnostic Software Programs …...................................................................... C.1 


\section{Figures}

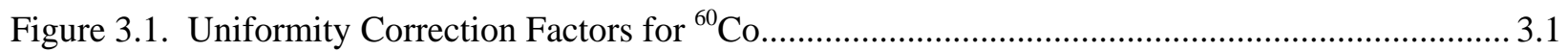

Figure 3.2. Room Scatter Measurements for ${ }^{137} \mathrm{Cs}$........................................................................ 3.2

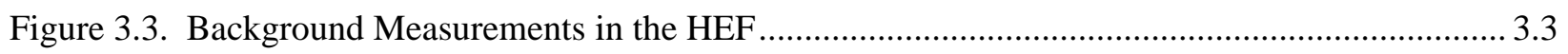

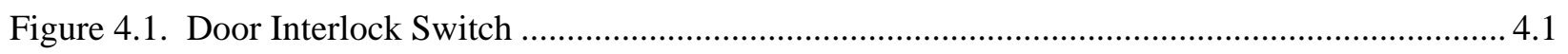

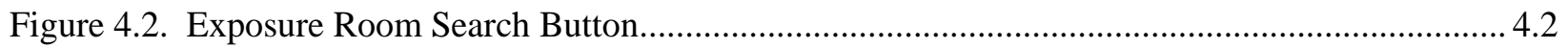

Figure 4.3. Area Radiation Monitor Remote Detector, Area Radiation Monitor Remote Indicator and Emergency Stop Button ........................................................................... 4.3

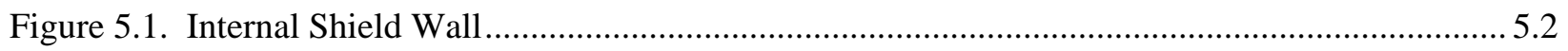

Figure 5.2. Doorway to Exposure Room ................................................................................... 5.2

Figure 5.3. (a) Photobeam Sensor and (b) Photobeam Reflector......................................................... 5.3

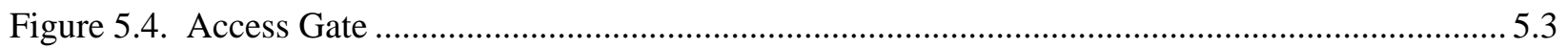

Figure 5.5. Source Carousel Assembly …............................................................................................ 5.4

Figure 5.6. Source Carousel.......................................................................................................... 5.4

Figure 5.7. Pit Showing Lead Brick Installation................................................................................. 5.4

Figure 5.8. Pit Showing Contamination Control Pan.......................................................................... 5.5

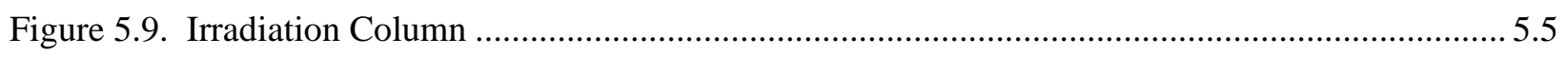

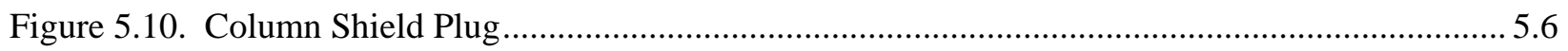

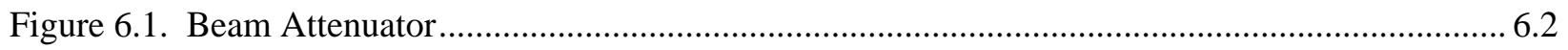

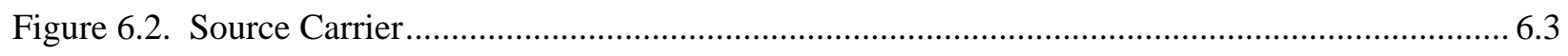

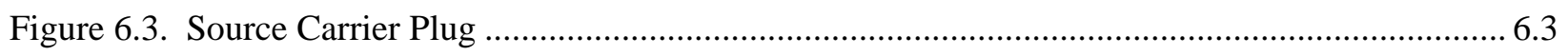

Figure 7.1. Column Base ............................................................................................................... 7.3

Figure 7.2. Source Blower and Solenoid Valve Control Enclosure...................................................... 7.3

Figure 7.3. Source Blower and Solenoid Valve Control Panel............................................................... 7.4

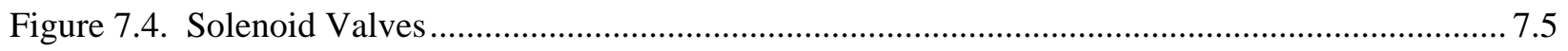

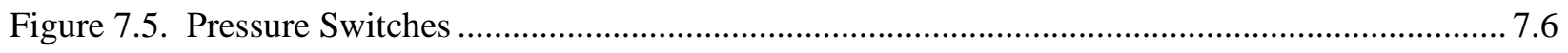

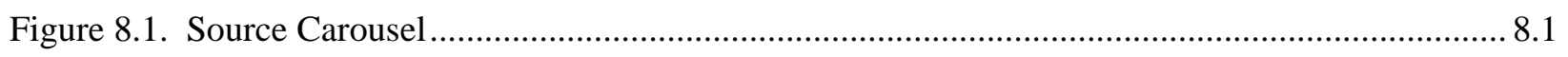

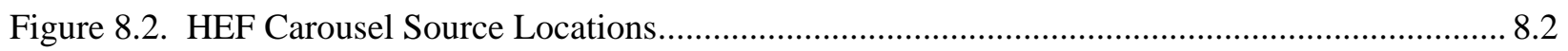

Figure 8.3. Carousel Drive Stepper Motor and Gear Reducer ................................................................ 8.4

Figure 8.4. Carousel Drive Assembly Showing Rotary Position Encoder and

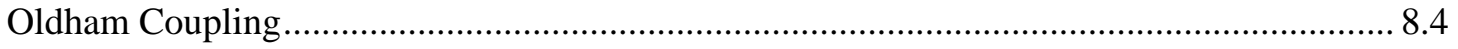

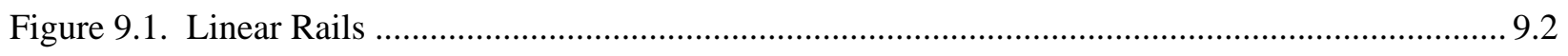

Figure 9.2. Instrument Platform Stepper Motor and Gear Reducer .................................................... 9.2

Figure 9.3. Stepper Motor Drive/Indexers and Shared Power Supply (enclosure removed) .................... 9.3

Figure 9.4. Stepper Motor Controllers and Rotary Position Encoder ..................................................... 9.4

Figure 9.5. Instrument Platform showing Exposure Room Video Monitor............................................ 9.5

Figure 9.6. Instrument Platform and Exposure Room Video Cameras.................................................. 9.5 


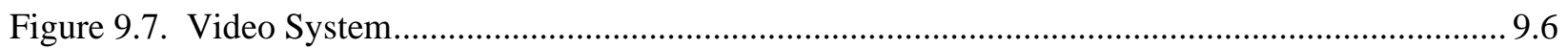

Figure 9.8. Remote Instrument Connections at Instrument Platform ..................................................... 9.6

Figure 9.9. Remote Instrument Connections at Control Panel................................................................. 9.7

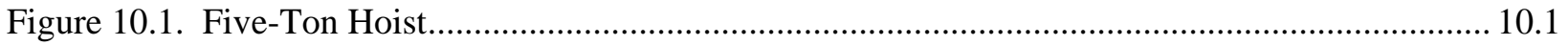

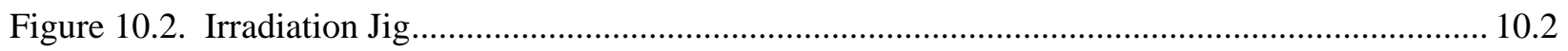

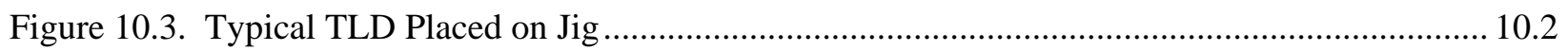

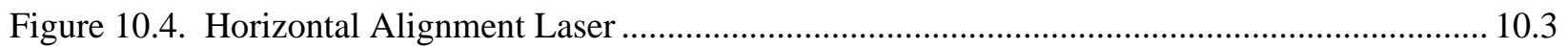

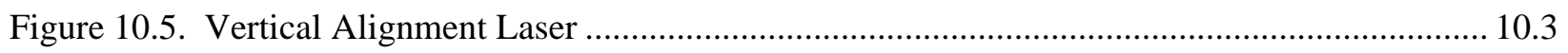

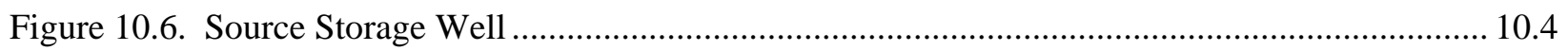

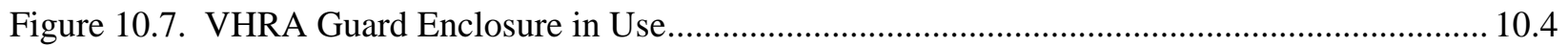

Figure 10.8. Graphic of Source Storage Transfer ............................................................................. 10.5

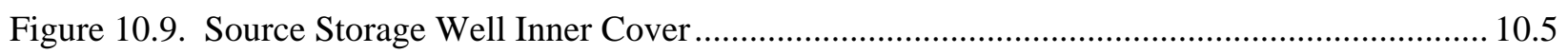

Figure 10.10. Source Storage Well Carbon Steel Shield Plug ......................................................... 10.6

Figure 10.11. Quality Control Measurement System......................................................................... 10.6

Figure 11.1. Source Control Panel ............................................................................................... 11.1

Figure 11.2. Rear Wiring of Source Control Panel....................................................................... 11.2

Figure 11.3. PLC and Associated Components. (1) CPU; (2) digital input model \#1;

(3) digital output module \#1; (4) digital input module \#2; (5) digital output module \#2; (6) toggle switch input module. .................................................................. 11.4

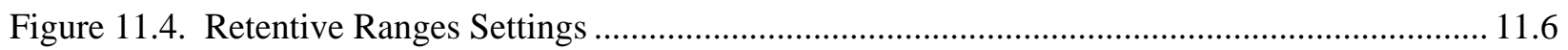

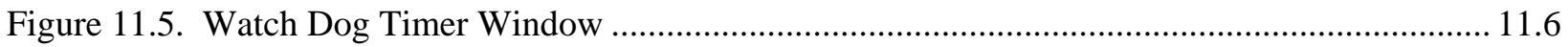

Figure 11.6. HEF Firmware Block Diagram.................................................................................. 11.8

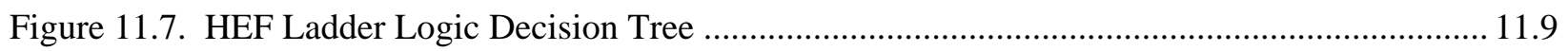

Figure 11.8. DirectSOFT32 Setup Communication Ports Window ................................................... 11.10

Figure 11.9. Radiation Warning Light Relay and Current Actuated Switch ..................................... 11.14

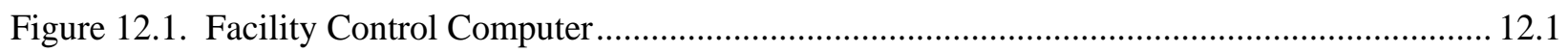

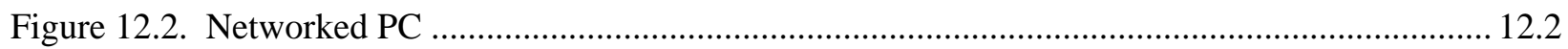

\section{Tables}

Table 8.1. Absolute Encoder Positions for the Various Source Positions ................................................ 8.3

Table 8.2. Configuration of the Carousel Drive..................................................................................... 8.3

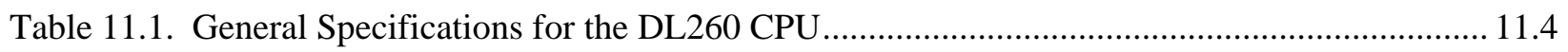

Table 11.2. Firmware File Functions ................................................................................................ 11.7

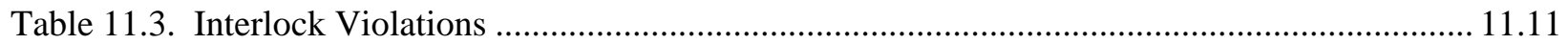

Table 12.1. BIOS Configuration of the Solid-State Hard Disc ............................................................. 12.3 


\section{Acronyms and Abbreviations}

$\begin{array}{ll}\text { ANSI } & \text { American National Standards Institute } \\ \text { ASCII } & \text { American Standard Code for Information Interchange } \\ \text { BCD } & \text { Binary Coded Decimal } \\ \text { BIOS } & \text { Basic Input Output System } \\ \text { CPE } & \text { Charged Particle Equilibrium } \\ \text { CPU } & \text { Central Processing Unit } \\ \text { DIN } & \text { Deutsches Institut für Normung } \\ \text { DOE } & \text { Department of Energy } \\ \text { DOS } & \text { Disk Operating System } \\ \text { HEF } & \text { High Exposure Facility } \\ \text { Hex } & \text { Hexadecimal } \\ \text { IBM } & \text { International Business Machines } \\ \text { IDE } & \text { Integrated Development Environment } \\ \text { ISA } & \text { Industry Standard Architecture } \\ \text { MB } & \text { Megabyte } \\ \text { NEMA } & \text { National Electrical Manufacturers Association } \\ \text { PC } & \text { Personal Computer } \\ \text { PIC } & \text { Pressurized Ion Chamber } \\ \text { PLC } & \text { Programmable Logic Controller } \\ \text { PNNL } & \text { Pacific Northwest National Laboratory } \\ \text { RAM } & \text { Random Access Memory } \\ \text { TLD } & \text { Thermoluminescent Dosimeter } \\ \text { VFD } & \text { Variable Frequency Drive } \\ \text { VHRA } & \text { Very High Radiation Area }\end{array}$





\subsection{History of the High Exposure Facility}

Building 318, located in the 300 Area, houses the radiological calibrations laboratory operated by Pacific Northwest National Laboratory (PNNL). This building consists primarily of offices, laboratories, and storage areas, and was originally constructed to house a high-temperature lattice test reactor (which operated from 1968 to 1972). The reactor and associated equipment were removed from the building between 1978 and 1982. The building shell and the related building services were subsequently reconfigured for use as part of the current radiological calibrations laboratory. Calibration services and related equipment were moved to Building 318 from Building 3745 in 1983. In that same year, installation of a collimated gamma irradiator named the High Exposure Facility (HEF) began in room 8, located in Building 318's former reactor room basement.

Building 318 has retained its classification as a radiological facility, based on the Hazard Category 3 threshold values defined by DOE-STD-1027-92. Operational limits and controls for this facility are defined in its facility use agreement, which specifically limits the quantity and form of radiological material to less than DOE-STD-1027-92 Hazard Category 3 material. Included in the radiological material inventory of this facility are a number of sealed sources that meet inventory-exclusion criteria (in DOE-STD-1027-92) for hazard categorization.

The HEF and associated equipment incorporate redundant safety features, remote monitoring equipment, and interlocks to protect personnel from inadvertent radiation exposure. Room 8 also contains a source storage well located in the floor near the HEF. The source storage well, separate from the HEF, is normally used to store sources or source carriers from the HEF during the maintenance of or modifications to the HEF.

The HEF was designed by PNNL engineering staff to meet the requirements of ANSI N543-1974 in support of the Radiological Instrument Calibration Program on the Hanford Site. Fabrication of individual components was performed by several off-site vendors, and the installation of these components was accomplished by PNNL bargaining-unit crafts. The irradiator had to fit inside the existing space of room 8 , and had to minimize scattered radiation and cover a range of $10 \mathrm{R} / \mathrm{h}$ to $20 \mathrm{kR} / \mathrm{h}$. (At that time, no commercially available irradiator could provide this exposure rate range.) Finally, it had to be designed to minimize exposure to the adjacent $\mathrm{X}$-ray exposure room, the surrounding facilities, and the personnel inside and outside the building.

\subsection{Breached Source Incident}

The HEF was removed from service in July 2005 due to a leaking ${ }^{60}$ Co source. As a result of the leaking source, several pneumatic system changes occurred. The facility was disassembled and decontaminated, and several changes to the pneumatic system followed. In August 2006, the HEF was reassembled, tested, and returned to service with a ${ }^{60} \mathrm{Co}$ source installed. Following that, 3 low-activity

${ }^{137}$ Cs sources were installed in October 2006, and a second ${ }^{60}$ Co source was loaded in June 2007. Finally, $2{ }^{137}$ Cs sources were installed in the facility in September 2007. 


\subsection{High Exposure Facility Testing}

The HEF is used to calibrate gamma cameras, accident- and low-level instruments, and photon dose and photon dose rate instruments. The HEF also subjects other instruments to gamma radiation to test for gamma interference. For instance, it can be used to test neutron detectors for any undesirable response to gamma radiation.

In addition to instrument calibration, the HEF tests many objects, including:

- fruit (particularly apples) to demonstrate food irradiation

- plant seeds, to influence plant (specifically, flower) color

- specimens for medical purposes

- electronics, from components to systems, to test for radiation hardness. 


\subsection{Design Criteria and Objectives}

As a result of the inherent hazards related to the HEF sources, several design objectives were established to create a safe working environment.

\subsection{Minimize Scatter Component}

The radiation beam of the HEF has been collimated to minimize the volume of air excited by the beam. This minimizes air scatter within the beam, and reduces the background levels outside of the beam. For instance, when the beam reads $60,000 \mathrm{R} / \mathrm{hr}$, radiation detectors outside the beam detect radiation levels around $4 \mathrm{R} / \mathrm{hr}$. Because the beam is collimated, beam intersections with the walls and floor are also minimized—further reducing the scattered radiation from these surfaces.

\subsection{Minimize Exposure to Control Room and X-Ray Facilities}

The HEF minimizes the exposure to its control room and other facilities. The collimated radiation beam strikes an exterior, sub-grade wall, then penetrates the ground surrounding the basement. The control room is directly behind the beam port, and the X-ray facilities are to the side of the beam. Highdensity concrete walls protect the HEF control room and the X-ray facilities from direct exposure to the sources and indirect exposure from backscatter.

\subsection{Minimize Background When Sources Are Stored}

Surrounding the source carousel assembly are 7 layers of 2-in. thick lead bricks to shield the exposure room from direct radiation when the sources are stored in the carousel. Also, the gaps between adjacent lead bricks have been minimized and staggered to minimize radiation streaming into the exposure room from the source carousel.

\subsection{Minimize Radiation Damage to Components}

Radiation damage to HEF components and auxiliary equipment is minimized by placing the electronic equipment and controls, like the emergency stop switches within the exposure room, outside of the area of the primary beam.

\subsection{Desired Exposure Rate Range}

In 1982, the HEF was designed to accommodate exposures of less than $10 \mathrm{R} / \mathrm{hr}$ to accident-range instruments, which are typically calibrated to $10,000 \mathrm{R} / \mathrm{hr}$. These instruments were required to be tested at double their usable range, so the HEF had to provide exposures of up to 20,000 R/hr. After the terrorist attacks of 9/11, testing the Department of Homeland Security's instruments necessitated an addition of several smaller sources to reduce the exposure rate levels to about $6 \mu \mathrm{R} / \mathrm{hr}$ above background. 


\subsection{Safe, High Throughput Operation}

The HEF is intended to support the calibration and exposure of large volumes of instruments and dosimeters. Its design is intended to maximize throughput by reducing the number of steps required to set up and take down irradiations, and to reduce the time required to cycle the facility. Additionally, the facility was designed with redundant protection features, so personnel and facilities remain safe from irradiation. 


\subsection{Radiological Characteristics}

Since the installation of any irradiator is unique to that irradiator, the radiological characteristics of each irradiator are also unique. These characteristics were determined by measurements completed after the irradiator was installed.

\subsection{Exposure/Air-Kerma Rates}

The parameter most used for calibrations, and which can be referenced to a National/Primary standard, involves the exposure or air-kerma rate of each HEF source. These values are measured for each source and at various distances using an ionization chamber that has been calibrated to a National Institute of Standards and Technology primary standard source. Calibrations are typically quoted in units of Roentgen per unit time (e.g., R/h) relative to $736 \mathrm{mg} / \mathrm{cm}^{2}$ depth in air-equivalent plastic, but can also be converted to air-kerma or absorbed dose rate. The range of exposure rates for the HEF is about $15 \mu \mathrm{R} / \mathrm{h}$ to almost $100,000 \mathrm{R} / \mathrm{h}$.

\subsection{Beam Uniformity}

The uniformity of the exposure rate for the HEF beams for a plane perpendicular to the beam axis, has been measured to be within $\pm 4 \%$ for a 30 - $\mathrm{cm}$ diameter circle relative to beam center at 100 -cm source distance. This uniformity of course improves as the source distance increases (see Figure 3.1).

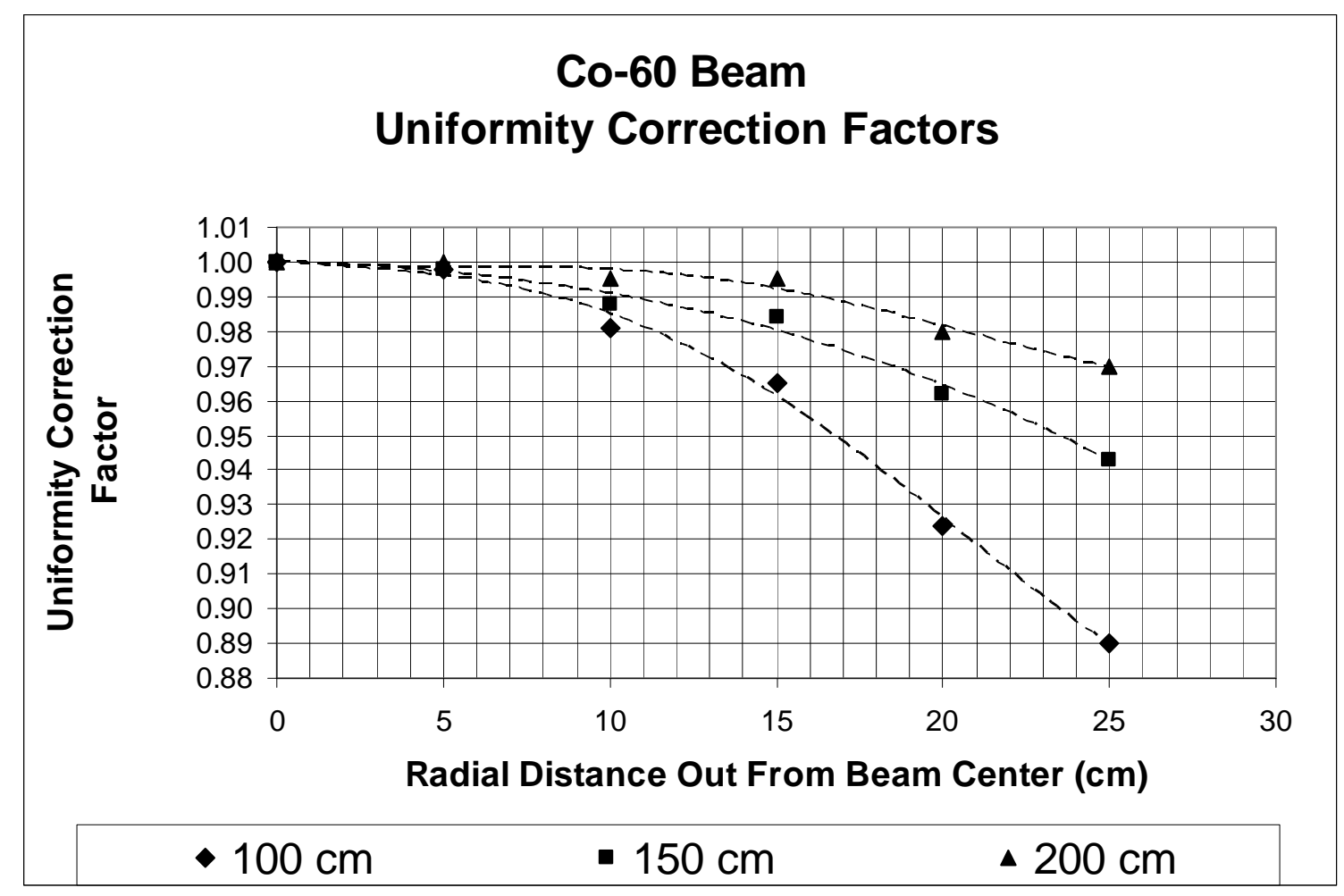

Figure 3.1. Uniformity Correction Factors for ${ }^{60} \mathrm{Co}$ 


\subsection{Room Scatter}

The percentage of the exposure rate that is due to the scatter off of the walls, ceiling, and floor of the room (i.e., not due to the primary uncollided beam) has been measured to vary between about $0.4 \%$ and $7.5 \%$ as the distance increases from $100 \mathrm{~cm}$ to $550 \mathrm{~cm}$ (see Figure 3.2). These values are relative to an ionization chamber response (which has a relatively flat energy response), and depend slightly upon the wall thickness of the chamber in use. Detectors with a relatively steep energy dependence curve around ${ }^{137} \mathrm{Cs}$ and/or ${ }^{60} \mathrm{Co}$ energies (e.g., scintillators or Geiger-Mueller counters) would likely show much higher responses to this energy-degraded room return.

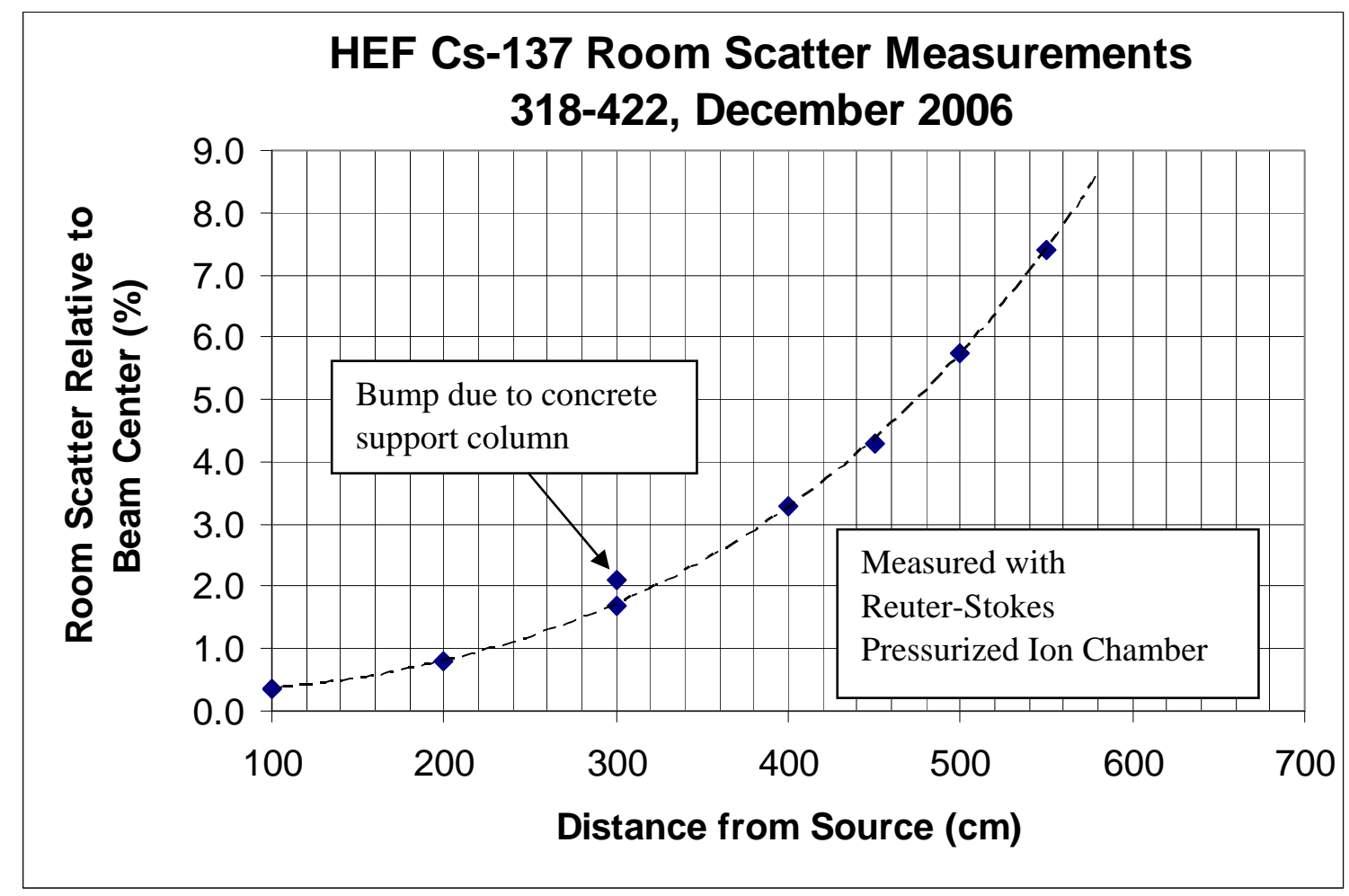

Figure 3.2. Room Scatter Measurements for ${ }^{137} \mathrm{Cs}$

\subsection{Establishing Charged-Particle Equilibrium Conditions}

Measuring radiation quantities accurately —and therefore being able to accurately state the dose delivered to objects-partially depends upon whether charged-particle equilibrium (CPE) exists for the radiation beam. Simply stated, CPE is achieved when the same number of electrons that are set in motion (in a given sample volume) come to rest in that same sample volume. For energies below approximately $250 \mathrm{keV}$, and for source distances on the order of $1 \mathrm{~m}$, the amount of air traversed is sufficient to provide CPE within the sample volume (e.g., a dosimeter's or ionization chamber's sensitive volume). However, for energies above $250 \mathrm{keV}$, coupled with detection devices that have insufficient build-up materials surrounding the detector volume (e.g., detectors used in the measurement of non-penetrating radiation), additional build-up material appropriate to the detection device may need to be placed in the beam to achieve CPE. For example, for the gamma-ray photons associated with ${ }^{137} \mathrm{Cs}(662 \mathrm{keV})$ and ${ }^{60} \mathrm{Co}$ 
(1250 keV) at distances $1 \mathrm{~m}$ to $3 \mathrm{~m}$, Lucite plate thicknesses required to achieve CPE are approximately $2 \mathrm{~mm}$ and $4 \mathrm{~mm}$, respectively. Such CPE conditions can be verified by comparing the response ratio of a detector with both $7 \mathrm{mg} / \mathrm{cm}^{2}$ (shallow dose) and $1000 \mathrm{mg} / \mathrm{cm}^{2}$ (deep dose) areal density buildup.

Guidance on establishing CPE conditions for gamma-ray beams like those present in the HEF can be found in ISO 4037-3 (1999).

\subsection{Background Radiation}

The radiation background in the HEF has been measured to vary between approximately $12 \mu \mathrm{R} / \mathrm{h}$ and $9.7 \mu \mathrm{R} / \mathrm{h}$ (Figure 3.3) for distances of $100 \mathrm{~cm}$ and $600 \mathrm{~cm}$ from the HEF irradiation column, respectively, due to the sources stored in the carousel assembly. Additionally, this background can increase by as much as $28 \mu \mathrm{R} / \mathrm{h}$ when high activity sources in adjacent facilities are in use.

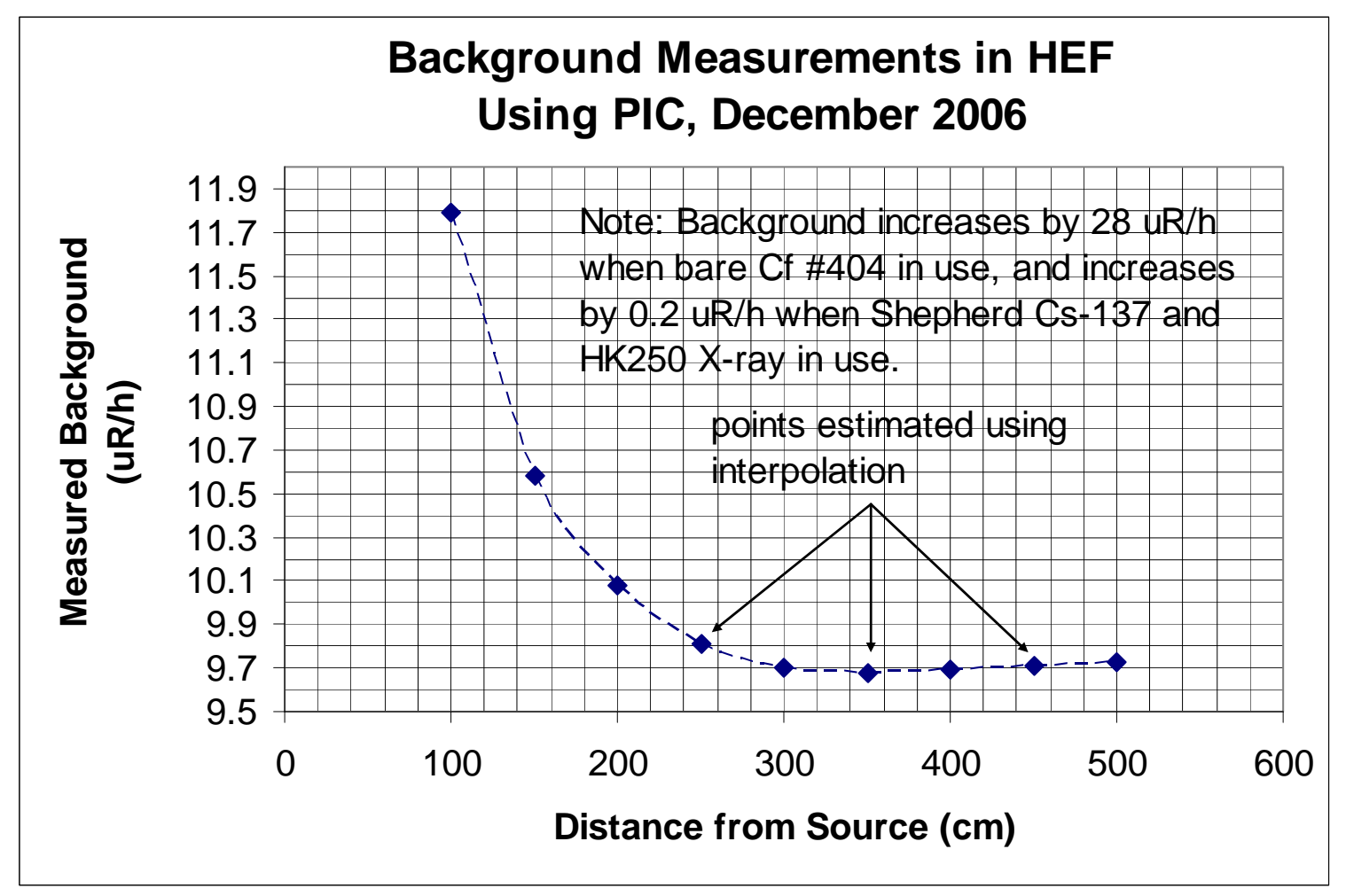

Figure 3.3. Background Measurements in the HEF

\subsection{Source Transit Dose}

The exposure of artifacts to an integrated quantity (e.g., exposure/air-kerma) is timed by the HEF system timer. Ideally, the timed exposure would translate to the instantaneous creation and cessation of the radiation field (or the insertion or removal of the artifact from the radiation field). Generally, however, there is an expected offset (usually an upward shift) to the intended delivered quantity, because of the transit of the source to the irradiation position at the beginning of the exposure, and the return to storage of the source at termination. It is also possible that the mechanism of the timing feature could induce a positive or negative offset, because of the programming that triggers the actual timing (coupled 
with the corresponding true position of the source). The ideal timer configuration includes starting the timer when the source begins exposure of the artifact and removing the source when the exposure time limit has been reached. Unfortunately, this cannot be easily accomplished with absolute certainty.

To maximize accuracy and/or to properly characterize the uncertainty of the delivered quantity, it is important to understand the net systematic offset resulting from the source transit and timing influences. Measurements were conducted to assess this influence via the use of a comparison of short, timed exposures and longer steady state exposures of an ionization chamber. The source assessed was 318-464; the smaller of the two ${ }^{60} \mathrm{Co}$ sources. It was found that the timed exposures imposed a slight deficit in the anticipated exposure/air-kerma. This shortfall most likely stems from the timer beginning its count prior to the source fully reaching the exposure position. The influence is translated as negative time per source transit, and the estimated parameter is $-0.87 \pm 0.35 \mathrm{~s} /$ transit. For instance, a 1.00 -min exposure would actually translate to $0.986 \mathrm{~min}$, or a shortfall of $1.5 \%$ in the desired delivered quantity.

It should be noted that because of individual source characteristics (e.g., construction, weight, and so forth), the associated transit influence may differ for each source. In addition, possible long-term variations of the source transport system and/or wear of the source encapsulation could lead to changes in transit influence - even for individual sources over time. For the present time, the above-indicated influence is assumed to be applicable to all sources. 


\subsection{Exposure Room}

The exposure room was designed with a range of safety features for personnel, minimizing any risk associated with operating the HEF. These safety features include door switches, emergency stop buttons, an audible warning device, radiation warning lights, a radiation detector, and a remote indicator.

\subsection{Layout}

To prevent the beam from intersecting a concrete support column, which would result in increased scatter radiation, the centerline of the irradiation column's beam port is offset from the centerline of the exposure room by 17 in. To compensate for the offset (so that the radiation beam cross-section strikes the rear wall in the center of the wall), the irradiation column beam port axis is at a 3.2-degree angle relative to perpendicular to the rear wall. This geometry causes the radiation beam to be asymmetrical relative to the exposure room. To view the HEF floorplan (as well as other HEF systems and assemblies), refer to PNNL’s Facilities \& Operations Document Center.

\subsection{Door Switches}

On the door between the control and exposure rooms, the HEF uses a door interlock (Figure 4.1) to prevent personnel from entering the exposure room when an irradiation is in progress. The interlock consists of two independent door switches wired to detect when the door is opened. If either switch detects that the door has been opened, an alarm sounds, the source is lowered out of the irradiation position, and the door open warning indicator on the control panel illuminates. Prior to operating the system, both switches must signal to the programmable logic controller (PLC) that the door is closed.

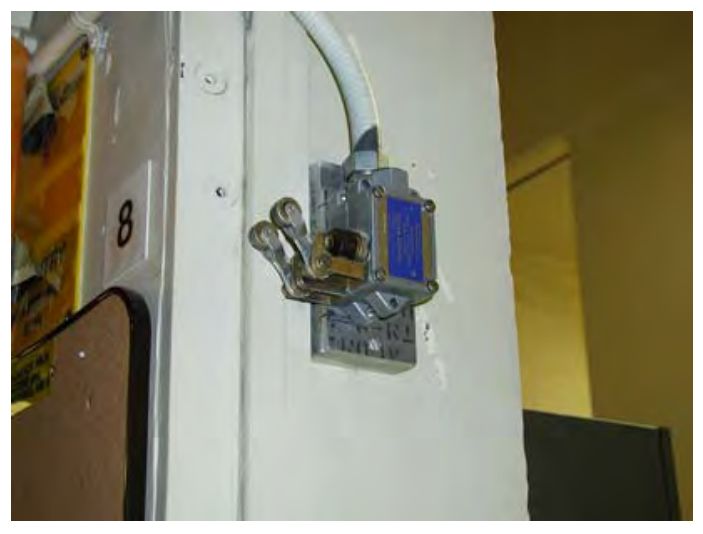

Figure 4.1. Door Interlock Switch

\subsection{Emergency Stop Buttons}

There are four emergency stop buttons inside the exposure room. Three are located on the north, and one on the south side walls. The number and placement were chosen to minimize the amount of time required to reach one from anywhere in the exposure room. Pushing any of these buttons shuts down the system; it also sounds an alarm at the control panel if the system were operating when the button was 
pressed. The emergency stop buttons are electrically wired in a series, so an open circuit by any one of them will shut the system down. Once a button has been pressed, it must be manually reset to resume operation of the HEF.

\subsection{Search Button}

Section 3.2.3.1 of ANSI N543-1974 requires an audible alarm to be activated in the exposure room for $20 \mathrm{~s}$ prior to the start of an exposure. This warns anyone that remains in the exposure room that operation is about to begin. The HEF search button (Figure 4.2) that sounds this warning is located in the exposure room's north wall near the emergency stop buttons. The placement of the search button forces the operator to check the exposure room for personnel before starting an exposure.

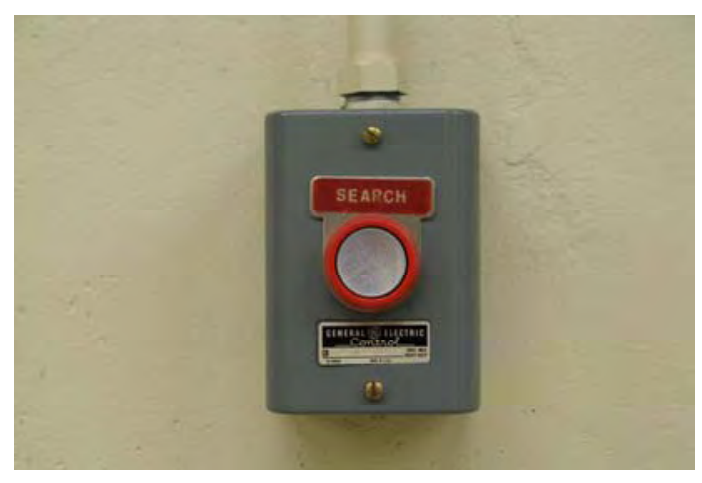

Figure 4.2. Exposure Room Search Button

\subsection{Audible Warning Devices}

An audible warning device in the exposure room alerts personnel that an exposure will soon start. A second audible warning device, located on the control panel, signals that an interlock violation has occurred. These are controlled by the PLC.

\subsection{Radiation Warning Lights}

Two radiation warning lights (Figure 4.3) are designed to flash when the radiation in the exposure room exceeds a predefined set point. The radiation warning lights also flash when a source is being raised. The lights are located inside the exposure room and at the entrance to the exposure room, and are controlled by the PLC.

\subsection{Area Radiation Monitor Detector and Remote Indicator}

The area radiation monitor detector (Figure 4.3) functions as the exposure room's radiation detector. It is constantly functioning, and is placed outside the primary radiation beam to measure scattered radiation. Resultantly, the detector reading is approximately 1/15,000 lower than levels within the primary beam. The monitor detector displays from $0.1 \mathrm{mR} / \mathrm{h}$ to $10,000 \mathrm{mR} / \mathrm{h}$ on a 5 -decade, logarithmic scale, and contains an audit circuit that will go into failure if it does not receive a pulse from the detector within a 2-min to 3-min period. This condition signals to the PLC that an area radiation monitor failure has occurred, and initiates a shutdown of the HEF if an exposure were in progress. 
The area radiation monitor remote indicator (Figure 4.3) informs personnel in the exposure room of the level of radiation in the room at the present time.

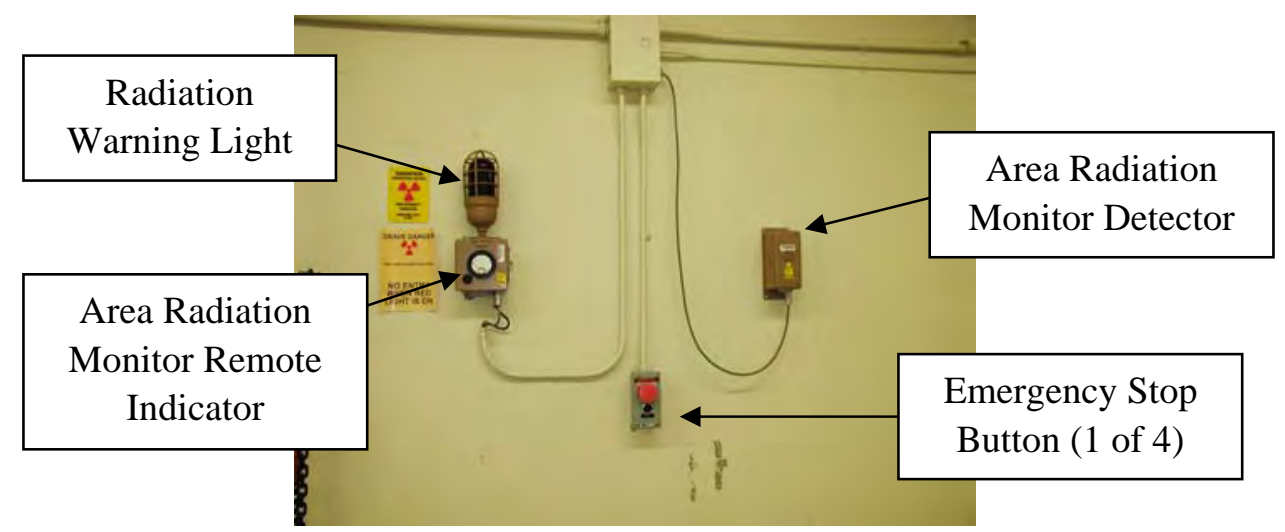

Figure 4.3. Area Radiation Monitor Remote Detector, Area Radiation Monitor Remote Indicator and Emergency Stop Button 



\subsection{Shielding}

Shielding in the HEF includes the use of natural and man-made barriers, and can be found in the HEF components, including the carousel assembly and the irradiation column.

\subsection{Exposure Room Walls and Ceiling}

The HEF was installed within the basement of an old reactor containment building. Consequently, its walls, floor, and ceiling are composed of rebar-reinforced, high-density concrete. The west wall of the exposure room, which shields the HEF control room, is $1 \mathrm{ft}$ thick. The north wall, which separates the HEF from the X-ray facility, is $2 \mathrm{ft}$ thick.

\subsection{Earth on Three Sides}

Additional shielding to the concrete floor and the two outside walls is provided to the HEF exposure room by way of earthen shielding. Radiation that passes through the floor and walls will pass harmlessly out of the exposure room.

\subsection{Internal Shield Wall}

A 1-ft thick wall of high-density concrete blocks most of the entryway into the HEF exposure room. During the first source loading in the 1980s, the source shipping cask would not fit past the original shield wall. As a result, the shield wall was narrowed, and this created a gap (Figure 5.1) resulting in a radiation area outside the exposure room door (Figure 5.2) when the highest activity source is used. Because a radiological work permit is not used to control the operation of this facility, entry into the radiation area during an exposure is prohibited. To control this, a photo beam (Figure 5.3) sensor was installed at the radiation area boundary. If an exposure is taking place and the beam is broken, the source is lowered from its irradiation position back into the carousel. Also, an access gate (Figure 5.4) is in place to prevent personnel from climbing over the door into the exposure room and entering a potential very high radiation area (VHRA). 


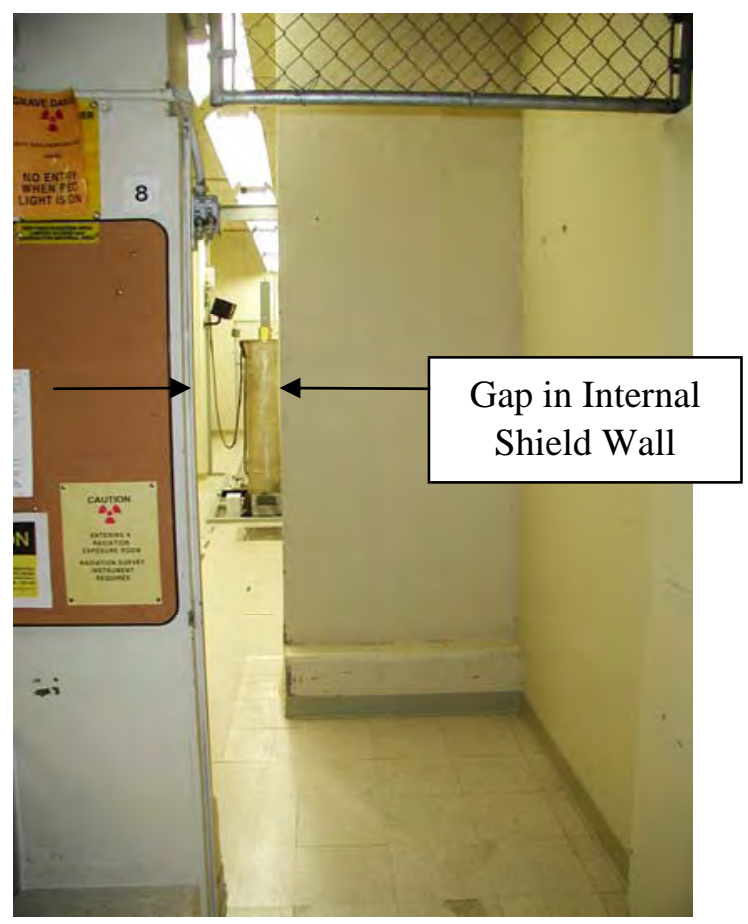

Figure 5.1. Internal Shield Wall

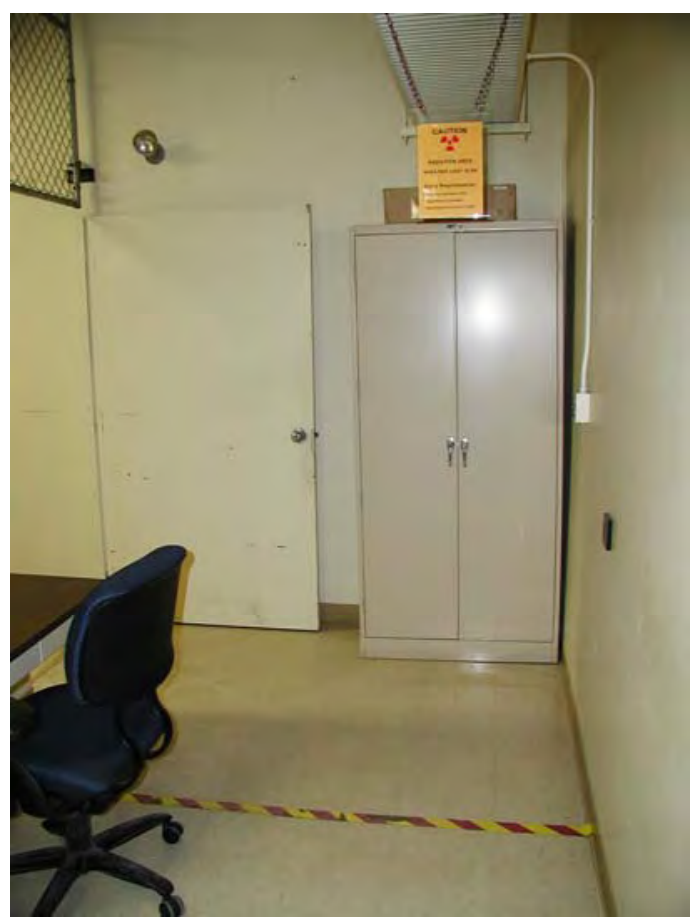

Figure 5.2. Doorway to Exposure Room 

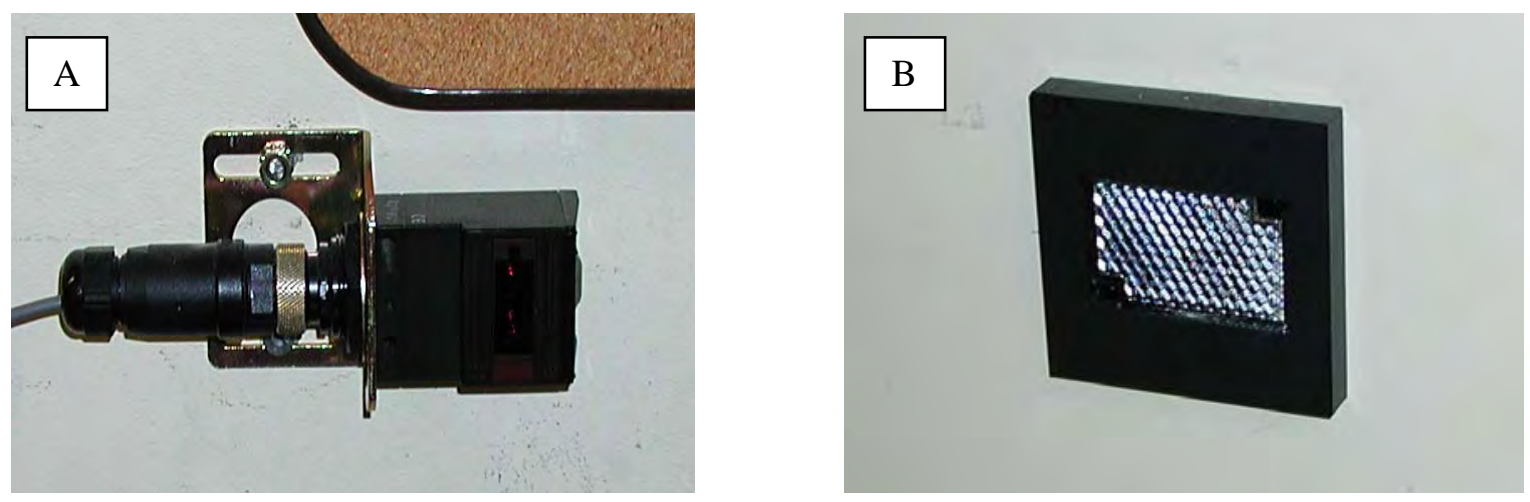

Figure 5.3. (a) Photobeam Sensor and (b) Photobeam Reflector

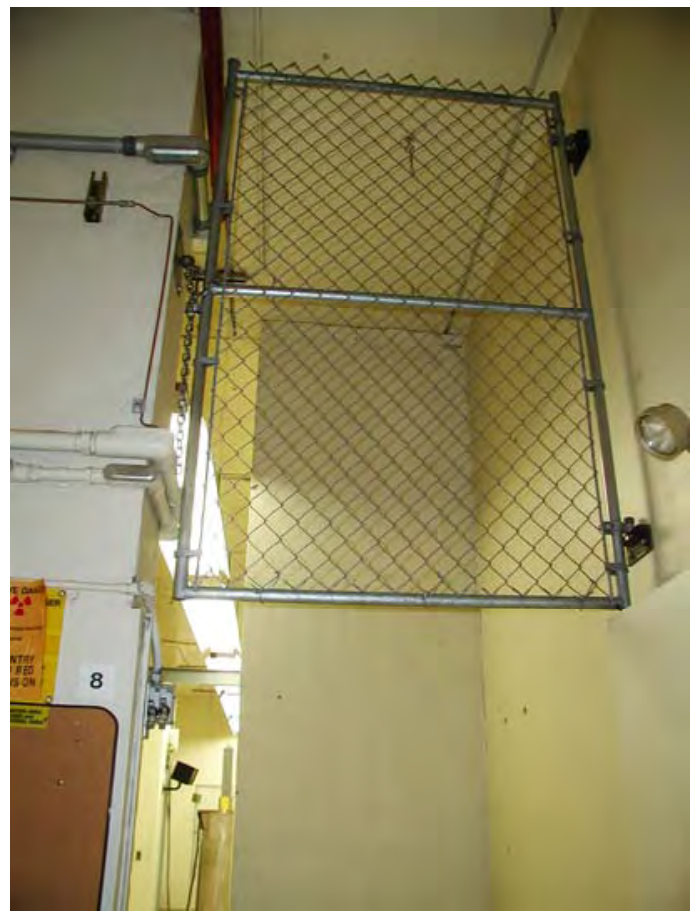

Figure 5.4. Access Gate

\subsection{Source Carousel Assembly}

The source carousel assembly (Figure 5.5) contains the source carousel (Figure 5.6) and its associated shielding. It is installed in a $3-\mathrm{ft}^{2} \times 21$-in. deep concrete-lined pit in the floor of the exposure room. This exposure room has 3 layers of 2-in. x 4-in. x 8-in. lead bricks lain into the floor (Figure 5.7), and a contamination control pan (Figure 5.8) over the lead bricks. The contamination control pan prevents contamination (from the concrete underneath the lead bricks deposited following the source breach) from re-entering the air flow stream over time. The visible recess in the center of the pan is 12 in. $^{2} \mathrm{x} 6$ in. deep, and is where the carousel resides. 


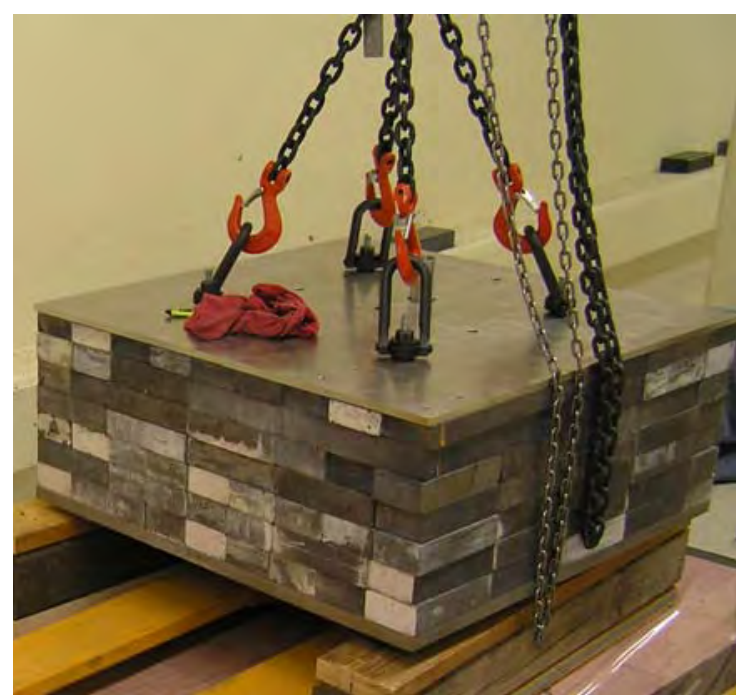

Figure 5.5. Source Carousel Assembly

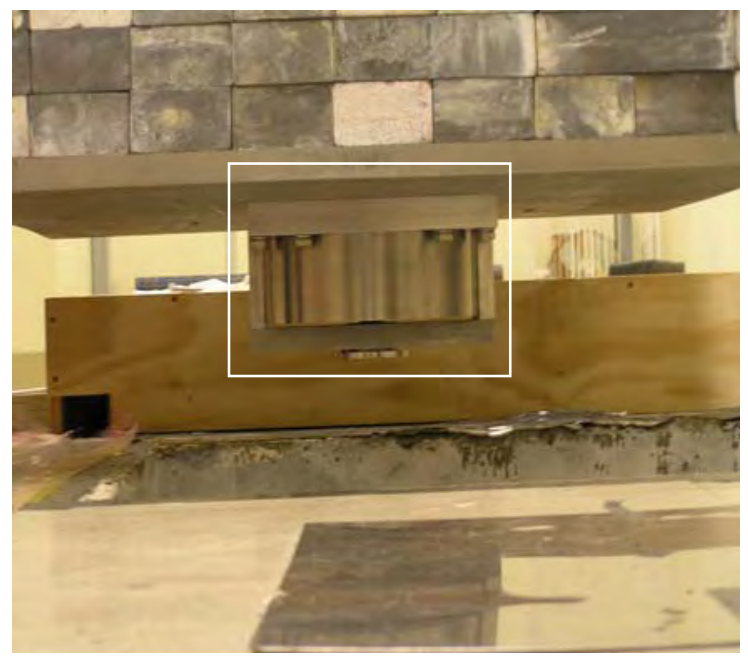

Figure 5.6. Source Carousel

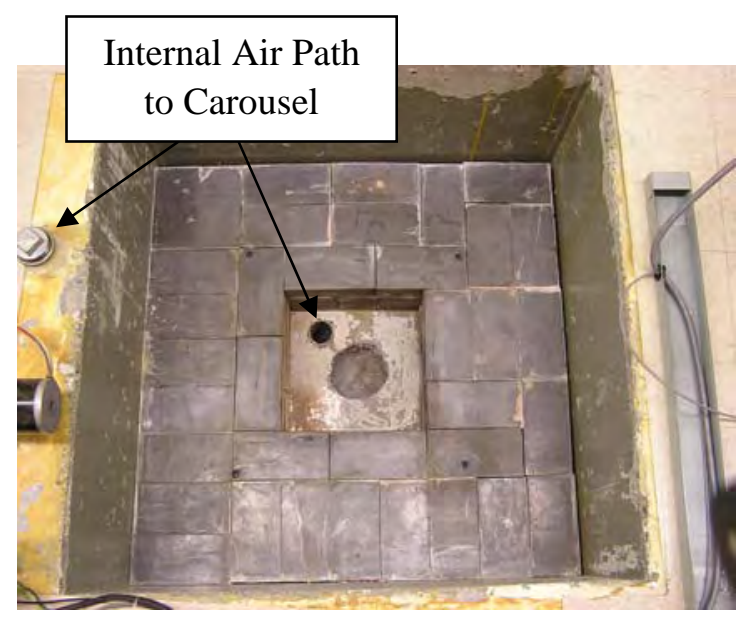

Figure 5.7. Pit Showing Lead Brick Installation 


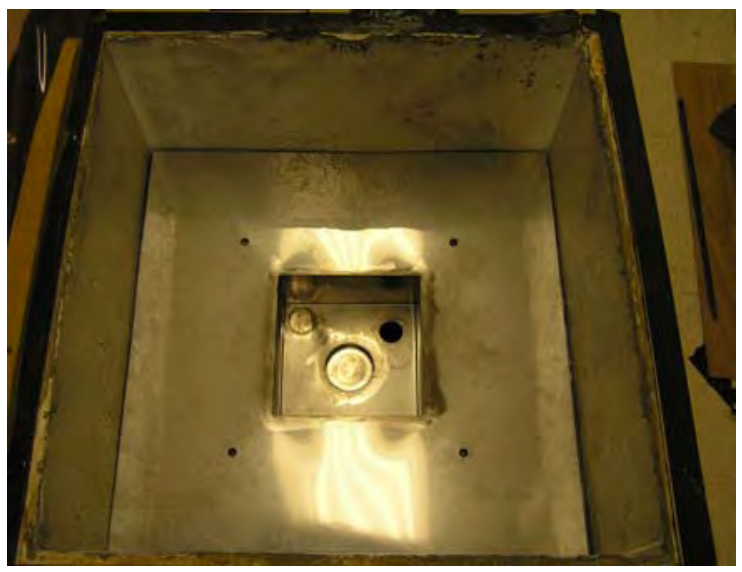

Figure 5.8. Pit Showing Contamination Control Pan

The source carousel assembly is lowered into the pit using a 5-ton overhead hoist. According to a calibrated strain-gage measurement, the carousel assembly weighs 7670 lbs.

\subsection{Irradiation Column}

The irradiation column (Figure 5.9) was fabricated from a 16-in. diameter x 6-ft, schedule 20 stainless steel pipe and a co-axial 1 1/2-in. i.d. pipe. The gap between the two pipes was filled with molten lead for shielding. The internal pipe provides a path for the sources to travel from the carousel to the beam port. Altogether, the irradiation column weighs 5515 lbs.

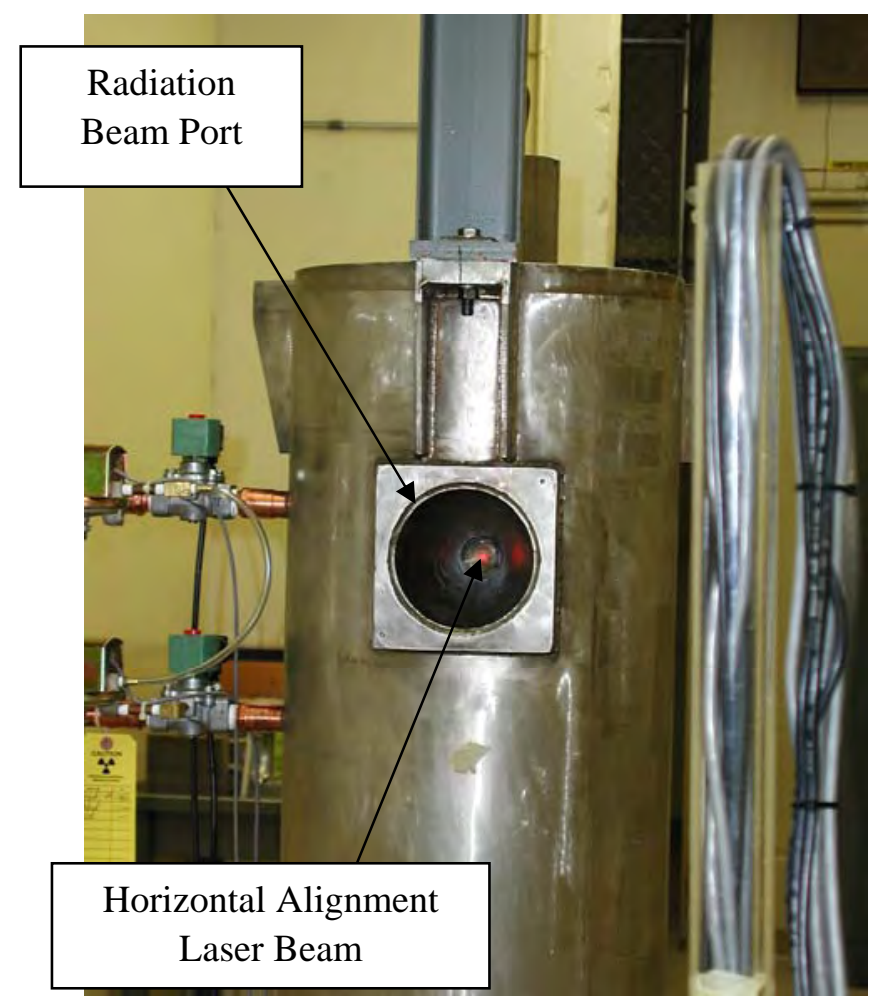

Figure 5.9. Irradiation Column 


\subsection{Irradiation Column Shield Plug}

The irradiation column's internal pipe extends beyond the beam port to the top of the column, where sources are added and removed. To prevent a beam of radiation from exiting the top of the column, as well as to prevent the sources from flying out of the irradiation column when raised to the beam port, a lead-filled plug (Figure 5.10) is placed into the top of the internal pipe. This plug extends from the top of the column to the top of the beam port, allowing the sources to rest against the plug's lower end when they are in position for irradiation.

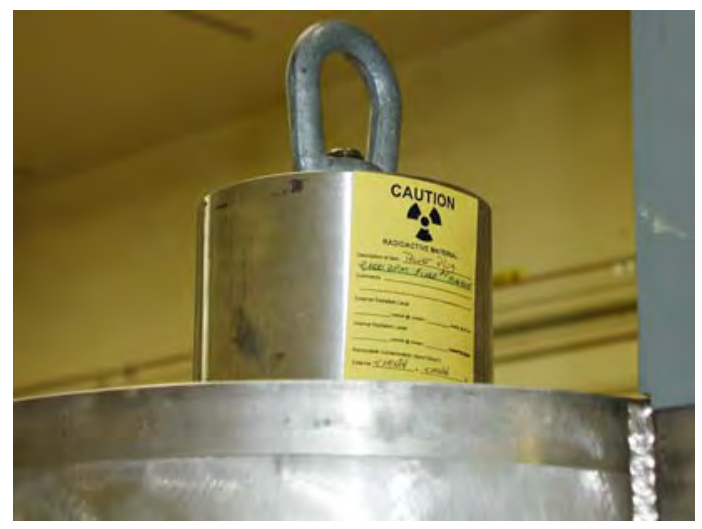

Figure 5.10. Column Shield Plug

\subsection{Effect of Lead Cold Flow}

Under extreme pressures and over long periods of time, lead will start to flow like a liquid. Eventually, the 5500-lb irradiation column will cause the lead bricks in the source carousel assembly to flatten and widen - which will decrease the mechanical clearances required to allow the carousel to rotate freely. Also, as the lead bricks flatten out, more of the irradiation pipe extending past the upper carousel plate will become exposed. This will reduce the clearance where this pipe meets the irradiation column, and could place even more stress on the source carousel. Fortunately, in HEF's 25-year history, problems have not yet been observed from this affect. However, when the irradiation column is removed for inspection or maintenance, these clearances should be re-measured. 


\subsection{Sources}

The sources used by the HEF, ${ }^{137} \mathrm{Cs}$ and ${ }^{60} \mathrm{Co}$, are of varying strengths. Each of the seven sources is double-encapsulated, then placed into a carrier designed to facilitate pneumatic manipulation.

\subsection{Source Transfers}

When originally constructed, the HEF had four sources installed: two ${ }^{137}$ Cs and two ${ }^{60}$ Co. In March 1987, a 5-ton hoist and source storage well were designed and installed in order to transfer the sources out of the HEF irradiation column and into the source storage well so carousel repairs could be performed. After repairs were completed, the four sources were transferred back into the carousel. In October 1995, the highest activity ${ }^{60} \mathrm{Co}$ source, no longer useful due to radioactive decay, was removed and replaced with a new $6000 \mathrm{Ci}{ }^{60} \mathrm{Co}$ source.

All 4 sources were again removed in February 2005 so the carousel could be replaced by an 8-source carousel. The four sources were loaded back into the eight-source carousel (which, at this time, had four empty source positions). Problems with source transport from the carousel to exposure position arose in December 2004. The four sources were then inverted to compensate for the omission of snap rings in the new carousel. In July 2005, 1 of the ${ }^{60}$ Co sources breached, and all 4 sources were removed and disposed. The HEF was out of service for a year while decontamination and rebuilding activities took place. Then, in July 2006, a new $6000 \mathrm{Ci}{ }^{60}$ Co source was installed. In October 2006, 3 low-activity ${ }^{137} \mathrm{Cs}$ sources were installed. Finally, 2 additional ${ }^{137}$ Cs were loaded in September 2007, bringing the HEF to a full complement of 7 sources.

\subsection{Exposure Rates}

With a full source complement, exposure rates can be generated from approximately $15 \mu \mathrm{R} / \mathrm{hr}$ to over $60,000 \mathrm{R} / \mathrm{hr}$. A beam attenuator made from lead (Figure 6.1) can be used to reduce the exposure rate for

any given source; however, with the recent addition of 3 small ${ }^{137} \mathrm{Cs}$ sources (which enable rates as low as $15 \mu \mathrm{R} / \mathrm{hr}$ ), and the exposure rate overlap between the various sources the attenuator is rarely needed. (For information related to the attenuator, please refer to High Exposure Facility Standard Operating Procedure (PNNL 2006). (This document can be provided by PNNL's Radiation and Health Technology Group.) 


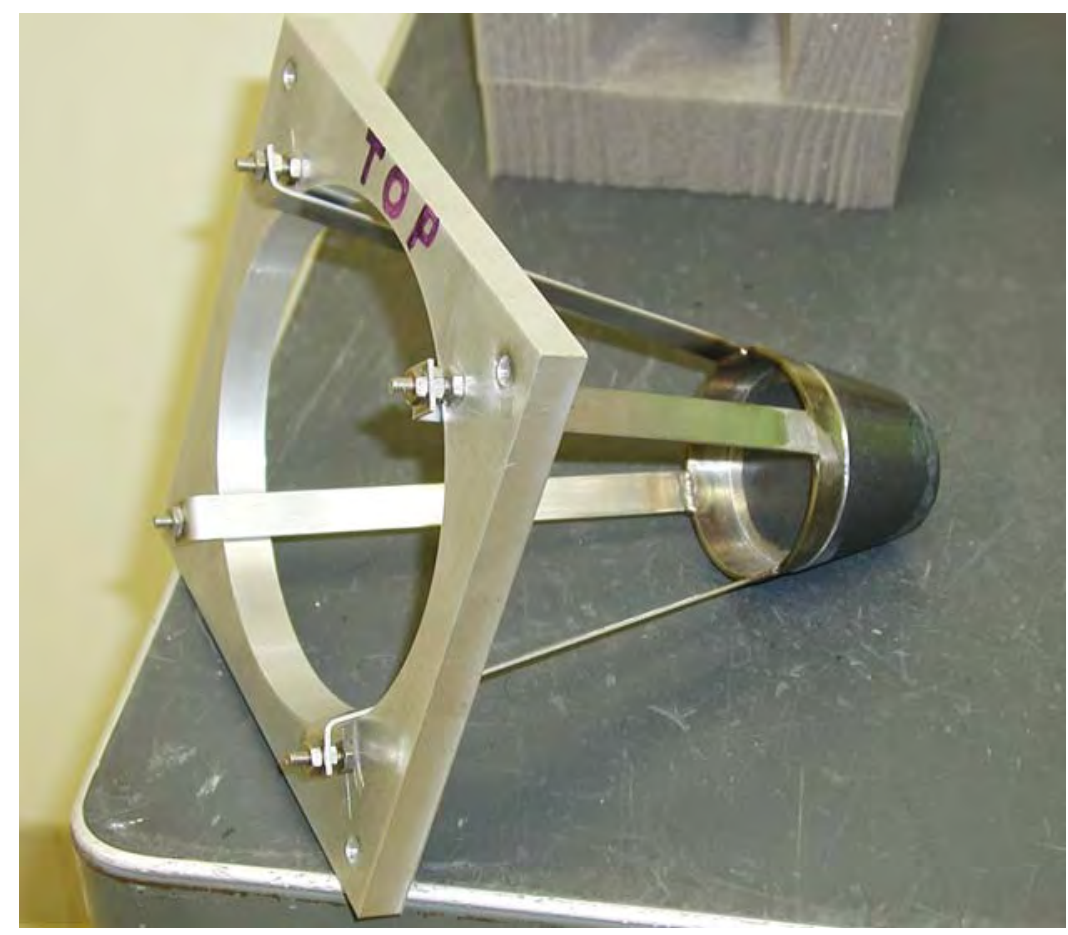

Figure 6.1. Beam Attenuator

\subsection{Isotopes}

The HEF currently uses two different radionuclides for irradiation: ${ }^{137} \mathrm{Cs}$ (in the form of CsCl) used to achieve the lower exposure rates, and ${ }^{60} \mathrm{Co}$ (in elemental form) for higher rates. With the higher rates, ${ }^{60} \mathrm{Co}$ is used because achieving these rates with ${ }^{137} \mathrm{Cs}$ requires enough material that self-shielding becomes an issue. Put another way, as the volume of ${ }^{137} \mathrm{Cs}$ material needed to attain the higher exposure rates increases, its gamma-ray dose constant (R/Ci) decreases due to self-attenuation.

\subsection{Source Encapsulation}

To be usable in the HEF, each source encapsulation must be designed to, tested to, and assigned a grade that meets or exceeds sealed source classification 96E43424 as defined in ANSI N43.6-1997. This is intended to minimize the possibility of, under normal use in an irradiator, a breached source. The source manufacturer initially loads the source material into a type $304 \mathrm{~L}$ stainless steel capsule, and then seals the capsule. This assembly is inserted welded-end-first into another slightly larger capsule, and its end cap welded on. These capsules remain very strong, even after receiving very large radiation doses.

\subsection{Source Carrier}

To optimize their aerodynamic characteristics, the source carriers (Figure 6.2) are dumbbell-shaped, as this provides the greatest amount of lift from the air stream and minimizes the contact surface area between the carrier and the pipe wall. The carriers are made from 300-series stainless steel, due to its high resistance to radiation and ozone damage. The source capsule resides inside the source carrier, which provides an additional barrier against the release of source material. 


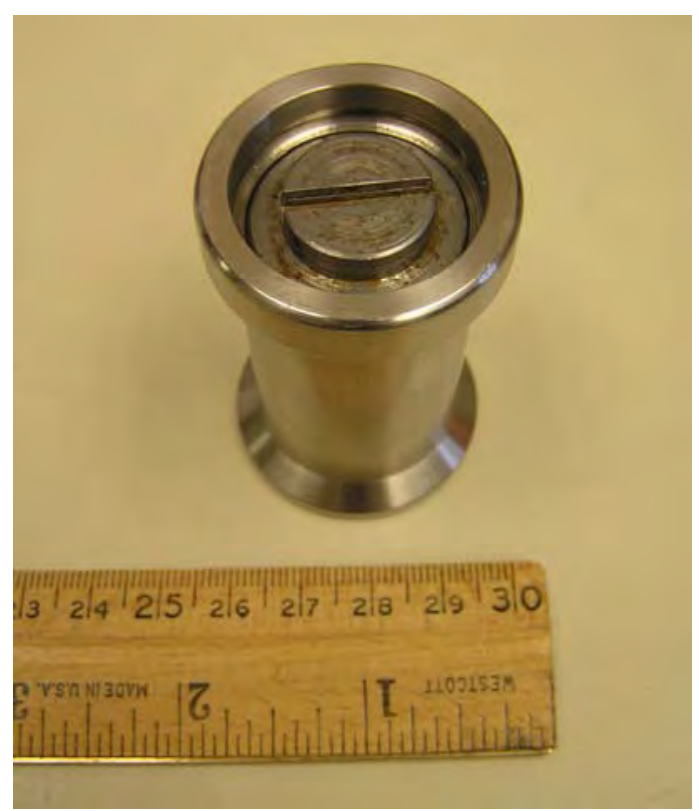

Figure 6.2. Source Carrier

A carbon steel plug (Figure 6.3), at the top of the carrier, is bottomed-out against the source capsule. The plug is made from 1000-series carbon steel so as to be paramagnetic (attracted to an external magnetic field). Dots have been drilled into the carrier plugs to allow easy identification of the sources from above. One dot indicates the source is a high-activity ${ }^{60} \mathrm{Co}$ source, located in either source position seven or eight in the carousel. Two dots indicate one of the three lowest-activity ${ }^{137} \mathrm{Cs}$ sources, located in source positions two through four. Three dots indicate the high-activity ${ }^{137} \mathrm{Cs}$ source, located in source position six. Four dots indicate the medium-activity ${ }^{137} \mathrm{Cs}$ source, located in source position five. The dummy source does not have dots on its plug, and is in position one.

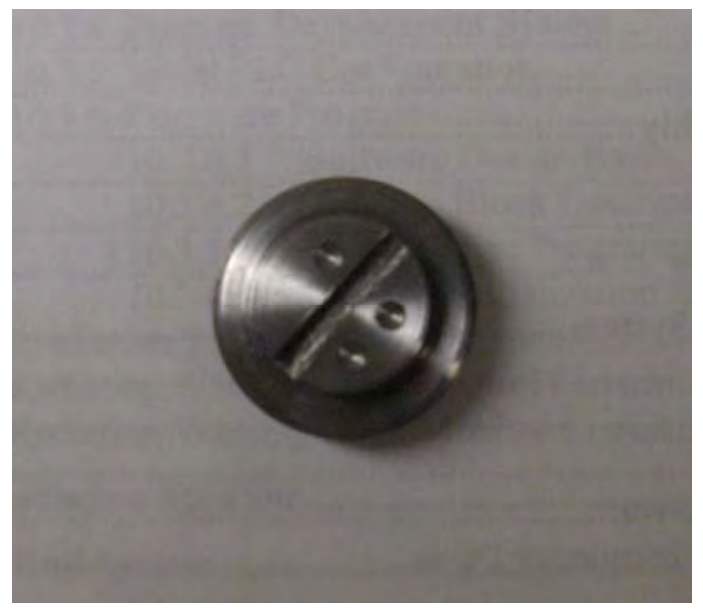

Figure 6.3. Source Carrier Plug 
A concave internal retaining ring, atop the plug to prevent the plug from unscrewing, is installed with the convex surface in contact with the plug. This orientation minimizes plug movement between the plug and the ring.

The source carriers are intended to be installed into the irradiator with the plug-end facing upward. This presents the opposite, smooth surface of the carrier to the airflow when the airflow is flowing in the lifting direction. Tests conducted with a source carrier installed upside down resulted in the carrier rattling in the source pipe as it rose to the exposure position. This was probably a result of the source carrier's plug end presenting an unsmooth surface for the airflow and creating a great deal of turbulence. Installing the source carrier into the irradiator plug-end upward also allows the carrier to be raised and lowered by permanent or electro magnet from the top of the irradiation column (with the shield plug removed). This is the preferred means to remove and install the lowest activity ${ }^{137}$ Cs sources.

\subsection{Dummy Source}

The dummy source is a source carrier filled with lead shot so that its total mass equals $280 \mathrm{~g}$; it is primarily used to test the pneumatic source transport system. The source carousel is arranged with the sources in an increasingly radioactive order: the lowest-activity source occupies source position two, and the highest-activity source is in source position eight. The dummy source is therefore always kept in source position one.

\subsection{Acceptable Mass Range of Sources}

Testing has determined the nominal mass for a source to be $280 \mathrm{~g}$ within a tolerance of $\pm 10 \mathrm{~g}$. Therefore, the HEF can use sources with masses of $270 \mathrm{~g}$ to $290 \mathrm{~g}$ and still operate correctly with a single set of air flow parameters. To accommodate the widely varied sizes and masses of the four different types of source capsules, each of the four types of source carriers had to be designed to meet this mass range. To illustrate the magnitude of the design challenge, the three smallest ${ }^{137} \mathrm{Cs}$ source capsules have a mass of approximately $2 \mathrm{~g}$ (measured by the manufacturer). The source carriers for the smallest sources have to be $278 \mathrm{~g}$ to balance the difference. The two large ${ }^{60} \mathrm{Co}$ source capsules are $80 \mathrm{~g}$ each (measured by their manufacturer), which means the large source carriers must be $200 \mathrm{~g}$. Increasing the total masses of the lighter sources to the 280 -g range was a challenge, and was ultimately accomplished by installing varying amounts of different materials internally to the source carrier. In all, aluminum (with a density of $2.7 \mathrm{~g} / \mathrm{cm}^{3}$ ), 300 series stainless steel (at $7.93 \mathrm{~g} / \mathrm{cm}^{3}$ ), and tungsten (the heavyweight at $17.24 \mathrm{~g} / \mathrm{cm}^{3}$ ) were used. 


\subsection{Pneumatic Source Transport System}

The HEF uses a closed-loop pneumatic system to raise and lower its sources. This helps prevent foreign material—which can cause the carousel rotation to bind-from entering the system. It also prevents contamination from reaching the exposure room in the event of a source breach. However, using a closed-loop system also results in the buildup of ozone within the pneumatic loop. Because ozone is a strong oxidizer, this causes all parts containing iron to rust. Resultantly, components that come into contact with the air flow path are made of stainless steel, wherever possible.

\subsection{Breached Source Changes}

Following a breached source incident in July 2005, an extensive investigation was conducted to determine probable causes of the breached source (the actual cause could not be definitely determined, partly because the high exposure rates prevented any physical examination of the source capsules). One of the likely causes that emerged from the investigation is that the impacts experienced by the source carriers ultimately resulted in a failure of one or both of the source capsule welds. As a result, several aspects of the pneumatic source transport system were redesigned to prevent a similar incident from occurring. The following is a list of the changes designed to reduce the source impact upon ascent:

- The air port path throttling valves were removed, as the butterfly valves were too coarse an adjustment, and testing indicated that the valves operate optimally when wide open. Blower speed control now reduces pressure/flow on ascent, rather than partially closing a valve to restrict flow.

- The single-speed blower was replaced with a blower and variable frequency drive for speed control. This was required to implement removal of the air port path throttling valves.

- An additional solenoid valve was installed in the bottom air port path to remove interdependencies between flows. With two valves installed, one valve remains open at a time with switchover occurring simultaneously. Both air paths are pneumatically identical, so air flow/pressure does not change when the valves alternate.

- The air path restrictions were reduced by replacing the $5 / 8$-in. trade size air path copper tubing (0.686-in. i.d., or 0.370 in. $^{2}$ ) with 1-in. trade size copper tubing (1.061-in. i.d., or 0.884 in. $^{2}$ ).

- All of the compression fittings were removed from the valves to eliminate their 0.620 -in. diameter restrictions, and replaced with soldered fittings.

- The carousel's lifting surface area on the source was increased by enlarging the diameter of the carousel air holes to $1.2 \mathrm{in}$. This is the largest hole-size that still provides enough remaining surface area for the source to land on. Testing demonstrated that as the air hole diameter increases, blower speed-necessary to guarantee liftoff-decreases, reducing the acceleration of the source carrier once in the source pipe. (Testing also showed that a tapered inlet to the carousel air hole made no detectable difference.)

- Air leakage was minimized by reducing the air gap between the carousel and the carousel upper mounting plate (and by maximizing the diameters of the carousel air holes, as noted above). This was accomplished by polishing the top surface of the carousel and the mating bottom surface of the carousel upper mounting plate, and adjusting the clearance to a minimum. Testing demonstrated that 
as the air gap decreases, so does blower speed — thereby reducing the acceleration of the source carrier once in the source pipe.

- A stainless steel pan between the bottom lead brick layers and the carousel assembly was installed, minimizing potential air leakage around the lead bricks. This also reduced the possibility that the air flow stream would pick up contamination affixed to the bottom of the concrete pit, deposited there as a result of the ${ }^{60} \mathrm{Co}$ source breach.

Likewise, the system was improved to reduce the source impact upon descent in the following manner:

- The blower motor brake was removed - the system now relies upon the use of the blower speed to control pressure and flow on descent.

- The source carrier plug was redesigned to transfer the impact forces to the end of the source capsule, rather than to the source capsule closure weld.

- Finally, the existing pressure switch was supplemented with an additional pressure switch to detect the source in position at the lower air port. If this switch does not detect the source carrier within $10 \mathrm{~s}$, the source is placed back into the carousel and the control panel issues a source pneumatic fail alarm.

\subsection{Pneumatic System Sequence of Operation}

With the current configuration, the pneumatic sequence of operation controls the raising and lowering of sources. After the PLC has successfully positioned a source under the source pipe in the irradiation column, the raise- and lower-source sequences can execute. Barring a source pneumatic fail alarm, the following steps occur:

1. The lower solenoid valve is energized, opening the lower air path.

2. The blower is energized at a speed (about 35\% of full speed) to raise the source into the pre-irradiate position.

3. The lower pressure switch detects the source in the pre-irradiate position.

4. The upper solenoid valve energizes while the lower solenoid valve de-energizes, pulling the source up into the irradiate position.

5. The blower speed is increased to $100 \%$. (The control system pauses in this state until the operator, via the PLC, lowers the source or an interlock violation occurs.)

6. When the source is lowered, the lower solenoid valve is energized (opened) while the upper solenoid valve is de-energized (closed), dropping the source into the pre-irradiate position.

7. The blower speed is reduced to a speed (about 30\% of full speed) that lowers the source back into the carousel.

8. The blower is energized to $100 \%$ in the reverse direction.

9. The upper pressure switch detects the source fully seated in the carousel.

10. The blower speed is reduced to zero.

11. The lower solenoid valve is de-energized. 


\subsection{Blower System}

The blower system consists of two parts: a regenerative blower (Figure 7.1) with an integral motor, and a variable frequency drive (VFD) in the valve control enclosure (Figures 7.2 and 7.3). When properly sized, the primary advantage of using a regenerative blower to raise, lower, and hold a source in the irradiate position is that it isn't capable of creating high pressure. Some other irradiator designs use pressure-regulated compressed air, for example. If the regulator is set too high, these systems can apply excessive forces to the sources. To further reduce the blower pressure, blower motor speed is reduced by the VFD.

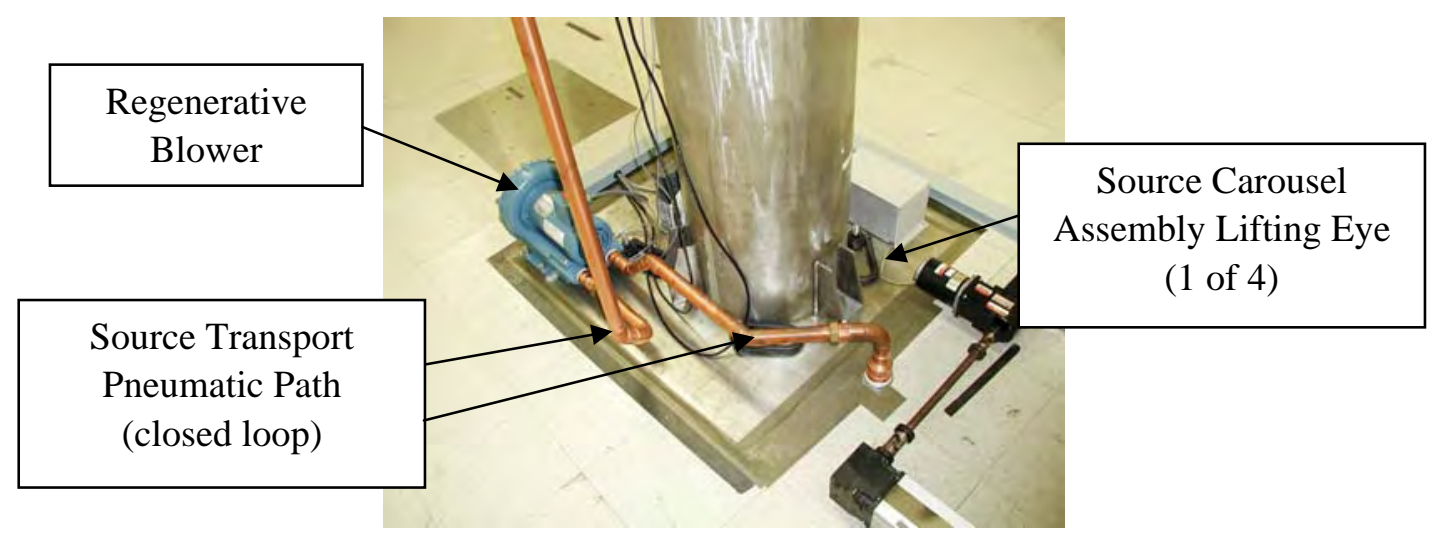

Figure 7.1. Column Base

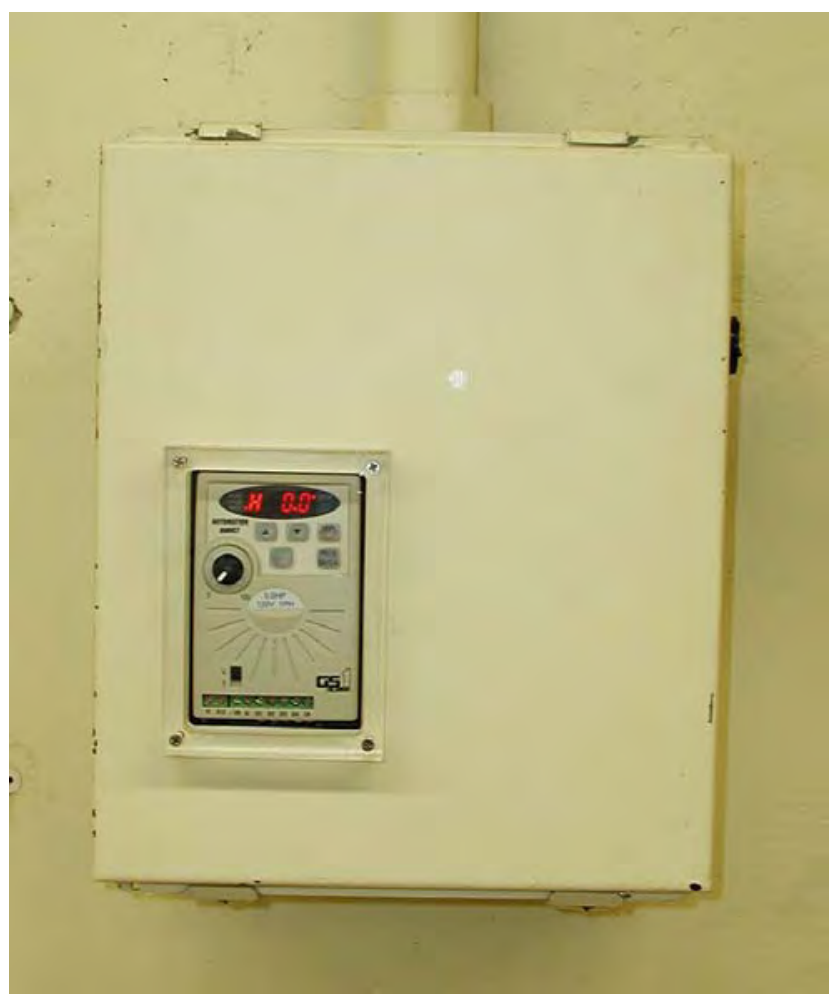

Figure 7.2. Source Blower and Solenoid Valve Control Enclosure 


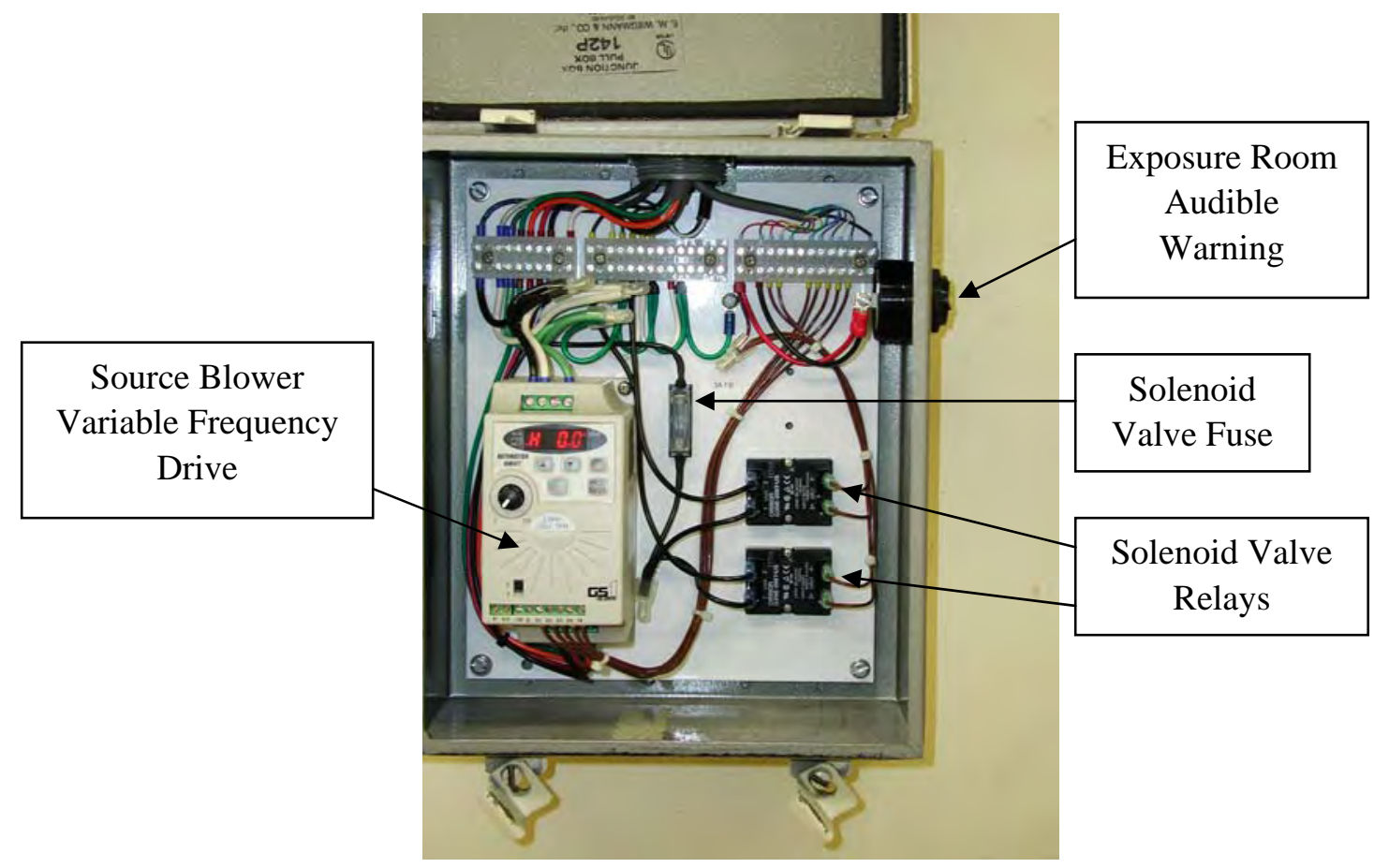

Figure 7.3. Source Blower and Solenoid Valve Control Panel

\subsubsection{Regenerative Blower}

A single-stage regenerative blower near the irradiation column base, equipped with a $1 / 2 \mathrm{hp}$, threephase motor creates a high-flow, low-pressure air stream to move the sources up and down in the source pipe. (AMETEK, Inc. manufactured this blower, model DR303AE72M.) This is the ideal type of blower for the application, given the low mass (280 g nominal) and large lifting surface area (1.65 in. ${ }^{2}$ ) of the sources to be raised. For these values and under ideal conditions (neglecting the pressure losses around the pneumatic transport loop), the blower needs to generate only slightly more than $0.374 \mathrm{lbs} / \mathrm{in}^{2}{ }^{2}$ to raise a source. To lower the excess pressure of the blower to the minimum pressure required for raising and lowering sources, one simply reduces the motor speed.

\subsubsection{Blower Variable Frequency Drive}

An AutomationDirect model GS1-10P5 VFD allows the blower speed to be fully controlled by the motor speed. This creates a variable amount of flow and pressure on the source and allows it to be raised and lowered gently. The $120-\mathrm{V}$, single-phase input, 240-V 3-phase output VFD was designed to control 3-phase motors up to $1 / 2 \mathrm{hp}$ in size.

\subsection{Air Paths and Valves}

Two solenoid valves (Figure 7.4) allow the source's position to be controlled when it is in the irradiation column. When the source is rising into position, the lower solenoid valve is open, forcing the source to stop below the exposure position. To raise the source into the exposure position, the lower valve must close and the upper valve must simultaneously open. 


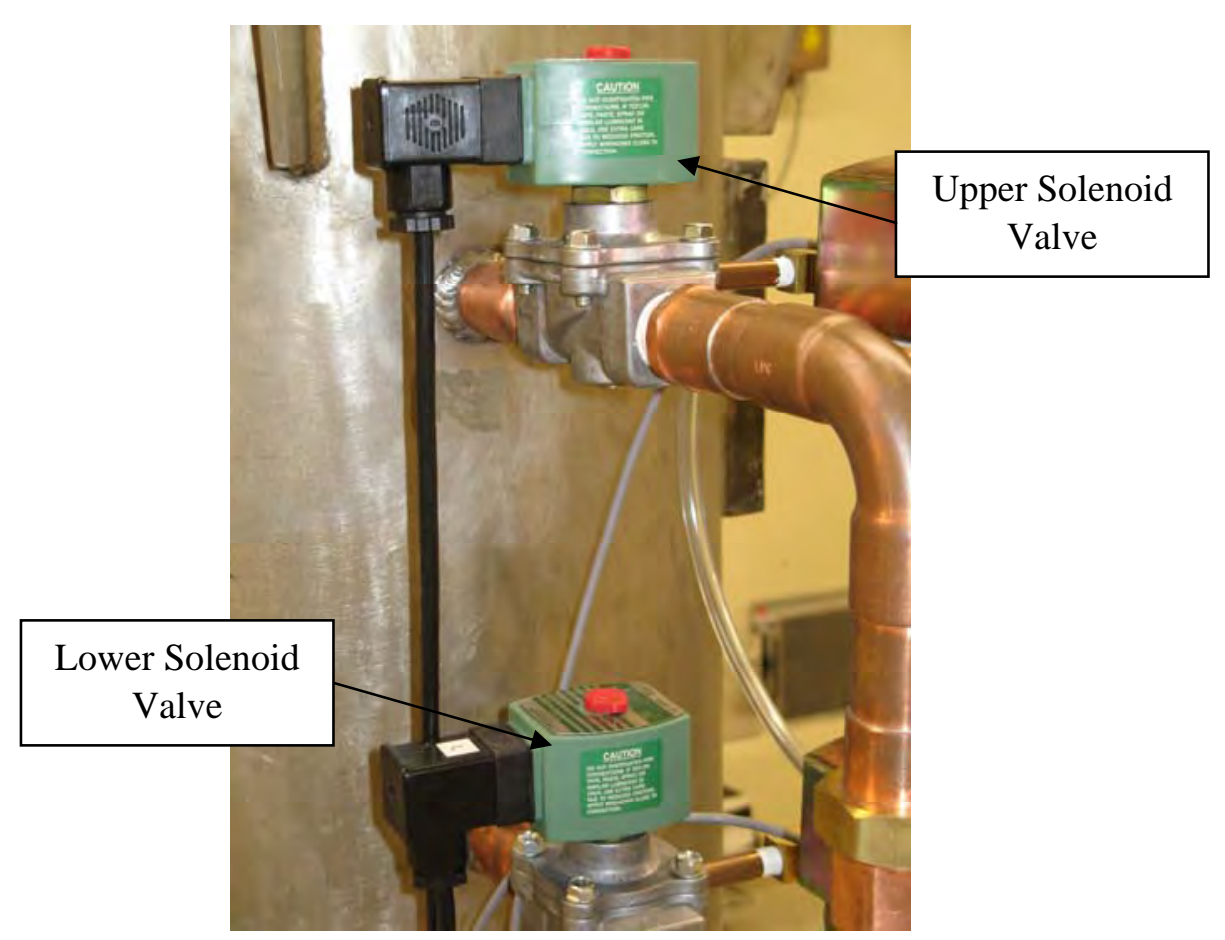

Figure 7.4. Solenoid Valves

The solenoid valves (ASCO Valves, Inc., model 8040G23) are fitted with an optional DIN connector. These valves were chosen for their high flow coefficient $\left(C_{v}=9.5\right)$, meaning that pressure drop across the valve is minimized as a function of air flow rate. Because these valves are direct-acting, no minimumpressure differential is required for the valves to open-meaning the valves will operate correctly, even when the air flow through the pneumatic system is essentially zero. (Because it is a variable speed blower, this condition is possible at low speed settings.) Solid-state relays in the VFD and solenoid valve control enclosure, under PLC control, energize the solenoid valves.

\subsection{Pressure Switches}

Two pressure switches (Figure 7.5) are used to determine where a source is located while it is being raised and lowered. These are Dwyer Instruments, Inc. Series 1800 low differential pressure switches with adjustable set points. Both switches can be adjusted with a small flathead screwdriver after removing the rubber protective cap. 


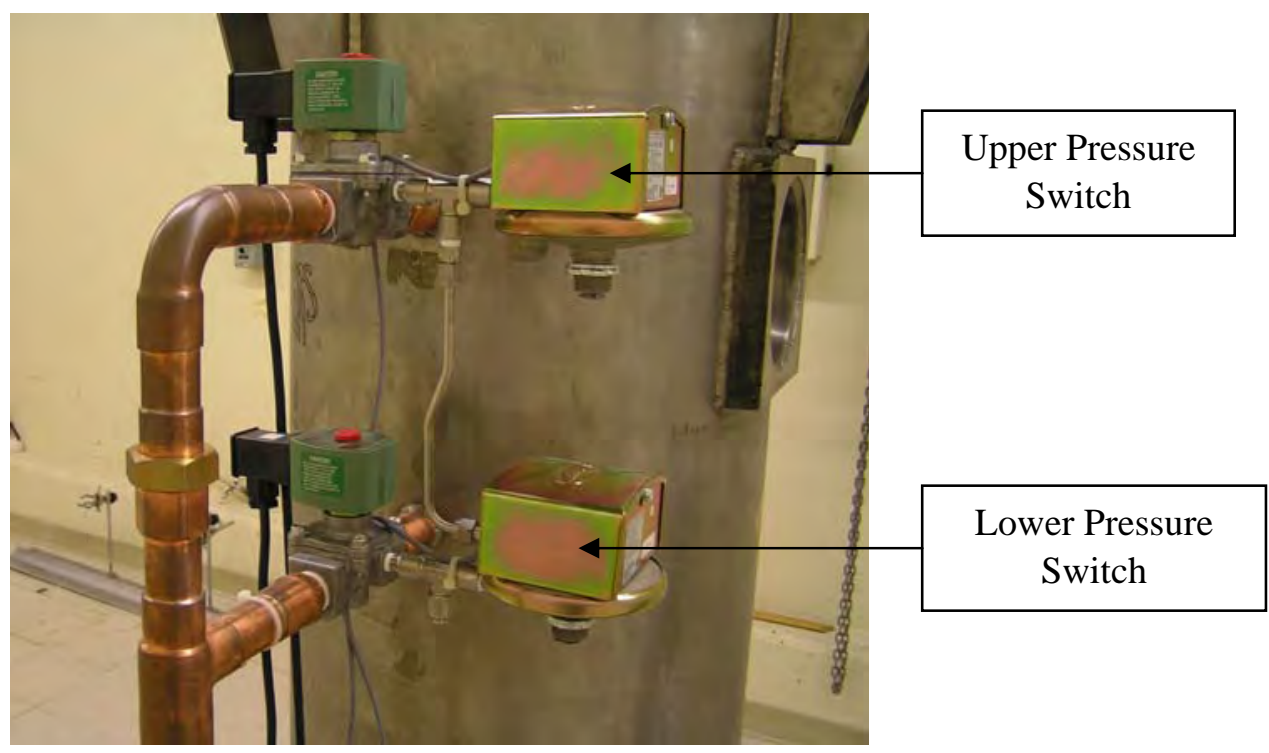

Figure 7.5. Pressure Switches

The lower pressure switch detects a source's arrival at the pre-irradiate position. If detection does not occur within $10 \mathrm{~s}$ after the blower starts raising the source, the PLC sequence is aborted and the operator receives an alarm on the control panel (the control panel will indicate a source pneumatic fail alarm). This alarm will stop the upper solenoid valve from opening, preventing the source from rising into the irradiate position. The lower pressure switch is plumbed into the pneumatic system with the positive pressure port connected to the upper solenoid valve side port, and the negative pressure port connected to the lower solenoid valve side port. In this configuration, the pressure switch detects a differential pressure of $5 \mathrm{in}$. to $7 \mathrm{in}$. of water when a source is in the proper pre-irradiate position, and detects about $4 \mathrm{in}$. of water when the source is not in position. Therefore, this switch must be adjusted to actuate at about 5 in. of water.

The upper pressure switch detects a source that is fully seated in the carousel. If this does not occur within $10 \mathrm{~s}$ after the blower has started to run in reverse, the PLC sequence is aborted and the operator receives source pneumatic fail alarm. In this case, the alarm will prevent the source carousel from being rotated. The upper pressure switch is plumbed into the pneumatic system with the positive pressure port connected to the upper solenoid valve side port and the negative pressure port left vented to the atmosphere. In this configuration, the pressure switch detects a differential pressure of about $16.5 \mathrm{in}$. of water when a source is inside the carousel and a differential pressure of about $11.5 \mathrm{in}$. of water when it is not. Therefore this switch is to be adjusted to actuate at a differential pressure of about $14 \mathrm{in}$. of water. 


\subsection{Carousel System}

The carousel system holds seven sources, and an eighth dummy source. The carousel, by means of a drive system that includes a stepper motor, a drive/indexer unit, a gear reducer, and a shared power supply, rotates to position the desired source for exposure under the irradiation column.

\subsection{Carousel Upgrades}

In November 1985, the source carousel started to bind during its rotation and as a result, the carousel positioning system failed to correctly position the desired source under the irradiation column. Frequent maintenance was required until the carousel finally failed in March 1987. That same month, the system was disassembled and the carousel shaft was repaired. In August 2004 the 4-source carousel was replaced by an 8-source carousel.

\subsection{Present-Day Carousel Design}

The carousel (Figure 8.1) was manufactured from a short cylinder of series-300 stainless steel. Even though unnecessary, internal material was removed from the underside of the carousel to lighten its mass, it still tips the scales at roughly $22.7 \mathrm{~kg}$. The carousel is rotated by a stepper motor that turns a shaft in the center of the carousel. Two bearings, one at the top and another at the bottom, are attached to the carousel. These allow the carousel to turn smoothly and with minimum drive torque.

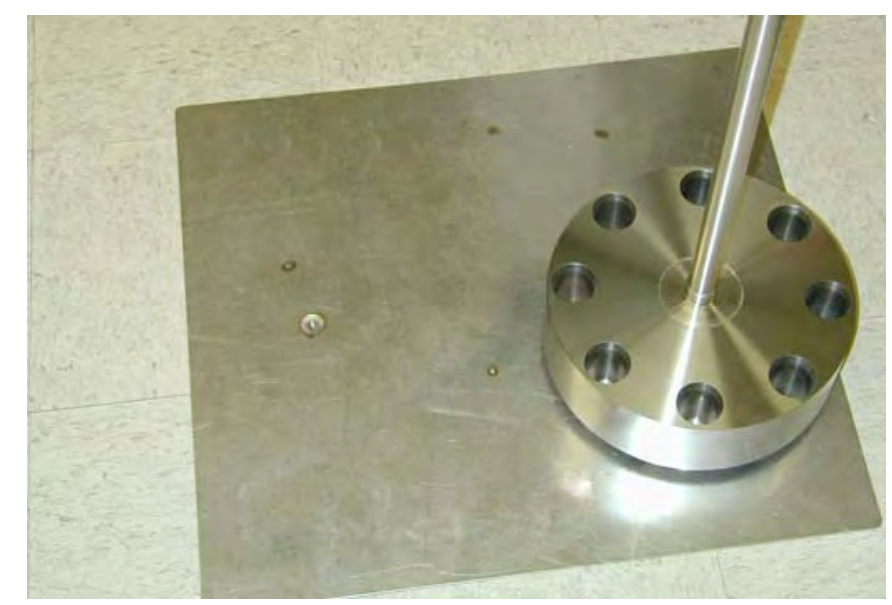

Figure 8.1. Source Carousel

\subsection{Drive System}

The drive system, as previously indicated, includes a stepper motor, a drive/indexer unit, a gear reducer, and a shared power supply. (The power supply also feeds the linear rail system.)

\subsubsection{Stepper Motor}

The stepper motor, mounted floor-level at the base of the column is a NEMA size 23 motor, manufactured by Compumotor, type OEM57-83-MO. A stepper motor differs from other types of motors 
in that its rotation is inherently incremental, as opposed to continuous. Typical stepper motors will rotate precisely one revolution with the application of 200 steps from the motor drive. A more recent innovation is the microstepping motor drive, which increases the motor's number of steps per revolution from 200 to almost any integer multiple of 200. In the case of the carousel drive, the number of steps per revolution was increased to 25,000 by the microstepping drive-resulting in very smooth rotation.

\subsubsection{Stepper Motor Drive/Indexer}

Controlling the stepper motor is an OEM650X microstepping drive/indexer, manufactured by Compumotor. It is connected to the motor in a series configuration, as recommended by Compumotor in conjunction with the OEM300 power supply. The drive is slaved to the PLC, which situates the carousel in one of its eight source locations (Figure 8.2). The stepper motor drive/indexer is mounted to the carousel assembly top plate (which functions as a heat sink), to the right of the shared power supply. To aid in the heat transfer, heat sink compound is applied to the drive mounting base before it is secured to the top plate.

Once the drive/indexer receives the command to move the carousel to a new position, the indexer calculates the number of steps that must be sent to the motor (based on the current carousel position indicated by the rotary position encoder and the new desired position). The indexer then increments the stepper motor shaft position at a speed that creates a trapezoidal motion profile to reach the desired carousel position. Source positions are located every 1000 encoder steps around the carousel. The source arrangement (Table 8.1) was chosen because it yields the lowest radiation background in the exposure room when the dummy source is positioned under the source pipe in the column-this is the safest configuration for personnel entering the exposure room. Should the blower turn on unexpectedly, only the dummy source would be raised.

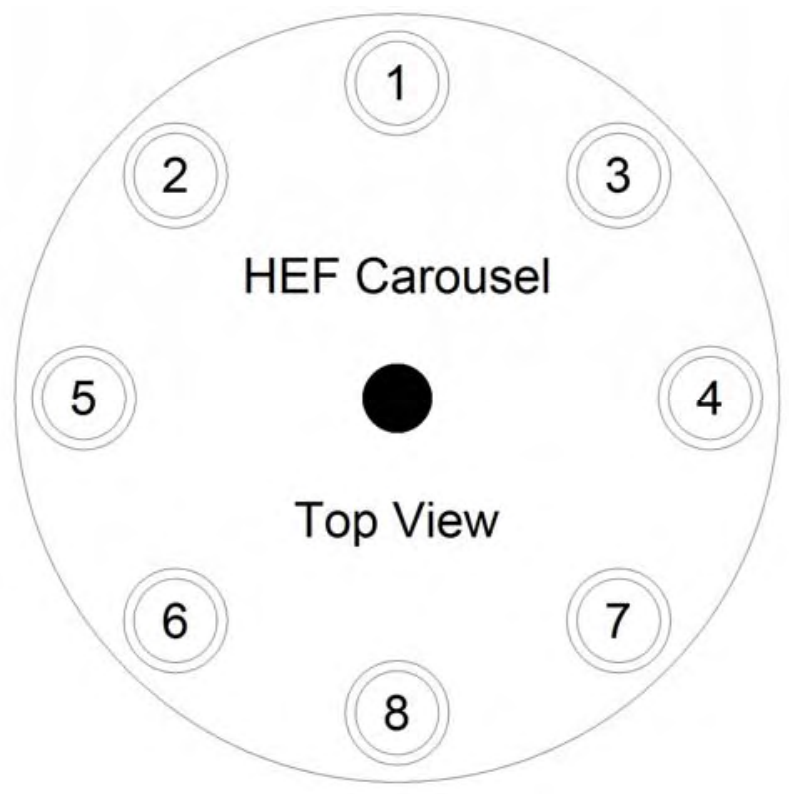

Figure 8.2. HEF Carousel Source Locations 
Table 8.1. Absolute Encoder Positions for the Various Source Positions

\begin{tabular}{||c|c||}
\hline Source Location & Position (encoder steps) \\
\hline \hline 1 & 0000 \\
\hline 2 & 1000 \\
\hline 3 & -1000 \\
\hline 4 & -2000 \\
\hline 6 & 2000 \\
\hline 7 & 3000 \\
\hline 8 & 5000 \\
\hline $\begin{array}{l}\text { Negative source positions indicate that the carousel must be rotated } \\
\text { in a counterclockwise direction to reach that source location. }\end{array}$ \\
\hline \hline
\end{tabular}

During installation, the drive needs to be manually configured as indicated in Table 8.2. (Refer to Compumotor's OEM Series Software Reference Guide Microstepper Products OEM650X/OEM350X/OEM010 [1993] for configuration details.)

Table 8.2. Configuration of the Carousel Drive. Reference Current Resistor $=13 \mathrm{k} \Omega \frac{1}{4} \mathrm{k}$ watt (resulting in 3.75 A maximum motor drive current).

\begin{tabular}{|c|c|l|l||}
\hline Jumpers & Config & \multicolumn{1}{|c|}{ Function } & \multicolumn{1}{|c||}{ State } \\
\hline \hline 1 & In & Motor Current Range & High Range \\
\hline 2 & In & Motor Resolution & 25,000 steps/rev \\
\hline 3 & In & Motor Resolution & \\
\hline 4 & In & Motor Resolution & \\
\hline 5 & In & Motor Resolution & \\
\hline 6 & In & Motor Waveform & $-4 \% 3^{\text {rd }}$ Harmonic \\
\hline 7 & In & Motor Waveform & \\
\hline 8 & In & Motor Waveform & \\
\hline 9 & Out & Standby Current & $25 \%$ of Normal \\
\hline 10 & Out & Standby Current & Disabled \\
\hline 11 & In & Auto Test &
\end{tabular}

\subsection{Shared Power Supply}

A Compumotor OEM300 power supply producing 75 V DC is shared by the source carousel stepper motor drive/indexer and the instrument platform stepper motor drive/indexer. It can supply $2.7 \mathrm{~A}$ of continuous current, with 4.0 A peak for $30 \mathrm{~s}$ at a $10 \%$ duty cycle, and is capable of powering both stepper motors continuously and simultaneously. The power supply is mounted to the carousel assembly top plate. To draw heat away from the power supply, heat sink compound is pressed between the power supply and the top plate.

\subsection{Gear Reducer}

The gear reducer (Figure 8.3) allows the carousel to be driven by a small, lower-torque motor; with the gear reducer, the carousel rotates once per every 100 motor revolutions. Motor size is important, as it is required to fit in the limited space at the base of the column. To fit, the Bayside Motion Group model NR23-S010-047LB gear reducer was factory-modified to reduce the output shaft length to $3 / 4 \mathrm{in}$. 


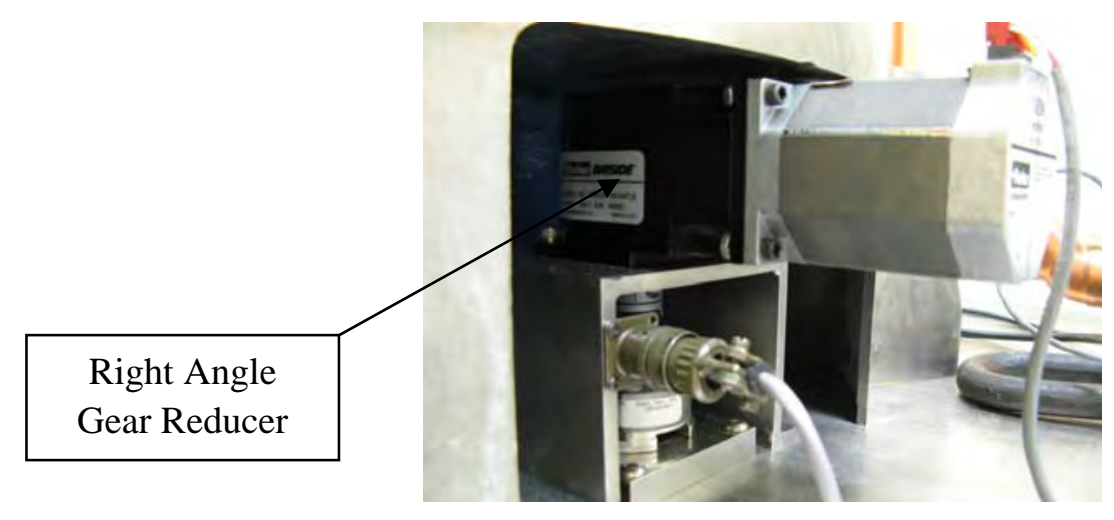

Figure 8.3. Carousel Drive Stepper Motor and Gear Reducer

\subsection{Oldham Coupling}

The Oldham coupling (Figure 8.4) is a three-piece shaft coupling used to compensate for any radial misalignment between the gear-reducer output and the carousel drive shafts. The coupling also acts as a mechanical fuse, shearing in the case that the torque required to turn the carousel rises above approximately $168 \mathrm{lb} \cdot \mathrm{in}$. This condition can be caused by a carousel bearing problem, the introduction of foreign material into the close clearances around the carousel, or when multiple source carriers end up in the same source position. There is one other advantage to this type of coupling: its quick disconnect feature. Tools are not required to separate the gear reducer assembly from the carousel drive shaft, as the coupling can be hand-separated into three pieces at the shear disk.

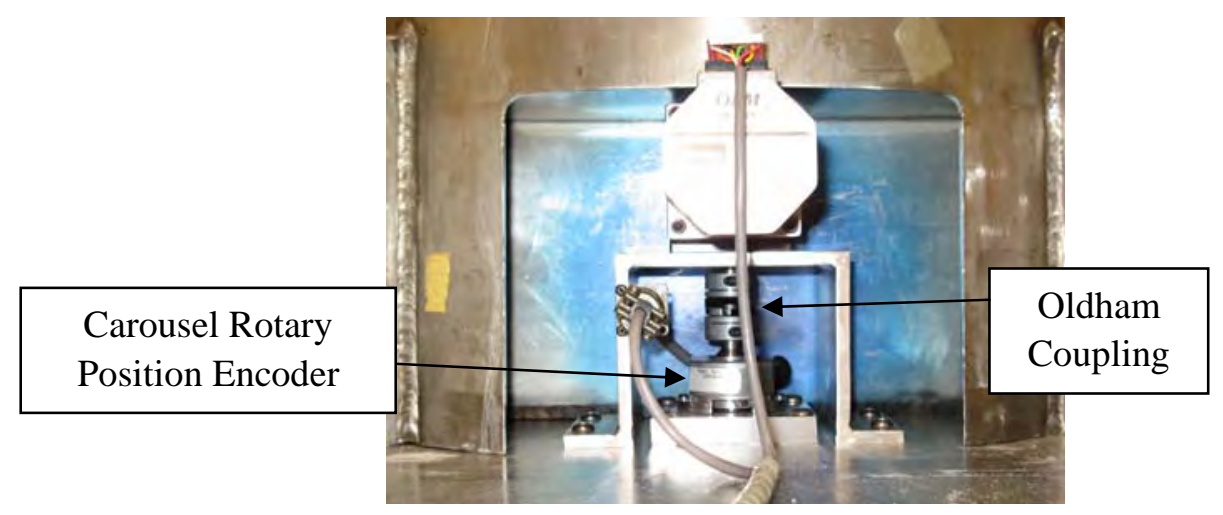

Figure 8.4. Carousel Drive Assembly Showing Rotary Position Encoder and Oldham Coupling

\subsection{Rotary Position Encoder}

The rotary position encoder for the carousel drive is an Encoder Products Co., Inc. type 121-N-A-511-200-R-PP-1-S-N encoder. This encoder provides position feedback to the carousel drive/indexer when the carousel is rotating to a new source storage position. With a resolution of 8000 pulses per revolution, it can resolve 0.045 degrees of carousel rotation. This translates into a source storage position misalignment, relative to the source travel pipe in the column, of less than $0.004 \mathrm{in}$. It is physically located below the Oldham coupling on the carousel drive shaft, so in the event of coupling slippage on the gear-reducer output or the carousel drive shafts, the encoder will always accurately reflect the position of the carousel. 


\subsection{Instrument Platform System}

The instrument platform system includes a linear rail system, a stepper motor, a stepper motor drive/indexer, a gear reducer, a rotary position encoder, and an instrument platform. The drive system shares its power supply with the carousel system.

\subsection{Linear Rail System}

Supporting the instrument platform are a pair of Parker Daedal extruded aluminum linear rails. These rails provide over $5 \mathrm{~m}$ of travel and are capable of supporting over $45 \mathrm{~kg}$. Running down the center of the rails are platens that provide the motive force necessary to move the instrument platform. Connected to the platens from inside the rails is a toothed polyurethane drive belt that forms a loop from one end of the rail system to the other. The square rail supports the weight of the instrument platform and encloses the belt to protect it from debris. A unique magnetic strip seal, formed by two strip magnets on each rail that run from one end to the other on either side of a center slot, completes the seal. This seal runs through the center of the platen and is pushed out of the way as it travels. A drive shaft runs from one rail to the other, in order to provide balanced drive torque to both rails.

Installation of these rails was quite a challenge, due to the unevenness of the floor. The top of the instrument platform was required to maintain a constant position, relative to the horizontal alignment laser over the entire length. Maintaining a constant distance between the rails, and keeping the rails parallel with the horizontal alignment laser from one end to the other were other challenges in the installation. These steps were accomplished by positioning a clear Lucite target on the instrument platform, training the laser onto the target, and running the platform from one end to the other. By trial and error, the rails were lain in the correct horizontal position. Obtaining the correct rail height required many aluminum shims to be machined and installed between the rails and the floor, every $4 \frac{1}{2} \mathrm{ft}$ along their lengths. The shims were then affixed to the floor using concrete wedge anchors.

Attached to one of the rails are three roller-plunger type microswitches that are operated by an actuator extending from the platen. One microswitch at each end of the rail signals to the linear rail drive/indexer that the instrument platform has come to the end of its travel. If this occurs, the drive/ indexer abruptly stops advancing the stepper motor (without the usual end-of-move deceleration). This is necessary to prevent the platens from running into the mechanical stops at the end of the rails. A third switch is used to signal the drive/indexer that the instrument platform is within the home, or zero region. When this switch is active in conjunction with an active home mark signal from the rotary position encoder, the instrument platform home position is established. This is the position that all future moves of the instrument platform will be relative to.

Affixed to the edge of the south-most rail is a graduated linear scale with metric markings and a resolution of $1 \mathrm{~mm}$ (Figure 9.1). It is used to determine a calibration coefficient for the rotary position encoder that relates output pulses from the encoder to linear displacement of the instrument platform (in millimeters). This is done by commanding the drive/indexer to move the instrument platform a specific number of encoder steps and then measuring the instrument platform displacement from the graduated scale. The number of steps used was initially determined by trial and error, until the instrument platform was traveling from the home position to the far end. It takes roughly 113,000 encoder steps for the 
instrument platform to traverse that distance, which results in $4240 \mathrm{~mm}$ of instrument platform displacement. From these numbers a value of $0.037522 \mathrm{~mm} /$ encoder step was originally determinedand it is still accurate. To provide a better-than-1-mm positioning accuracy of the instrument platform after a transit of more than $4 \mathrm{~m}$ requires that 5 significant digits of the calibration coefficient be usedhence the value of $0.037522 \mathrm{~mm} / \mathrm{encoder}$ step.

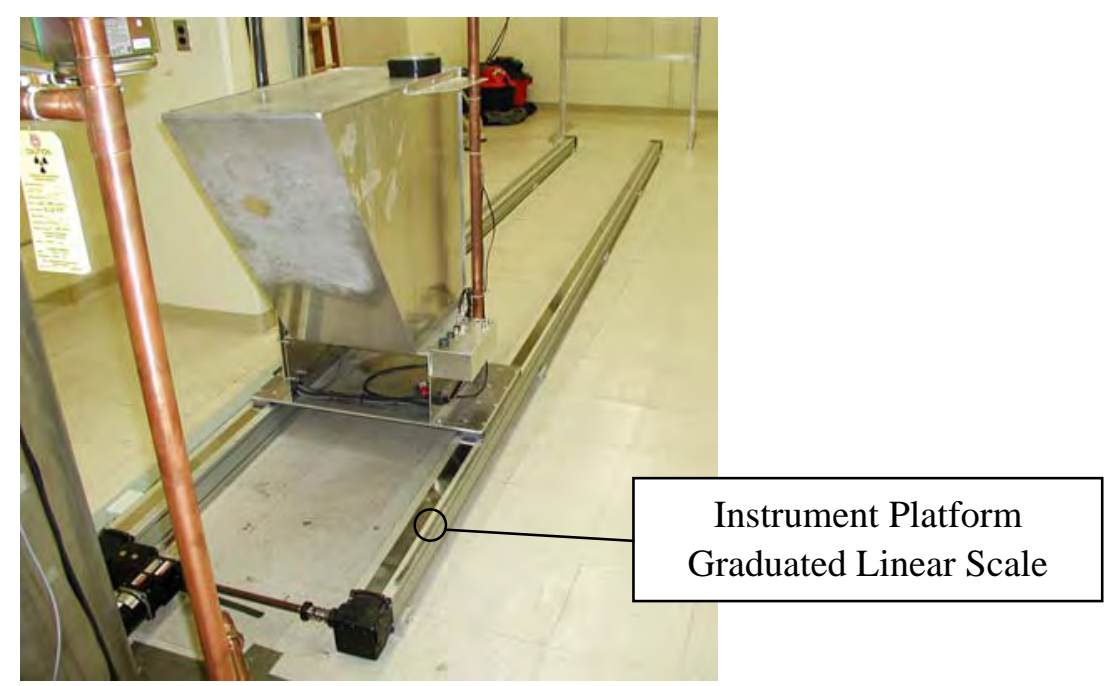

Figure 9.1. Linear Rails

\subsection{Stepper Motor}

A stepper motor (Figure 9.2), mounted at the end of the rail system nearest the irradiation column, drives the instrument platform. This motor is a NEMA size 34 motor, manufactured by Compumotor, type OEM83-135-MO.

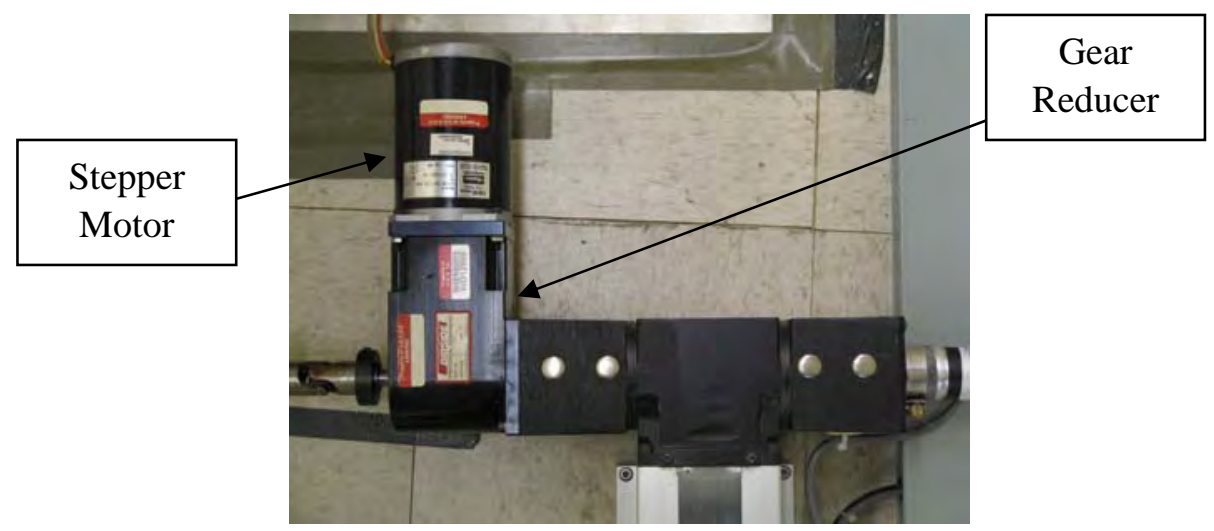

Figure 9.2. Instrument Platform Stepper Motor and Gear Reducer

\subsection{Stepper Motor Drive/Indexer}

An OEM650X microstepping drive plus indexer (Figure 9.3), manufactured by Compumotor, controls the stepper motor. The drive/indexer receives its instructions from the facility control computer 


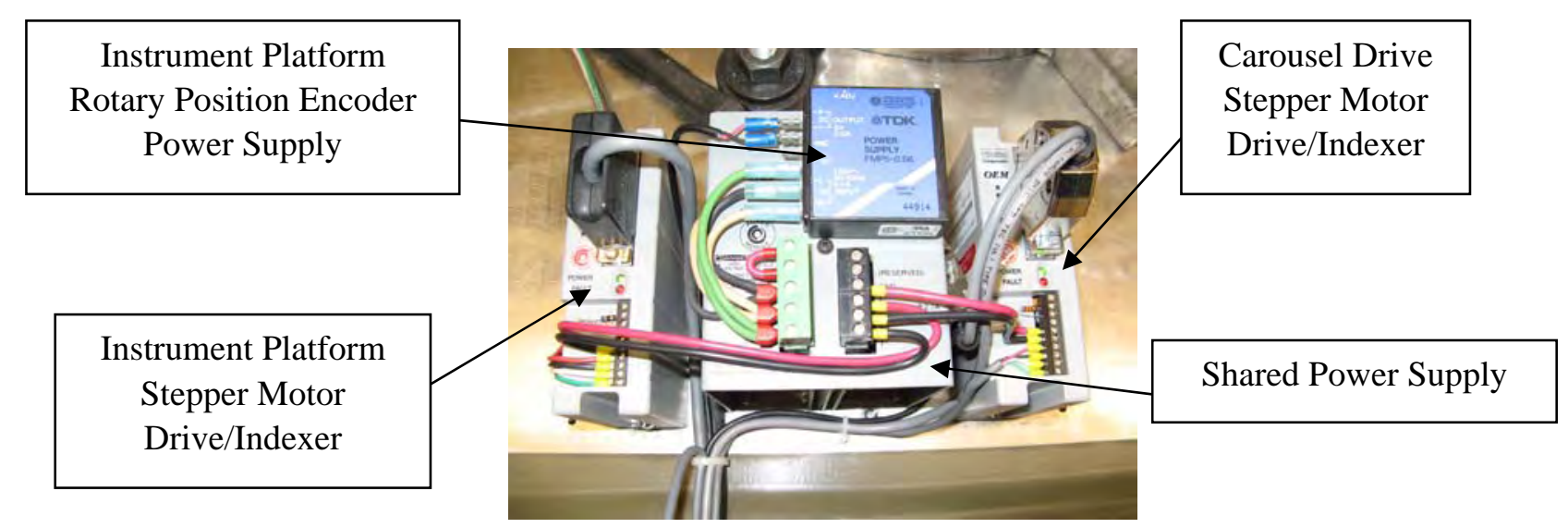

Figure 9.3. Stepper Motor Drive/Indexers and Shared Power Supply (enclosure removed)

to adjust the instrument platform along the linear rails. Once the drive receives the command to move the instrument platform to a new position, the indexer portion of the drive calculates the number of steps that must be sent to the motor (based on the current position indicated by the rotary position encoder and the desired position), and using a trapezoidal motion profile, moves the platform.

\subsection{Shared Power Supply}

A Compumotor OEM300 power supply (Figure 9.3), producing $75 \mathrm{~V} \mathrm{DC}$, is shared by the instrument platform stepper motor drive and source carousel stepper motor drive. For more information, refer to the Carousel System section within this document.

\subsection{Gear Reducer}

The gear reducer (Figure 9.2), with a gear ratio of 5:1 or 5 motor shaft revolutions per 1 output shaft revolution, allows a lower-torque motor to drive the instrument platform. A Bayside Motion Group model NR34D-005 gear reducer couples the instrument platform system's stepper motor output to the linear rail system drive shafts. This is a right-angle, dual-output shaft type with an integral mount for a NEMA size 34 motor.

\subsection{Rotary Position Encoder}

The instrument platform's rotary position encoder (Figure 9.4) is an Encoder Products Co., Inc. type 755A-31-S-1000-R3-PP-1-23A-S-N encoder. It generates 4000 pulses/revolution, which translates into a linear position resolution of $0.037522 \mathrm{~mm} /$ encoder step. The encoder provides two outputs in quadrature plus a home mark signal output, and has push-pull output drivers. It has a NEMA size 23 mounting with a coupling to connect to a $1 / 4$-in. diameter shaft. This encoder is powered by a TDK FMP5-0.6K power supply rated at $5 \mathrm{~V}$ DC with a maximum load capacity of $600 \mathrm{~mA}$. 


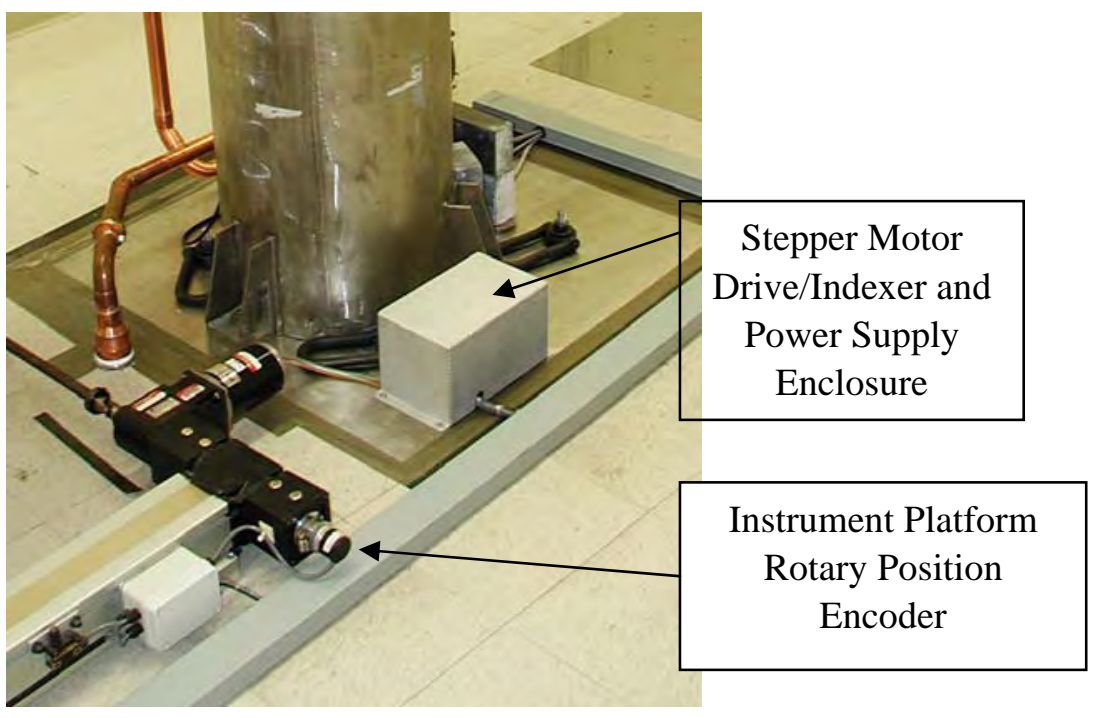

Figure 9.4. Stepper Motor Controllers and Rotary Position Encoder

\subsection{Instrument Platform}

An irradiation instrument platform (Figure 9.5), placed in the irradiation beam, holds material within the beam. Since most of the materials irradiated in the HEF are large relative to the diameter of the beam, they must be held as radially close to the center of the beam as possible. (The instrument platform can position objects horizontally along the beam, as well.) The platform can move variable distances relative to the vertical alignment laser, which acts as the 1-m reference. Software limits restrict the platform to moving distances of $0.365 \mathrm{~m}$ to $5.365 \mathrm{~m}$ from the center of the irradiation column. Micro switches provide a second set of limits by restricting the platform to distances of $0.355 \mathrm{~m}$ to $5.382 \mathrm{~m}$ from the center of the column. Finally, the platform is physically restricted between to distances of $0.275 \mathrm{~m}$ and $5.457 \mathrm{~m}$ from the center of the column.

\subsection{Video Cameras}

Two video cameras are installed in the exposure room (Figure 9.6) to provide video images to the operator (Figure 9.7). The cameras are $1 / 3$-in. medium resolution charge coupled device color video cameras with automatic light level control that can accept a variety of C- or CS-mount lenses. The camera on the instrument platform is equipped with a manually focused, 8.5-mm fixed focal length, F1.3 aperture lens with a manually adjustable iris. (Personnel use the video monitor in the exposure room as the reference for lens adjustments.) This camera is used by personnel to remotely observe the meter readings of radiation detection instruments undergoing calibration. It is expected to last two years at most, due to frequent use in the primary radiation beam.

The wall-mounted camera is the same type used on the instrument platform; however, the lens is different, and the camera is mounted on a pan and tilt drive. It has an F1.4 aperture motorized zoom lens with a focal range of $6 \mathrm{~mm}$ to $60 \mathrm{~mm}$. This camera is primarily used to observe the interior of the exposure room and to confirm that items placed onto the instrument platform have not shifted position during platform movement. It can be controlled from the control panel by using the pan, tilt and zoom controls. 


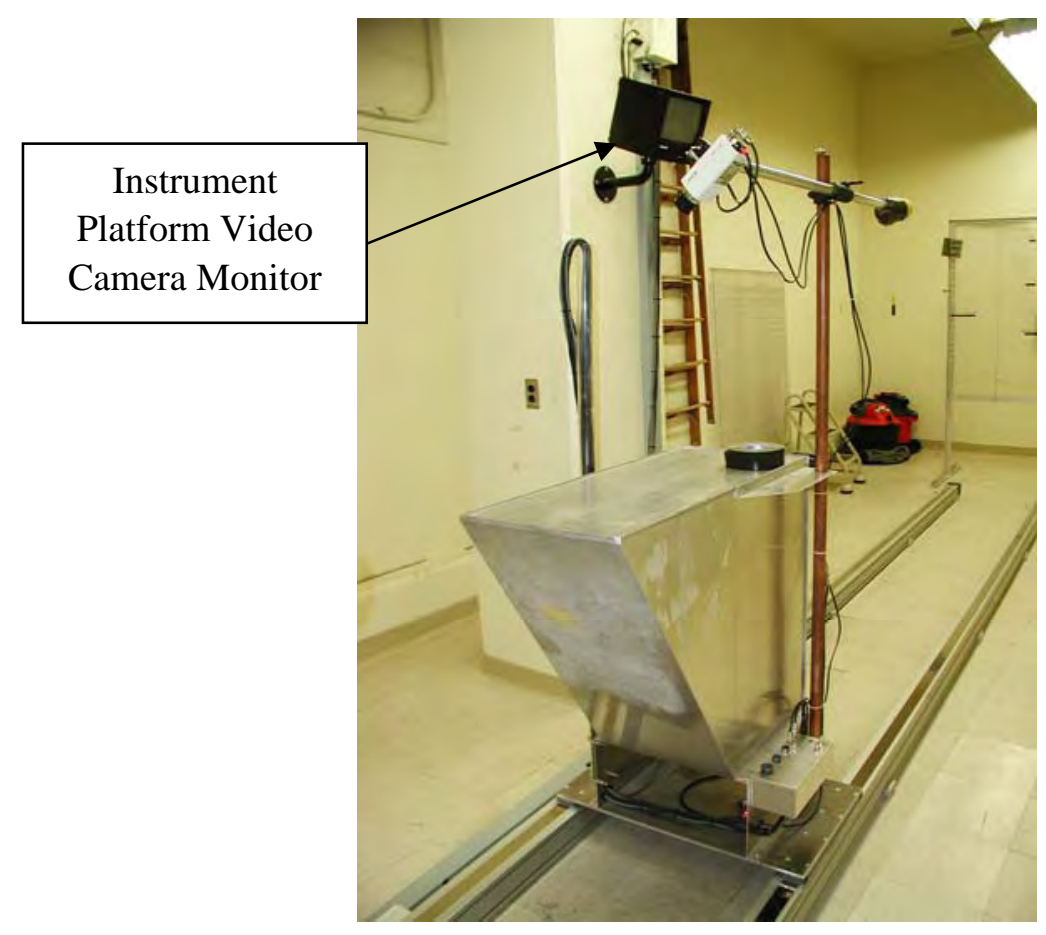

Figure 9.5. Instrument Platform showing Exposure Room Video Monitor

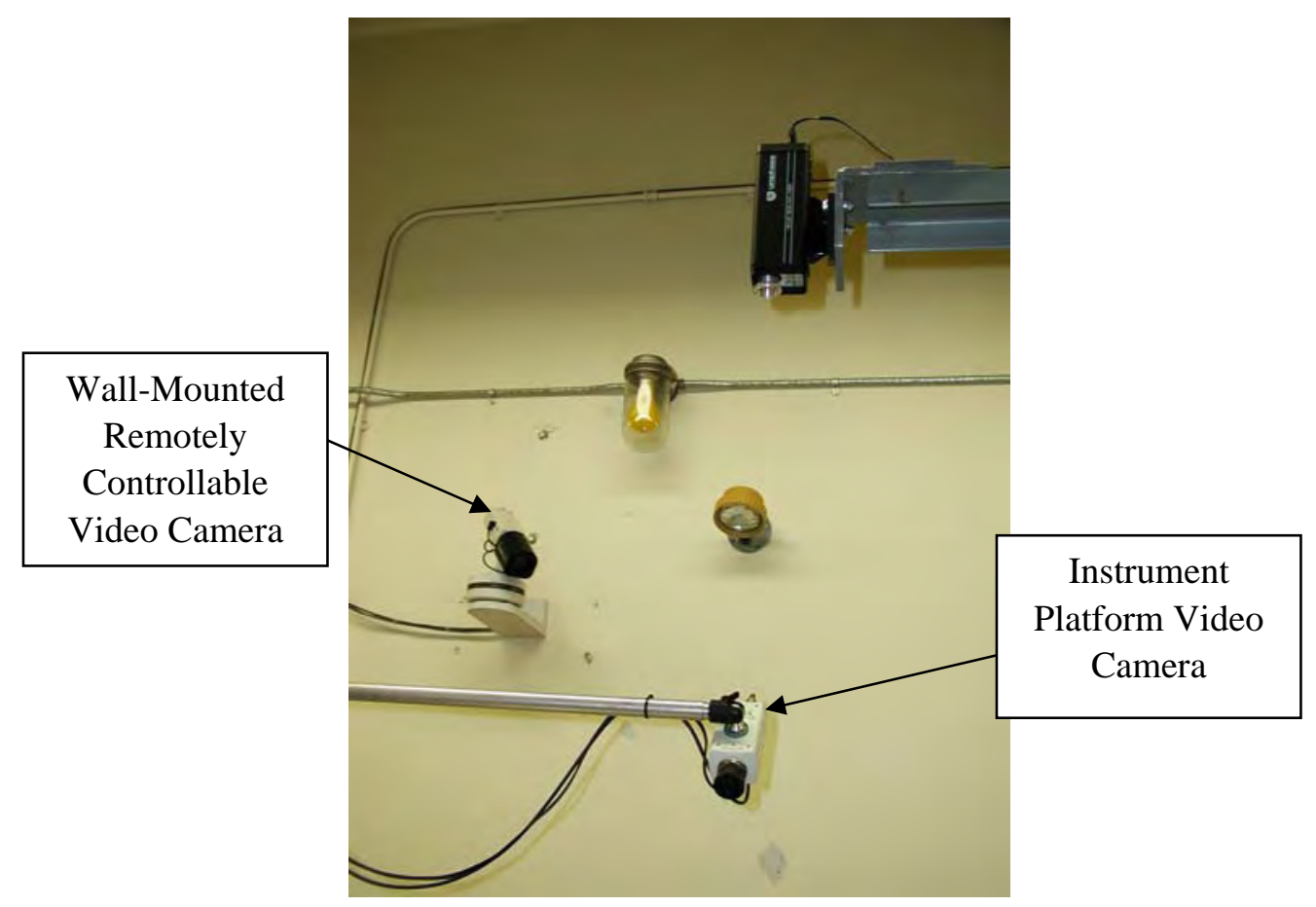

Figure 9.6. Instrument Platform and Exposure Room Video Cameras

The output taps under the video monitors (Figure 9.7) can be used to connect additional monitors and video recorders as they supply a composite video feed. For instance, they have been used to connect additional video screens during remote source transfers. 


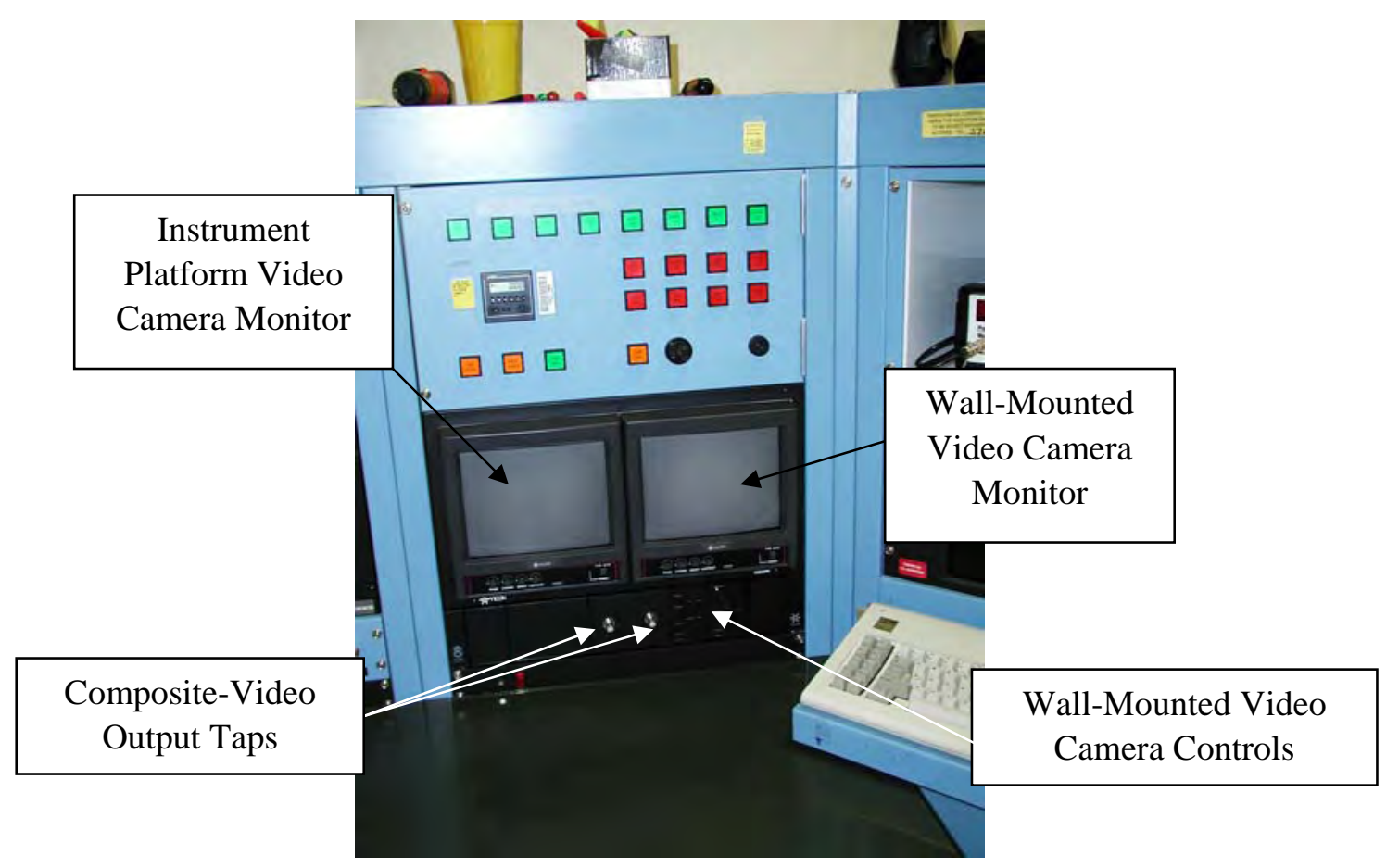

Figure 9.7. Video System

\subsection{Instrument Wiring}

Built-in wiring allows personnel to separate the radiation detector from its readout indicator during calibration. Three multi-conductor cables and two coaxial cables run from the instrument platform (Figure 9.8) to the control panel (Figure 9.9), allowing a wide variety of instruments to be connected remotely.

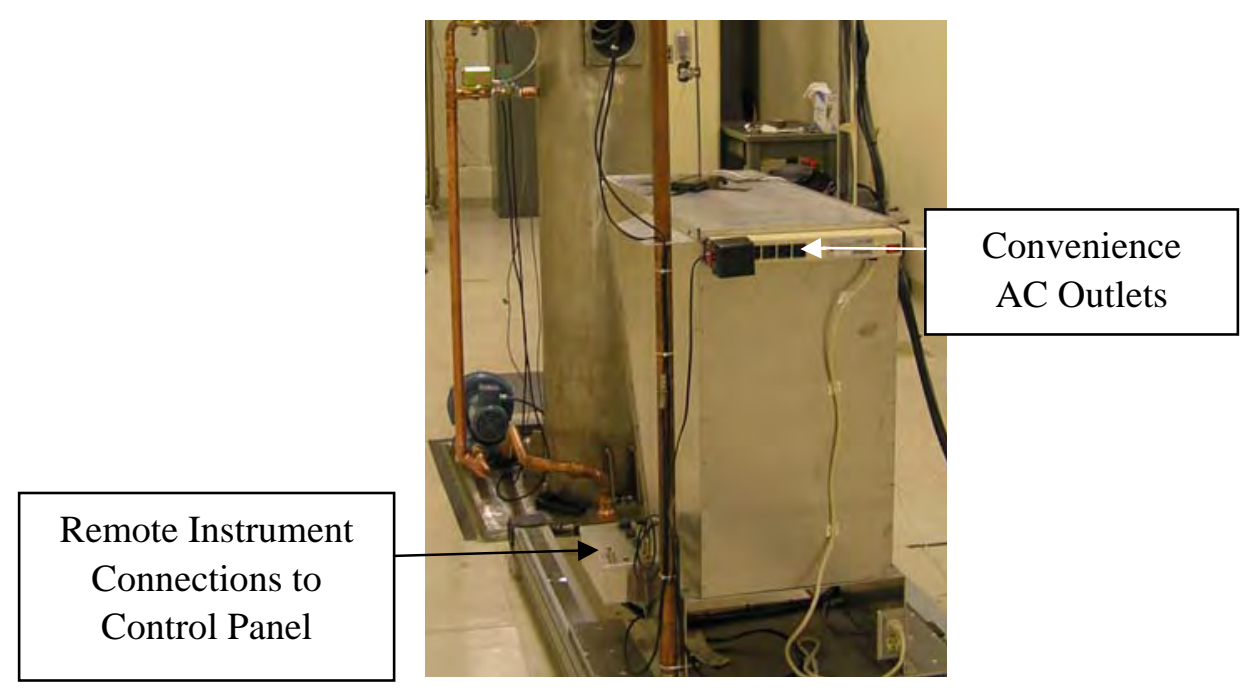

Figure 9.8. Remote Instrument Connections at Instrument Platform 


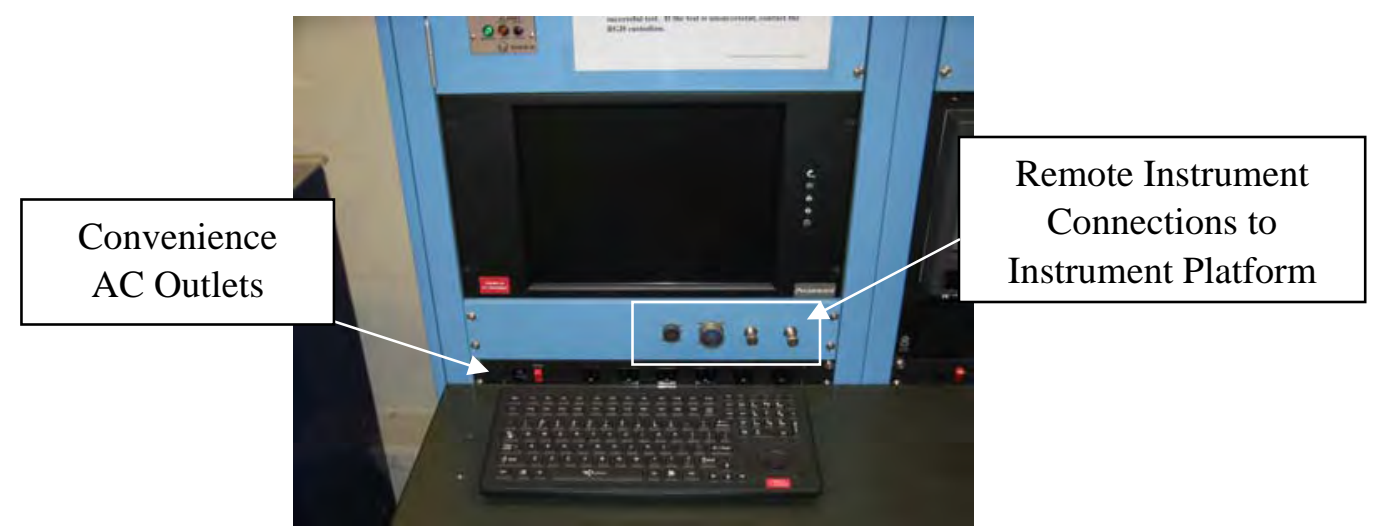

Figure 9.9. Remote Instrument Connections at Control Panel

\subsection{AC Power}

Additionally, convenient sources of $120-\mathrm{V}$ power are available at the control panel and the instrument platform; these power sources were intended to provide electricity for line-powered devices, if required. However, these sources are shared with other devices - it is important to restrict the load to less than $5 \mathrm{~A}$. In the case of the instrument platform power source, supplemental overcurrent protection, in the form of a resettable circuit breaker, is provided to dump the load on the power strip if it exceeds 5 A. This circuit breaker is located on the side of the instrument platform umbilical cable's junction box. 



\subsection{Supplementary Physical Components of the HEF}

The HEF relies upon several supplementary components for maintenance, testing, and quality control purposes. These components include a five-ton hoist, a dosimeter irradiation jig, a laser alignment system, a source storage well, and a quality control measurement system.

\subsection{Five-Ton Hoist}

A standard steel I-beam hoist (Figure 10.1) with a trolley attached is the primary mechanism used to move the irradiation column and the source carousel assembly for maintenance purposes. It was designed to be a low-headroom hoist because it requires the capacity to lift the irradiation column from the ground-and a regular hoist would not provide enough clearance. This hoist moves in north and south directions by moving the trolley along the I-beam and raises the load via a chainfall.

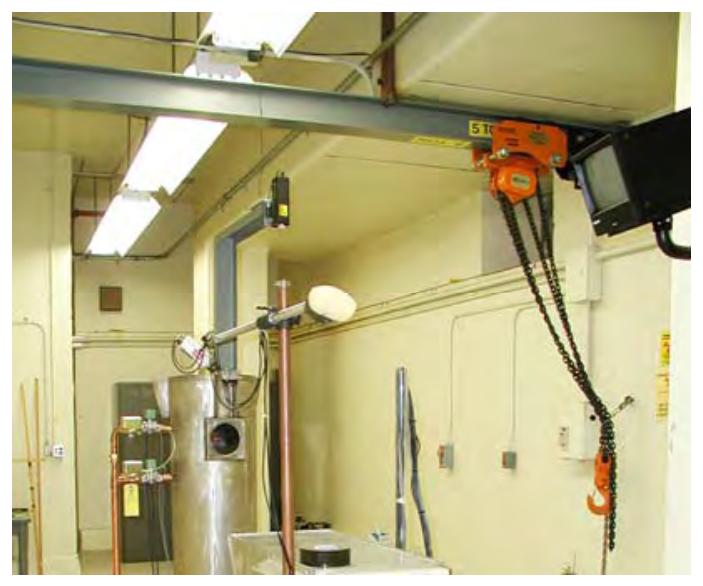

Figure 10.1. Five-Ton Hoist

\subsection{Dosimeter Irradiation Jig}

The dosimeter irradiation jig is a target used to hold dosimeters during calibration. It can hold nearly 700 dosimeters, and is $7.12 \mathrm{~m}$ from the center of the source in the irradiator. Because it is a set distance from the source, it is possible to put a known dose on the dosimeters. The HEF has a jig deployed for use (Figure 10.2), and one spare. Special yellow lights have been installed along the south wall for use during dosimeter irradiations. Thermoluminescent dosimeters (TLDs) (Figure 10.3) are sensitive to exposure to light in the blue spectrum, which causes elevated exposure readings. When the TLDs are placed onto the jig, as well as during their radiation, the yellow lights are switched on and the regular lighting is turned off. 


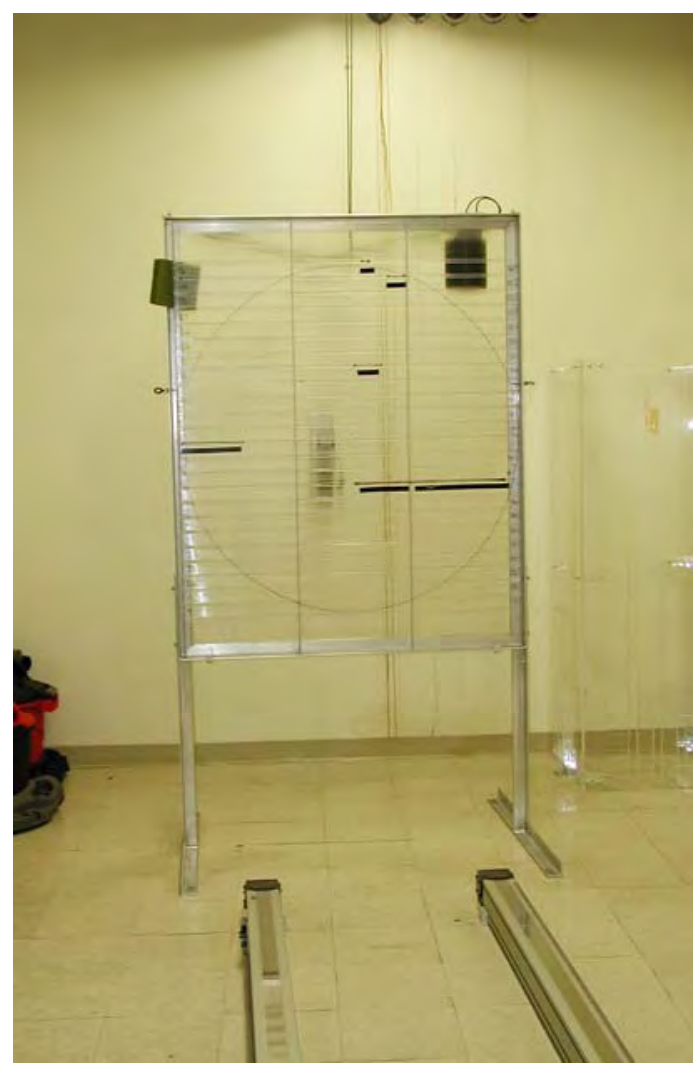

Figure 10.2. Irradiation Jig

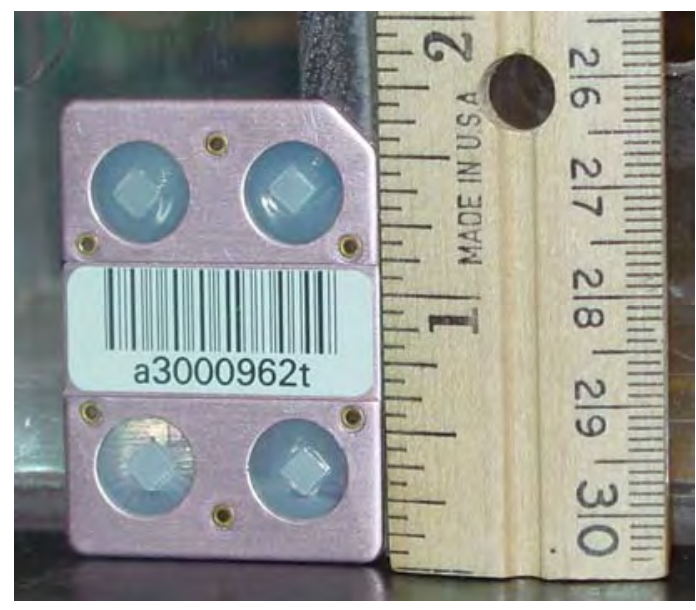

Figure 10.3. Typical TLD Placed on Jig

\subsection{Laser Alignment System}

Alignment lasers, made by JDS Uniphase Corp., are self-contained class II helium-neon lasers with a minimum power output of $0.5 \mathrm{~mW}$ (0.95 mW maximum). The horizontal alignment laser (Figure 10.4) defines a line at the center of the radiation beam cone. This allows materials being irradiated to be placed in the beam's most uniform area (the center). The vertical alignment laser (Figure 10.5) defines a point $1 \mathrm{~m}$ from the center of the source. This is the position to which all other distances will be relative. 


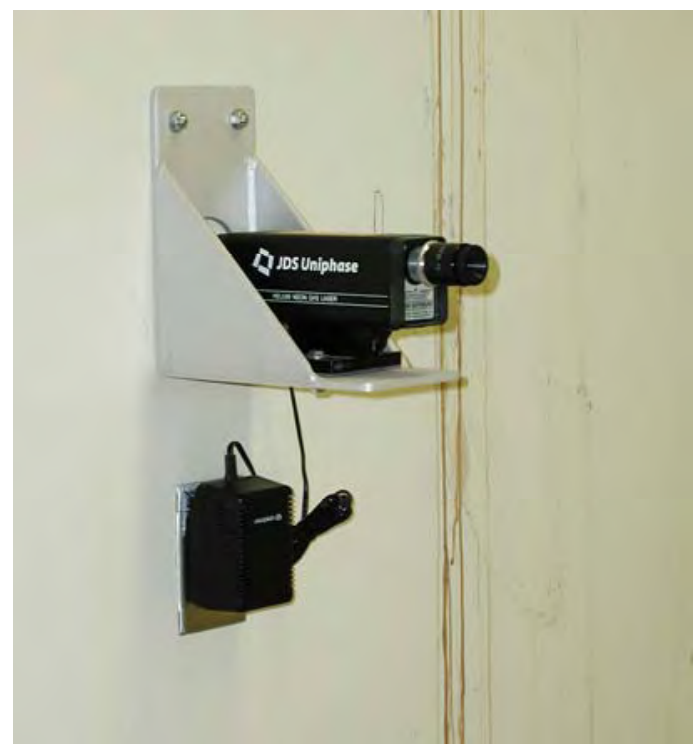

Figure 10.4. Horizontal Alignment Laser

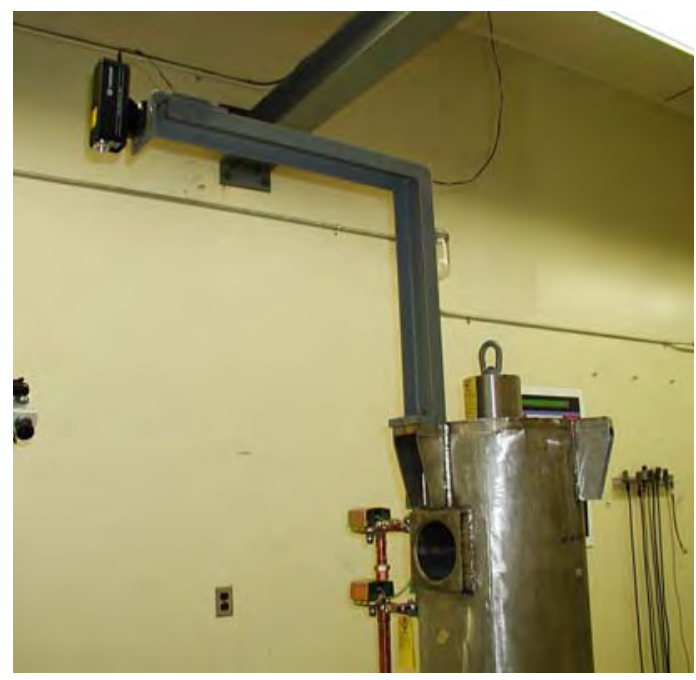

Figure 10.5. Vertical Alignment Laser

\subsection{Source Storage Well}

The HEF has a source storage well (Figure 10.6) that allows up to five sources to be placed in a radiologically safe location while the irradiation column, shielding, and/or carousel assembly are being disassembled for maintenance. A VHRA guard enclosure (Figure 10.7) is placed around the opening, to prevent personnel from accidentally stepping into or over the storage well when it contains sources in an unshielded configuration. (When a source is unshielded in the well, the room can still be safely entered, as only a 2-in. diameter collimated air space-directly above the storage well—is exposed to radiation. This beam travels upward and eventually hits the ceiling, so the only radiation that personnel in the room have to be concerned about is backscattered radiation from the air the beam travels through, and what returns off of the ceiling.) 


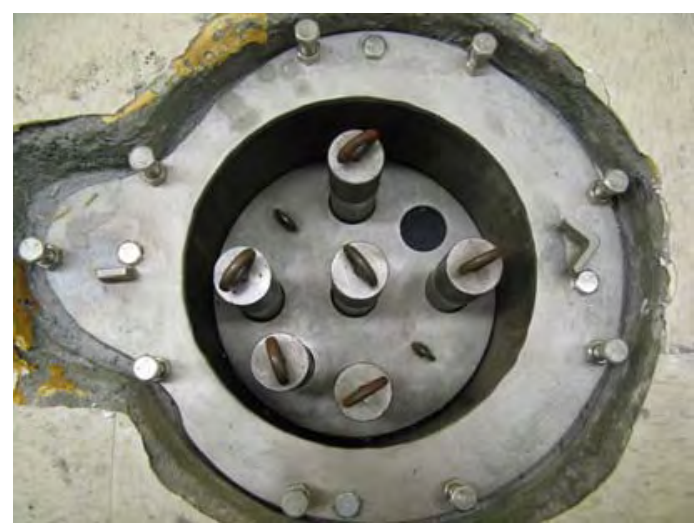

Figure 10.6. Source Storage Well

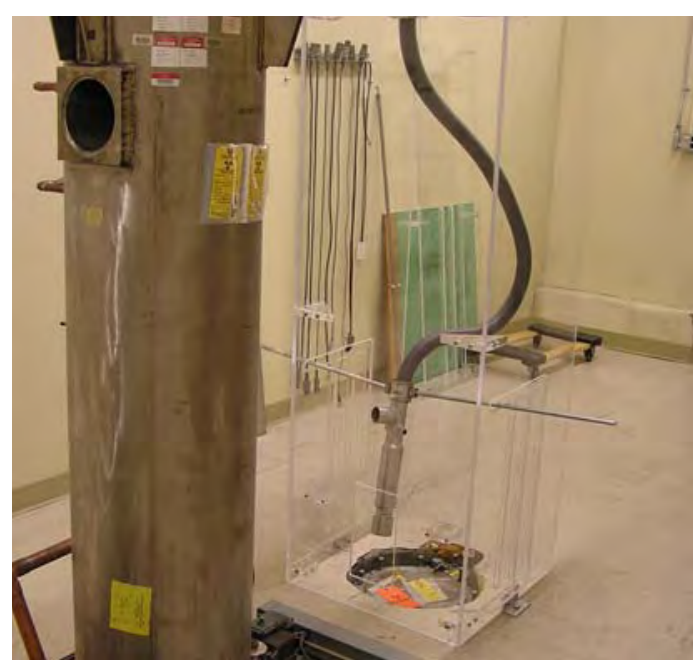

Figure 10.7. VHRA Guard Enclosure in Use

The procedure for transferring these sources from the column to the storage well (Figure 10.8) is described in PNNL's High Exposure Facility Source Transfer Procedure (2006). The cover of the inner storage well (Figure 10.9) is constructed of $3 / 8$-in. thick stainless steel; however, its primary purpose is security. Each of the 5 source storage pipes within the well has an 18-in. carbon steel plug (Figure 10.10) that provides shielding. Of the remaining sources not stored in the storage well, one is the dummy source; the final two are low-activity sources that can be lifted into and out of the column using a magnet attached to a lifting device and stored in small radioactive source storage casks. 


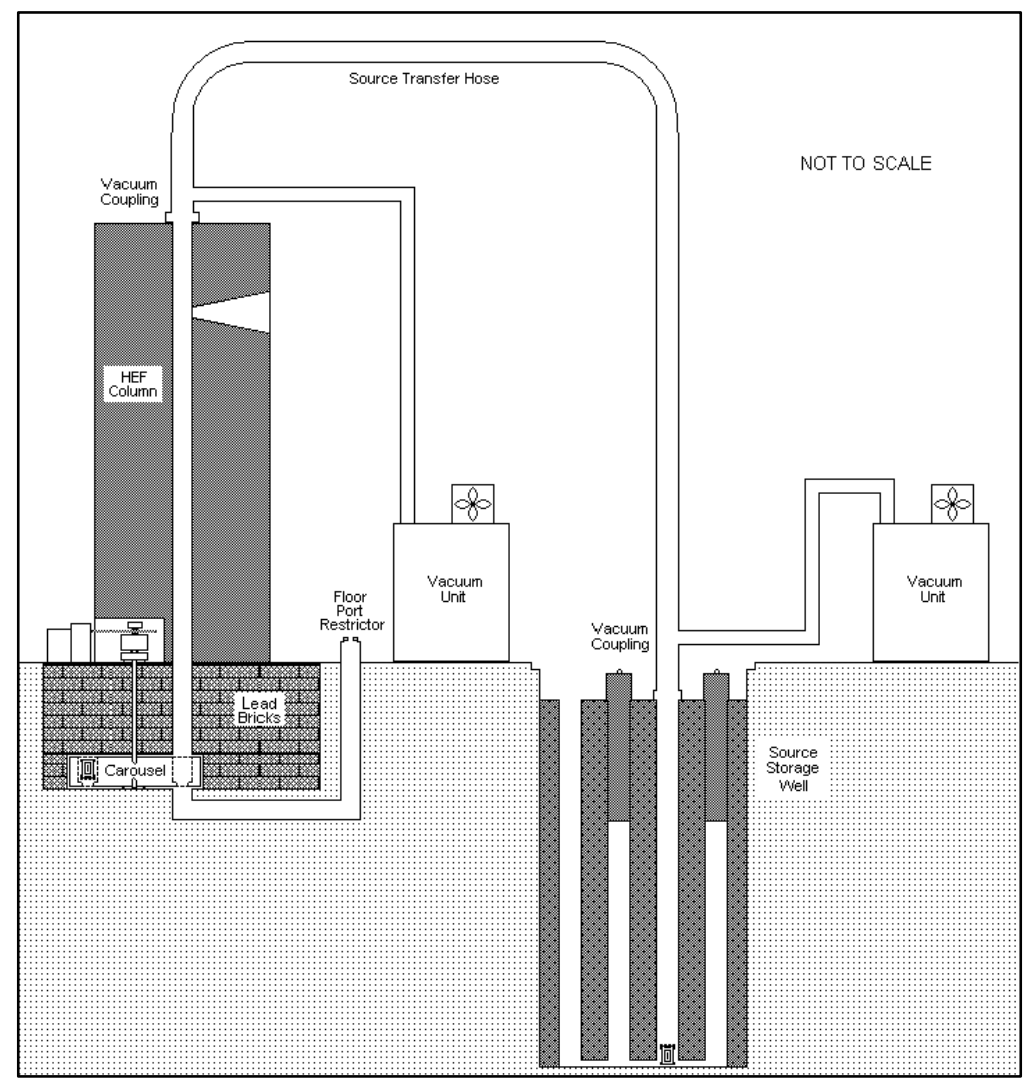

Figure 10.8. Graphic of Source Storage Transfer

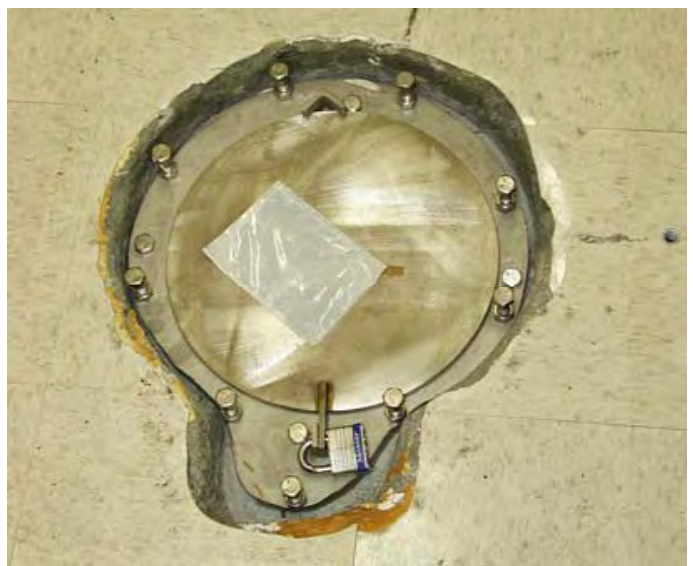

Figure 10.9. Source Storage Well Inner Cover 


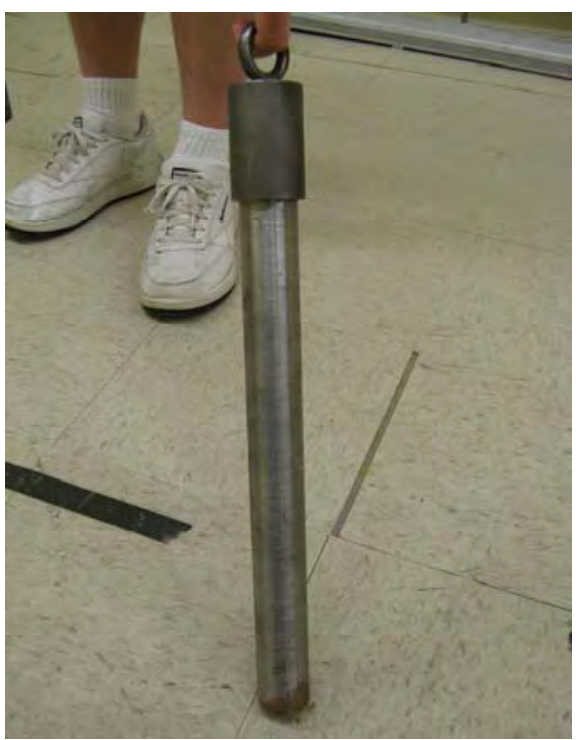

Figure 10.10. Source Storage Well Carbon Steel Shield Plug

\subsection{Quality Control Measurement Systems}

The quality control measurement system (Figure 10.11) consists of two ion chamber-based systems that are used to accumulate total radiation exposure delivered over time. One, a Far West Technology model $1000 \mathrm{~cm}^{3}$ ion chamber, with a sensitivity of $8.3 \mathrm{E}-11 \mathrm{~A} / \mathrm{R} / \mathrm{hr}$, is permanently attached to the TLD irradiation jig. The other measurement system can be attached to the instrument platform, and is a model PM-30 ion chamber, produced by Capintec. It is roughly $28 \mathrm{~cm}^{3}$ in volume, and has a sensitivity of about $2.4 \mathrm{E}-12 \mathrm{~A} / \mathrm{R} / \mathrm{hr}$. The ion chambers' output signals are collected by electrometers, which integrate the total charge created by radiation-ionizing a counting gas. The electrometers have very high input impedance and gain, with the latter yielding a high-input sensitivity. For higher-level signals, the charge can also be displayed by the electrometer directly in amperes. This measurement is reserved for measurements made at higher exposure rates because, at these levels, the electrical noise is a smaller fraction of the signal level's total. By applying the conversion factors to the electrometer indication determined for the ion chambers during calibration, the total exposure can be calculated.

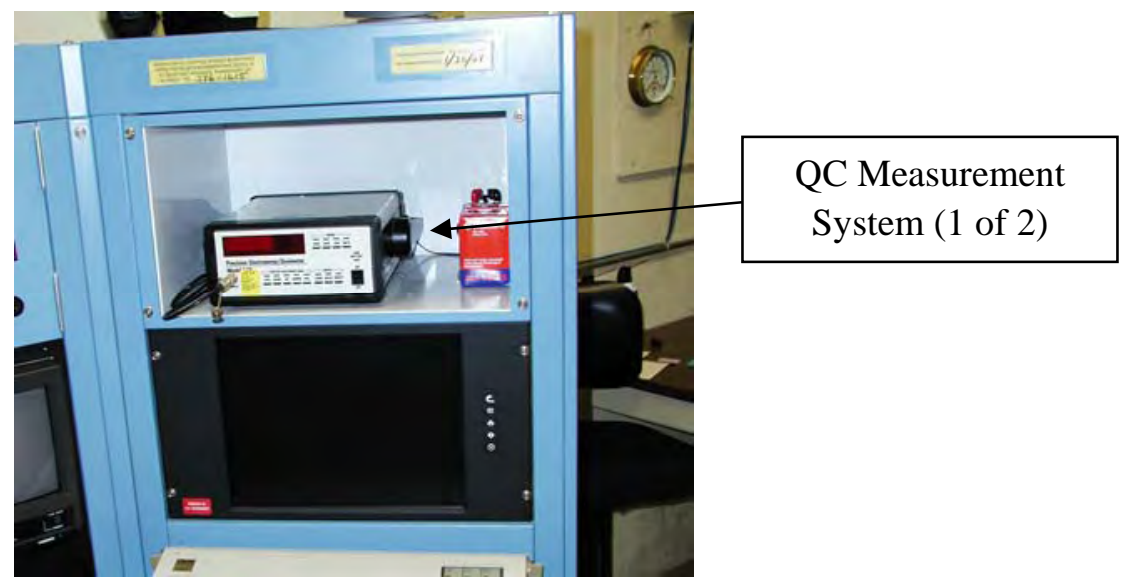

Figure 10.11. Quality Control Measurement System 


\subsection{Control System}

The control system is used to select a specific source, monitor irradiation functions, display alarms and warnings, and clear existing alarms. The system features luminescent indicators, a digital timer, a PLC, digital inputs and outputs, and a ladder logic program. The current system was installed in September 2003 in conjunction with the move from a 4-source to an 8-source carousel.

\subsection{Control Panel Layout}

Protected by a key switch located at the bottom-right, the control panel (Figures 11.1 and 11.2) can only be operated by trained personnel, as only trained operators have access to the key. The key switch prevents the system from being operated while the switch is set to the off position; additionally, if the key is turned to the off position while the system is in operation, an orderly shutdown of the system will occur.

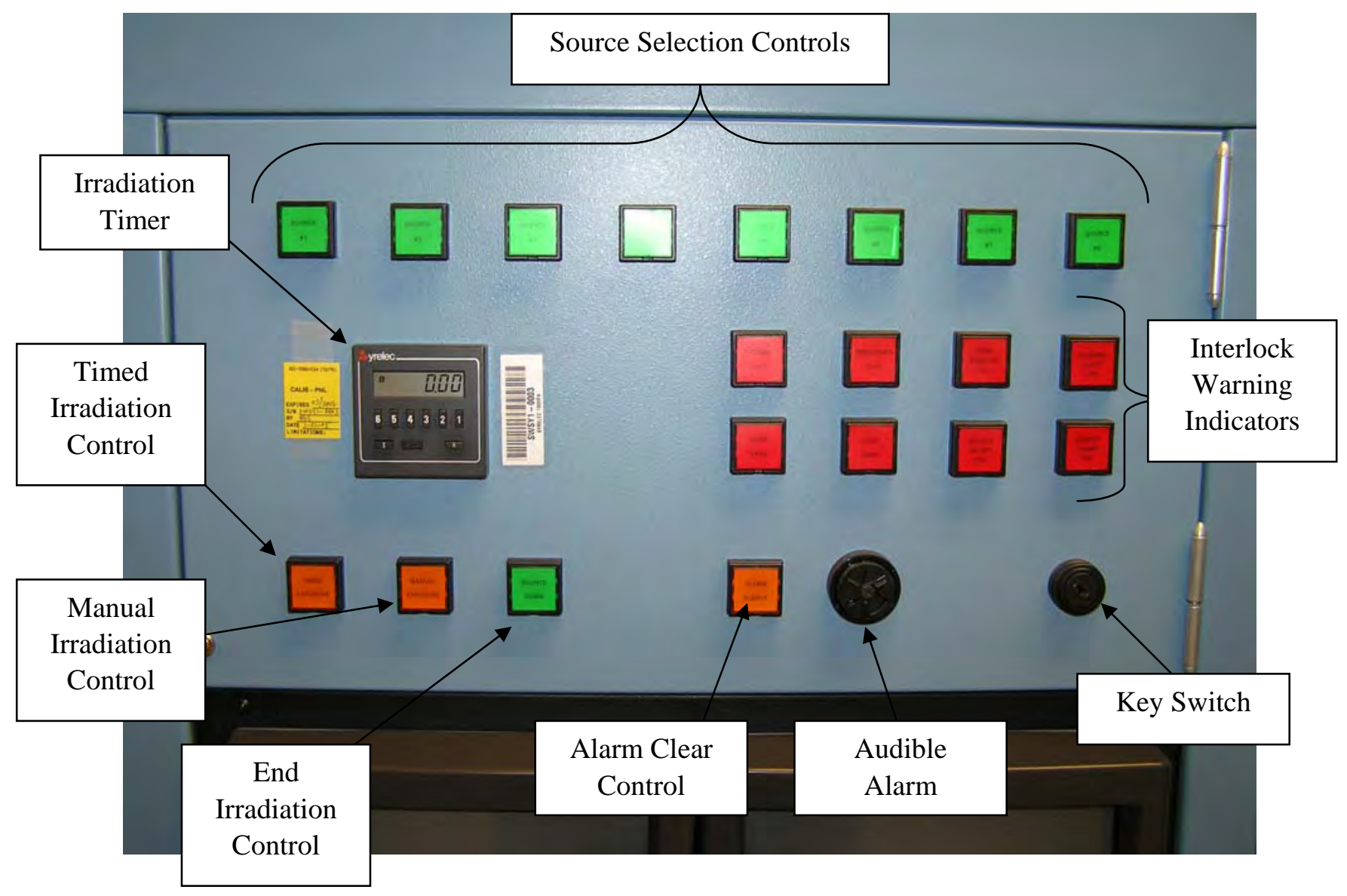

Figure 11.1. Source Control Panel 


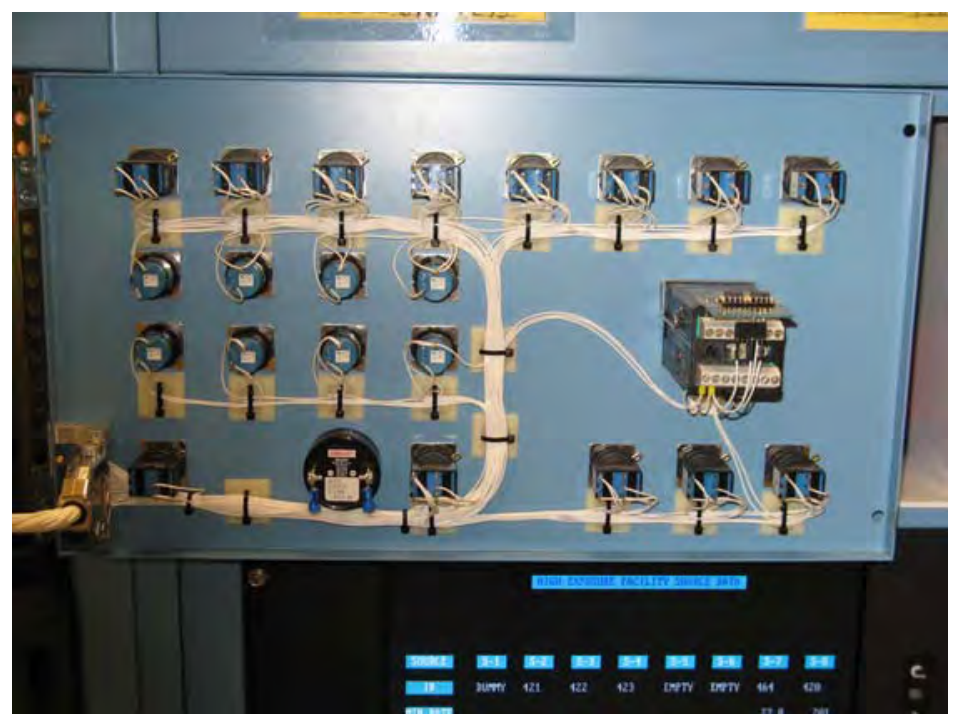

Figure 11.2. Rear Wiring of Source Control Panel

The source selection controls allow operators to choose a source for irradiation. They range, from left to right, as source one through source eight, respectively.

The interlock warning indicators illuminate when alarms exist. They are, from top-left to bottomright:

- Power Fail. This occurs when the PLC program is interrupted by a loss of AC power. If this happens during an irradiation, the system shuts down in an orderly fashion (after the resumption of power), and the irradiation timer (which has an internal battery backup) retains the remaining irradiation time.

- Emergency Stop. An emergency stop button has been depressed, or an emergency stop button was pressed while an irradiation was in progress.

- Area Monitor Fail. The area monitor has failed, or the area monitor went into failure while an irradiation was in progress. (The area monitor will go into failure if a circuit in the area monitor does not receive a pulse from the detector within a 2-min to 3-min period.)

- Warning Light Fail. One or both of the radiation warning lights failed (burned out) while an irradiation was in progress.

- Door Open. The exposure room door has been opened or was opened while an irradiation was in progress.

- Light Beam. The light beam has been interrupted, or was interrupted while an irradiation was in progress.

- Source Select Fail. The stepper motor drive/indexer has failed to report the correct carousel position back to the PLC within 15 s.

- Source Pneumatic Fail. The source failed to reach the pre-irradiation staging position while being raised within $10 \mathrm{~s}$, or the source has failed to reach its storage position in the carousel while being lowered within $10 \mathrm{~s}$. Two differential pressure switches determine these states for the PLC. 
The timed irradiation control button is used to start an irradiation; the irradiation will end when the irradiation timer reaches zero. (This is the only control that activates the irradiation timer. To set the irradiation timer, refer to High Exposure Facility Standard Operating Procedure [PNNL 2006]. This document can be provided by PNNL's Radiation and Health Technology Group.) The manual irradiation control button is used to start an irradiation of indefinite length. The end irradiation control button terminates a timed or manual irradiation. If a timed irradiation is terminated early using this control button, the irradiation timer will retain the amount of irradiation time remaining.

The alarm clear control button acknowledges and clears an alarm-caused termination of an irradiation. This control button will only function when illuminated, indicating that the cause of the alarm has been corrected. (For example, if an emergency stop button in the exposure room was pressed while an irradiation was in progress, but the emergency stop button has not yet been reset, the alarm clear control will not be illuminated and pressing the control will not clear the alarm.)

Finally, the audible alarm on the control panel is used to alert personnel that someone has opened the door to the exposure room, or that someone in the exposure room pressed an emergency stop button while an exposure was in progress.

\subsection{Panel Controls}

Idec LW series square switch and indicator devices were chosen for the operator controls on the control panel, as the indicators use multi-element light emitting diodes which should never burn out, and the square flat lenses of the indicators are easily labeled using a labeling machine loaded with black-onclear tape. Additionally, the contacts are gold plated, which should provide many years of trouble-free operation.

\subsection{Irradiation Timer}

The Syrelec irradiation timer is a microprocessor-based, crystal-controlled, count-down-to-zero timer. It has accuracy of $\pm 50 \mathrm{ppm}$, or about $0.005 \%$. It can time up to $9999.99 \mathrm{~min}$ (almost 7 days), or as short as $0000.01 \mathrm{~min}(0.6 \mathrm{~s})$. When the timer reaches zero, the source is lowered back into the carousel. If timing is interrupted, the timer retains the remaining irradiation time. In the event of an AC power outage, the timer has a backup battery capable of maintaining its memory for approximately 1500 hours.

\subsection{Programmable Logic Controller}

The HEF's PLC (Figure 11.3), manufactured by Koyo, consists of a 6-slot expansion base with integral 120-V AC input, 24-V DC output power supply, a central processing unit (CPU) module, 2 digital input modules, 2 digital output modules and a toggle-switch input module. 


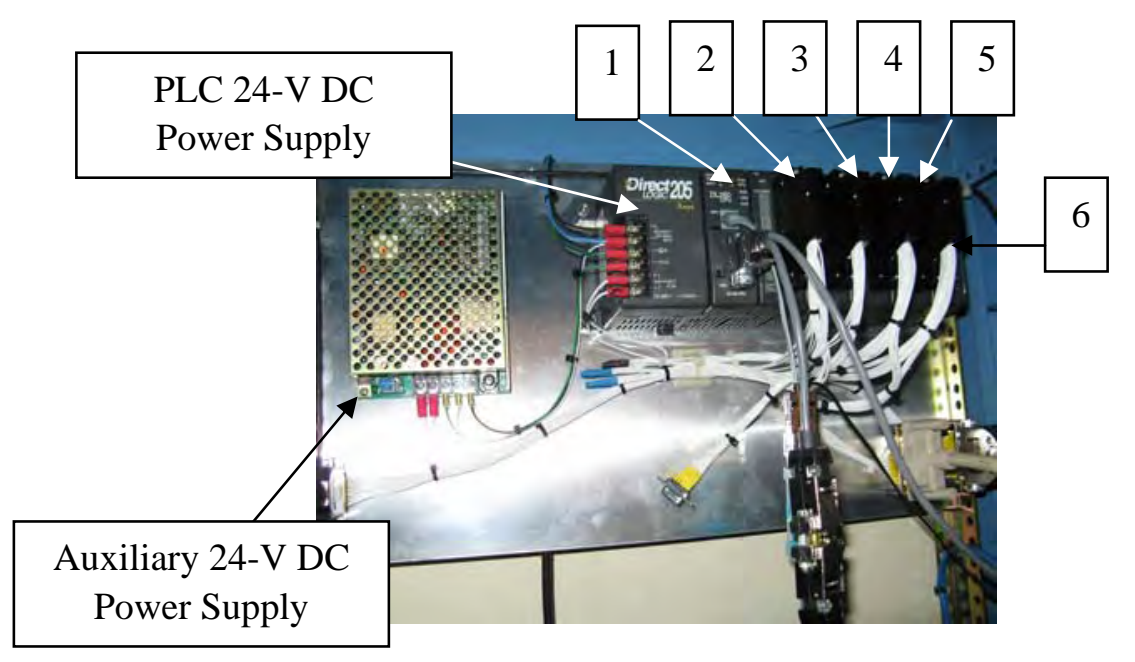

Figure 11.3. $\quad$ PLC and Associated Components. (1) CPU; (2) digital input model no. 1; (3) digital output module no. 1; (4) digital input module no. 2; (5) digital output module no. 2; (6) toggle switch input module.

\subsubsection{Central Processing Unit Module}

The CPU module is an AutomationDirect DL205 series, type DL260 residing in slot one of the PLC's six-slot expansion base. This is the lowest-level CPU available from AutomationDirect that provides two RS-232C communication ports, and that has extended commands to handle ASCII text strings. Two ports are required-port one links to a personal computer to input programming, and port two links to the carousel drive stepper motor drive/indexer. Refer to Table 11.1 for the CPU's general specifications.

Table 11.1. General Specifications for the DL260 CPU

\begin{tabular}{||l|c|}
\hline \hline Total program memory: & $30.4 \mathrm{k}$ words \\
\hline Ladder program memory: & 15,872 words \\
\hline Local I/O points available: & 256 \\
\hline Number of CPU instructions: & 231 \\
\hline Number of control (internal) relays: & 2,048 \\
\hline Number of special (system) relays: & 144 \\
\hline Number of timers: & 256 \\
\hline Number of counters: & 256 \\
\hline System error logs: & 1 \\
\hline User error logs: & 1 \\
\hline Watchdog timers: & 1 \\
\hline Scan time (running HEF firmware): & 5 ms or 200 scans/s \\
\hline
\end{tabular}

\subsubsection{Input/Output Modules}

Analog input and output modules are neither used nor needed by the control system. All discrete control signals are digital. 


\subsubsection{Digital Inputs}

AutomationDirect D2-32ND3 modules are used as digital inputs. They are located in the PLC's expansion base, slots two and four. Each module has 32 input points, a design input voltage of 24 V DC, a noise margin of $12 \mathrm{~V}$ DC, and optical input isolation.

The module used for toggle switch inputs is an AutomationDirect F2-08SIM, and it is located in the PLC’s expansion base, slot 6 . The module features eight toggle switches.

\subsubsection{Digital Outputs}

AutomationDirect D2-32TD1 modules are used for digital outputs. They are located in the PLC's expansion base, slots three and five. Each module has 32 output points, a design output voltage of $24 \mathrm{~V} \mathrm{DC}$, an output current rating of $0.1 \mathrm{~A}$ /output, and optical output isolation. The modules also feature an NPN open collector (current sinking) output type.

\subsubsection{Power Supply}

Included as part of the PLC's expansion base is a 120 V AC input, 24 V DC output, low-voltage power supply. This supply is capable of providing $300 \mathrm{~mA}$ output current, and is used exclusively to power the indicators on the control panel. All other devices requiring $24 \mathrm{~V} \mathrm{DC}$ are powered by the auxiliary 24 V DC power supply.

\subsubsection{Program Development System}

DirectSOFT32 version 4.0 was used to edit, compile and test the HEF firmware for the PLC. It was configured to create a relay ladder logic program for the CPU, as this software allows the programmer to enter the ladder logic diagram into the CPU, then compile and download it directly to the PLC. The programming software provides several interesting capabilities. For example, with the programming software running, the PLC will send the current state of every relay to the ladder logic diagram being displayed by the programming software. From this display, personnel are able to determine how the system is operating based on the precise state of the program.

\subsubsection{Initial Setup}

Prior to running the firmware in the PLC, certain hardware configuration parameters need to be set using DirectSOFT32 with an active communication link to the PLC. These parameters cannot be set from within the HEF firmware. The first of these parameters is the memory ranges for data retention during a loss of power. From DirectSOFT32 open the retentive ranges window (Figure 11.4), and enter the values shown. 


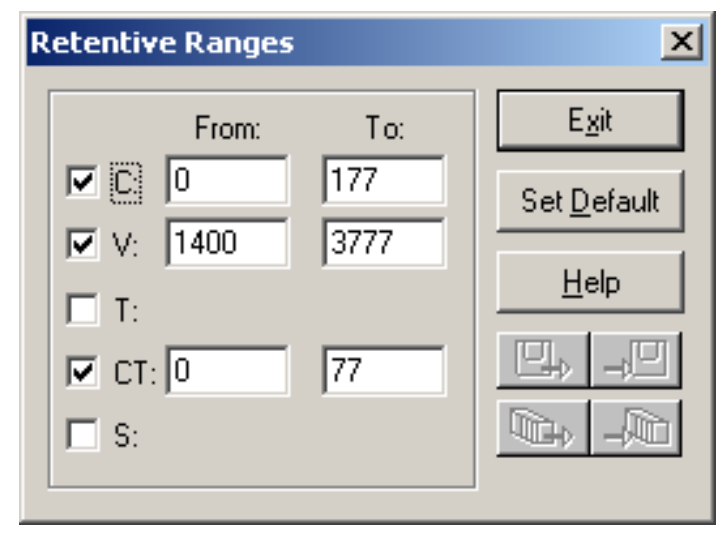

Figure 11.4. Retentive Ranges Settings

The second parameter is the watch dog timer value. This is a safety function that sets up a timeout value. It will prevent a firmware error from locking up the program, which would cause a loss of control of the outputs. To confirm that the timer is set to $200 \mathrm{~ms}$, open the watch dog timer window (Figure 11.5) in DirectSOFT32. If the program execution time exceeds this value, the PLC will switch into program mode and de-energize all outputs. With all of the outputs off, the HEF will completely shut down into a safe state. Since the scan time of the HEF firmware program is $5 \mathrm{~ms}$ to $6 \mathrm{~ms}$, only a catastrophic failure could cause this event. Even though $0.2 \mathrm{~s}$ may seem large relative to the firmware program's scan time, it is still fast enough to terminate program execution if needed.

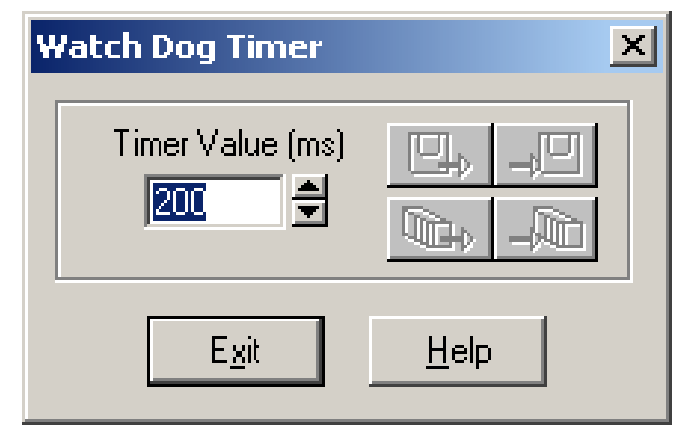

Figure 11.5. Watch Dog Timer Window

\subsection{Firmware Program}

The firmware program is a relay ladder logic program that controls the primary functions of the HEF, including all of the safety aspects. Together, a collection of files define the program (Table 11.2), each of which contributes specific functions. (Each file was created automatically by the DirectSOFT32 development software on the networked PC; once complete, the firmware files are downloaded to the PLC.) 
Table 11.2. Firmware File Functions

\begin{tabular}{||l|l||}
\hline \hline File Name & \\
\hline \hline hef.esd & Element documentation (nickname, wiring information, description) \\
\hline hef.esx & Index file for the element documentation \\
\hline hef.inf & Project information \\
\hline hef.lcd & Ladder comment data \\
\hline hef.lcx & Index file for the ladder comment data \\
\hline hef.da & Maps rung comments to rung numbers \\
\hline hef.ldo & Online only, maps rung comments to rung numbers \\
\hline hef.prj & Ladder program \\
\hline hef.prt & Print layout configuration \\
\hline hef.scd & Stage comment data \\
\hline hef.scx & Index file for the stage comment data \\
\hline hef.tls & PLC parameters, I/O configuration, pause bit settings, etc. \\
\hline hef.vd & V-memory data \\
\hline hef.vf & V-memory editor viewing format for each location (BCD, hex, etc.) \\
\hline hef.wsp & Position of the program windows, colors, etc. \\
\hline \hline
\end{tabular}

\subsubsection{Design Objectives}

The firmware was designed to meet the following objectives:

- Minimize the gaps in real-time response to operator input (minimum scan time). This prevents repeated button-pushing by providing immediate operator feedback.

- Reduce real-time responses to interlock violations (minimum scan time). This is mandatory to minimize radiation exposure, should an operator enter the exposure room while a source is exposed.

- Address all (or as many as possible) PLC configuration parameters within the firmware program (as opposed to being set from the DirectSOFT32 programming application). In the event of a PLC memory corruption, there is less for the firmware custodian to reconfigure.

- Use default configuration settings whenever possible. In the event of a PLC memory corruption, there is less for the firmware custodian to reconfigure.

- Capture error logs, as this aids with troubleshooting.

- Maximize the availability of in-line documentation or comments. This helps explain the function of the program to others.

\subsubsection{Program Block Descriptions}

The firmware was developed as a set of functional blocks (Figure 11.6) to bring organization to and improve the readability of the program. Refer to Figure 11.6 to see an overview of the HEF firmware block diagram. 


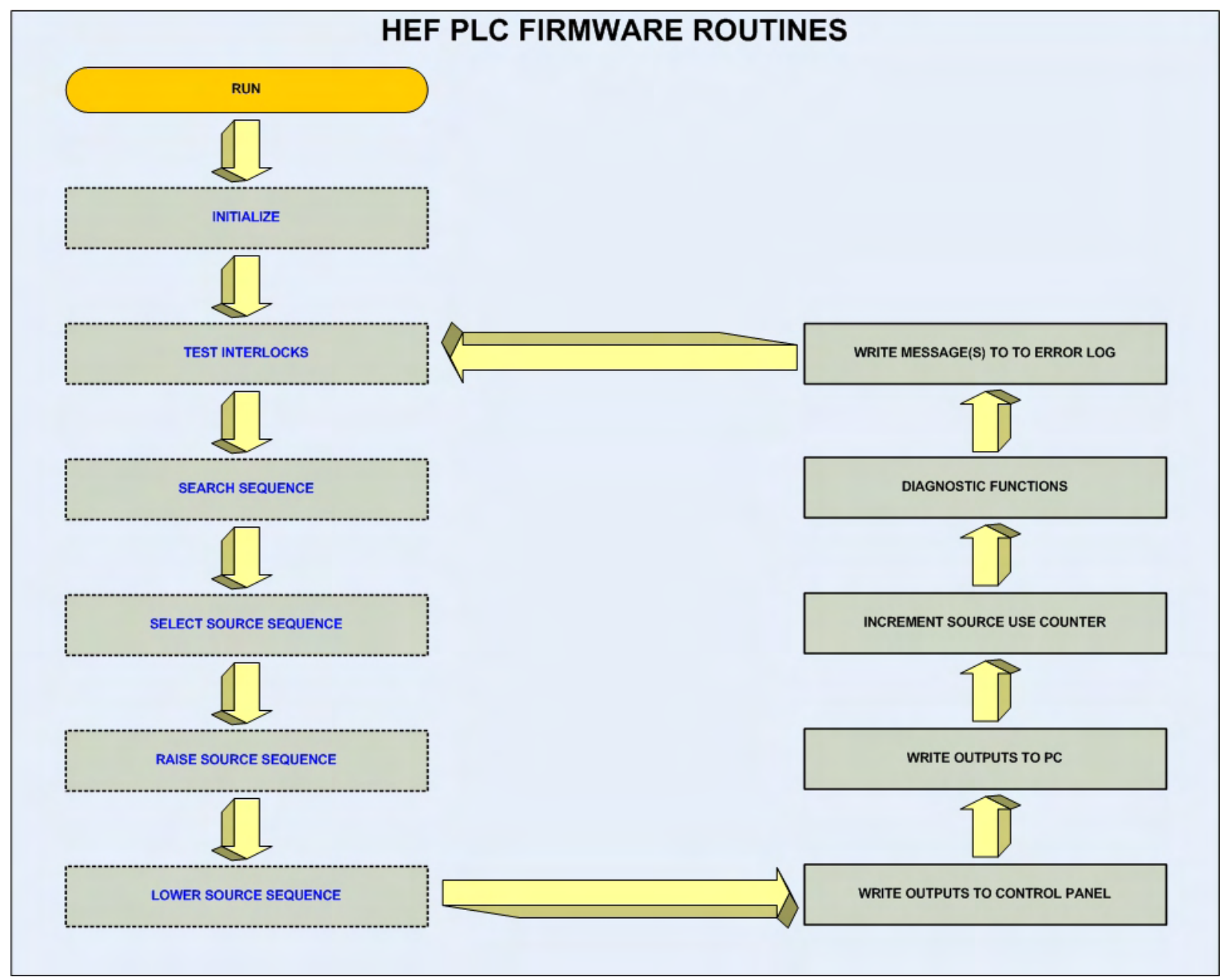

Figure 11.6. HEF Firmware Block Diagram

\subsubsection{Relay Ladder Logic Programming}

Relay ladder logic programming is a schematic-based entry program that allows electrical diagrams to be entered into software that will later be compiled for downloading to a PLC. In effect, it takes a hardware design and converts it into a form that the PLC can emulate. This type of programming is well suited to process control systems that are inherently sequential and are primarily binary in nature. Refer to Figure 11.7 for an overview of the HEF ladder logic decision tree. For a complete printout of the HEF PLC ladder logic programming, refer to Appendix A. 


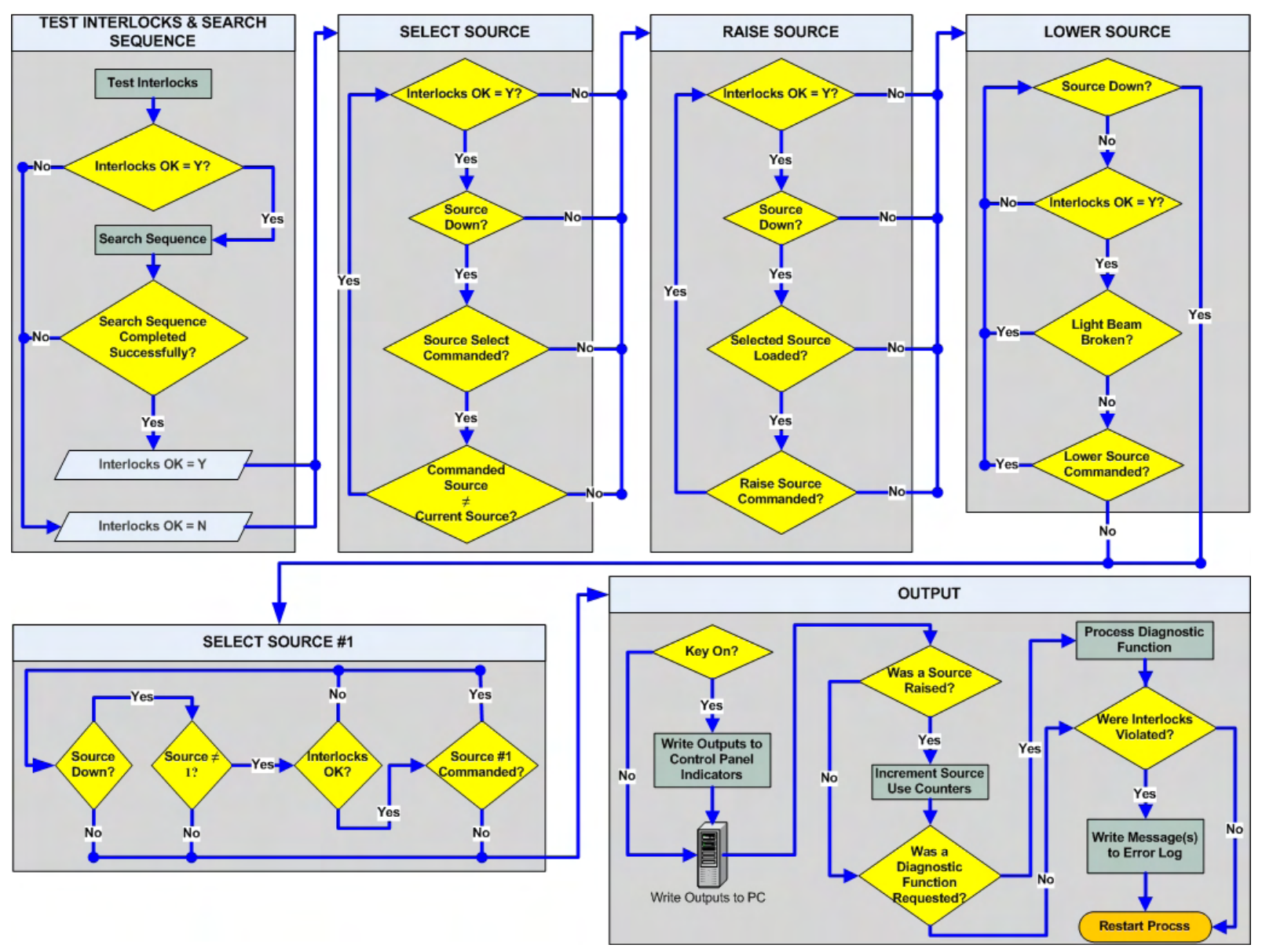

Figure 11.7. HEF Ladder Logic Decision Tree

\subsubsection{Program Initialization Logic}

Initialization logic occurs during execution of ladder rungs one and two. Rung one is executed only during the first scan of the program, which occurs after a restoration of power or when the PLC is changed to the run mode from the program or test modes. The first series of commands in this rung configures communication port two (used to send commands to the carousel drive/indexer). In this group of commands, binary encoded values are loaded into variable memory locations (which store data for the ladder program and for configuration settings) $7650_{\text {octal }}$ through $7657_{\text {octal }}$. (Refer to AutomationDirect Application Note AN-D2-002 [2004] to determine the correct binary encoded values.) Once these parameters have been set from within the program, they can be confirmed by accessing the setup communication ports window (Figure 11.8) in DirectSOFT32. 


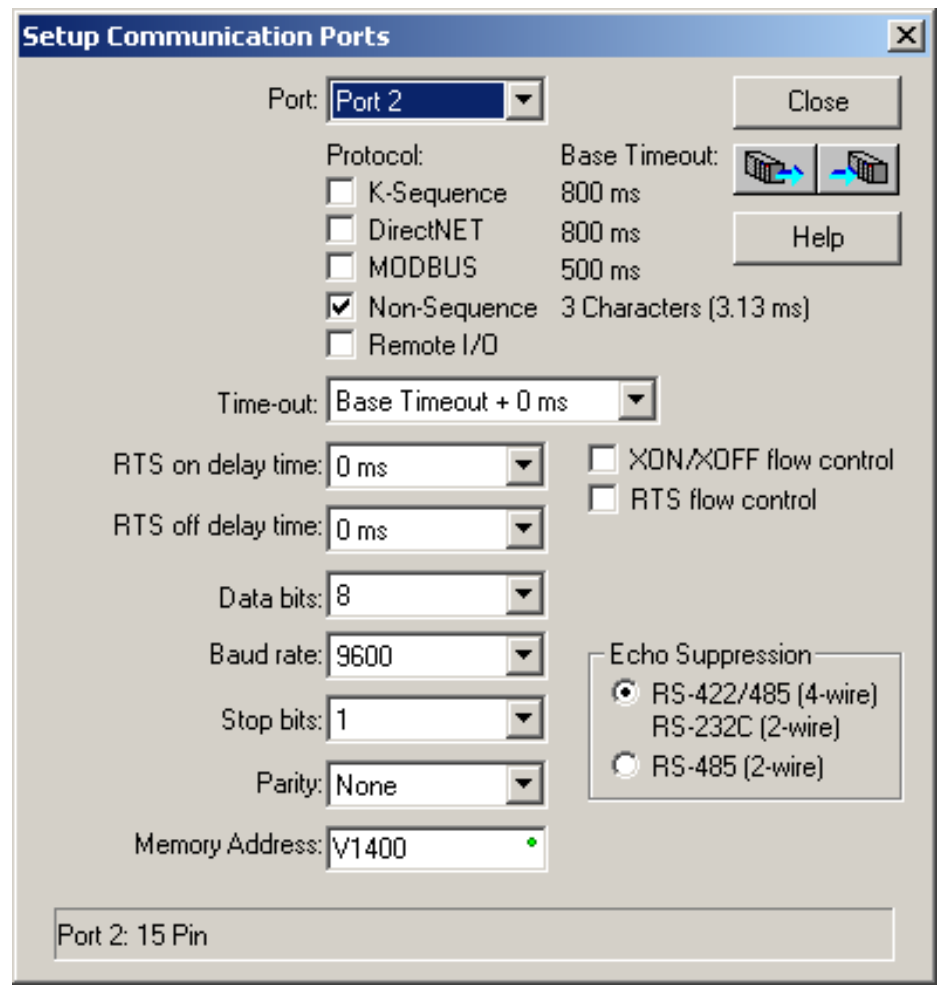

Figure 11.8. DirectSOFT32 Setup Communication Ports Window

The second section in rung one is a series of predefined ASCII commands that are used to control the carousel stepper motor. These command strings are loaded into several sequential variable memory locations. Refer to Compumotor's OEM Series Software Reference Guide Microstepper Products OEM650X/OEM350X/OEM010 (1993) to determine the correct usage and syntax for these strings. The third series in rung one starts at variable memory location $1500_{\text {octal }}$ and when sent, sets up the basic operating configuration of the drive/indexer. If this string is not programmed correctly, subsequent commands to the carousel stepper motor will not execute properly. Rung one's fourth series of commands occupy variable memory locations $1600_{\text {octal }}$ through $1670_{\text {octal }}$, and are used by diagnostic routines for troubleshooting and testing. The fifth and final set of command strings in rung one occupies variable memory locations $2000_{\text {octal }}$ through $2700_{\text {octal }}$, and is used to rotate the carousel to source positions one through eight.

Rung two executes when the key switch (on the control panel) is turned on (except during the initial PLC scan). When rung two executes, the ASCII command string stored in variable memory location $1500_{\text {octal }}$ is sent to the carousel drive/indexer from the PLC. This is the string that initially configures the carousel drive/indexer, and it occurs every time the control panel is activated.

\subsubsection{Test Interlocks Logic}

Rungs 3 through 26 make up the interlock test section. Here, the state of each of the eight interlocks warning indicators is determined and saved if active, until cleared by the alarm silence switch on the control panel. (Using this switch requires that the condition that triggered the alarm has been resolved.) Table 11.3 shows how each interlock violation affects the various program sections. 
Table 11.3. Interlock Violations

\begin{tabular}{|c|c|c|c|c|}
\hline & \multicolumn{4}{|c|}{ Result of Interlock } \\
\hline & Control Disable & Source to be Lowered & Source 1 to be Selected & Operator Alert \\
\hline \multicolumn{5}{|l|}{ Interlock: } \\
\hline Power Fail & $\mathrm{Y}$ & $\mathrm{Y}$ & $\mathrm{Y}$ & $\bar{Y}$ \\
\hline Emergency Stop & $\mathrm{Y}$ & $\mathrm{Y}$ & $\mathrm{Y}$ & $\mathrm{Y}$ \\
\hline Area Monitor Fail & $\mathrm{Y}$ & $\mathrm{Y}$ & $\mathrm{Y}$ & $\mathrm{Y}$ \\
\hline Warning Light Fail & $\mathrm{Y}$ & $\mathrm{Y}$ & $\mathrm{Y}$ & $\mathrm{Y}$ \\
\hline Door Opened & $\mathrm{Y}$ & $\bar{Y}$ & $\mathrm{Y}$ & $\bar{Y}$ \\
\hline Light Beam Interrupted & $\mathrm{N}$ & $\mathrm{Y}$ & $\mathrm{N}$ & $\mathrm{Y}$ \\
\hline Source Select Fail & $\mathrm{N}$ & Already Down & $\mathrm{N}$ & $\mathrm{Y}$ \\
\hline Source Pneumatic Fail & $\mathrm{N}$ & $\bar{Y}$ & $\mathrm{~N}$ & $\overline{\mathrm{Y}}$ \\
\hline
\end{tabular}

\subsubsection{Search Sequence Logic}

Rungs 27 through 33 implement the exposure room search sequence. This starts when an operator presses the search button in the exposure room, and ends in a system-enabled state if the operator closes the exposure room door within 20 s. During the 20-s period, an audible alarm is active in the exposure room to warn personnel in the room that an exposure is about to start.

\subsubsection{Select Source Sequence Logic}

Rungs 34 through 54 contain the logic to select a specific source in the carousel, to send the appropriate ASCII command string to the carousel drive/indexer, and to receive and process the driver/indexer's reply. Rungs 37 through 42 capture the source selection using 1-of-8 logic. Rungs 43 through 50 send the appropriate command string to the carousel drive/indexer. Rungs 51 through 53 receive the reply, which is decoded by rung 54 . Rungs 55 and 56 provide the logic for the source select fail interlock. Finally, rung 57 passes on to the raise source sequence when a source is in position and ready to be raised.

\subsubsection{Raise Source Sequence Logic}

Rungs 58 through 68 cause relays to be set in a timed sequence that controls the raising of the selected source. First, the lower solenoid valve is opened to enable the source to move into the preirradiate position (concurrently, the radiation warning lights begin to flash). Second, the blower is energized at a speed that starts a low-speed source accent, causing the source to move into the preirradiate position. Next, after receiving a positive indication from the source-up pressure switch, the two solenoid valves in the air path reverse states-with the lower one closing and the upper one opening. This causes the source to rise roughly 6 in. into the final irradiate position. If the upper pressure switch does not detect that the source is in the pre-irradiate position within $10 \mathrm{~s}$, a source pneumatic fail alarm will occur, and the lower source sequence will be initiated. Lastly, the blower speed is increased to $100 \%$, locking the source firmly in the irradiate position for the duration of the exposure. 


\subsubsection{Lower Source Sequence Logic}

Rungs 69 through 76 control the lowering of the source back into the carousel. This can be caused by a variety of reasons including:

- pressing the emergency stop button in the exposure room

- failure of the area radiation monitor

- failure of a radiation warning light

- opening the door into the exposure room

- interrupting the light beam outside of the exposure room door

- occurrence of a source pneumatic fail alarm during the raise source sequence

- pressing the source down pushbutton on the control panel

- the irradiation timer reaching zero in timed irradiation mode

- a request from the facility control computer to lower the source

- turning off the key switch on the control panel.

When the source is lowered back into the carousel, the states of the solenoid valves are reversed by closing the upper solenoid valve and opening the lower solenoid valve. This causes the source to drop back down into the pre-irradiate position. While the solenoid valves are articulating, the blower speed is reduced for $10 \mathrm{~s}$ for source descent. After this movement is completed, the rotational direction of the blower is reversed, and its speed ramped up to $100 \%$. If the source is fully seated in the carousel, which blocks the air path, the source down pressure switch will detect an increase in back pressure. If this doesn't occur within $10 \mathrm{~s}$, a source pneumatic fail alarm will be result, and the blower and solenoid valves will de-energize. With this alarm present, the PLC will prevent the selection of a new source position. Pressing the alarm silence pushbutton to clear the alarm will cause the blower to restart in the reverse direction and the source down pressure switch to re-test. If the switch is detected within the $10 \mathrm{~s}$ window, the blower and solenoid valves are de-energized without the alarm, and normal operation of the system is resumed.

\subsubsection{Write Outputs to Control Panel Logic}

Rungs 77 through 101 control the output signals to the control panel's controls-including all of the lighted indicators, the output to the audible alarm, and the timing signal to the irradiation timer. This section of the program also contains the timer elements that cause the lighted indicators to flash when necessary. In all, 22 control panel devices are controlled from this section.

\subsubsection{Write Outputs to PC Logic}

Rungs 102 through 110 are used to control the output signals to the facility PC in an 8-bit binary-encoded format. There are a total of eight signals controlled from this section:

- Bit 7 wakes up the application program hef.exe.

- Bit 6 informs hef.exe that the PLC is ready to accept commands.

- Bit 5 informs hef.exe that a source is up.

- Bit 4 informs hef.exe that all sources are down.

- Bit 3 informs hef.exe that the current source position equals the desired source position. 
- Bits 2 (the most significant bit), and 1 and 0 (the least significant bits), when decoded from binary to decimal, inform hef.exe which source is in position. They decode to 0 through 7 , which represent source positions 1 through 8 , respectively.

\subsubsection{Diagnostics and Maintenance Logic}

Rungs 111 through 118 contain non-resettable counters that are used to accumulate the total number of times each source has been used since July 2006. To view the current source use count, start DirectSOFT32, establish a communications link to the PLC, and activate the status function. Scroll to rungs 111 through 118, and inside the counter outline, displayed in blue, will be the current source use count.

Rung 119 contains an override feature that is not to be used during routine operation-therefore its use is not covered in the HEF standard operating procedures. This rung is used to simulate the sourcedown signal after attempting to lower a non-existent source, or to override a malfunctioning source-down pressure switch. If either of these cases occur, the result will be a source pneumatic fail alarm on the control panel—which cannot be cleared. To clear and prevent recurrence of this alarm, cause the PLC to think that it has received a good source-down signal by pressing and holding the end irradiation control button and the alarm silence button, both of which are on the control panel.

Rungs 120 through 127 contain functions that send diagnostic command strings from port 2 of the PLC to the drive/indexer. These eight strings were defined previously in the initialization section at the beginning of the program. To view the responses from these strings, terminate the hef.exe file on the facility control computer, and then execute carousel.exe. With the control panel key switch in the on position, and while depressing the end irradiation control switch, press one of the eight source select buttons. This will send one of the following command strings:

- Source 1: 8R

- Source 2: 8RB

- Source 3: 8RC

- Source 4: 8FS

- Source 5: 8IS

- Source 6: 8PR

- Source 7: 8PX

- Source 8: S.

To interpret the responses to these command strings, refer to OEM Series Software Reference Guide Microstepper Products OEM650X/OEM350X/OEM010 (1993) from Compumotor. 


\subsubsection{Error Log Logic}

Rungs 129 through 140 define 6 ASCII constants that form the text to be placed in DirectSOFT32's fault messages window upon detection of certain failure conditions. (Prior to viewing this window, establish a communications link to the PLC.) These conditions are:

- power fail

- area monitor fail

- rad light fail

- source select fail

- source up fail

- source down fail.

\subsection{Radiation Warning Light Control Circuit}

Two radiation warning lights flash when the control system raises a source, or if the area radiation monitor detects elevated radiation levels in the exposure room. This is controlled by a zero-crossing solid state relay (Figure 11.9) that turns on and off for half-second durations under control of the PLC.

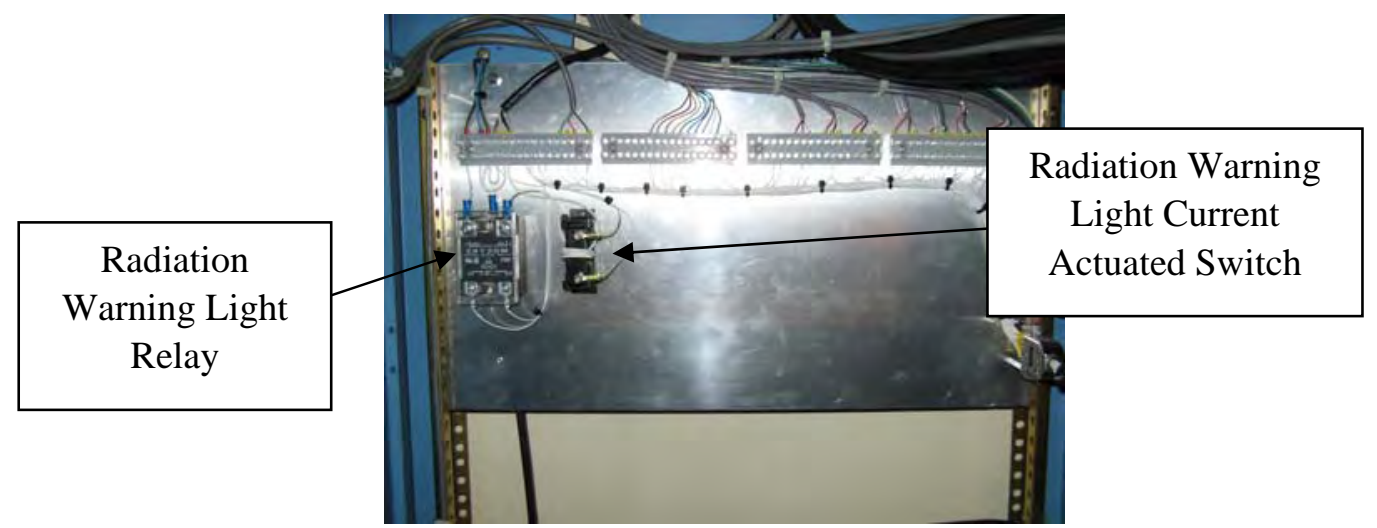

Figure 11.9. Radiation Warning Light Relay and Current Actuated Switch

\subsection{Radiation Warning Light Monitor Circuit}

A Smith Research \&Technology type CAS-3-NO AC current actuated switch (Figure 11.9) is used to detect a failed lamp in either one of the two radiation warning lights. Current flowing through a wire on its way to the radiation warning lights passes through the toroidal transformer core of the sensor, and switches a solid state output into a low impedance state when an adjustable set point is exceeded. For a single pass of a current-carrying conductor through the toroid core, this set point can be adjusted for a trip point between $1 \mathrm{~A}$ and $10 \mathrm{~A}$. To increase the sensitivity for use in the HEF, the current-carrying conductor that supplies power to the radiation warning lights makes three passes through the toroid core, thus reducing the set point range to $0.33 \mathrm{~A}$ to $3.3 \mathrm{~A}$. A small, flathead screwdriver is used to adjust the miniature set point potentiometer on the side of the sensor. If both 100-watt lamps are functioning, the sensor is adjusted to switch into the low impedance output state, which indicates to the PLC that there is no failure. However, the sensor set point needs to be high enough such that with a single 100-watt lamp 
functioning, the PLC will detect the second lamp’s failure. If the PLC detects a failed lamp, a system shutdown is initiated.

Because the lights alternate on and off, and because the radiation warning light monitor circuit is continuously monitoring the current supplying the warning lights, the lights appear to be failed half of the time. Therefore, the PLC is programmed not to act on the signal from the current sensor when the lights are intentionally not energized. 



\subsection{Facility Control Computer}

The facility control computer (Figure 12.1) is a dedicated, non-networked industrial-grade computer. This computer employs a $25 \mathrm{MHz}$ Intel 80386SX microprocessor-based, 7 ISA expansion-slot motherboard with an additional 80387 math co-processor and 1 MB of installed RAM.

The facility control computer is neither networked nor connected to the Internet, so its processes are not shared. This prevents upgrades and other network processes from taking up CPU time, and allows the system to maximize near real-time control. Processes such as sending e-mail and conducting online research are handled by a separate, networked PC (Figures 12.2a and 12.2b).

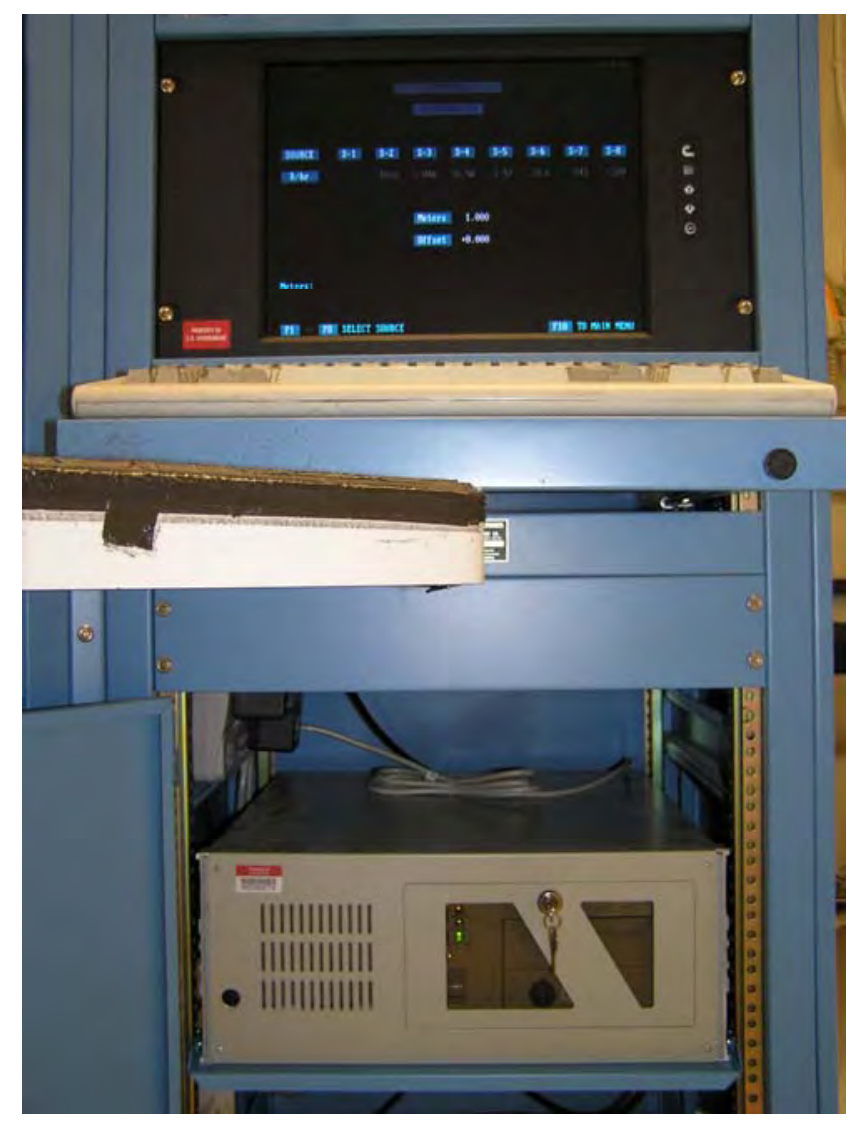

Figure 12.1. Facility Control Computer 


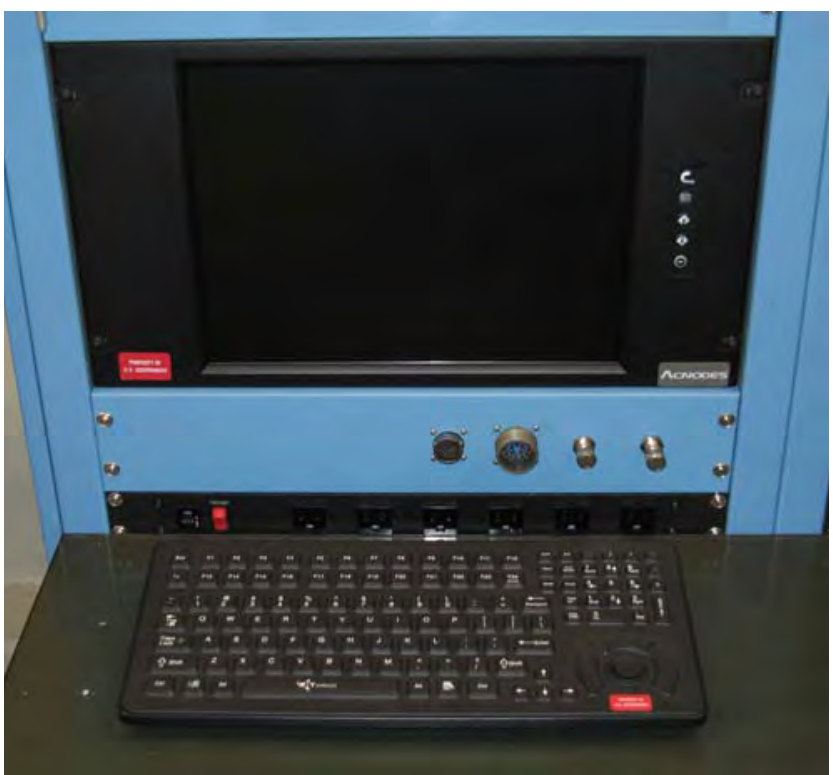

(a)

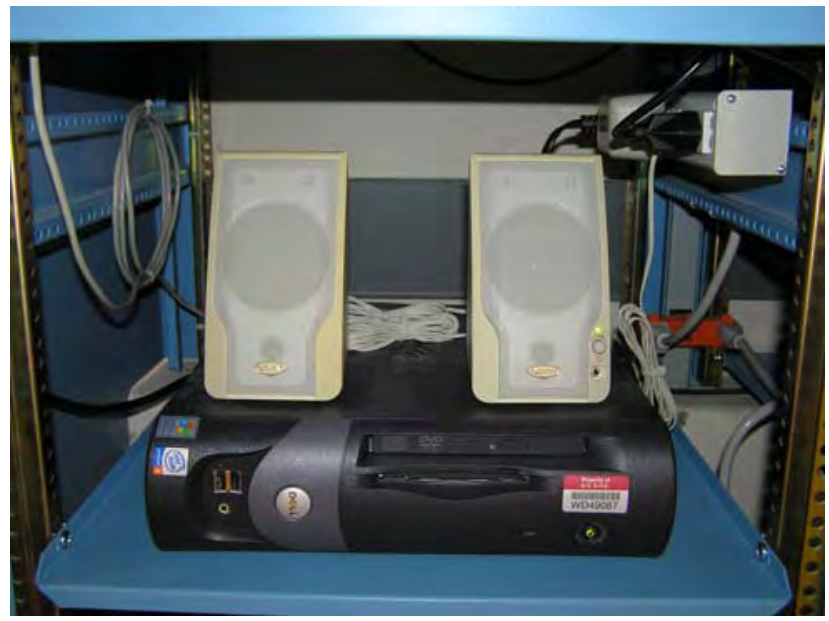

(b)

Figure 12.2. Networked PC

\subsection{Solid State Hard Disk}

The facility control computer employs a flash disk solid state drive with an IDE interface, rather than a traditional spinning hard drive. Because the drive does not have to spin to be read (and thus does not require rotating mechanical parts), the facility control computer benefits from faster data transfer, greater reliability, and less seek time and latency. The hard disk currently in use was manufactured by msystems $^{\mathrm{TM}}$, now a part of SanDisk. It is a 4 MB IDE-FD18-4, with a form factor of $1.8 \mathrm{in}$. Refer to Table 12.1 for the correct BIOS configuration for this disk. 
Table 12.1. BIOS Configuration of the Solid-State Hard Disk

\begin{tabular}{||l|c||}
\hline Hard disk C: type & 47 = USER TYPE \\
\hline Cylinders & 28 \\
\hline Head & 8 \\
\hline Wpcom & 65535 \\
\hline Lzone & 0 \\
\hline Sect & 32 \\
\hline
\end{tabular}

\subsection{Facility Control Computer and Programmable Logic Control Interface}

An 8-bit input and output digital input/output card (manufactured by Sealevel Systems, Inc., part number $3096 \mathrm{H}$ ), is used to provide the interface between the facility control computer and the PLC. This card is unique, in that it is specifically designed to connect to control systems operating at $24 \mathrm{~V} \mathrm{DC}$ input/output levels, typically used with PLCs. This provides for eight bits in each direction of bit-parallel communications. The card is configured to occupy input/output base address 320 Hex and to not generate interrupts. It is then inserted into the facility control computer's motherboard (in any available ISA slot).

\subsection{Instrument Platform Control Interface}

The facility control computer is used to move the instrument platform. An RS-232C interface-from the computer's COM1 terminal to the instrument platform drive/indexer's serial port-provides the command path. The RS-232C communications parameters (the default values for the drive/indexer) consist of a baud rate of 9600, 8 data bits, 1 stop bit, and parity set to none.

\subsection{Carousel Control Diagnostic Interface}

A two-way diagnostic RS-232C link has also been provided from port two of the PLC to COM2 of the facility control computer. This allows a special program to review the communications from the carousel drive/indexer for diagnostic purposes (specifically, carousel control problems and debugging). The program must configure the facility control computer COM2 serial port to the same default communications settings as those of the carousel drive/indexer-which are the same as those listed in section 12.3 for the instrument platform stepper motor drive/indexer. Because the carousel drive/indexer is configured to retransmit all text strings received from the PLC back to the PLC, this link can observe the communication in both directions (by merely tapping the drive/indexer's transmit line).

\subsection{Operating System}

The facility control computer runs IBM DOS version 3.30 for its operating system. This older operating system continues to be used because of its stability. Second, support is not needed for network connections, large memory spaces, high-resolution graphics, multitasking, multithreading, and so forth. Finally, the operating system doesn't require security patches, as do the more recent versions of Microsoft Windows ${ }^{\circledR}$. The only part of DOS that is needed is the command processor. Therefore, none of the usual external commands are present on drive C. 


\subsection{Control Software Program}

The control software program is composed of three files that control all auxiliary HEF processes. These files—one auto-executing batch file, one executable program file, and one data file-are named autoexec.bat, hef.exe, and hef.dat, respectively, and reside in drive C's root directory. The autoexec.bat file displays the DOE computer warning banner on the video monitor, then executes hef.exe after restoration of power or a hardware reset. Hef.exe is a custom-developed file written in BASIC, and compiled to an executable program using PowerBASIC for DOS version 3.5. Once executing, hef.exe loads the data file hef.dat. This data file contains all of the operational parameters needed by the executable program. The control software program then goes inactive until an operator reactivates it using the control panel key switch or by pressing the exclamation point key on the keyboard. To review the compiler input for the control software program, refer to Appendix B.

\subsection{Instrument Platform Control}

Move platform, a subroutine in the hef.exe program, is used to control the position of the instrument platform by sending ASCII command strings to the instrument platform drive/indexer. After the instrument platform has finished moving, the subroutine is executed a second time to determine if the instrument platform is within $2 \mathrm{~mm}$ of the final desired position. If it is not, a second move is initiated to correct the position error; this process continues until the platform is within $2 \mathrm{~mm}$ of the final position.

This routine is also used to detect a stepper motor stall, upon which it will send a stop command to the instrument platform drive/indexer if one is detected. (Motor stalls can occur if a heavy object has been left in the path of the instrument platform and it runs into it, for instance.) By design, a stall will not damage anything - the motor will merely slip poles until the move is terminated by the stop command.

\subsection{Manipulating the Programmable Logic Controller}

Source control, a subroutine named in the hef.exe program, is used to control all output signals from the facility control computer to the PLC via the input/output interface card. There are a total of eight signals that can be controlled from this section; currently, two of these are unused. Depending on the current state of the PLC, this subroutine will send commands that are either accepted and executed, or ignored entirely by the PLC. Therefore, it is the responsibility of the hef.exe program to know what state the PLC is in before sending it a request. This is determined by reading the inputs on the input/output interface card from the PLC and decoding its current state. These signals make the following command requests to the PLC in an 8-bit, binary-encoded format:

- Bits 7 and 6 are currently undefined and unused.

- Bit 5 is a request from the facility control computer for the PLC to raise a source.

- Bit 4 is a request from the facility control computer for the PLC to lower a source.

- Bit 3 is a request from the facility control computer for the PLC to select the source defined by bits 2 , 1 , and 0 . (As a cautionary note, these bits must be given enough time to reach legal states before bit 3 is asserted-or an incorrect source selection may occur.)

- Bits 2 (the most significant bit), 1, and 0 (the least significant bit) are binary coded decimal values that define the source that the facility control computer would like selected by the PLC. The sources are encoded 0 through 7, representing source positions 1 through 8, respectively. 


\subsection{Exposure Rate Versus Distance Algorithms}

A total of two equations are used to approximate exposure rates as a function of distance, and distance as a function of an exposure rate. The first equation represents the case where the distance (D) is known, and exposure rate $(\mathrm{E})$ is desired:

$$
\mathrm{E}^{1 / 2}=\mathrm{J}_{0}+\mathrm{J}_{1} \cdot \mathrm{D}^{-1}+\mathrm{J}_{2} \cdot \mathrm{D}^{-2}+\mathrm{J}_{3} \cdot \mathrm{D}^{-3}+\mathrm{J}_{4} \cdot \mathrm{D}^{-4}+\mathrm{J}_{5} \cdot \mathrm{D}^{-5}+\mathrm{J}_{6} \cdot \mathrm{D}^{-6}+\mathrm{J}_{7} \cdot \mathrm{D}^{-7}
$$

The second equation represents the case where the exposure rate (E) is known and the corresponding distance (D) is desired:

$$
\mathrm{D}^{-1}=\mathrm{K}_{0}+\mathrm{K}_{1} \cdot \mathrm{E}^{1 / 2}+\mathrm{K}_{2} \cdot \mathrm{E}^{1}+\mathrm{K}_{3} \cdot \mathrm{E}^{3 / 2}+\mathrm{K}_{4} \cdot \mathrm{E}^{2}+\mathrm{K}_{5} \cdot \mathrm{E}^{5 / 2}+\mathrm{K}_{6} \cdot \mathrm{E}^{3}+\mathrm{K}_{7} \cdot \mathrm{E}^{7 / 2}
$$

Performing a least-squares curve fit on a set of exposure rates versus distance calibration data provides the coefficients $\mathrm{J}$ and $\mathrm{K}$. This is performed by a program called Calcpoly.exe that has been specifically tailored for the equations above. (For more information on Calcpoly.exe, refer to PNNL's High Exposure Facility Periodic and Non-Routine Maintenance and Adjustment Procedures (2007), which is available from PNNL's Radiation \& Health Technology Group.) These equations take the general form of a seventh-order polynomial (or less, depending on the resulting precision). In practice, the higher the radiation scatter contribution (relative to the primary beam), the higher the order of the polynomial required to achieve a good data fit. This is because a higher scatter component translates into a greater deviation from the inverse square law for exposure rates, and greater difficulty for a polynomial to fit the data. Once these coefficients have been calculated, they are then inserted into the data file hef.dat. Since there are seven sources (excluding the dummy source) in the HEF, there will be seven sets of these coefficients altogether.

\subsubsection{Decay Correction}

Decay correction is implemented in two different ways, and depends upon whether the distance is known and the exposure rate is to be calculated, or whether the exposure rate is known and the distance is to be calculated. If the distance is known, then the following equation is applied to the exposure rate value calculated from Equation 1:

$$
\mathrm{E}_{\mathrm{t}}=\mathrm{E}_{0} \cdot \exp \left(-0.693 / \mathrm{T}_{1 / 2} \cdot \mathrm{t}\right)
$$

where $\mathrm{T}_{1 / 2}$ equals the half-life for either ${ }^{137} \mathrm{Cs}$ or ${ }^{60} \mathrm{Co}$ in months, $\mathrm{t}$ is equal to the number of months elapsed since the date of last calibration, $\mathrm{E}_{\mathrm{t}}$ is the current exposure rate, and $\mathrm{E}_{0}$ is the exposure rate calculated from equation 1.

If the distance is to be calculated from a desired exposure rate, then the following equation is applied to the exposure rate value before it is used to calculate the distance:

$$
E_{0}=E_{t} / \exp \left(-0.693 / T_{1 / 2} \cdot t\right)
$$

where $\mathrm{T}_{1 / 2}$ equals the half-life for either ${ }^{137} \mathrm{Cs}$ or ${ }^{60} \mathrm{Co}$ in months, $\mathrm{t}$ is equal to the number of months elapsed since the date of last calibration, $\mathrm{E}_{0}$ is the exposure rate that will be input as $\mathrm{E}$ into Equation 2, and $\mathrm{E}_{\mathrm{t}}$ is the desired exposure rate. 


\subsubsection{Temperature and Pressure Correction}

Temperature and pressure correction is available to compensate the exposure rate values for the environmental factors that effect air-vented ion chambers. These corrections are implemented in two different ways, depending upon whether the distance is known and the exposure rate is to be calculated, or whether the exposure rate is known and the distance is to be calculated. If the distance is known, then the following equation is applied to the exposure rate value after it has been calculated:

$$
\mathrm{E}_{\mathrm{AMB}}=\mathrm{E}_{\mathrm{STP}} \cdot \frac{532}{T+460} \cdot \frac{P}{29.92}
$$

where $\mathrm{T}$ equals the ambient temperature in degrees Fahrenheit, $\mathrm{P}$ is equal to the ambient pressure in inches of mercury, $\mathrm{E}_{\mathrm{AMB}}$ is the current exposure rate when adjusted to the current ambient conditions, and $\mathrm{E}_{\mathrm{STP}}$ is the exposure rate determined at the time of calibration measurement relative to standard temperature and pressure.

If the distance is to be calculated from a desired exposure rate, then the following equation is applied to the exposure rate value before it is used to calculate the distance:

$$
\mathrm{E}_{\mathrm{STP}}=\mathrm{E}_{\mathrm{AMB}} \cdot \frac{T+460}{532} \cdot \frac{29.92}{P}
$$

where $\mathrm{T}$ equals the ambient temperature in degrees Fahrenheit, $\mathrm{P}$ is equal to the ambient pressure in inches of mercury, $\mathrm{E}_{\mathrm{STP}}$ is the exposure rate determined at the time of calibration measurement relative to standard temperature and pressure, and $\mathrm{E}_{\mathrm{AMB}}$ is the desired exposure rate when adjusted to current ambient conditions.

\subsection{Automated Instrument Calibration Routines}

Contained in the hef.exe and defined in the hef.dat files are a set of instrument routines that automate the selection of calibration points for the defined instruments. By using these, calibration time per instrument is minimized. These routines allow an operator to step through a predetermined set of exposure rate points for instruments that are more frequently calibrated.

\subsection{Data Files}

The hef.dat file contains all of the configuration parameters required by the executable program hef.exe.

\subsection{Diagnostic Software Programs}

Two diagnostic programs are available for troubleshooting and testing purposes. These are both PowerBASIC for DOS version 3.5 compiled basic programs that are named Carousel.exe and Instplat.exe. To run either of these programs requires that hef.exe execution be terminated and the new program be started. To do this, press Shift +1 on the facility control computer's keyboard (to wake up the main program), then press Ctrl + Break (to terminate hef.exe and display the command prompt). Type in the name of the program you wish to run and press the enter key. To view the compiler inputs for Carousel.exe and Instplat.exe, refer to Appendix C. 


\subsection{Conclusion}

Development of the HEF should be considered a work in progress to maintain its current and future capabilities. This development will become necessary when individual components become obsolete, if regulatory requirements or work scope changes, and as radiological techniques evolve. Therefore, this

document is also a work in progress, and is expected to reflect significant changes to the facility in future revisions. 



\subsection{References}

ANSI N43.6-1997. 1998. Sealed Radioactive Sources Classification. American National Standards Institute and Health Physics Society. McLean, Virginia.

ANSI N543-1974. 1994R. General Safety Standard for Installations Using Non-Medical X-Ray and Sealed Gamma-Ray Sources, Energies up to $10 \mathrm{MeV}$. American National Standards Institute and Health Physics Society. New York, New York.

AutomationDirect. 2004. CPU Communication Port Setup Parameters. Cumming, Georgia.

Compumotor. 1993. OEM Series Software Reference Guide Microstepper Products OEM650X/OEM350X/OEM010. 88-013785-01, Rev A. Rohnert Park, California.

DOE-STD-1027-92. 1997. Hazard Categorization and Accident Analysis Techniques for Compliance With DOE Order 5480.23, Nuclear Safety Analysis Reports. U.S. Department of Energy. Washington, D.C.

ISO 4037-3. 1999. X and Gamma Reference Radiation for Calibrating Dosimeters and Doserate Meters and for Determining Their Response as a Function of Photon Energy. International Organization for Standardization (ISO). Geneva, Switzerland.

PNNL(Pacific Northwest National Laboratory). 2006. High Exposure Facility Source Transfer Procedure. 318-MP-01, Rev 2. August 2006. Pacific Northwest National Laboratory, Richland, Washington.

PNNL(Pacific Northwest National Laboratory). 2006. High Exposure Facility Standard Operating Procedure. 318-SOP-01, Rev 2. Pacific Northwest National Laboratory, Richland, Washington.

PNNL(Pacific Northwest National Laboratory). 2007. High Exposure Facility Periodic and NonRoutine Maintenance and Adjustment Procedures. 318-MP-04, Rev 0. TBD FY 2007. Pacific Northwest National Laboratory, Richland, Washington. 



\subsection{Bibliography}

10CFR835.502. 2006. Code of Federal Regulations: Part 835 Occupational Radiation Protection. U.S. Department of Energy (DOE). Washington, D.C.

AMETEK, Inc. 2000. Service and Parts Manual for Blower Model: DR068-DR353. Blower Manual, Rev E. Kent, Ohio.

AMETEK, Inc. 2004. DR 303M \& CP 303M Regenerative Blower. Specifications, Rev 2/04. Kent, Ohio.

ASCO Valve, Inc. Direct Acting or Piloted Aluminum Body Solenoid Valves. Specifications, Rev 1. Florham Park, New Jersey.

AutomationDirect. 2002. GS1 Series Drives User Manual. GS1-M. Cumming, Georgia.

AutomationDirect. 2002. DL205 PLC User Manual, Volume 1 of 2. D2-USER-M. Cumming, Georgia.

AutomationDirect. 2002. DL205 PLC User Manual, Volume 2 of 2. D2-USER-M. Cumming, Georgia.

AutomationDirect. 2002. Programming Software User Manual. PC-DSOFT32-M, ${ }^{\text {nd }}$ Ed. Cumming, Georgia.

Bayside Controls, Inc. 1997. NEMA23 Right Angle Outline Drawing. NR23. Port Washington, New York.

Compumotor. 1993. OEM650/OEM650X/OEM350/OEM350X Drive and Drive/Indexer User Guide. 88-013157-02, Rev A. Rohnert Park, California.

Compumotor. 1995. OEM300 Power Module User Guide. 88-013513-01, Rev C. Rohnert Park, California.

Dwyer Instruments, Inc. 2003. Series 1800, Low Differential Pressure Switches for General Industrial Service. 24-440256-00, Rev 1. Michigan City, Indiana.

Encoder Products Co. Inc. 2002. Model 121, Style A. 121-ASTYLE, Rev C. Sagle, Idaho.

Encoder Products Co. Inc. 2005. Model 121 Installation Instructions. TB-511, Rev F. Sagle, Idaho.

Encoder Products Co. Inc. 2005. Model 121 Auto-Aligning Modular. Datasheet, Rev 2. Sagle, Idaho.

Encoder Products Co. Inc. 2005. Electrical Reference. Electrical Reference Rev B. Sagle, Idaho.

International Business Machines Corp. 1987a. Disk Operating System Version 3.30 Reference. April 1987. Boca Raton, Florida. 
International Business Machines Corp. 1987b. Disk Operating System Version 3.30 Technical Reference. April 1987. Boca Raton, Florida.

International Isotopes Inc. 2006. INIS-SF-2.3-04-K. INIS-DWG-0012. June 2006. Idaho Falls, Idaho.

JDS Uniphase Corp. 2003. Self-Contained Helium-Neon Laser Systems 1500 Series. 10138846, Rev 2. Milipitas, California.

OMRON Corp. 2005. Solid State Relay G3NE. JB301-E3-01. Schaumburg, Illinois.

Pacific Northwest National Laboratory (PNNL). 2002a. High Exposure Facility Assembly. H-3-54023, Rev. 3, Page 1 of 1. Pacific Northwest National Laboratory, Richland, Washington.

Pacific Northwest National Laboratory (PNNL). 2002b. High Exposure Facility Column Assembly. H-3-54024, Rev. 1, Page 1 of 5. Pacific Northwest National Laboratory, Richland, Washington.

Pacific Northwest National Laboratory (PNNL). 2002c. High Exposure Facility Column Details. H-3-54024, Rev. 1, Pages 2-5 of 5. Pacific Northwest National Laboratory, Richland, Washington.

Pacific Northwest National Laboratory (PNNL). 2005. Justification for Continued Operation: Removal of Leaking Co-60 Sealed Source from Building 318. Pacific Northwest National Laboratory, Richland, Washington.

Pacific Northwest National Laboratory (PNNL). 2005a. Structural Modifications Conc. @ El (-) 14'-6”. H-3-310422, Page 1 of 3. Pacific Northwest National Laboratory, Richland, Washington.

Pacific Northwest National Laboratory (PNNL). 2005b. Structural Modifications Lead Brick Layout. H-3-310422, Page 2 of 3. Pacific Northwest National Laboratory, Richland, Washington.

Pacific Northwest National Laboratory (PNNL). 2005c. Structural Modifications Lead Brick Details. H-3-310422, Page 3 of 3. Pacific Northwest National Laboratory, Richland, Washington.

Pacific Northwest National Laboratory (PNNL). 2006a. High Exposure Facility Mechanism Assembly. H-3-54025, Rev. 4, Page 1 of 7. Pacific Northwest National Laboratory, Richland, Washington.

Pacific Northwest National Laboratory (PNNL). 2006b. High Exposure Facility Mechanism Details. H-3-54025, Rev. 3, Pages 2, 3, and 5 of 7. Pacific Northwest National Laboratory, Richland, Washington.

Pacific Northwest National Laboratory (PNNL). 2006c. High Exposure Facility Mechanism Details. H-3-54025, Rev 2, Pages 4 and 6 of 7. Pacific Northwest National Laboratory, Richland, Washington.

Pacific Northwest National Laboratory (PNNL).2006d. High Exposure Facility Mechanism Details. H-3-54025, Page 7 of 7. Pacific Northwest National Laboratory, Richland, Washington.

Pacific Northwest National Laboratory (PNNL). 2007a. High Exposure Facility Jumper Details. H-3-54574, Rev. 2, Page 1 of 2. Pacific Northwest National Laboratory, Richland, Washington. 
Pacific Northwest National Laboratory (PNNL). 2007b. High Exposure Facility Jumper Details. H-3-54574, Rev. 0, Page 2 of 2. Pacific Northwest National Laboratory, Richland, Washington.

Pacific Northwest National Laboratory (PNNL). 2007c. High Exposure Facility Source Carrier Type 1. H-3-54026, Rev. 5, Page 1 of 4. Pacific Northwest National Laboratory, Richland, Washington.

Pacific Northwest National Laboratory (PNNL). 2007d. High Exposure Facility Source Carrier Type 2. H-3-54026, Rev. 1, Page 2 of 4. Pacific Northwest National Laboratory, Richland, Washington.

Pacific Northwest National Laboratory (PNNL). 2007d. High Exposure Facility Source Carrier Type 3. H-3-54026, Rev. 0, Page 3 of 4. Pacific Northwest National Laboratory, Richland, Washington.

Pacific Northwest National Laboratory (PNNL). 2007d. High Exposure Facility Source Carrier Type 4. H-3-54026, Rev. 0, Page 4 of 4. Pacific Northwest National Laboratory, Richland, Washington.

PowerBASIC, Inc. 1997a. Basic Compiler User’s Guide. Carmel, California.

PowerBASIC, Inc. 1997b. Basic Compiler Reference Guide. Carmel, California.

Ruland Manufacturing Co., Inc. PARADRIVE ${ }^{\mathrm{TM}}$ Couplings. OCT16-6-A. Marlborough, Massachusetts.

TDK. AC Input Single Output, General Purpose, UL/C-UL Approved F Series.

003-01/ 20051206/ ea122_fak. Garden City, New York.

Wiremold/Legrand. 2005. Plug-In Outlet Center ${ }^{\circledR}$ Units. ED795R6. West Hartford, Connecticut. 

Appendix A - Firmware Programming 



\section{Appendix A - Firmware Programming}

The following sequence is the printed ladder logic from the High Exposure Facility’s PLC. 

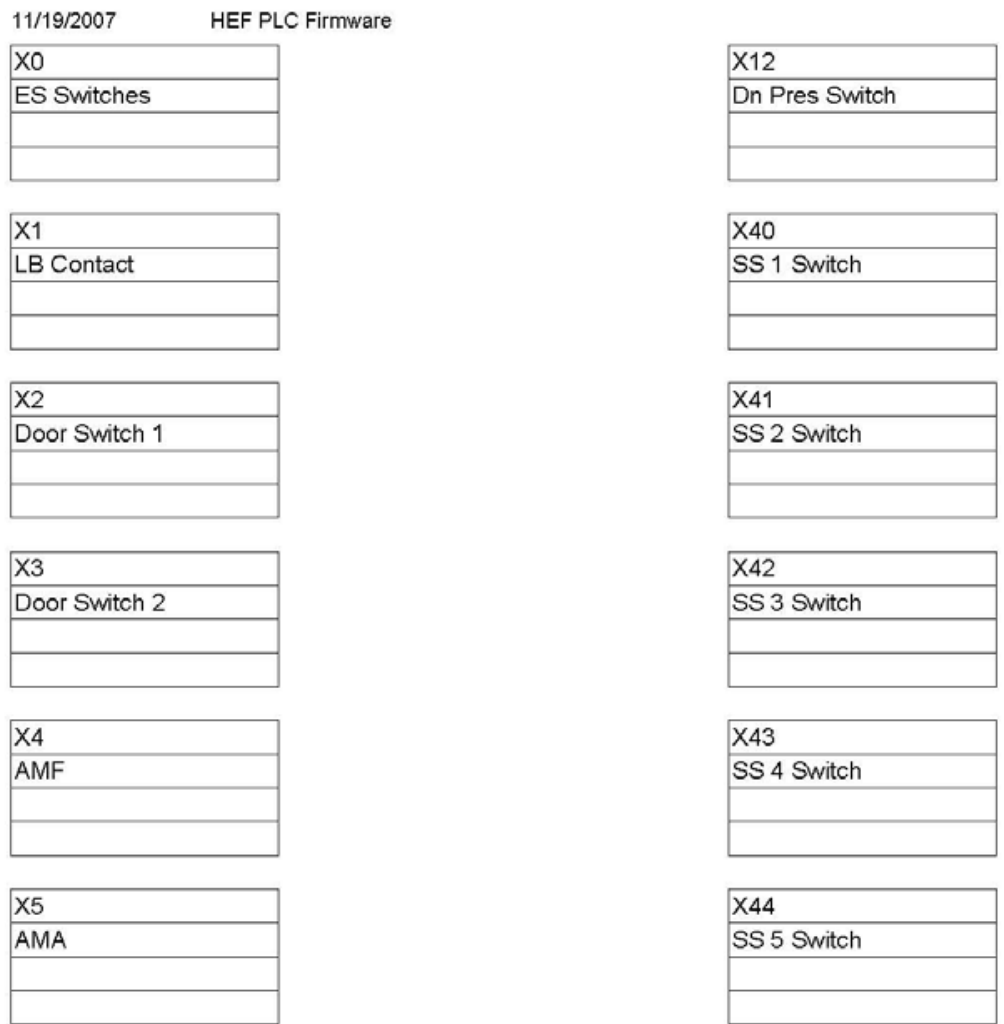

X44
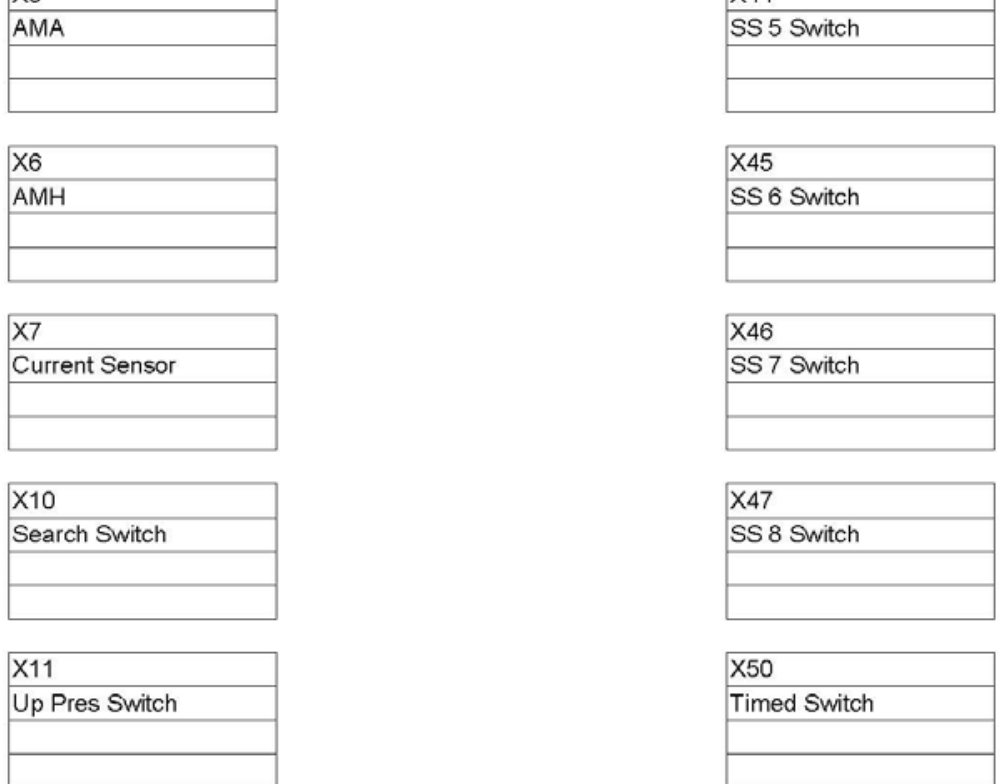

X50

Timed Switch

Page 1 

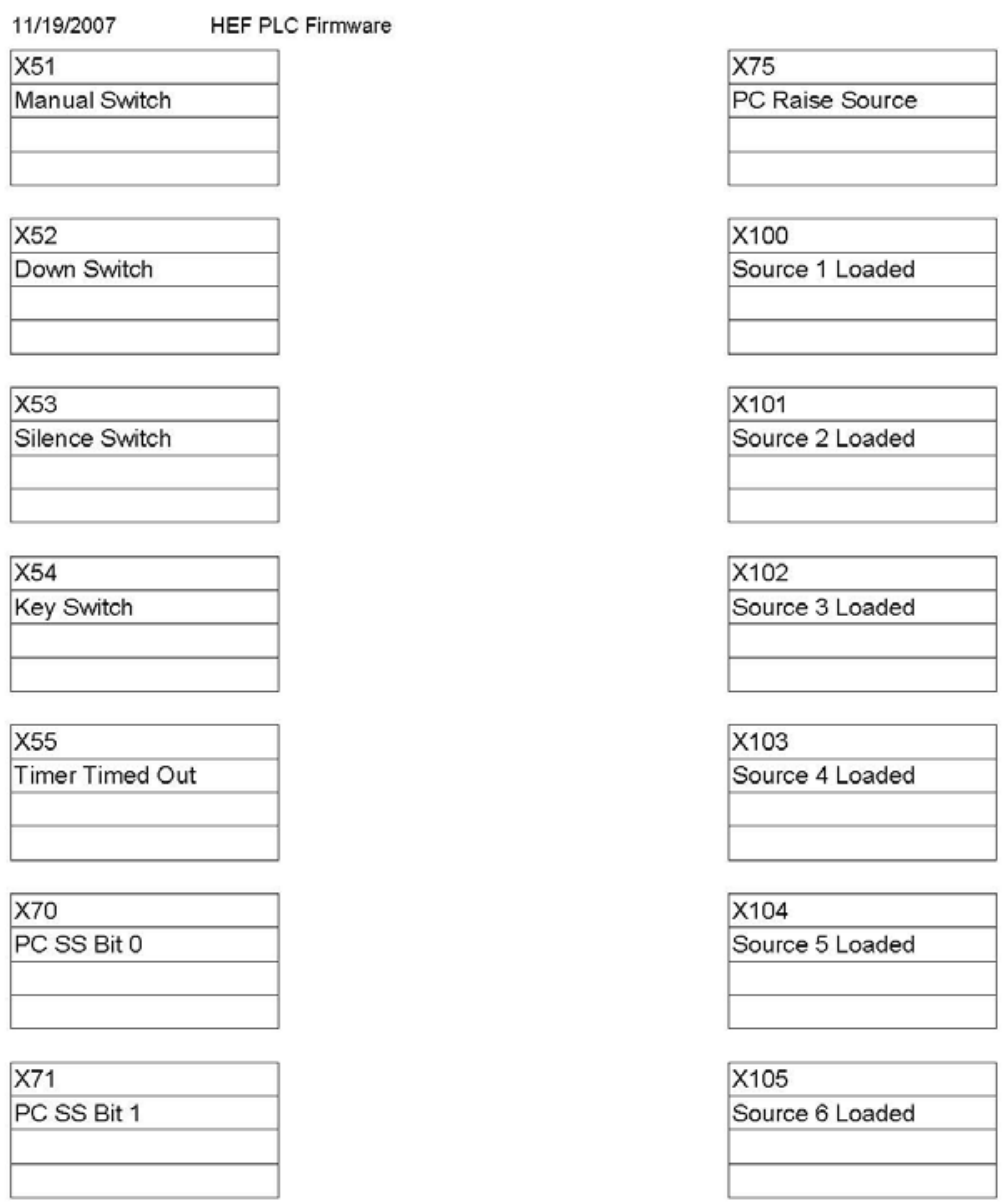

X105

Source 6 Loaded
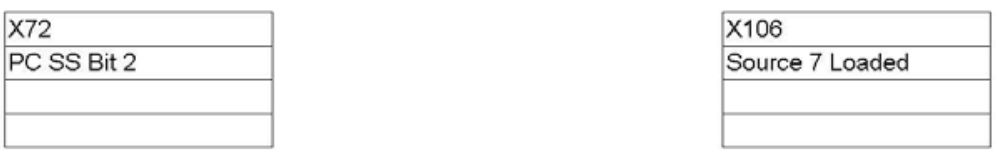

X73

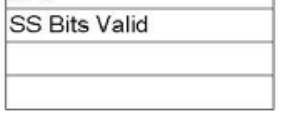

X107

Source 8 Loaded

X74

PC Lower Source

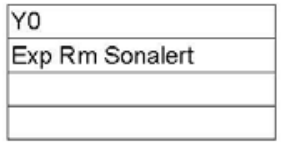

Page 2 

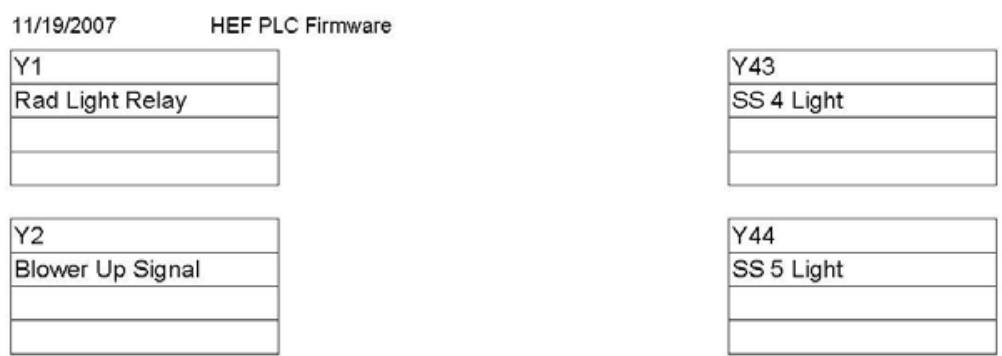

Y44

SS 5 Light
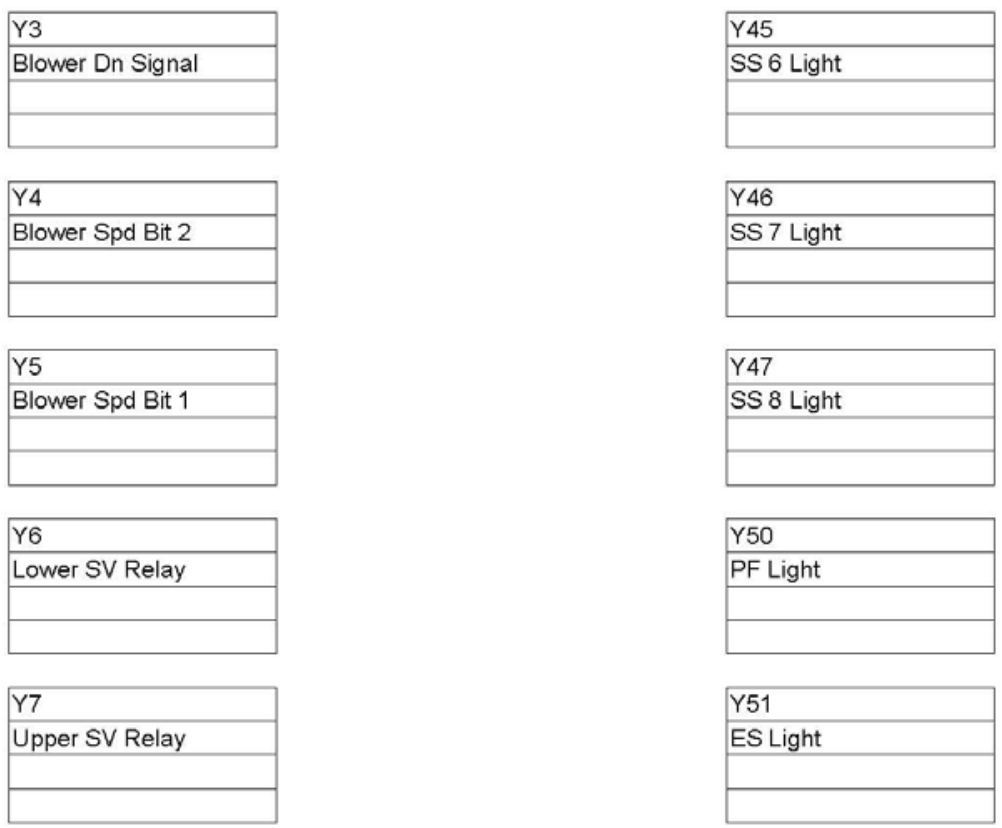

Y51
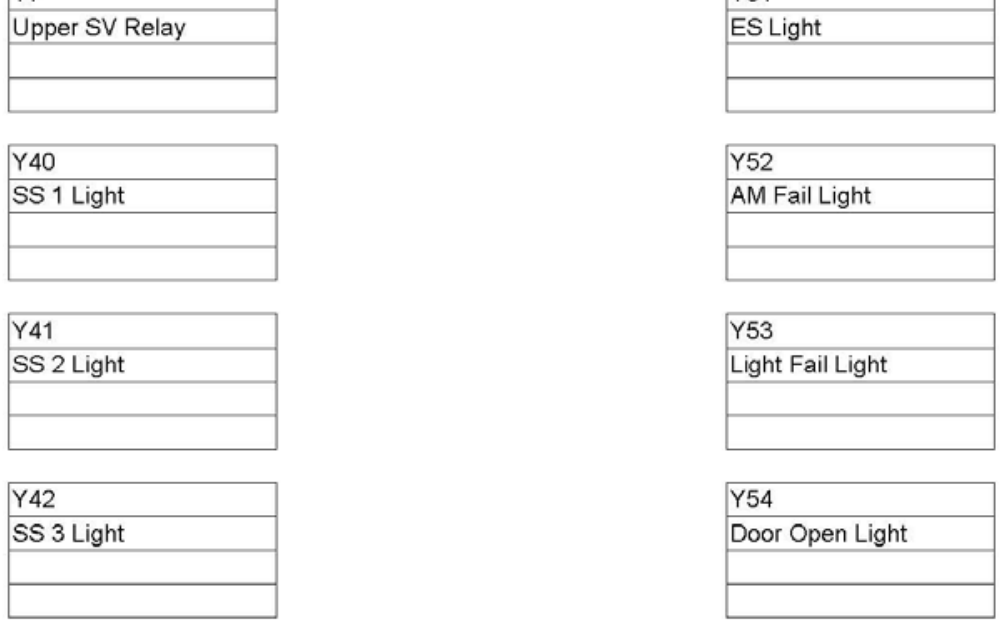

\begin{tabular}{|l|}
\hline Y54 \\
\hline Door Open Light \\
\hline \\
\hline
\end{tabular}

Page 3 

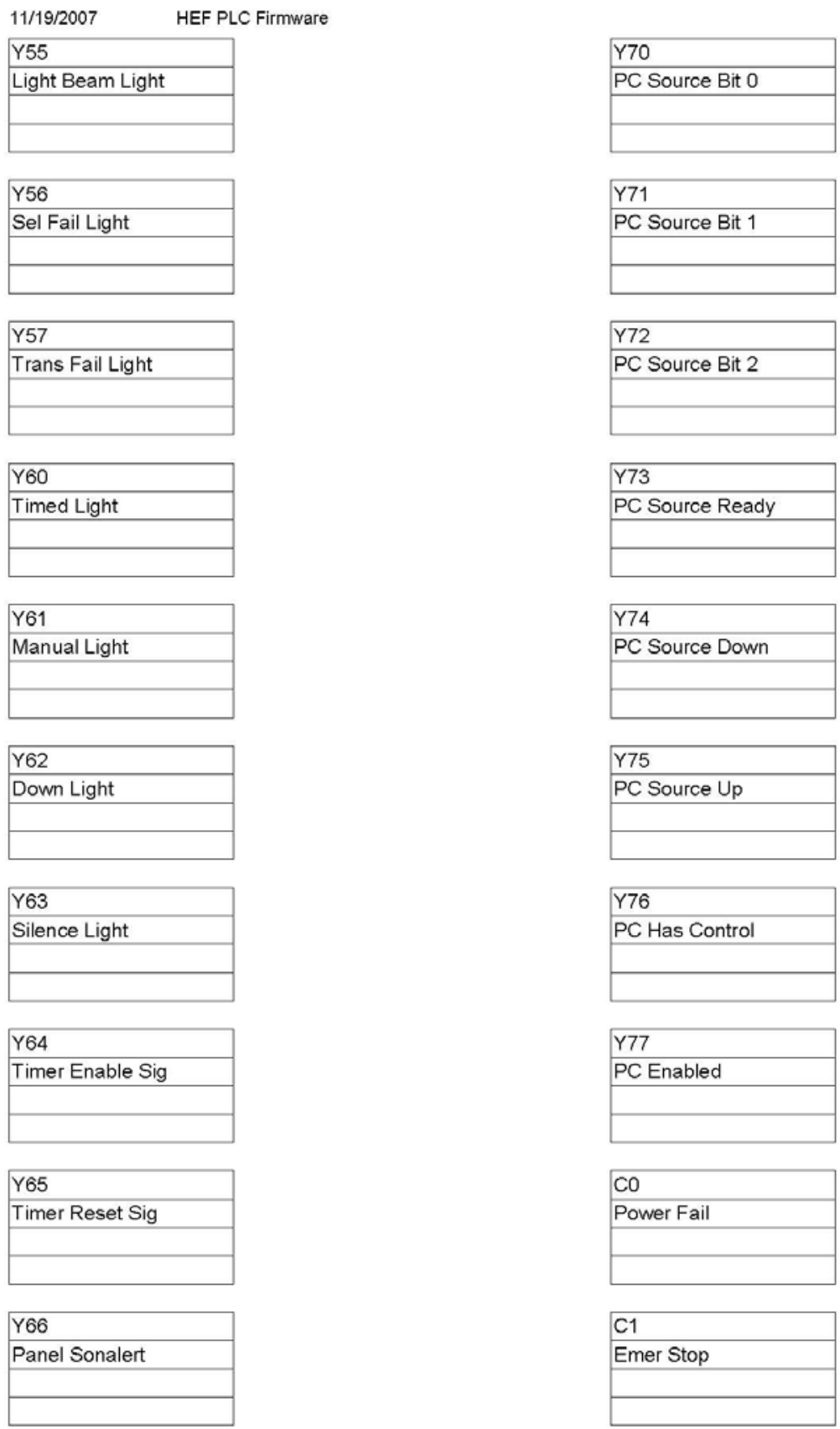

Page 4 

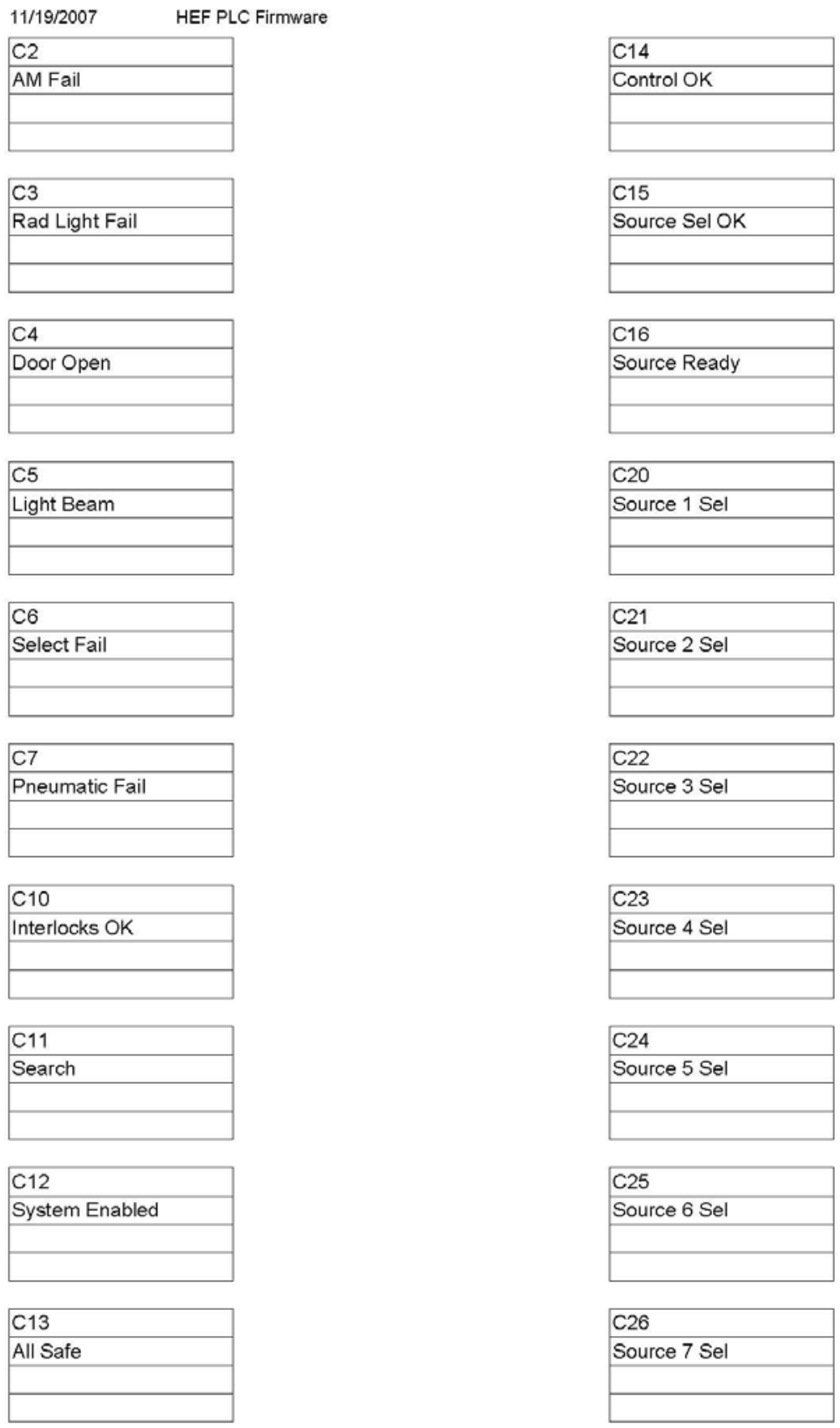

Page 5 

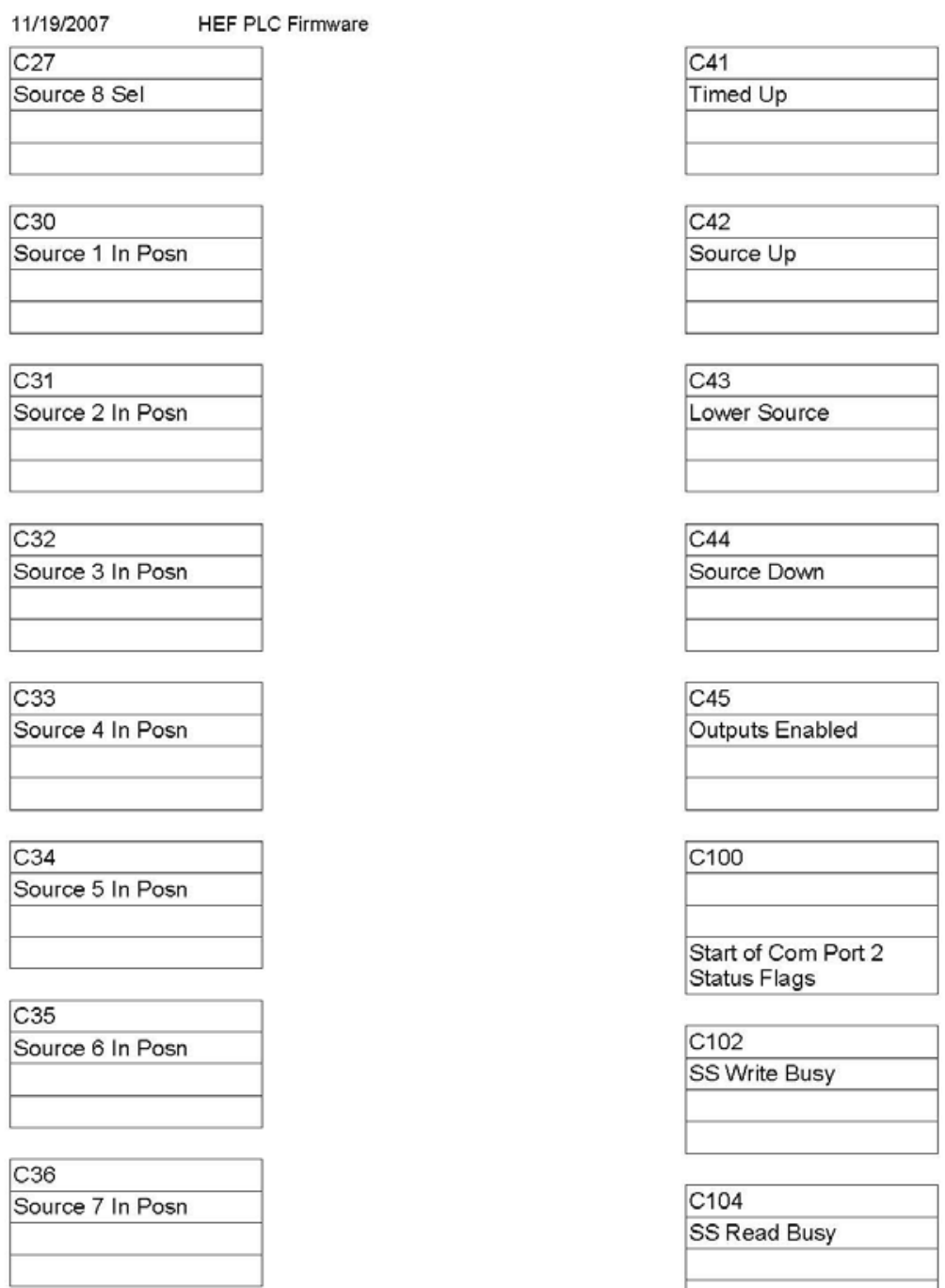

C104 SS Read Busy

C37
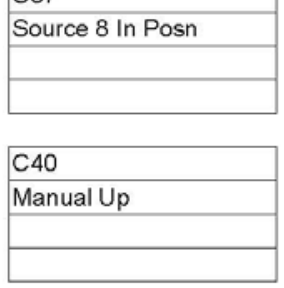

C107

SS Read Done

End of Com Port 2 Status Flags

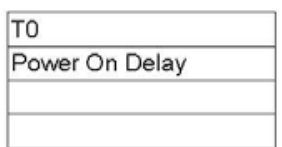

Page 6 

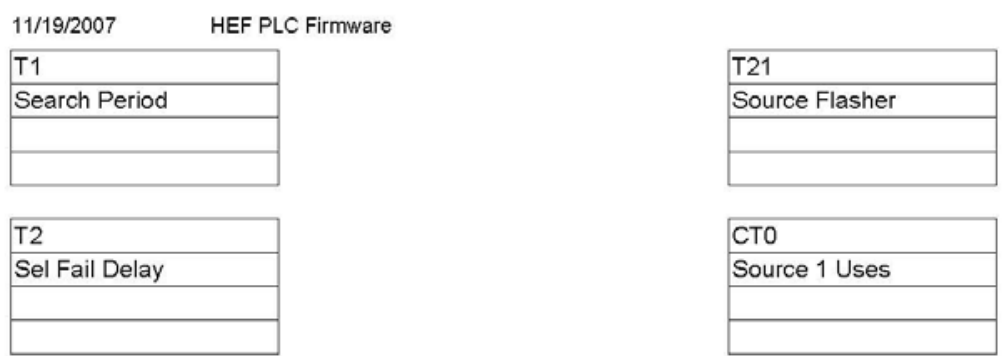

CTO

Source 1 Uses
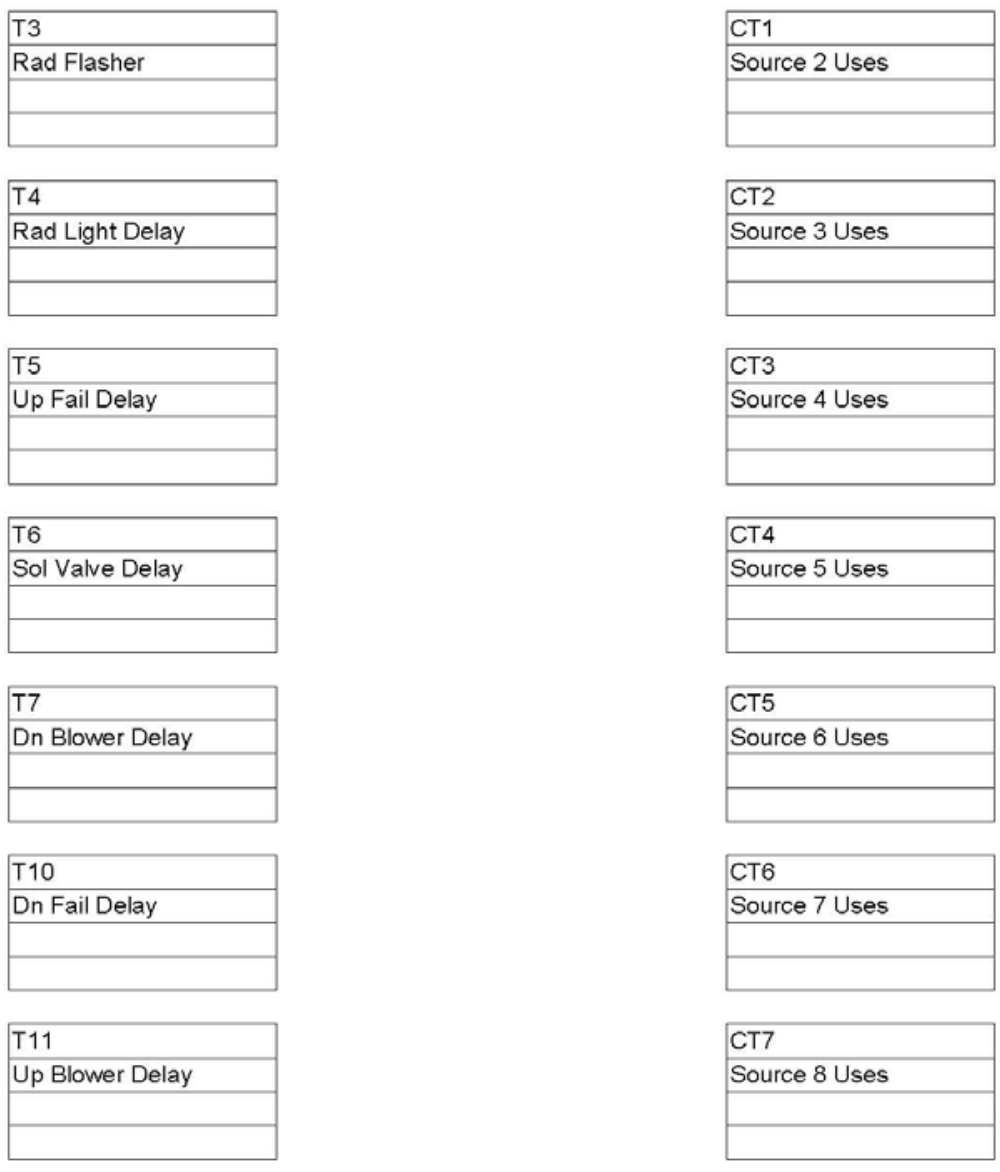

CT7
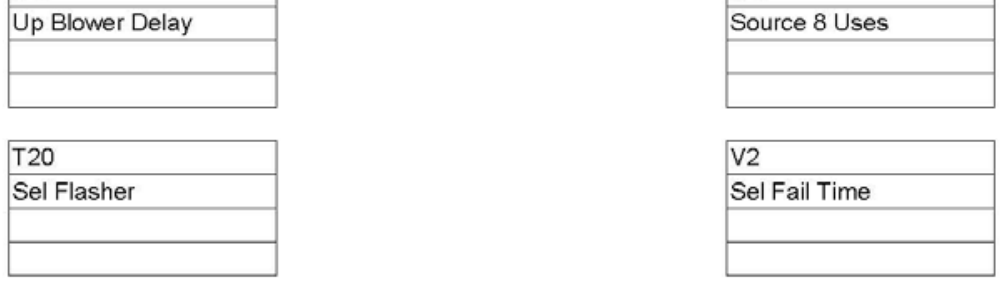

Page 7 


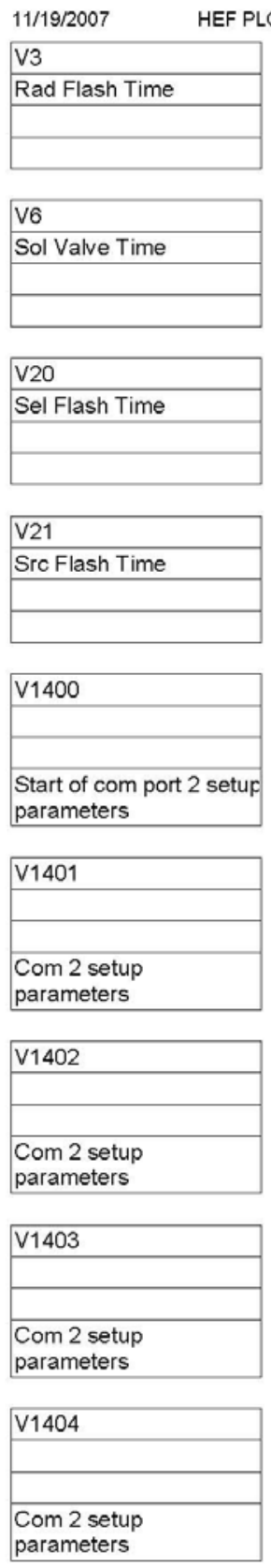

\begin{tabular}{|l|}
\hline V1405 \\
\hline \\
\hline $\begin{array}{l}\text { Com 2 setup } \\
\text { parameters }\end{array}$ \\
\hline
\end{tabular}

\begin{tabular}{|l|}
\hline V1406 \\
\hline \\
\hline $\begin{array}{l}\text { Com 2 setup } \\
\text { parameters }\end{array}$ \\
\hline
\end{tabular}

\begin{tabular}{|l|}
\hline V1407 \\
\hline \\
\hline $\begin{array}{l}\text { Com 2 setup } \\
\text { parameters }\end{array}$ \\
\hline
\end{tabular}

V1410

Com 2 setup

parameters

\begin{tabular}{|l|}
\hline V1411 \\
\hline \\
\hline $\begin{array}{l}\text { Com 2 setup } \\
\text { parameters }\end{array}$ \\
\hline
\end{tabular}

\begin{tabular}{|l|}
\hline $\mathrm{V} 1412$ \\
\hline \\
\hline $\begin{array}{l}\text { Com } 2 \text { setup } \\
\text { parameters }\end{array}$ \\
\hline
\end{tabular}

\begin{tabular}{|l|}
\hline V1413 \\
\hline \\
\hline $\begin{array}{l}\text { Com } 2 \text { setup } \\
\text { parameters }\end{array}$ \\
\hline
\end{tabular}

\begin{tabular}{|l|}
\hline V1414 \\
\hline \\
\hline $\begin{array}{l}\text { Com 2 setup } \\
\text { parameters }\end{array}$ \\
\hline
\end{tabular}

\begin{tabular}{|l|}
\hline V1415 \\
\hline \\
\hline $\begin{array}{l}\text { Com 2 setup } \\
\text { parameters }\end{array}$ \\
\hline
\end{tabular}

Page 8 


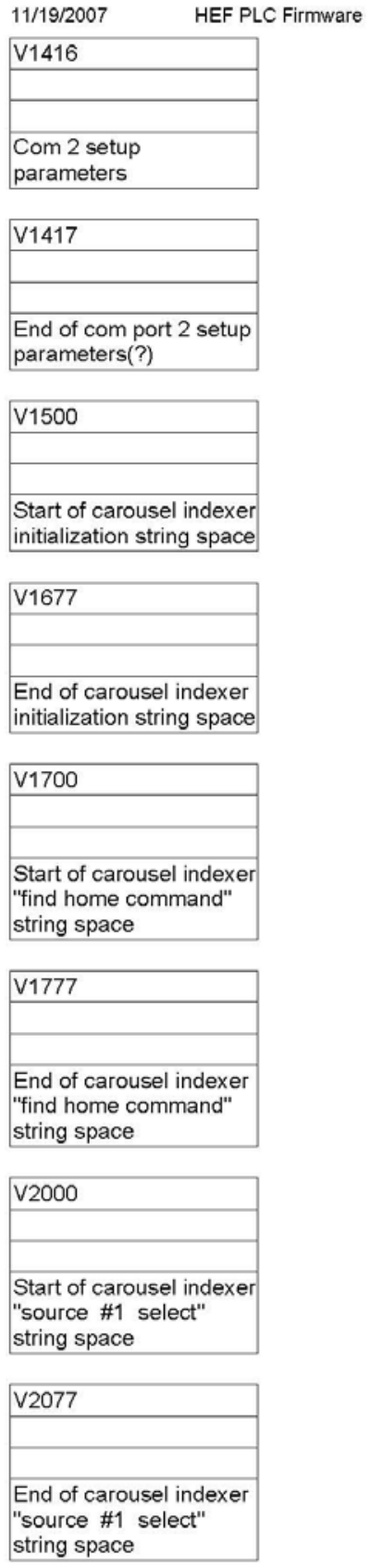

\begin{tabular}{|l|}
\hline V2100 \\
\hline \\
\hline $\begin{array}{l}\text { Start of carousel indexer } \\
\text { "source \#2 select" } \\
\text { string space }\end{array}$ \\
\hline
\end{tabular}

V2177

End of carousel indexer "source \#2 select" string space

\begin{tabular}{|l|}
\hline V2200 \\
\hline \\
\hline $\begin{array}{l}\text { Start of carousel indexer } \\
\text { "source \#3 select" } \\
\text { string space }\end{array}$ \\
\hline
\end{tabular}

\begin{tabular}{|l|}
\hline V2277 \\
\hline \\
\hline $\begin{array}{l}\text { End of carousel indexer } \\
\text { "source \#3 select" } \\
\text { string space }\end{array}$ \\
\hline
\end{tabular}

V2300

Start of carousel indexer "source \#4 select" string space

\begin{tabular}{|l|}
\hline V2377 \\
\hline \\
\hline $\begin{array}{l}\text { End of carousel indexer } \\
\text { "source \#4 select" } \\
\text { string space }\end{array}$ \\
\hline
\end{tabular}

\begin{tabular}{|l|}
\hline V2400 \\
\hline \\
\hline $\begin{array}{l}\text { Start of carousel indexer } \\
\text { "source \#5 select" } \\
\text { string space }\end{array}$ \\
\hline
\end{tabular}

Page 9 


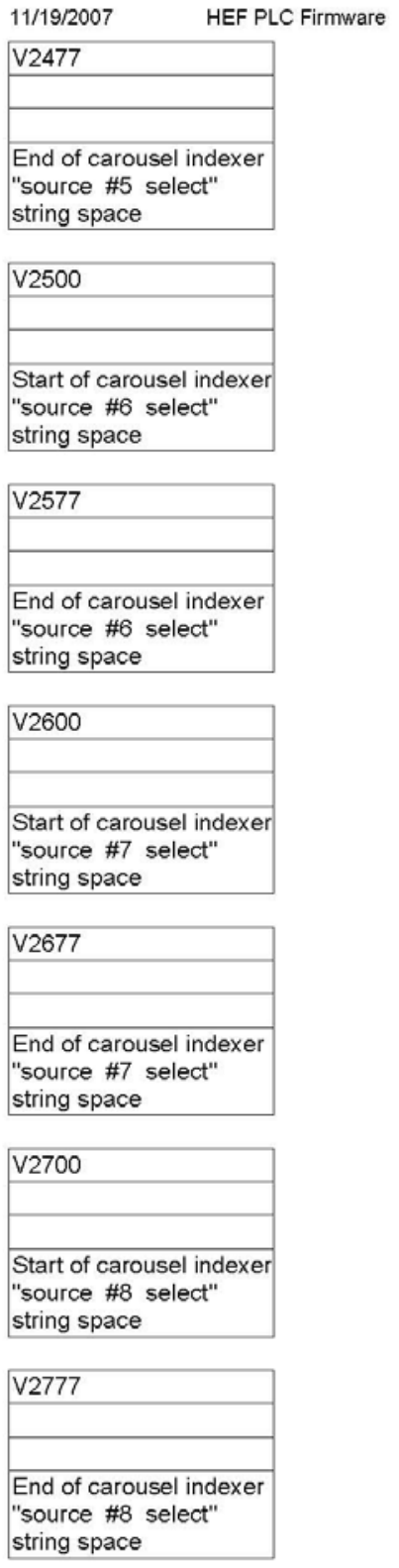

\begin{tabular}{|l|}
\hline V3000 \\
\hline \\
\hline $\begin{array}{l}\text { Start of carousel indexer } \\
\text { source select string } \\
\text { receive buffer }\end{array}$ \\
\hline
\end{tabular}

V3017

End of carousel indexer source select string

receive buffer

V3020

Offset used to locate

source select number in

source select string

receive buffer

\begin{tabular}{|l|}
\hline V3021 \\
\hline \\
\hline Source select number \\
\hline
\end{tabular}

\begin{tabular}{|l|}
\hline V7650 \\
\hline \\
\hline $\begin{array}{l}\text { Start of com port } 2 \\
\text { configuration space }\end{array}$ \\
\hline
\end{tabular}

V7657

End of com port 2

configuration space

\begin{tabular}{|l|}
\hline SPO \\
\hline FirstScan \\
\hline \\
\hline
\end{tabular}

Page 10 
11/19/2007 HEF PLC Firmware

Page 11

A.12 


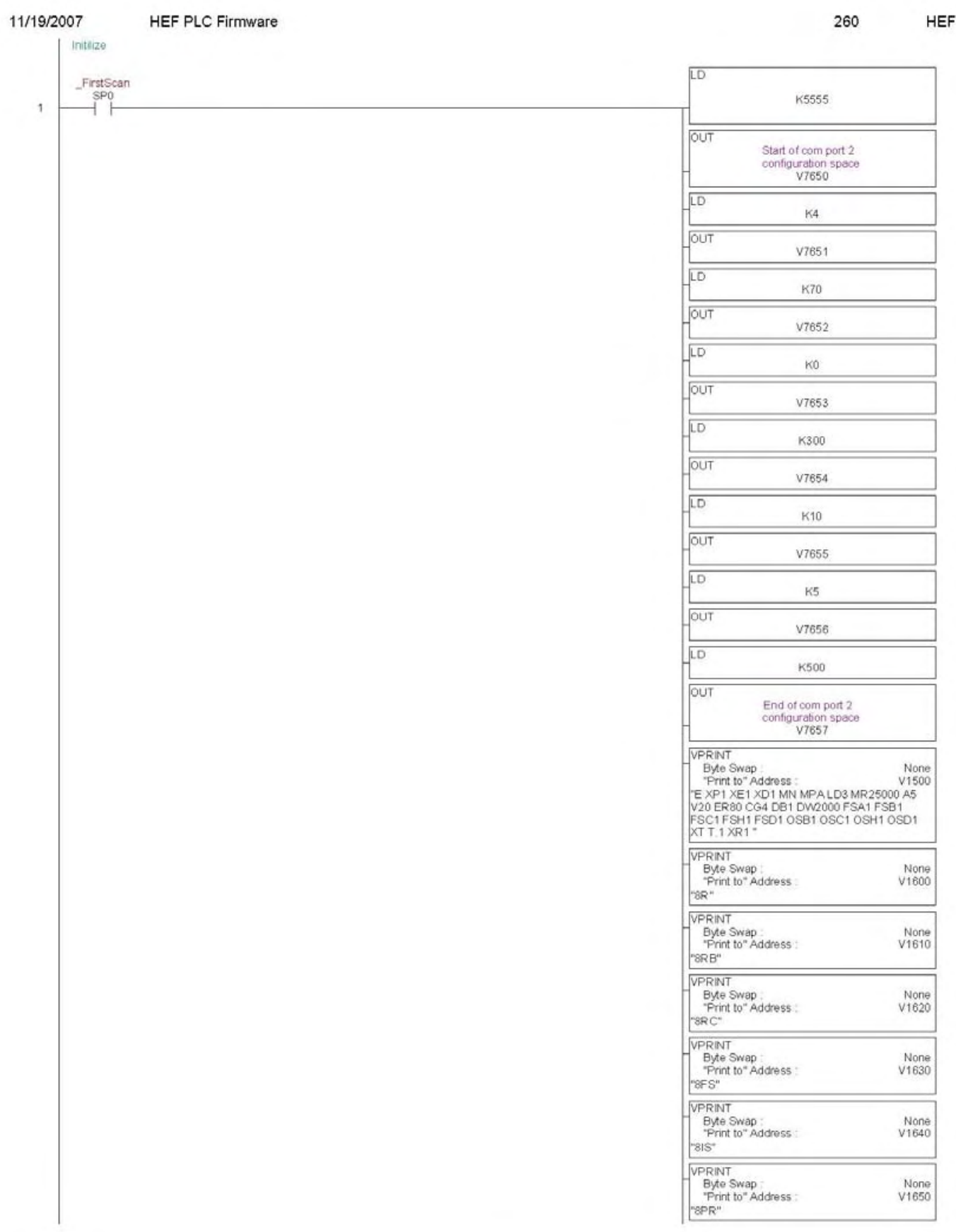

Page 12

A.13 


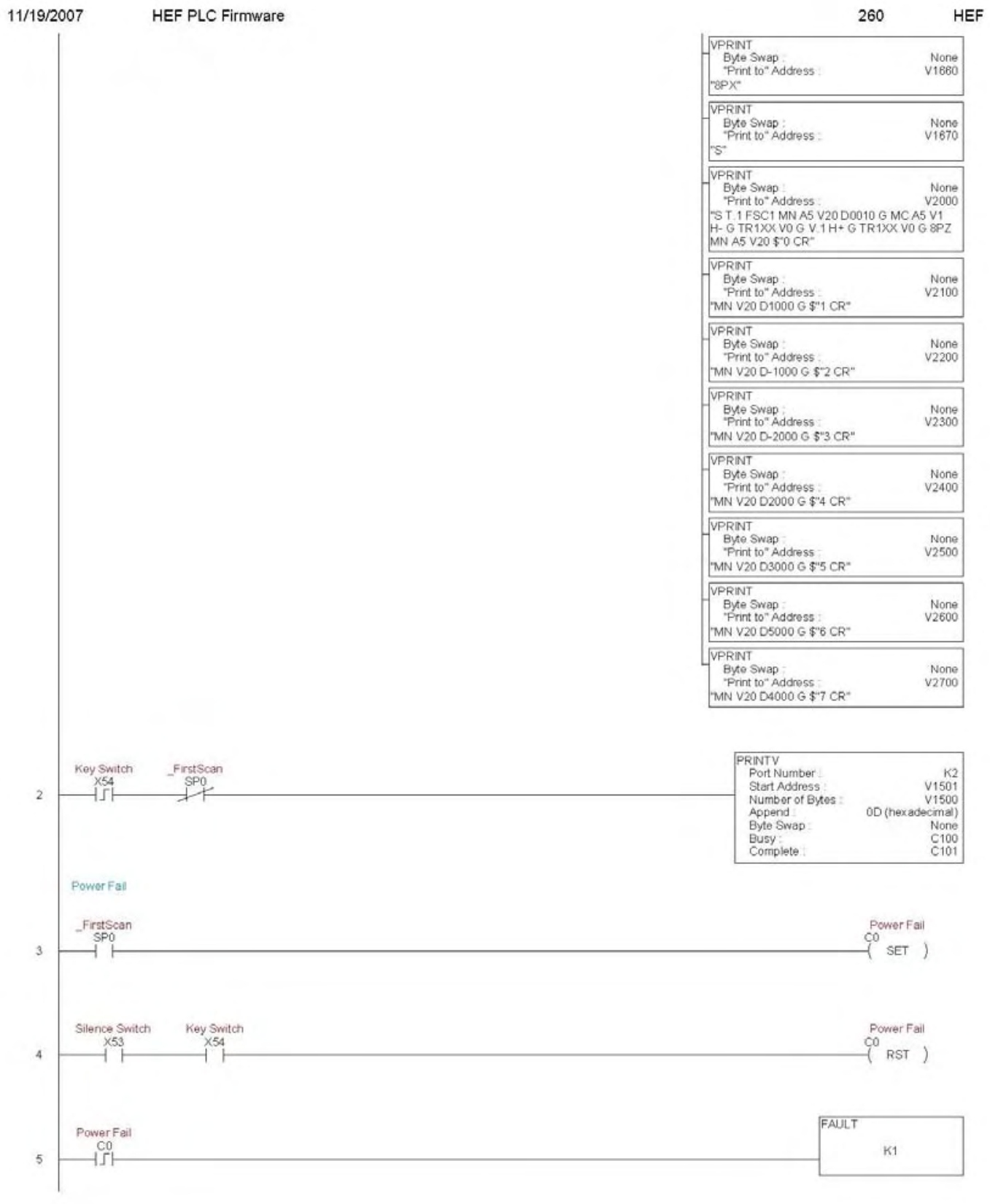

Page 13

A.14 


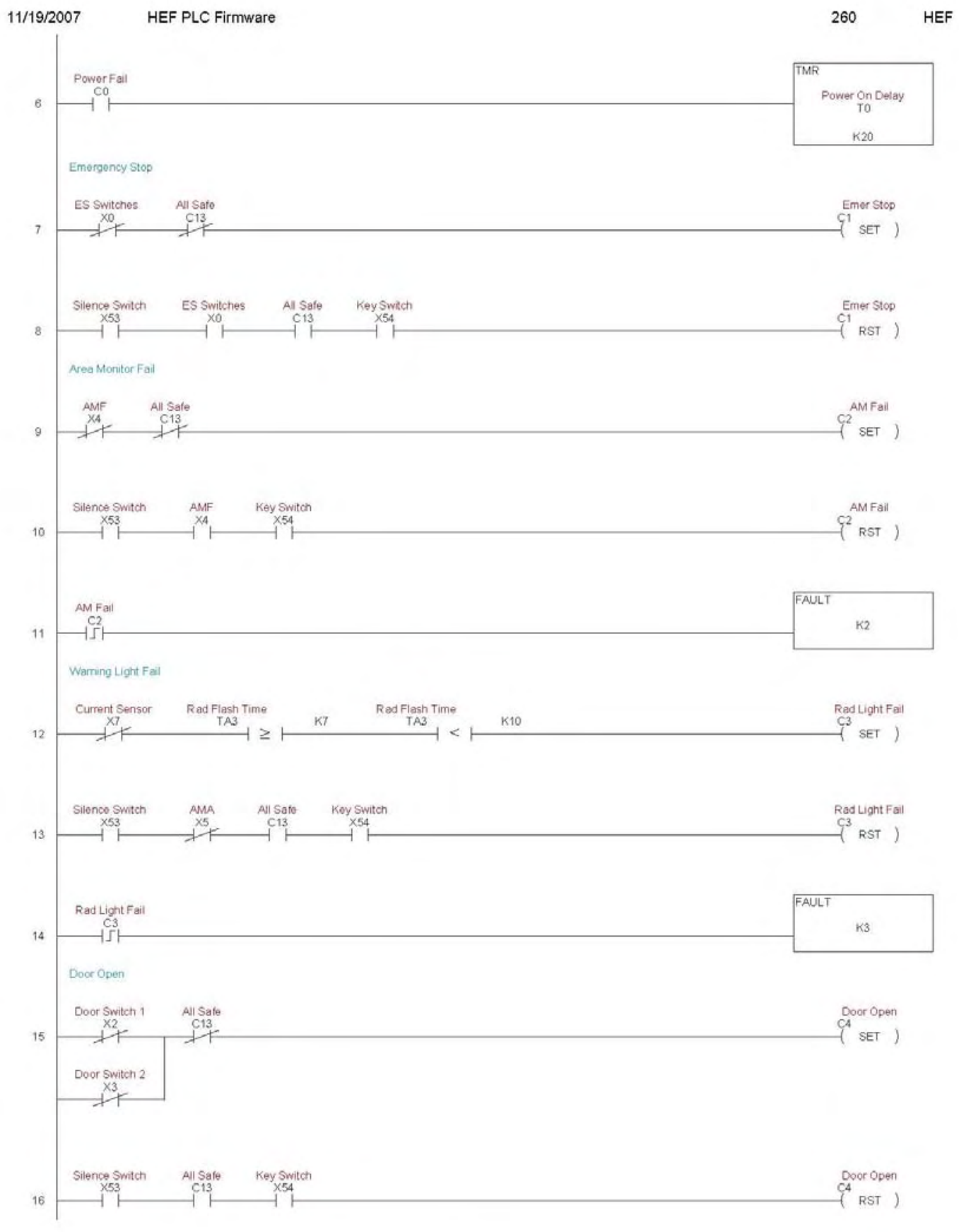

Page 14 


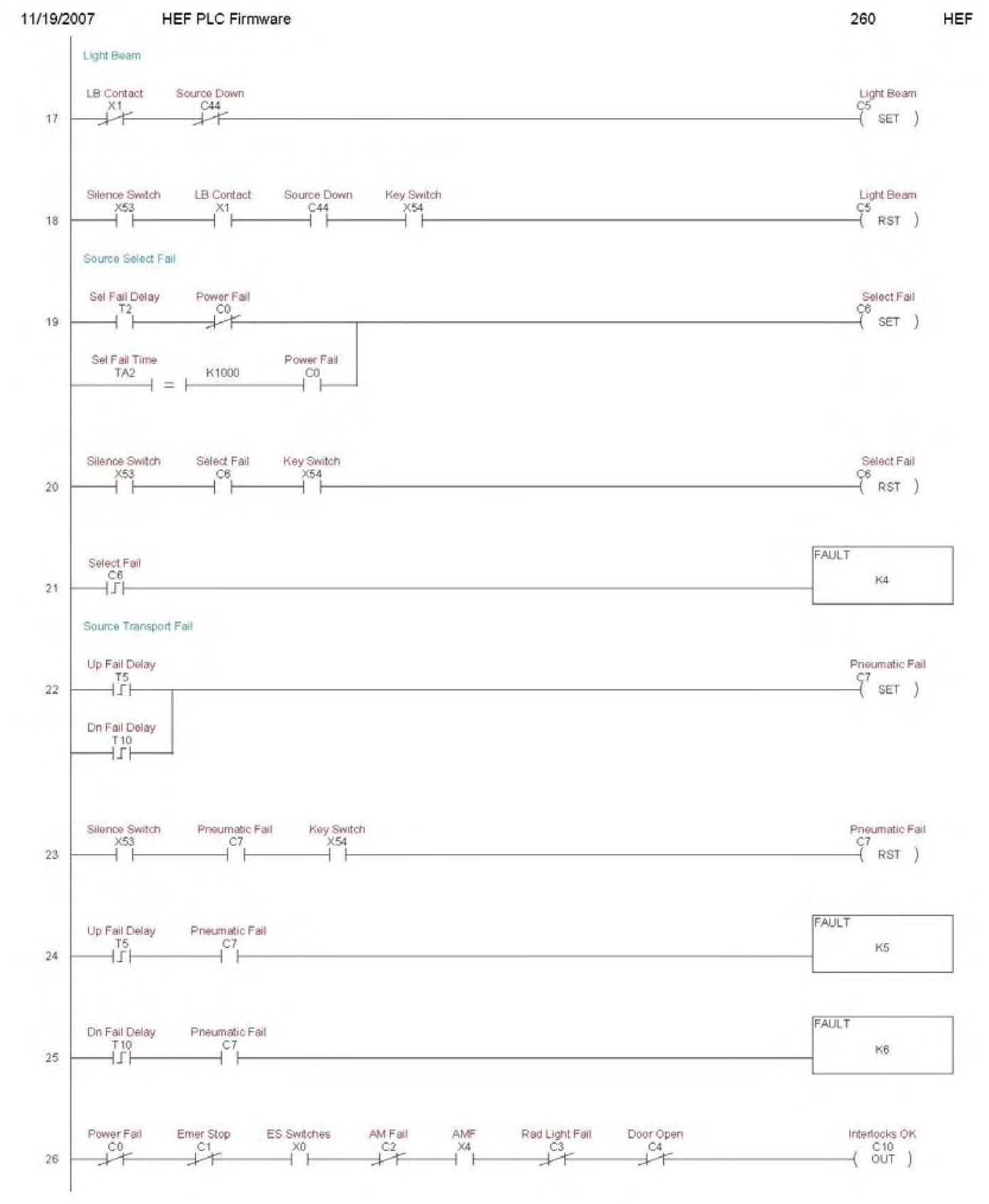

Page 15 


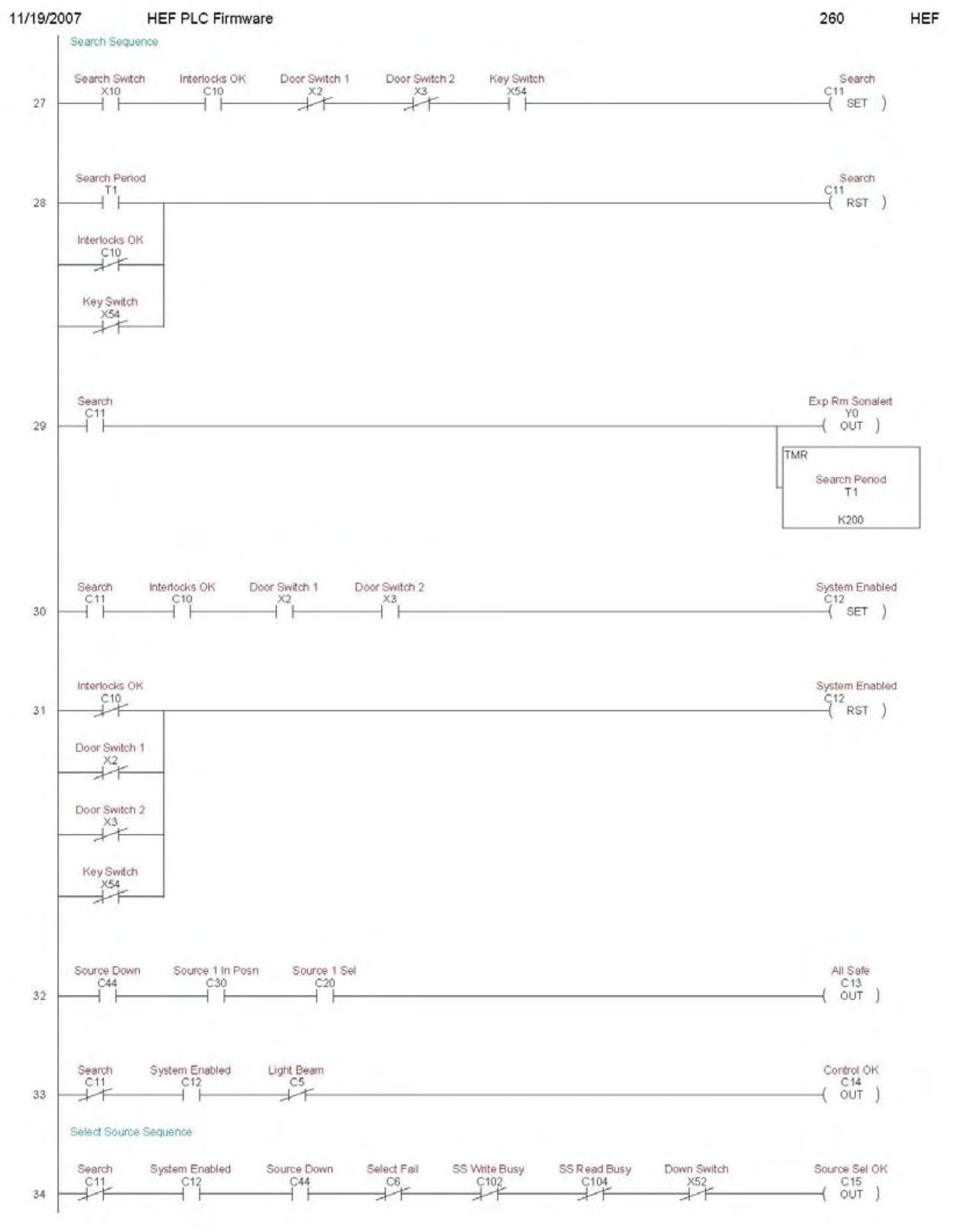

Page 16

A.17 


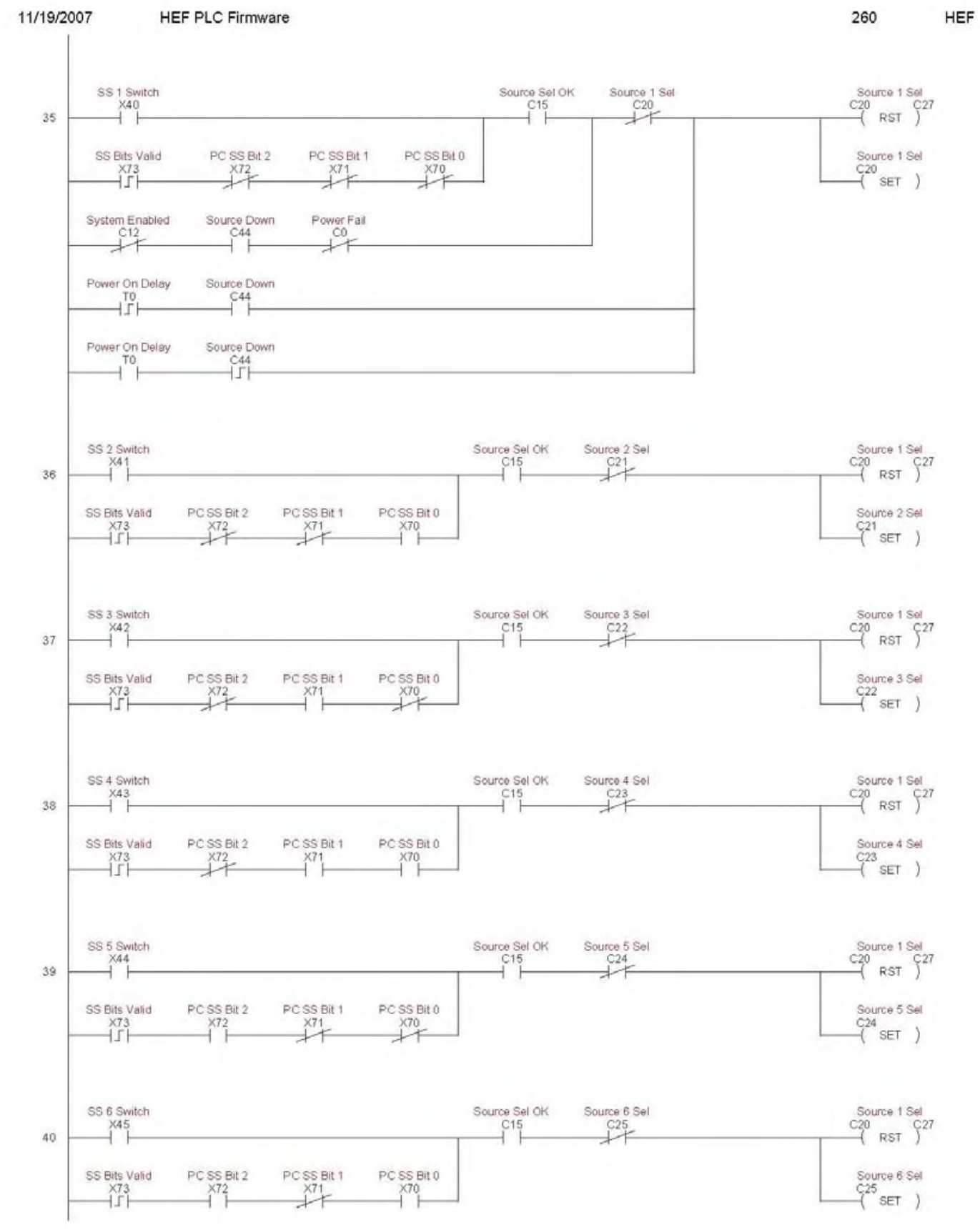

Page 17 


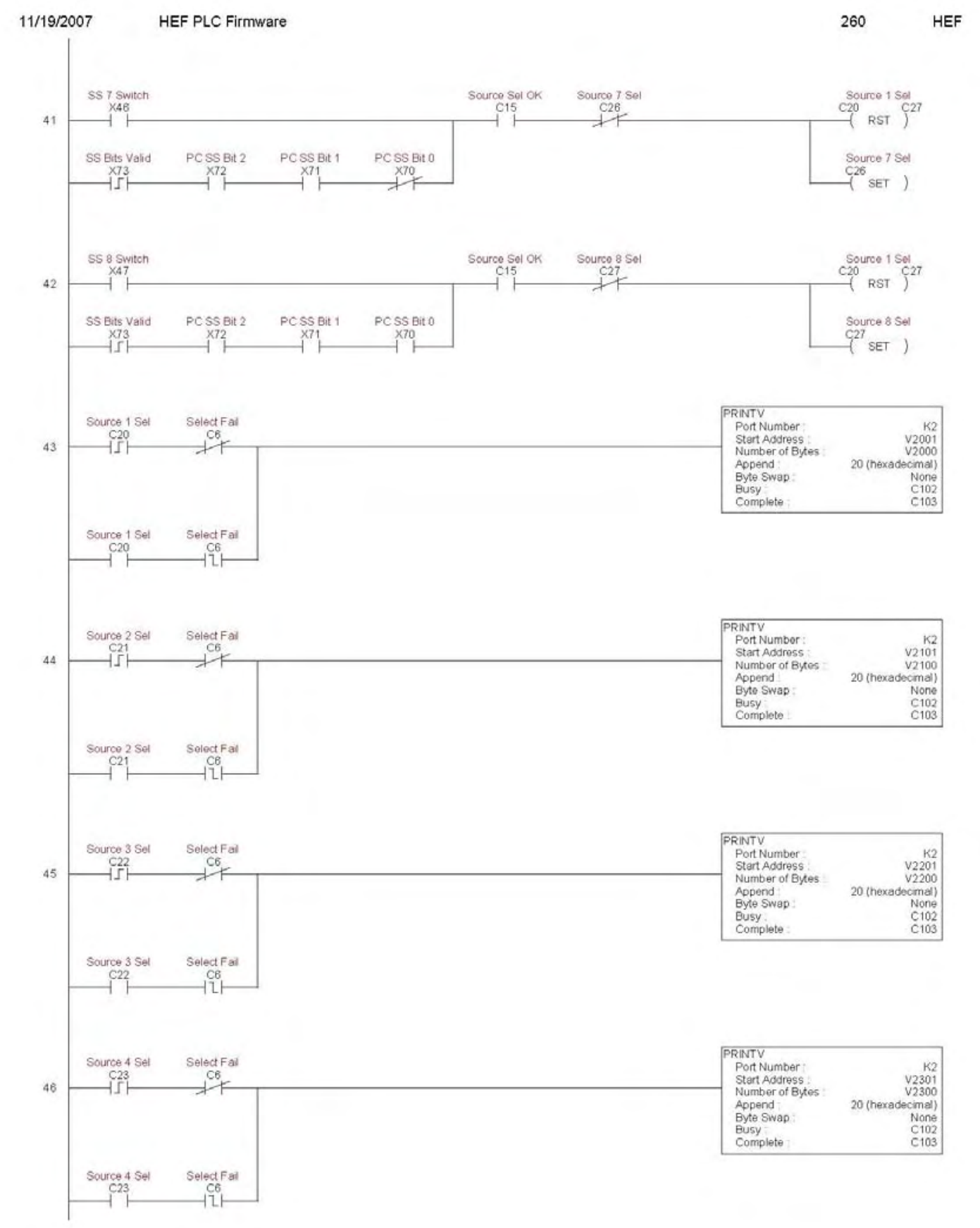

Page 18

A.19 


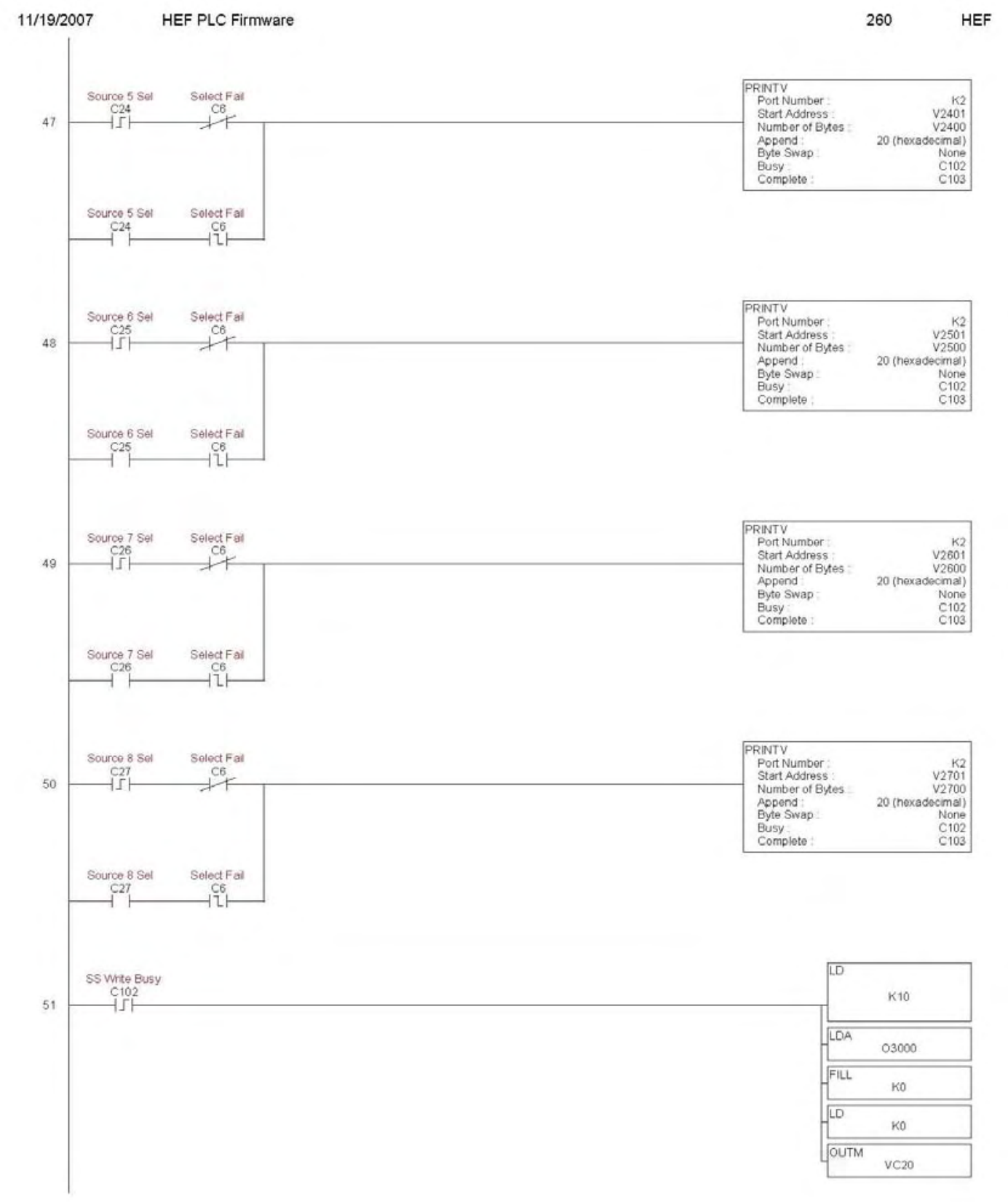

Page 19 


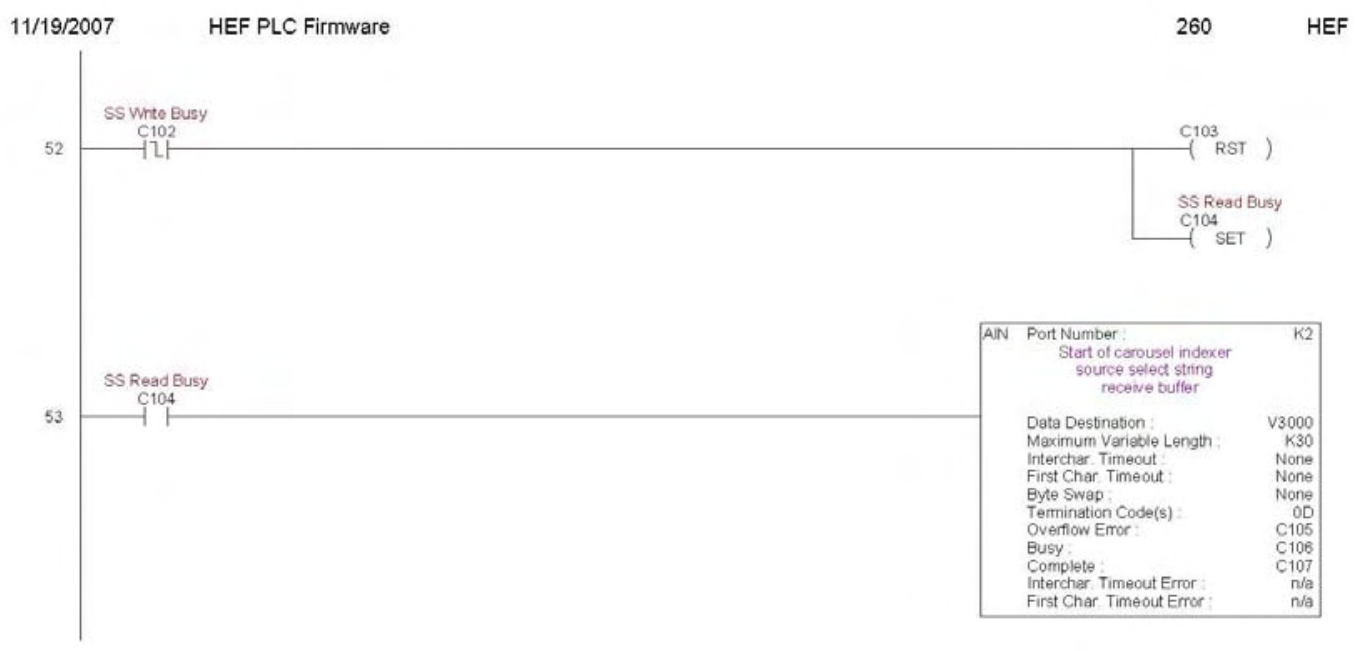

Page 20

A. 21 


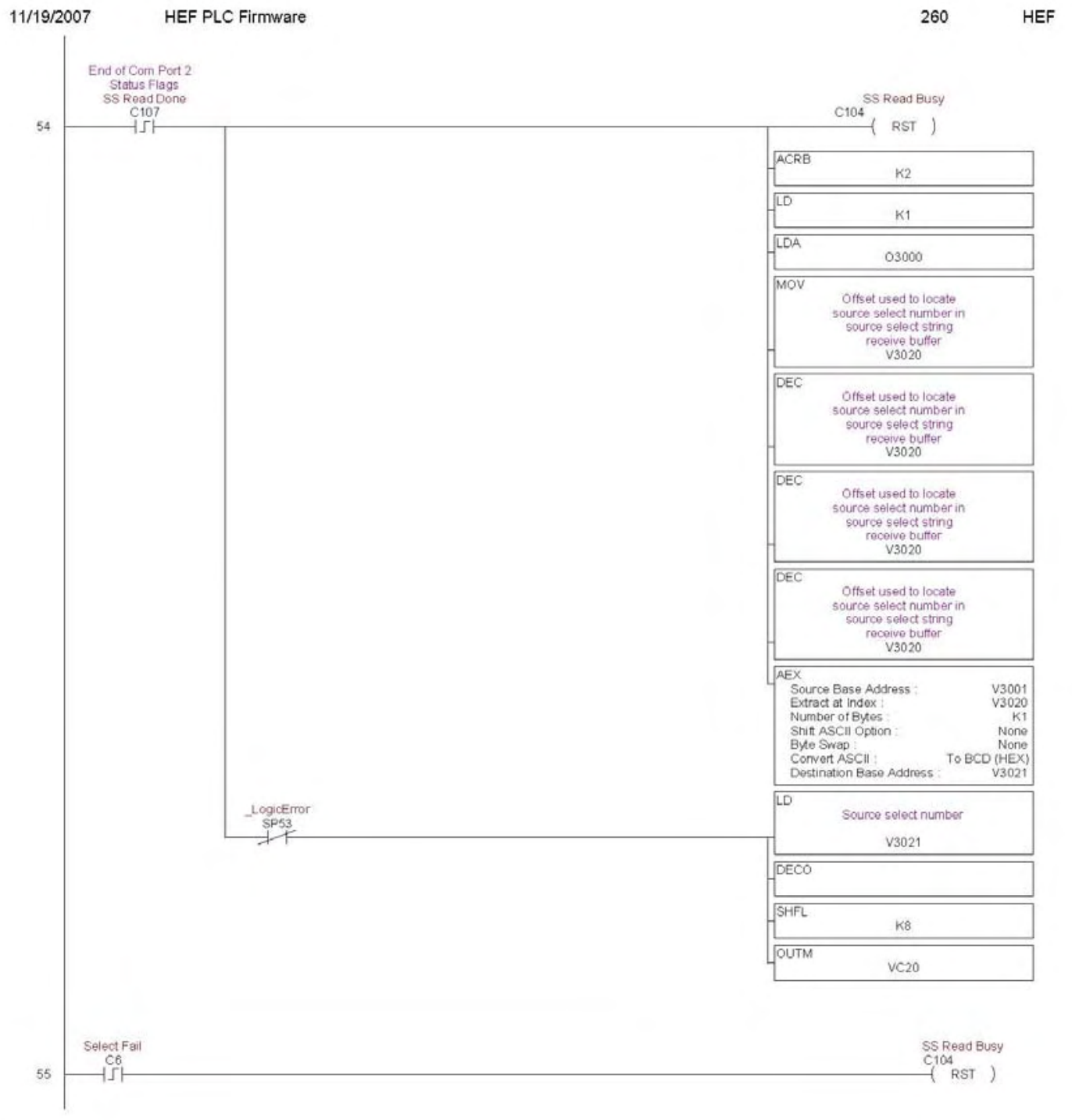

Page 21

A. 22 


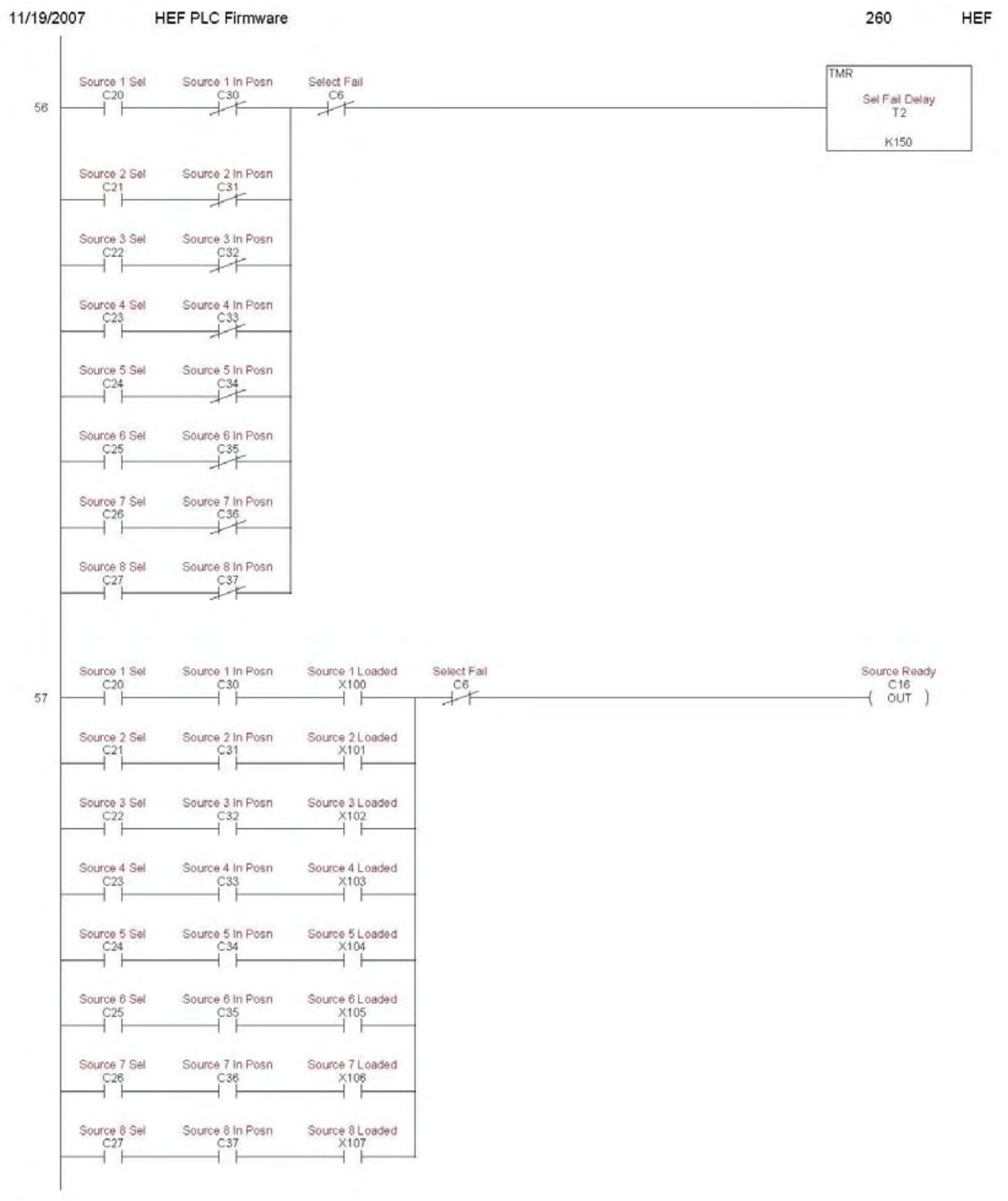

Page 22 


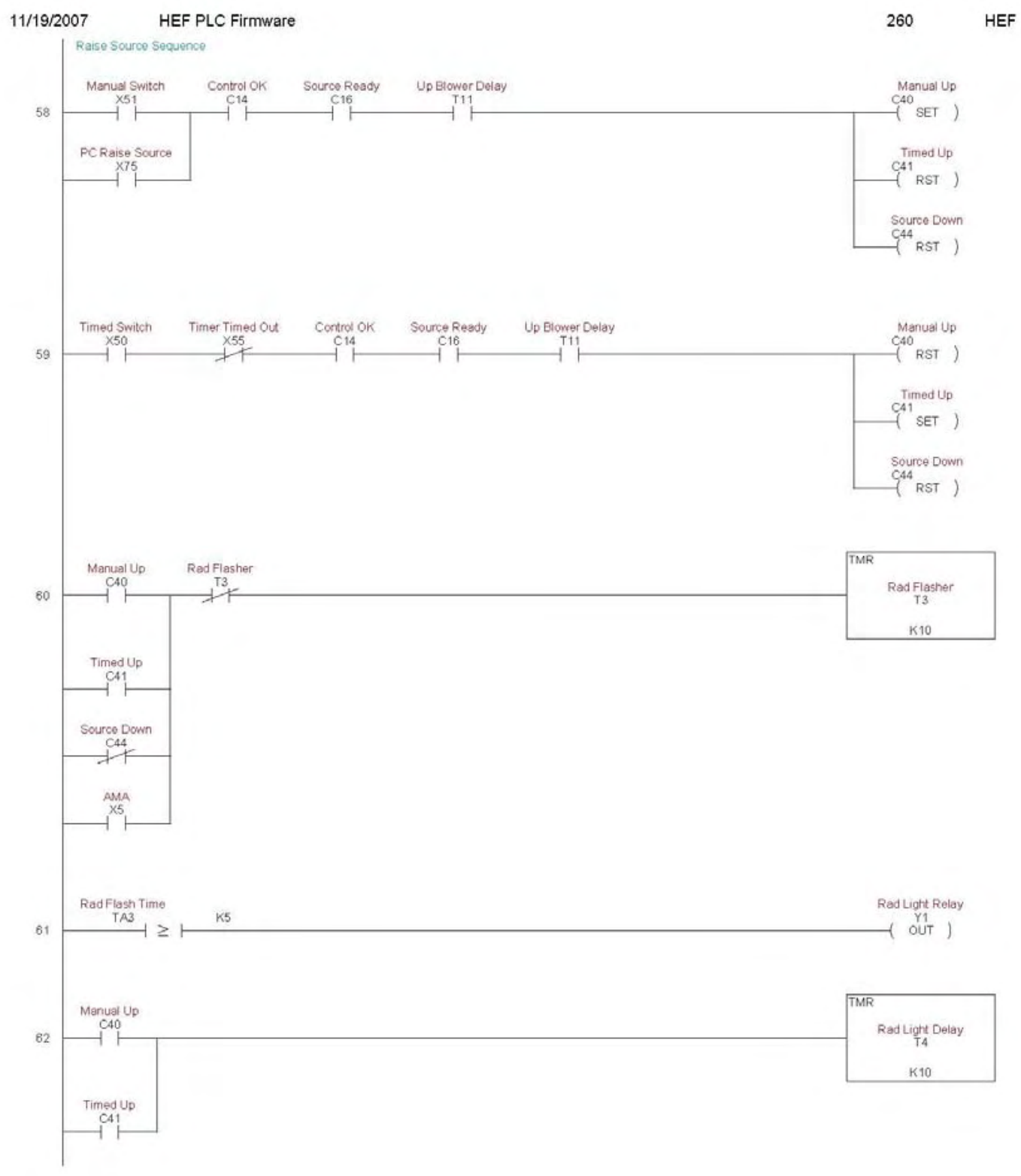

Page 23 


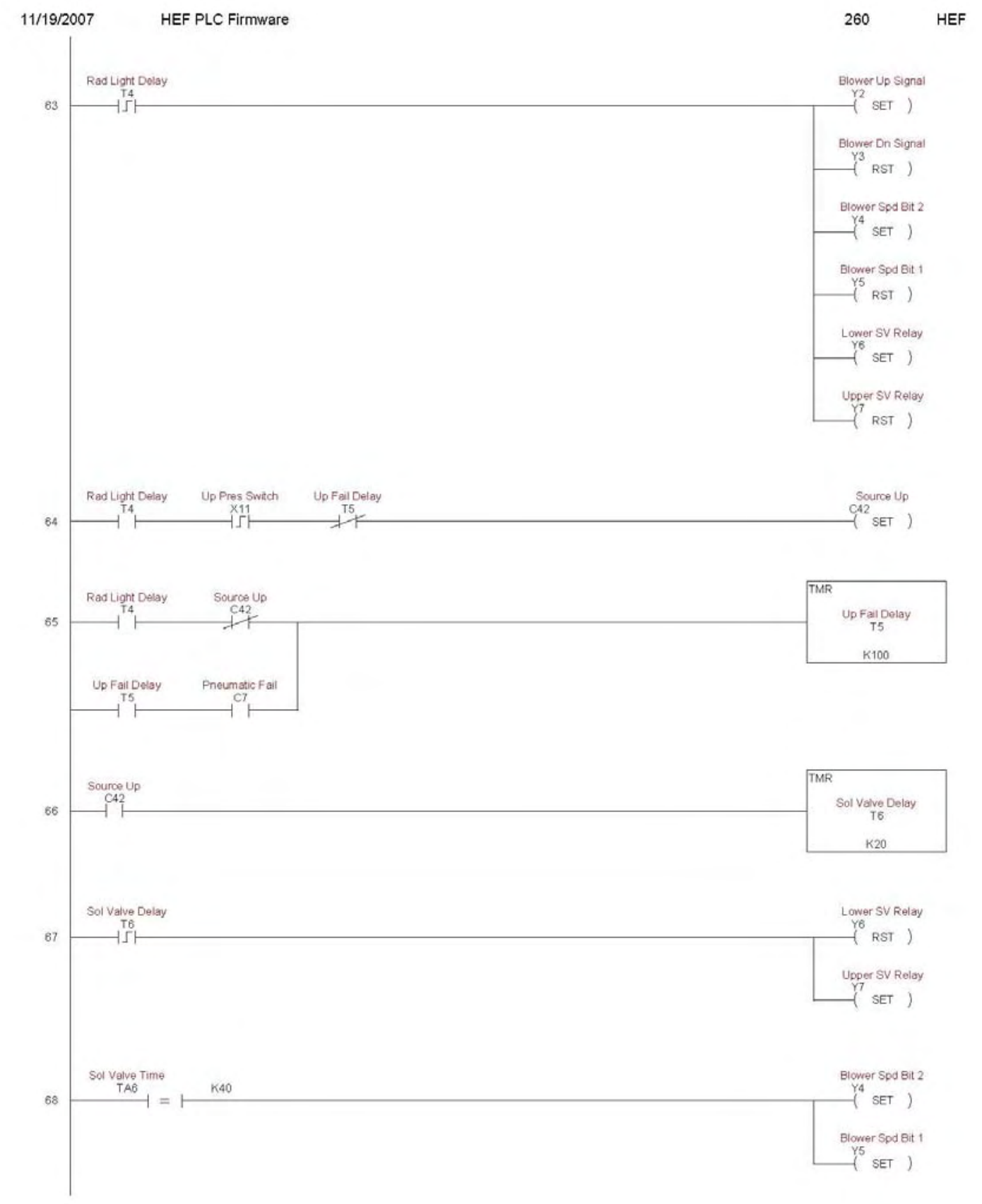

Page 24 


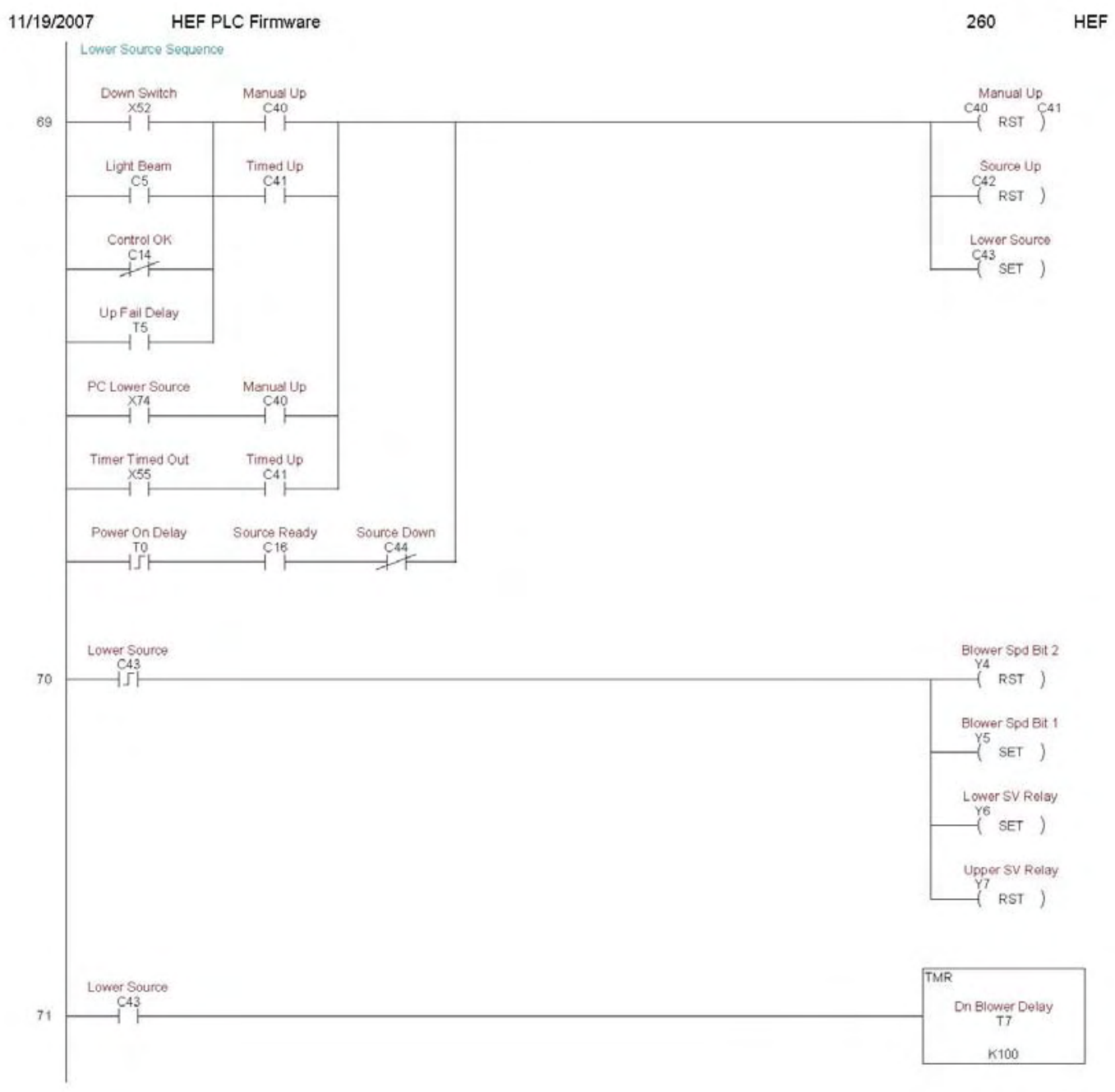

Page 25 


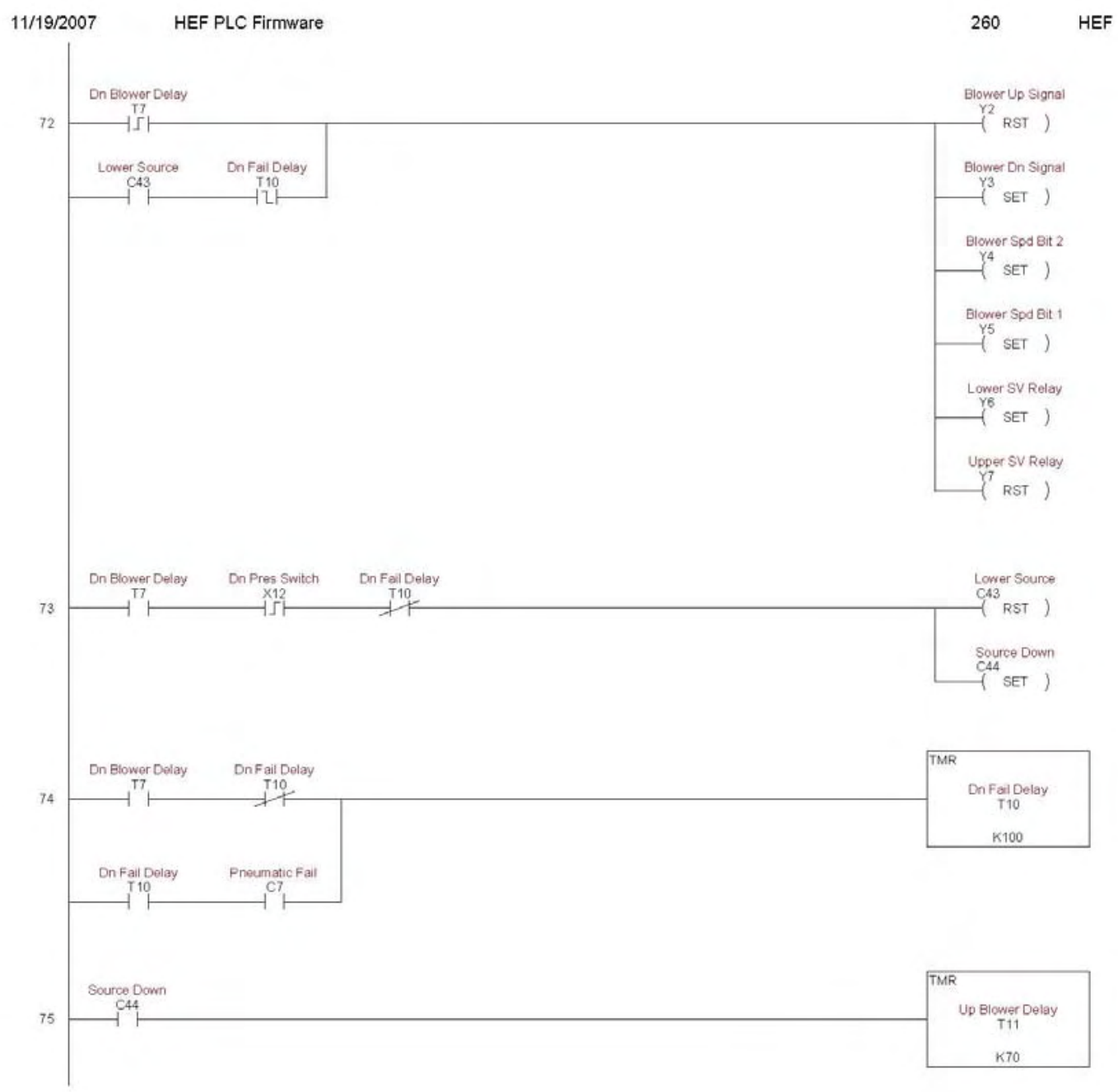

Page 26 


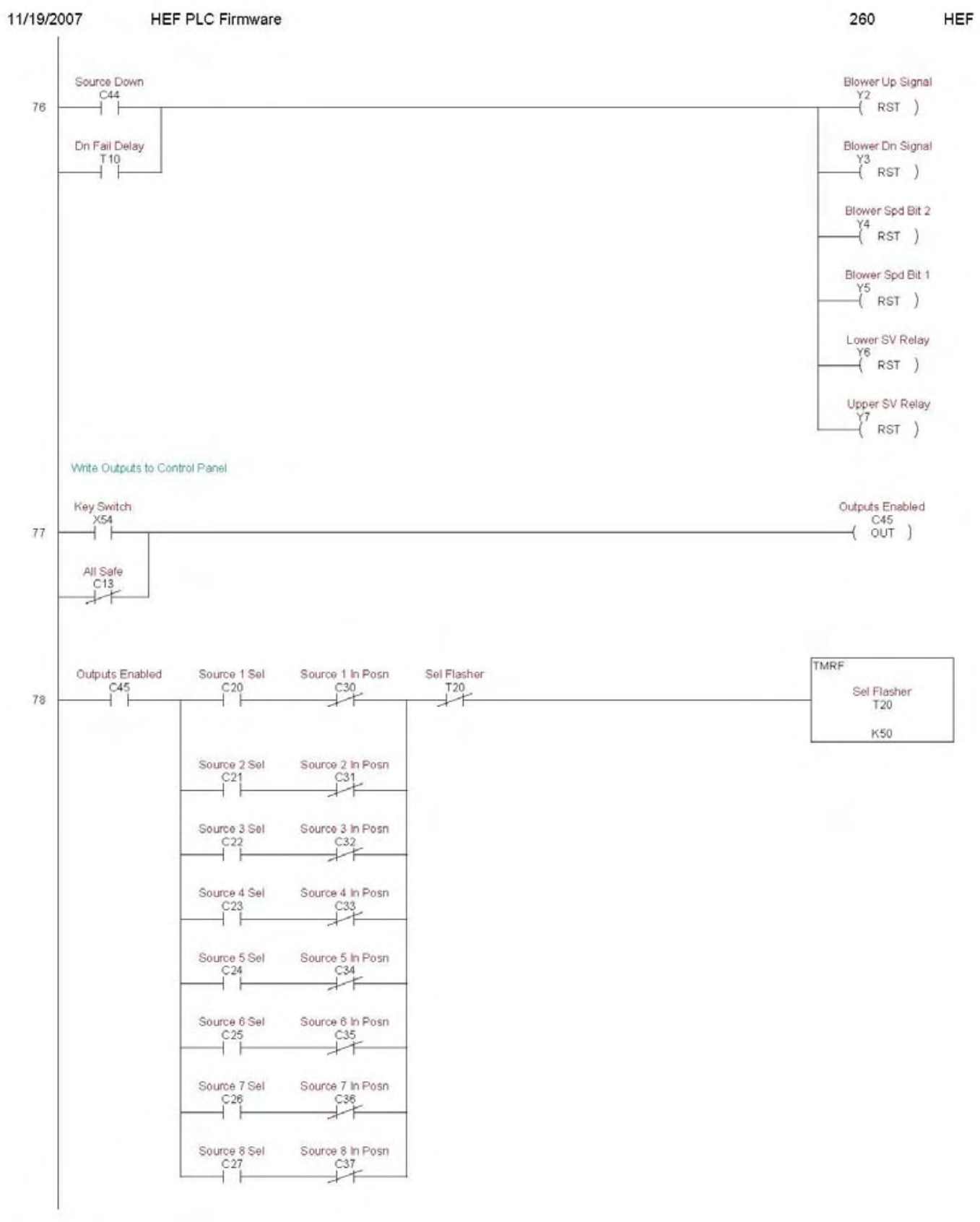

Page 27 


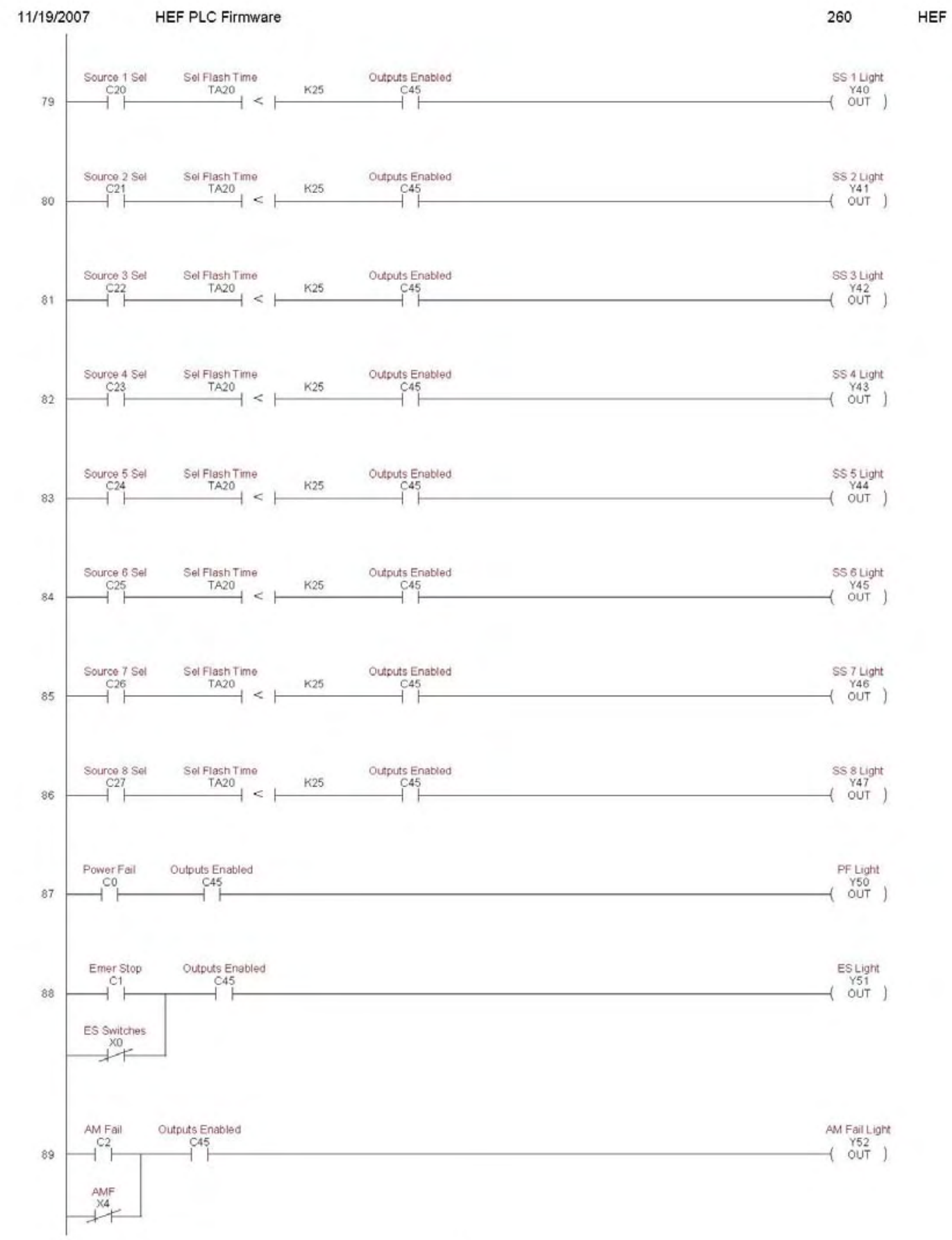

Page 28 


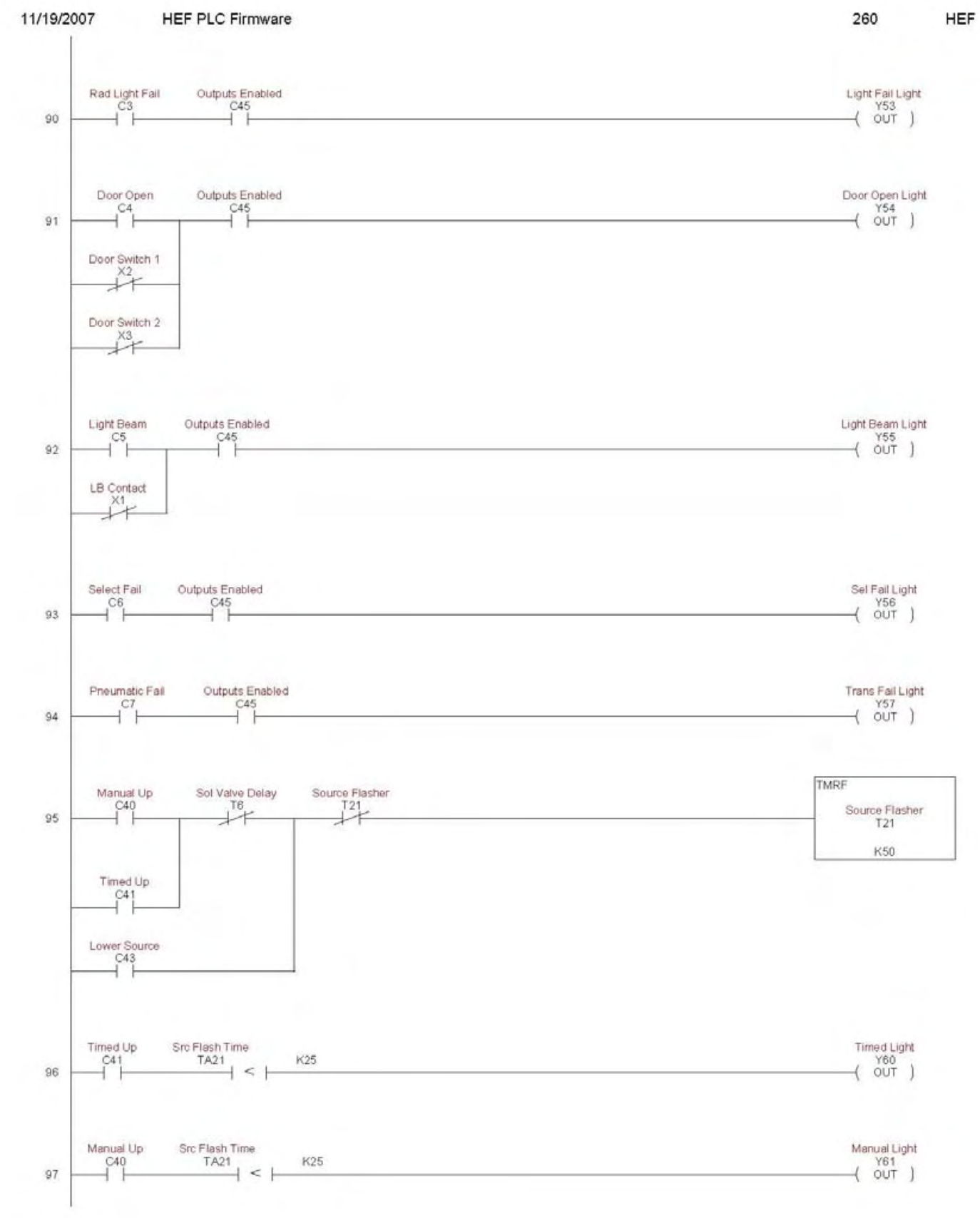

Page 29 


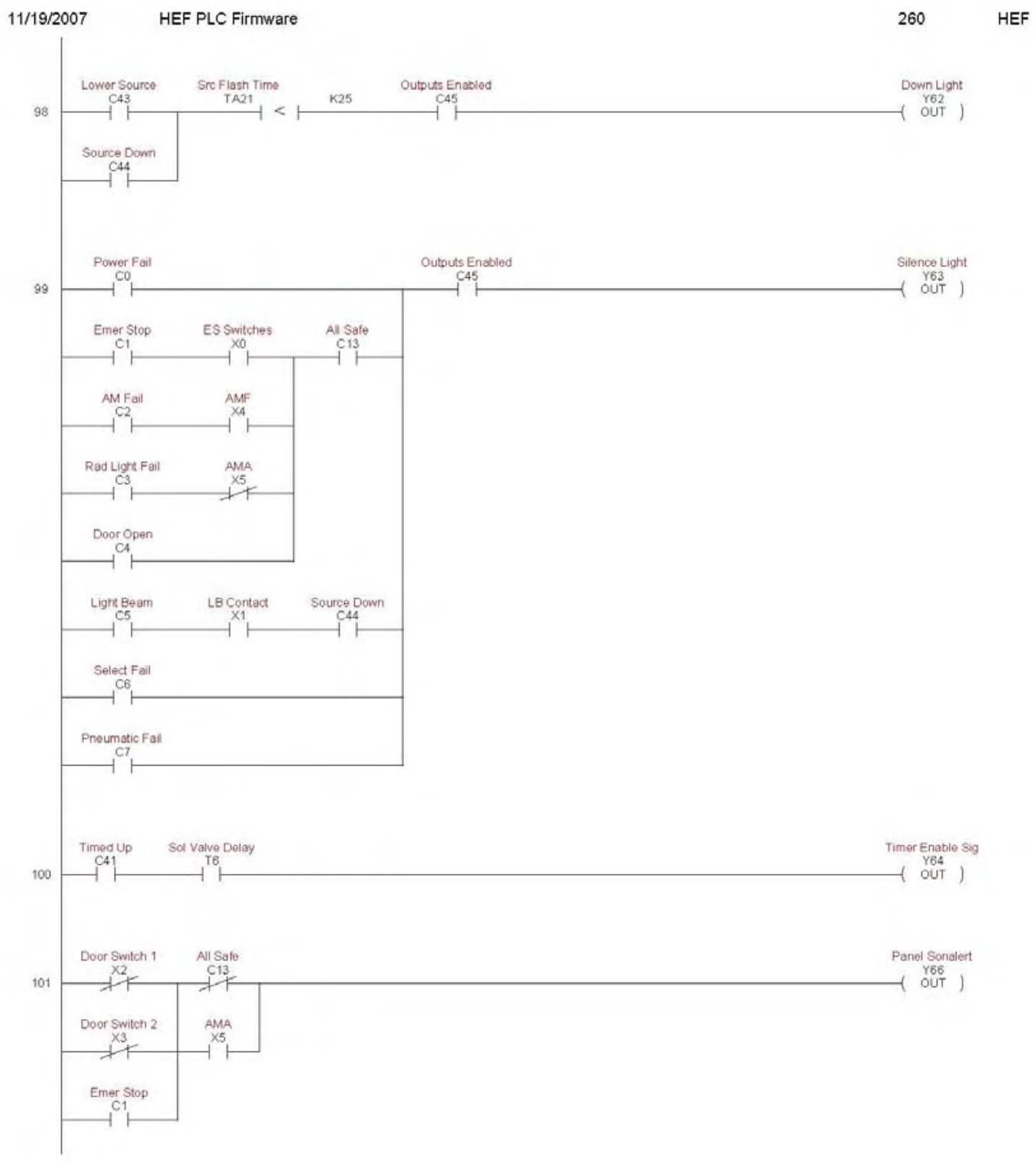

Page 30

A.31 


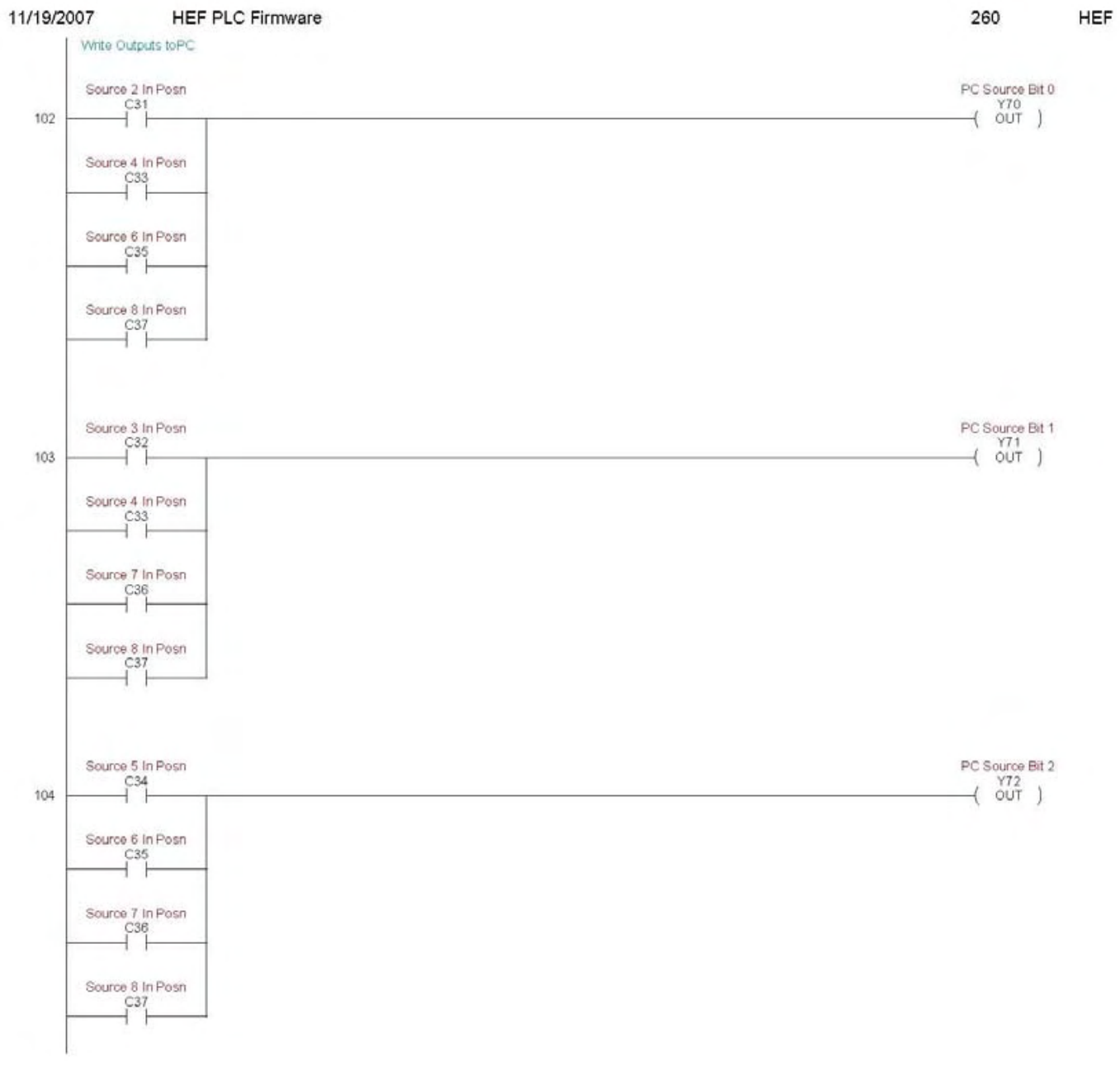

Page 31

A.32 


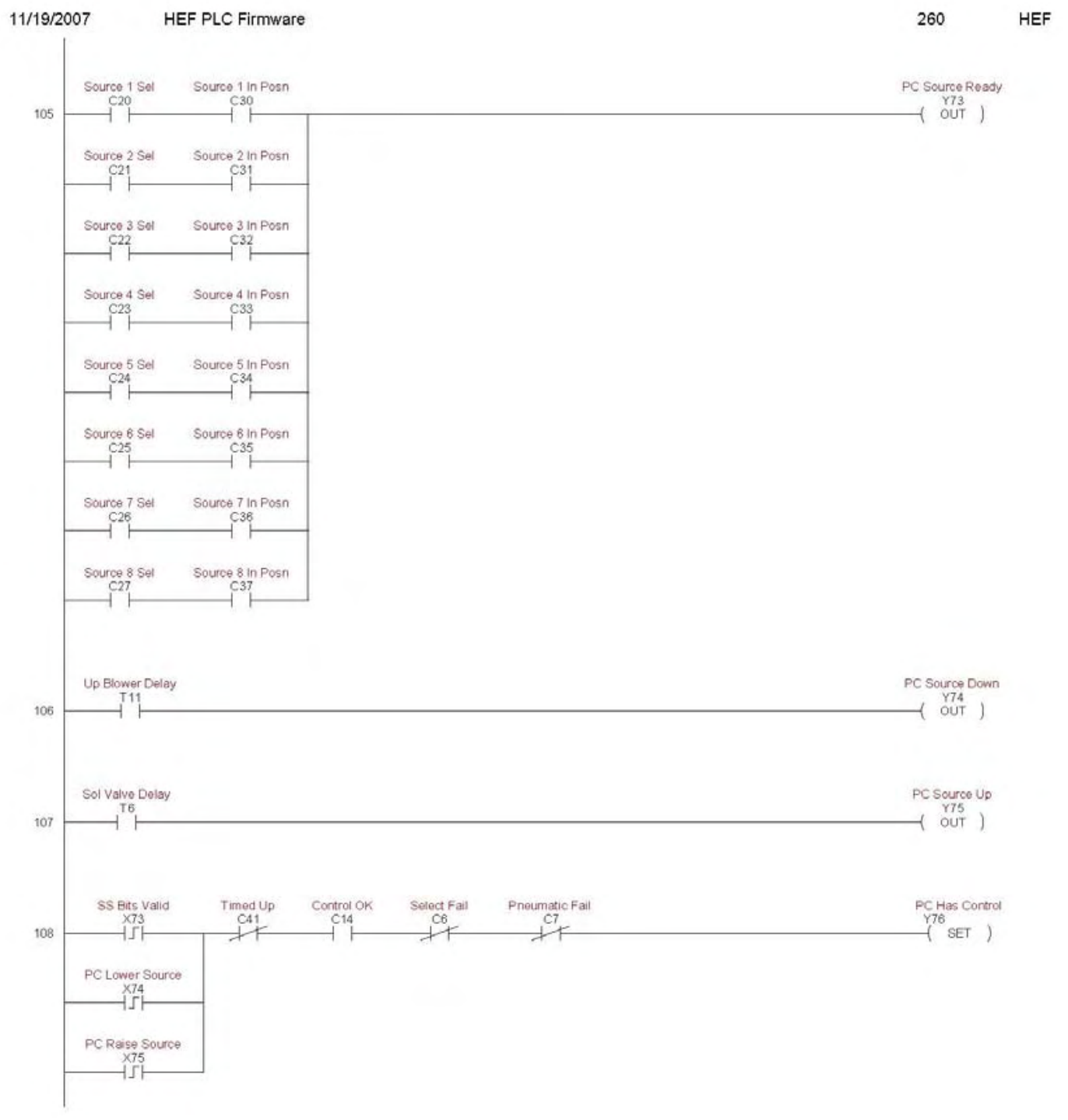

Page 32 


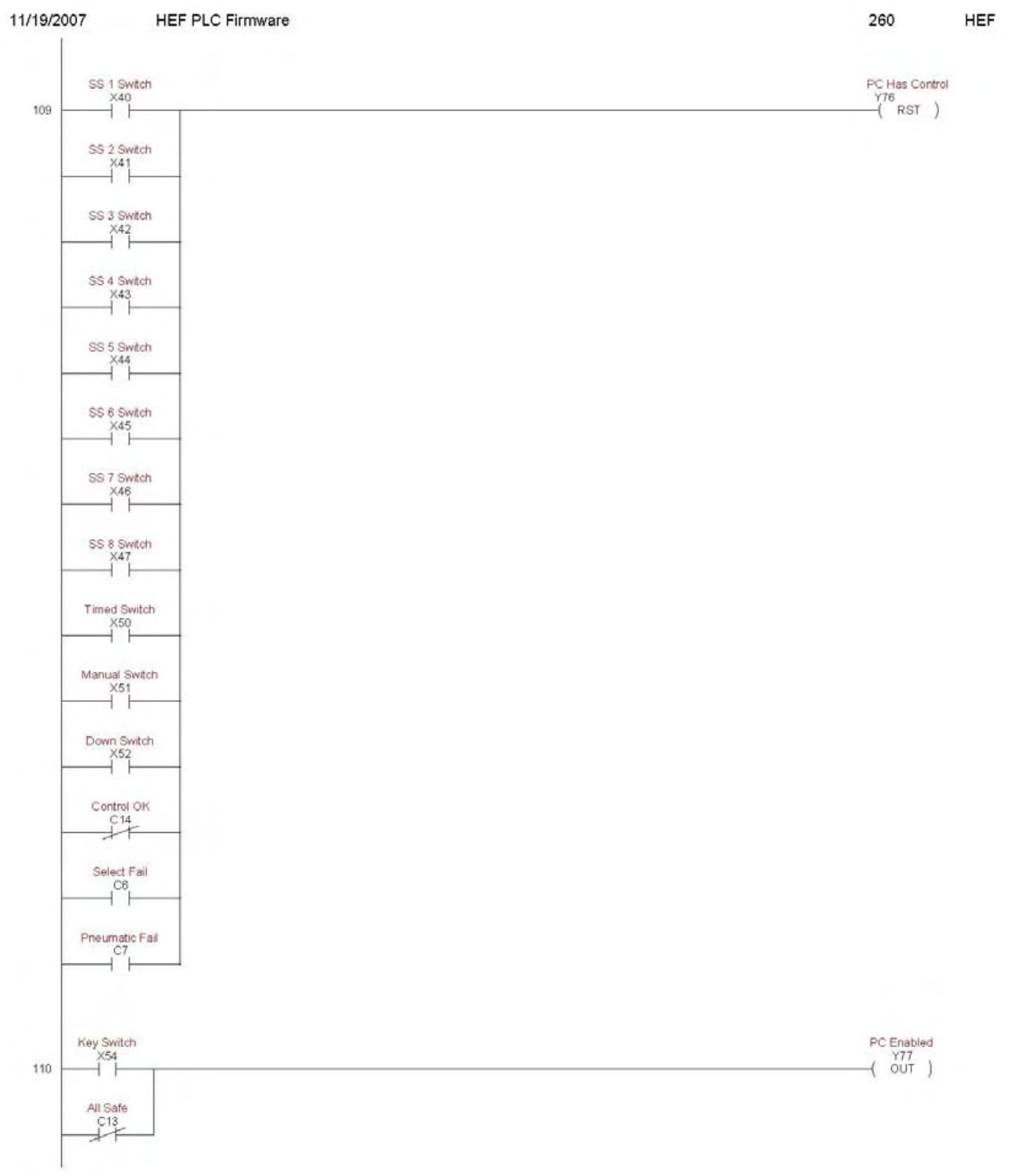

Page 33

A.34 


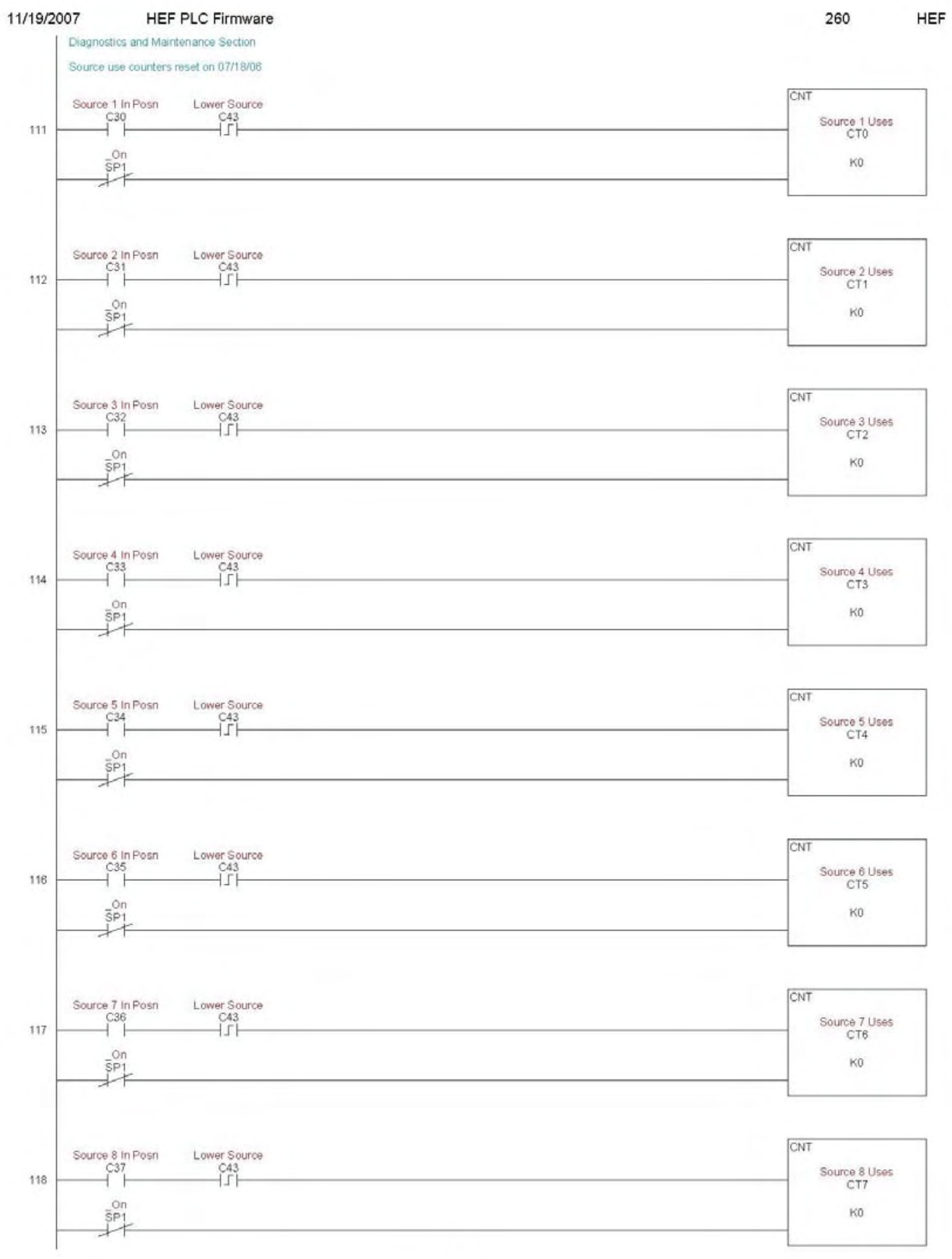

Page 34 


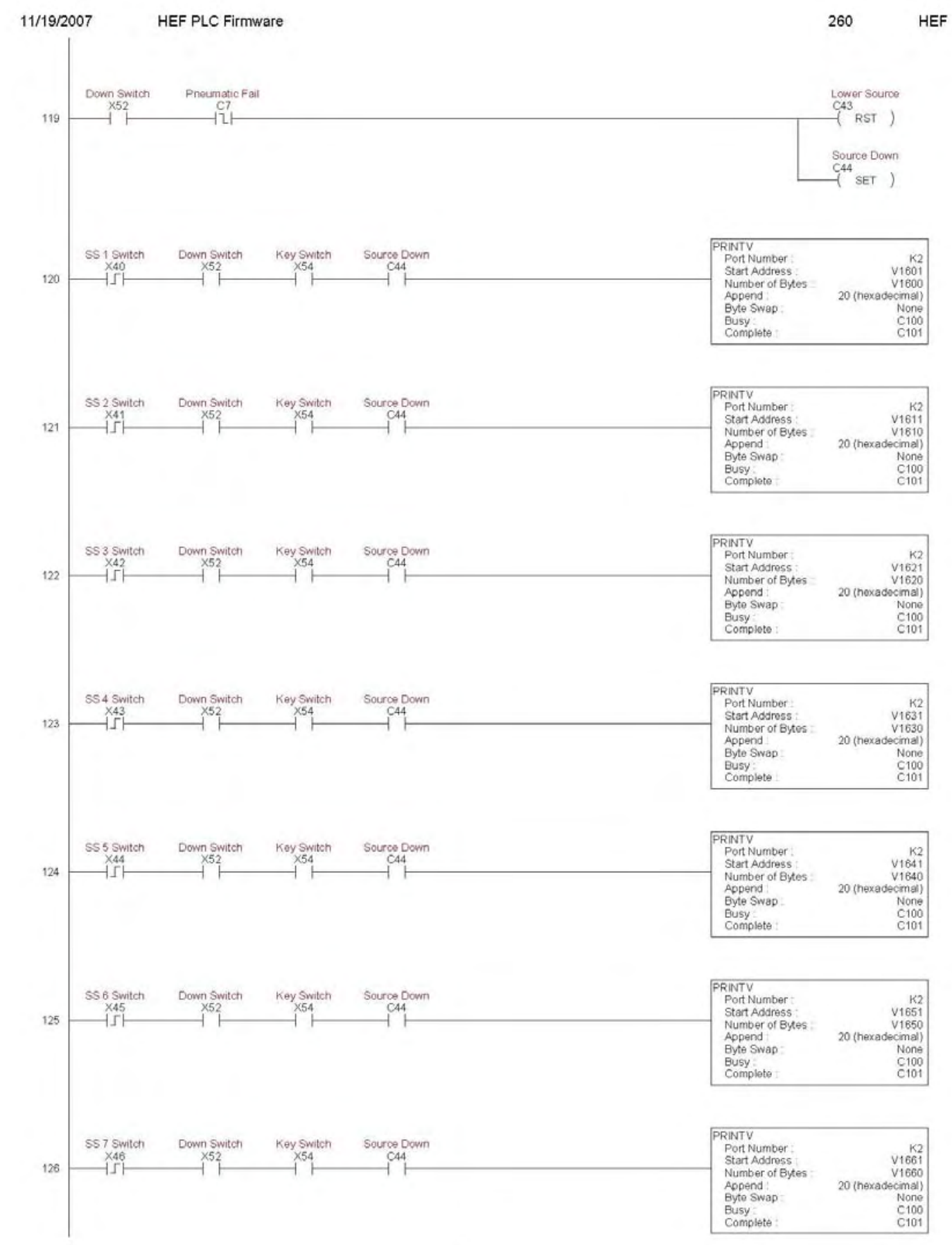

Page 35 


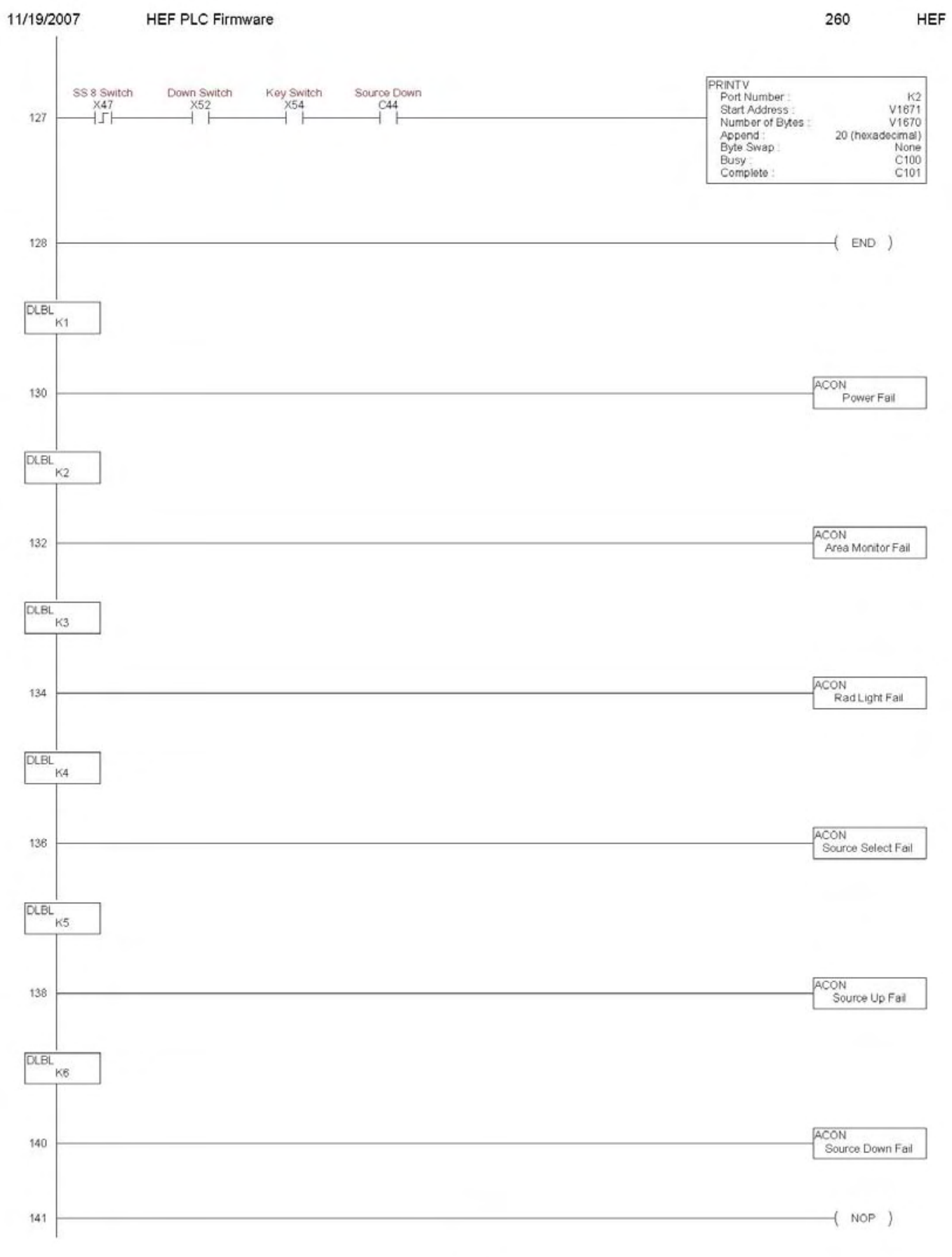

Page 36 



\section{Appendix B - Control Software Program}





\section{Appendix B - Control Software Program}

The control software program includes three files that control all auxiliary HEF processes, as previously noted. The software is generated by writing a compiler input, which PowerBasic uses to generate the HEF executable code. (PowerBASIC for DOS version 3.5 was used to edit and compile the HEF software for the facility control computer.)

\section{B.1 Compiler Input for the Control Software Program}

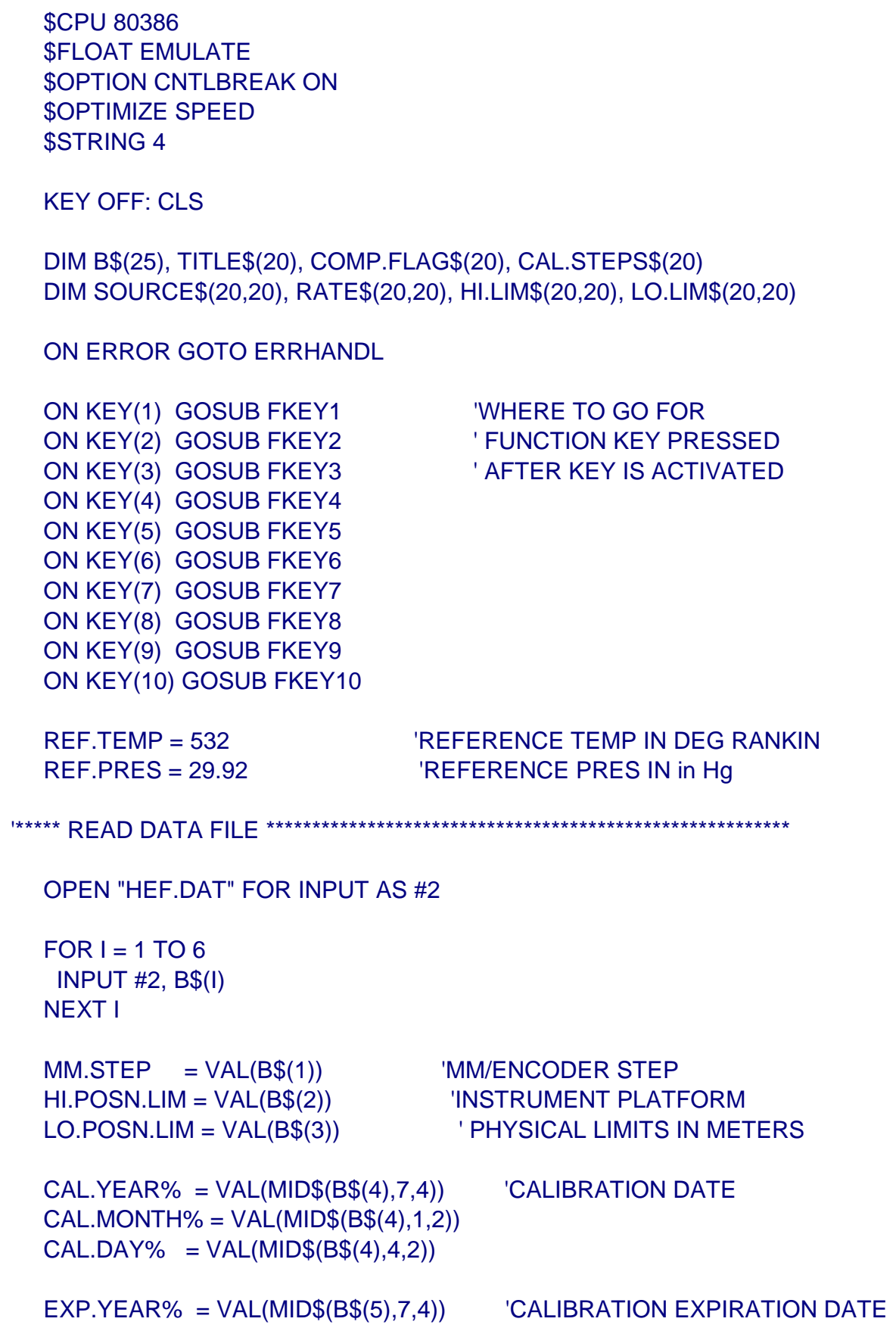




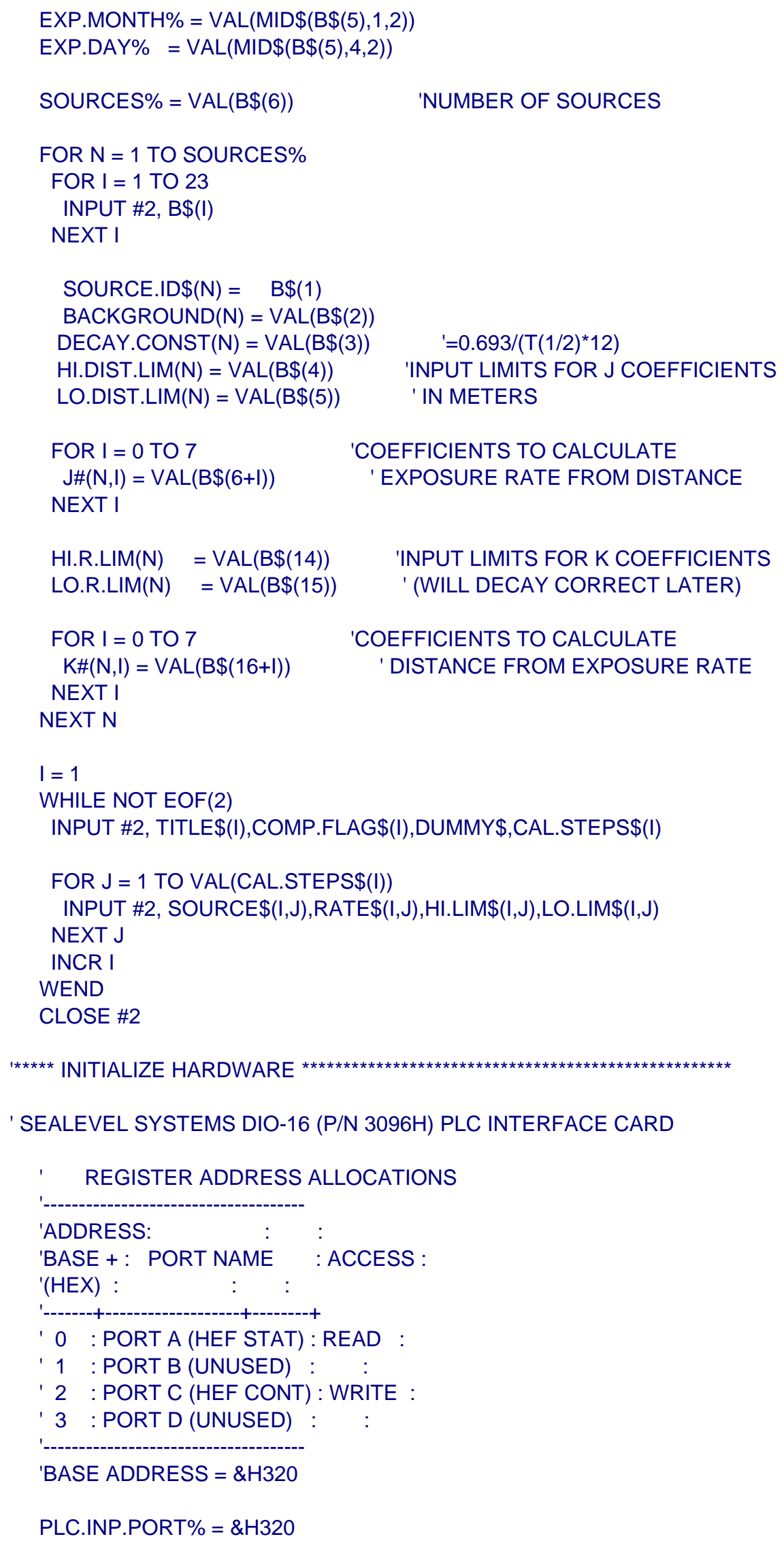


PLC.OUT.PORT\% $=\& H 322$

' COMPUMOTOR 650X INDEXER/DRIVE

' $Z$ = RESET INDEXER (MUST WAIT 1 SEC BEFORE NEXT COMMAND)

' $M N=$ MODE NORMAL FOR PRESET MOVES

' $M C=$ MODE CONTINUOUS FOR JOG KEYS

'MPA = MODE POSITION ABSOLUTE

' MR18000 = 18k MOTOR STEPS/REV * 1 MOTOR REV/30 mm = 600 MOTOR STEPS $/ \mathrm{mm}$

' ER800 = 1000 PPR * 4 QUADRATURE / 5 GEAR REDUCTION = 800 ENCODER STEPS/REV

' $\mathrm{FSB} 1=$ MOVES MADE IN ENCODER STEPS (NOT MOTOR STEPS)

' OSBO = STOP ON FIRST EDGE ENCOUNTERED OF HOME REGION

' SSH1 = SAVE COMMAND BUFFER AFTER "STOP" COMMAND

'A8 = MOTOR ACCELERATION/DECELERATION FOR NORMAL MOVES IN REVS/SEC^2

'A8 = MOTOR ACCELERATION/DECELERATION FOR JOG KEY MOVES

' V15 = MAX MOTOR VELOCITY FOR NORMAL MOVES IN REVS/SEC

' $\mathrm{V} 2$ = MAX MOTOR VELOCITY FOR JOG KEY MOVE

' DsXXXX = DESIRED POSITION IN ABSOLUTE ENCODER STEPS

' $\mathrm{G} \quad=$ BEGIN MOVE

' GH-2 = GO HOME AT MAX MOTOR VELOCITY OF 2 REVS/SEC

' $S$ = STOP WITH DECELERATION FOR JOG MOVE

'ST1 = SHUT DOWN MOTOR DRIVE (NO HOLDING CURRENT)

' STO = ENABLE MOTOR DRIVE (MUST WAIT .5 SEC BEFORE NEXT COMMAND)

INDEXER.INIT\$ = "MN MPA MR18000 ER800 FSB1 " + "OSB0 SSH1 A8 V15"

GOHOME.1\$ = "GH-2 CR"

GOHOME.2\$ = "MC A8 V.2 G TRX1X V0 G V.2 H G TR1XX V0 G MN A8 V15 CR"

GOHOME.3\$ = "PZ"

JOG.OUT\$ = "MC A8 V2 H+ G"

JOG.IN\$ = "MC A8 V2 H- G"

JOG.DONE\$ = "S MN A8 V15"

OPEN "COM1: 9600, N, 8, 1, RS, CS, DS" AS \#1

CALL INDEXER.IO ("Z",0,1,ANSWER\$,COM1.FAIL\%) IINDEXER RESET

DELAY 1.5

CALL INDEXER.IO (INDEXER.INIT\$,0,1,ANSWER\$,COM1.FAIL\%) 'INITIALIZE

${ }^{\prime * \star \star \star \star * ~ B E G I N ~}$

START:

CALL INDEXER.IO ("8TS",5,1,ANSWER\$,COM1.FAIL\%)

IF MID $\$($ ANSWER $\$, 7,1)=$ "1" THEN 'IF OUTSIDE OF

CALL INDEXER.IO (GOHOME.1\$,1,120,ANSWER\$,COM1.FAIL\%) ' HOME REGION END IF

CALL INDEXER.IO ("8TS",5,1,ANSWER\$,COM1.FAIL\%)

IF MID\$(ANSWER $\$, 6,1)=$ "0" THEN

'IF NOT AT

CALL INDEXER.IO (GOHOME.2\$,1,15,ANSWER \$,COM1.FAIL\%) ' ENCODER "Z"

END IF

' MARK

CALL INDEXER.IO ("8TS",5,1,ANSWER\$,COM1.FAIL\%) 


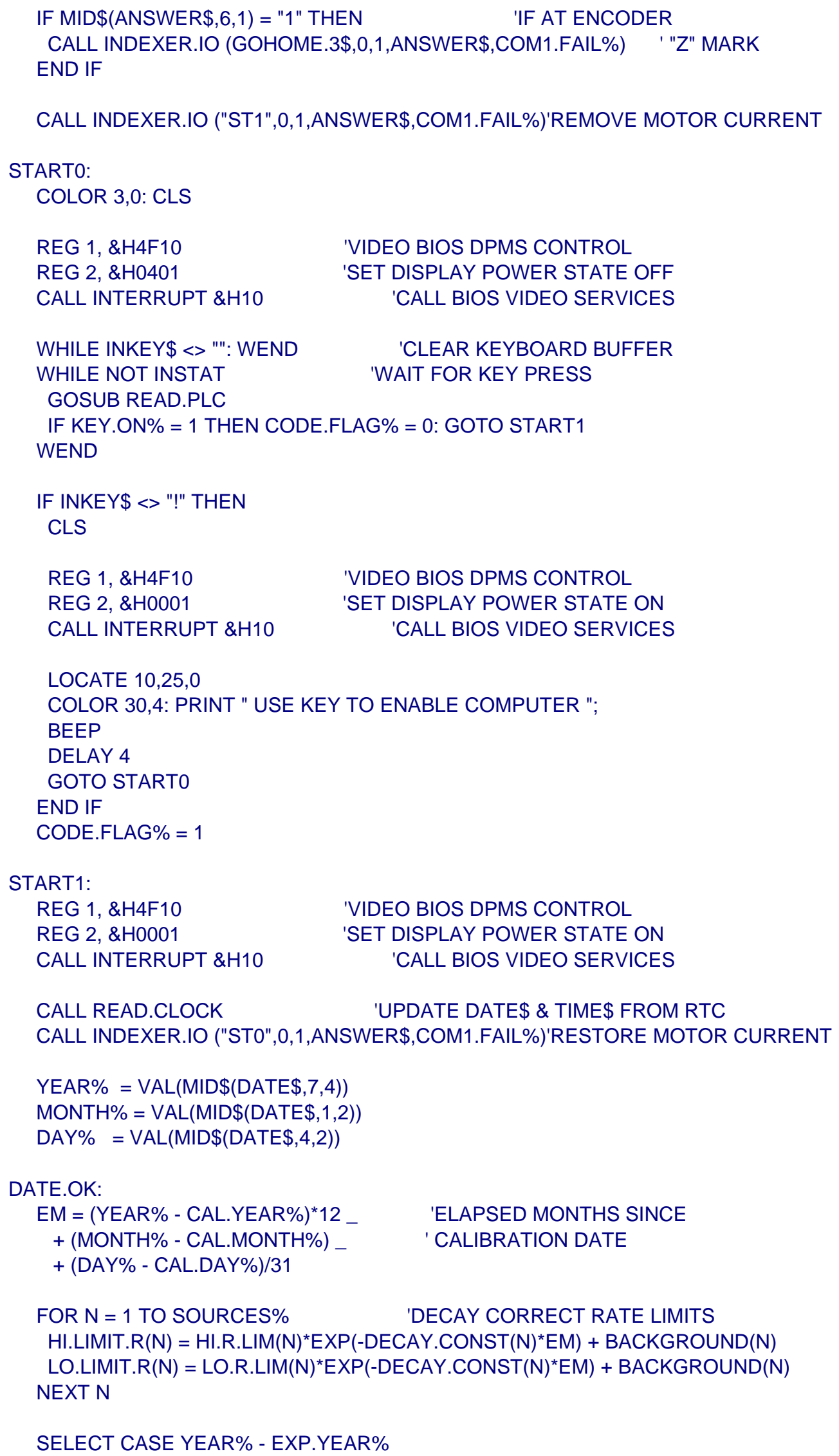




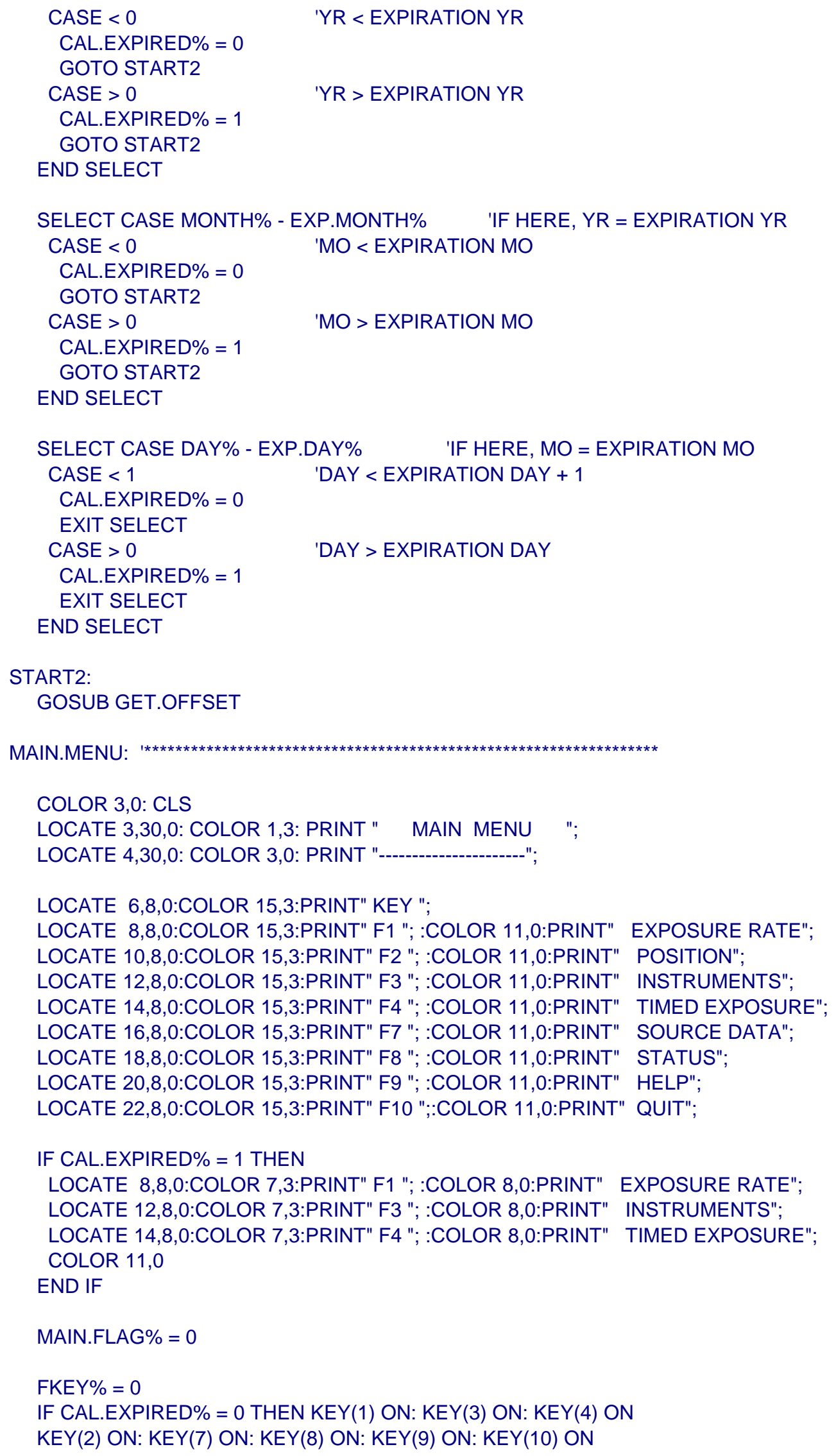




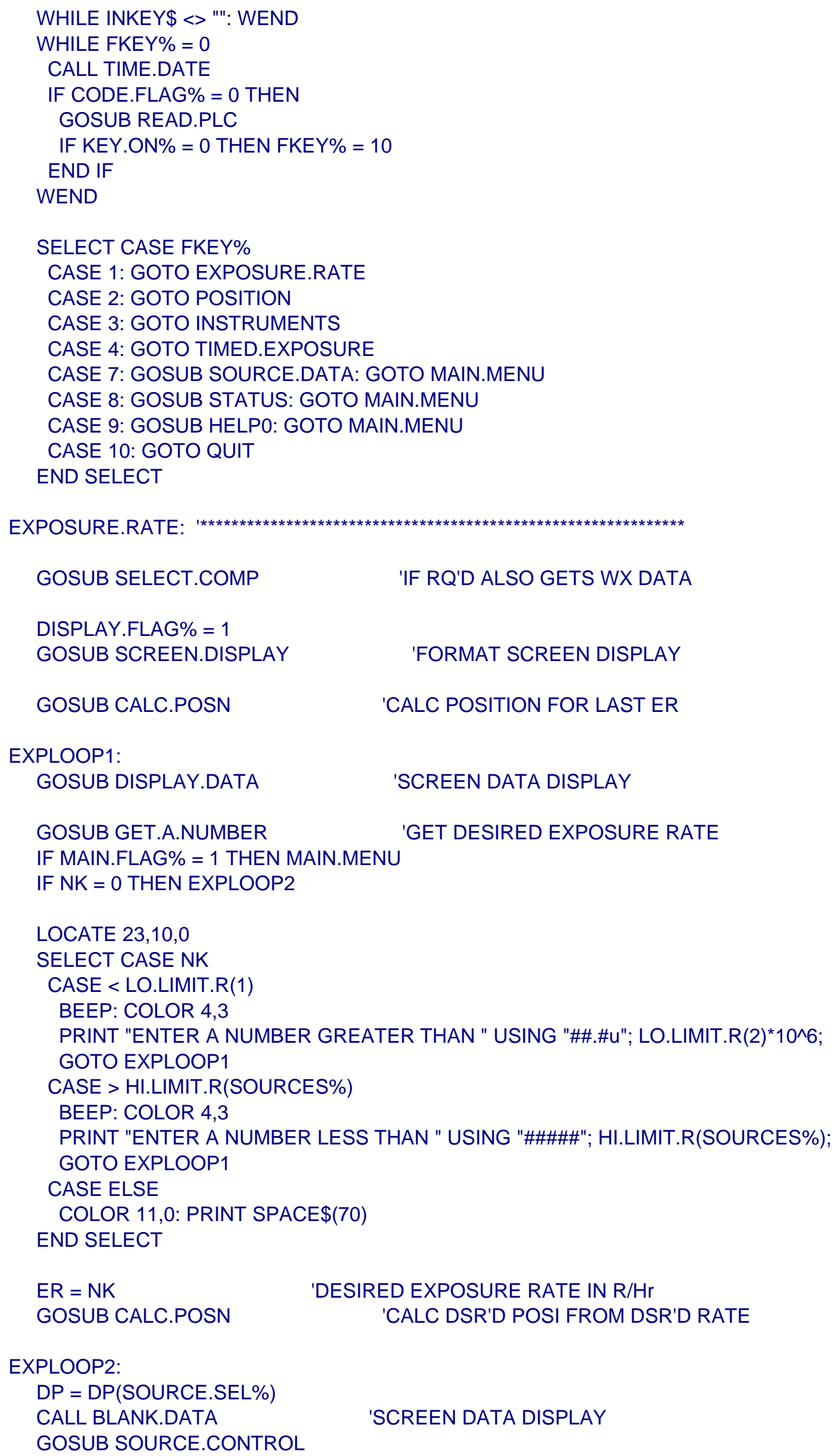




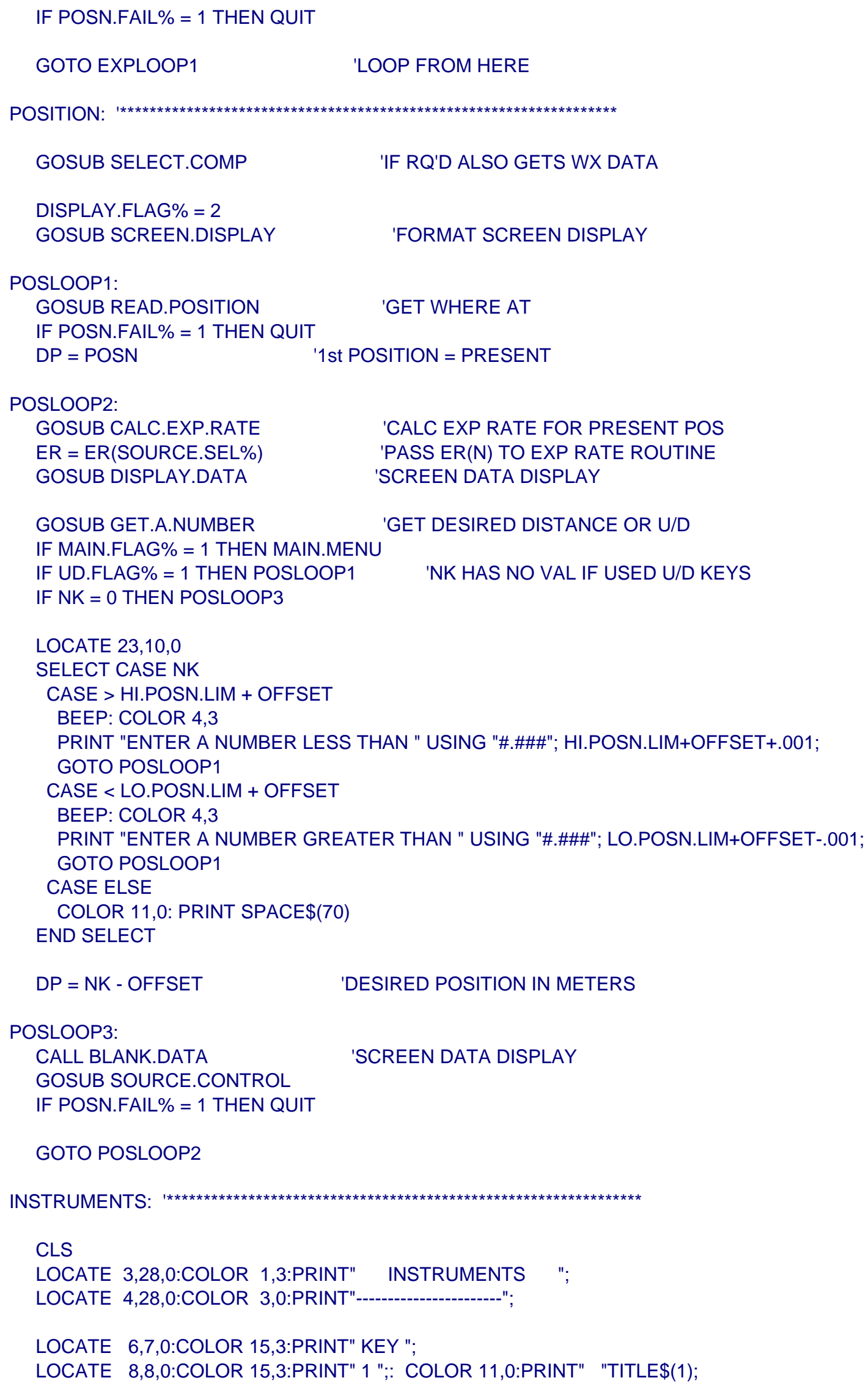




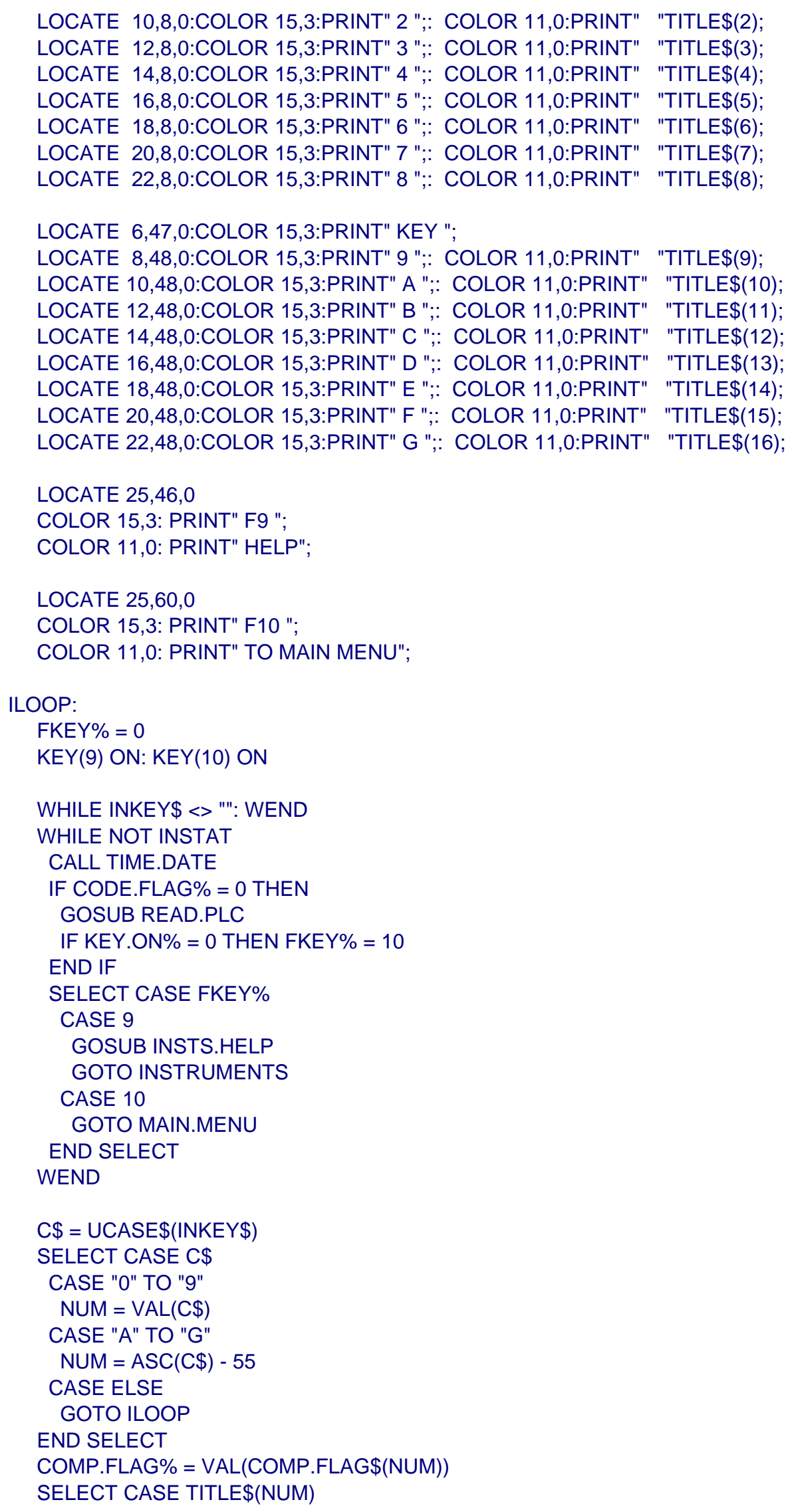




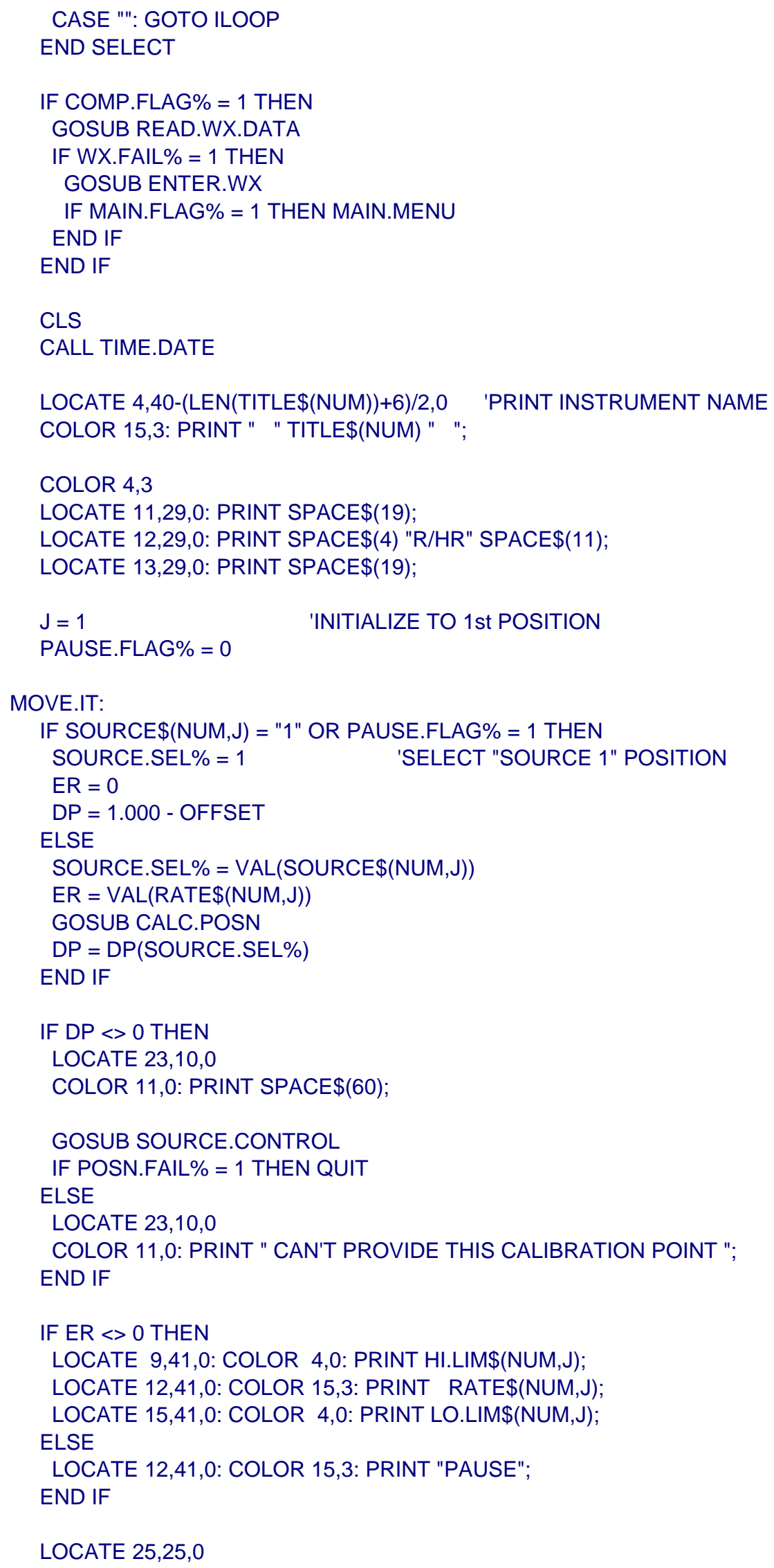




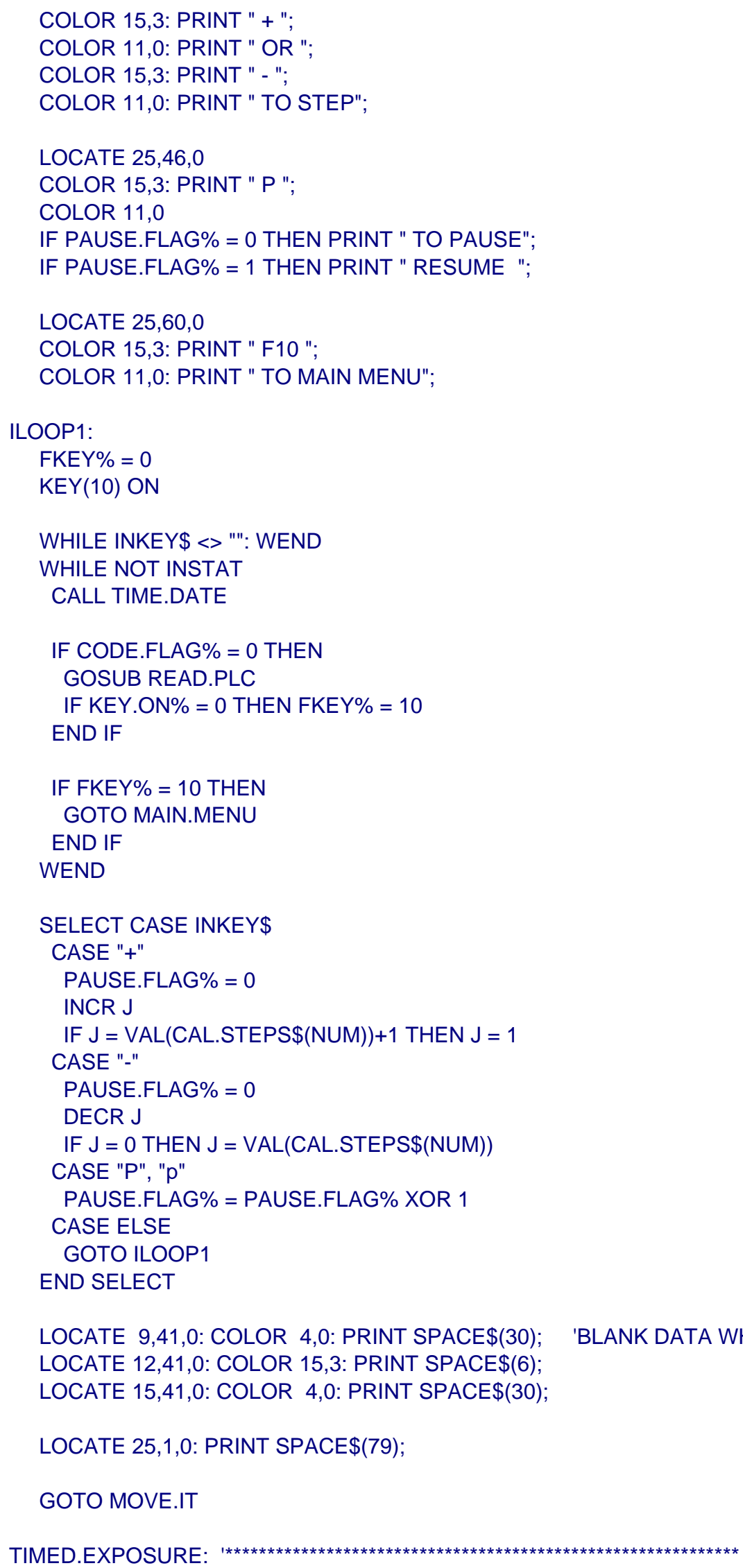




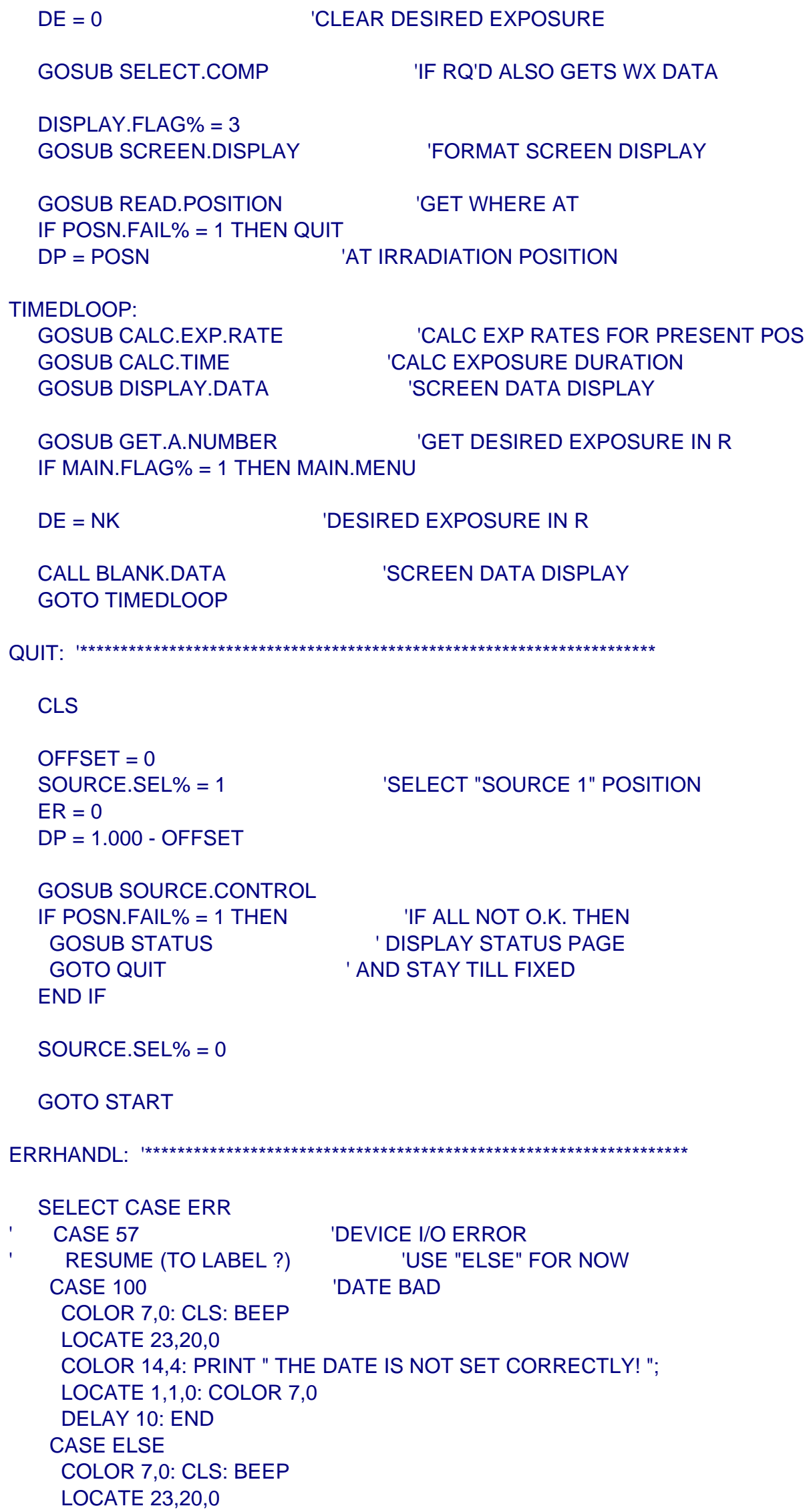




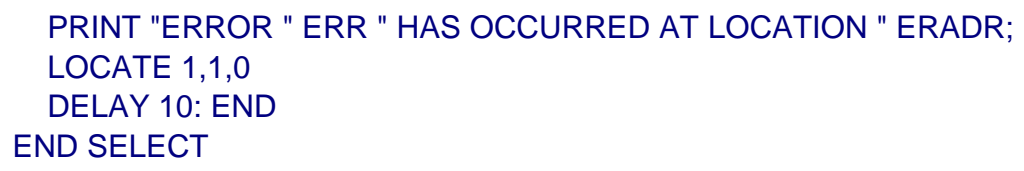




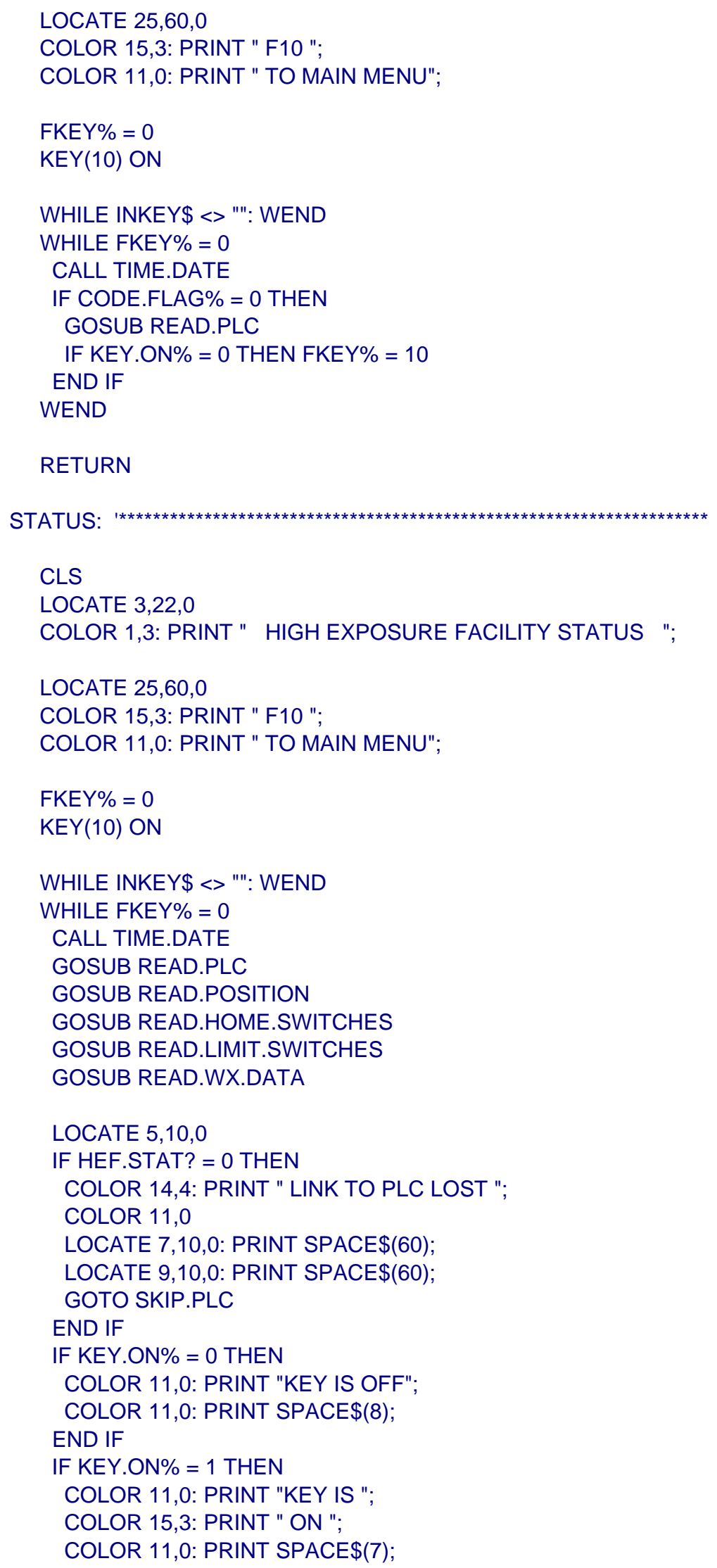


END IF

LOCATE 7,10,0

SELECT CASE SOURCE.NUM\%

CASE 0

COLOR 11,0: PRINT "CAROUSEL IS ";

COLOR 15,3: PRINT " ROTATING ";

COLOR 11,0: PRINT SPACE\$(12);

CASE 1 TO 8

COLOR 11,0: PRINT "SOURCE ";

COLOR 15,3: PRINT USING " \# "; SOURCE.NUM\%;

COLOR 11,0: PRINT " IS SELECTED" SPACE\$(10);

END SELECT

LOCATE 9,10,0

IF SOURCE.DN\% = 1 THEN

COLOR 11,0: PRINT "SOURCE IS DOWN";

COLOR 11,0: PRINT SPACE\$(8);

END IF

IF SOURCE.UP\% $=1$ THEN

COLOR 11,0: PRINT "SOURCE IS ";

COLOR 15,3: PRINT " UP ";

COLOR 11,0: PRINT SPACE\$(8);

END IF

IF SOURCE.DN\% $=0$ AND SOURCE.UP\% $=0$ THEN

COLOR 11,0: PRINT "SOURCE IS ";

COLOR 15,3: PRINT " IN TRANSIT ";

END IF

SKIP.PLC:

LOCATE $11,10,0$

IF COM1.FAIL\% = 1 THEN

COLOR 14,4: PRINT " LINK TO INDEXER LOST ";

COLOR 11,0: PRINT SPACE\$(13);

GOTO SKIP.POSITION

END IF

IF POSN.FAIL\% $=1$ THEN

COLOR 11,0: PRINT "POSITION TRANSDUCER IS ";

COLOR 14,4: PRINT " FAILED ";

COLOR 11,0: PRINT SPACE\$(4);

ELSE

COLOR 11,0: PRINT "PLATFORM POSITION IS ";

COLOR 15,3: PRINT USING " \#.\#\#\# "; POSN;

COLOR 11,0: PRINT " Meters";

END IF

SKIP.POSITION:

LOCATE 13,10,0

IF COM1.FAIL\% = 1 THEN

COLOR 14,4: PRINT " LINK TO INDEXER LOST ";

COLOR 11,0: PRINT SPACE\$(7);

LOCATE 15,10,0: PRINT SPACE\$(60);

GOTO SKIP.HOME.SWITCHES

END IF

IF ENCODER.Z\% = 1 THEN

COLOR 11,0: PRINT "ENCODER Z CHANNEL IS ";

COLOR 15,3: PRINT " ACTIVE "; 
END IF

IF ENCODER.Z\% = 0 THEN

COLOR 11,0: PRINT "ENCODER Z CHANNEL IS INACTIVE";

END IF

LOCATE 15,10,0

IF HOME.REF.SW\% $=0$ THEN

COLOR 11,0: PRINT "HOME REFERENCE SWITCH IS ";

COLOR 15,3: PRINT " ACTIVE ";

END IF

IF HOME.REF.SW\% = 1 THEN

COLOR 11,0: PRINT "HOME REFERENCE SWITCH IS OFF";

COLOR 11,0: PRINT SPACE\$(5);

END IF

SKIP.HOME.SWITCHES:

LOCATE $17,10,0$

IF COM1.FAIL $\%=1$ THEN

COLOR 14,4: PRINT " LINK TO INDEXER LOST ";

COLOR 11,0: PRINT SPACE $\$(7)$;

LOCATE 19,10,0: PRINT SPACE\$(60);

GOTO SKIP.LIMIT.SWITCHES

END IF

IF FAR.LIMIT.SW\% $=0$ THEN

COLOR 11,0: PRINT "FAR LIMIT SWITCH IS OK";

COLOR 11,0: PRINT SPACE\$(7);

END IF

IF FAR.LIMIT.SW\% = 1 THEN

COLOR 11,0: PRINT "FAR LIMIT SWITCH IS ";

COLOR 15,3: PRINT " TRIPPED ";

END IF

LOCATE 19,10,0

IF NEAR.LIMIT.SW\% $=0$ THEN

COLOR 11,0: PRINT "NEAR LIMIT SWITCH IS OK";

COLOR 11,0: PRINT SPACE\$(7);

END IF

IF NEAR.LIMIT.SW\% = 1 THEN

COLOR 11,0: PRINT "NEAR LIMIT SWITCH IS ";

COLOR 15,3: PRINT " TRIPPED ";

END IF

SKIP.LIMIT.SWITCHES:

LOCATE 21,10,0

IF WX.FAIL $\%=1$ THEN

COLOR 11,0: PRINT "WEATHERSTATION HAS ";

COLOR 14,4: PRINT " FAILED ";

COLOR 11,0: PRINT SPACE\$(20);

LOCATE 23,10,0: PRINT SPACE $\$(60)$;

ELSE

COLOR 11,0: PRINT "TEMPERATURE IS ";

COLOR 15,3: PRINT USING " \#\#\# "; TEMP;

COLOR 11,0: PRINT " " CHR\$(248) "F" SPACE\$(10);

LOCATE 23,10,0

COLOR 11,0: PRINT "PRESSURE IS ";

COLOR 15,3: PRINT USING " \#\#.\#\# "; PRES; 


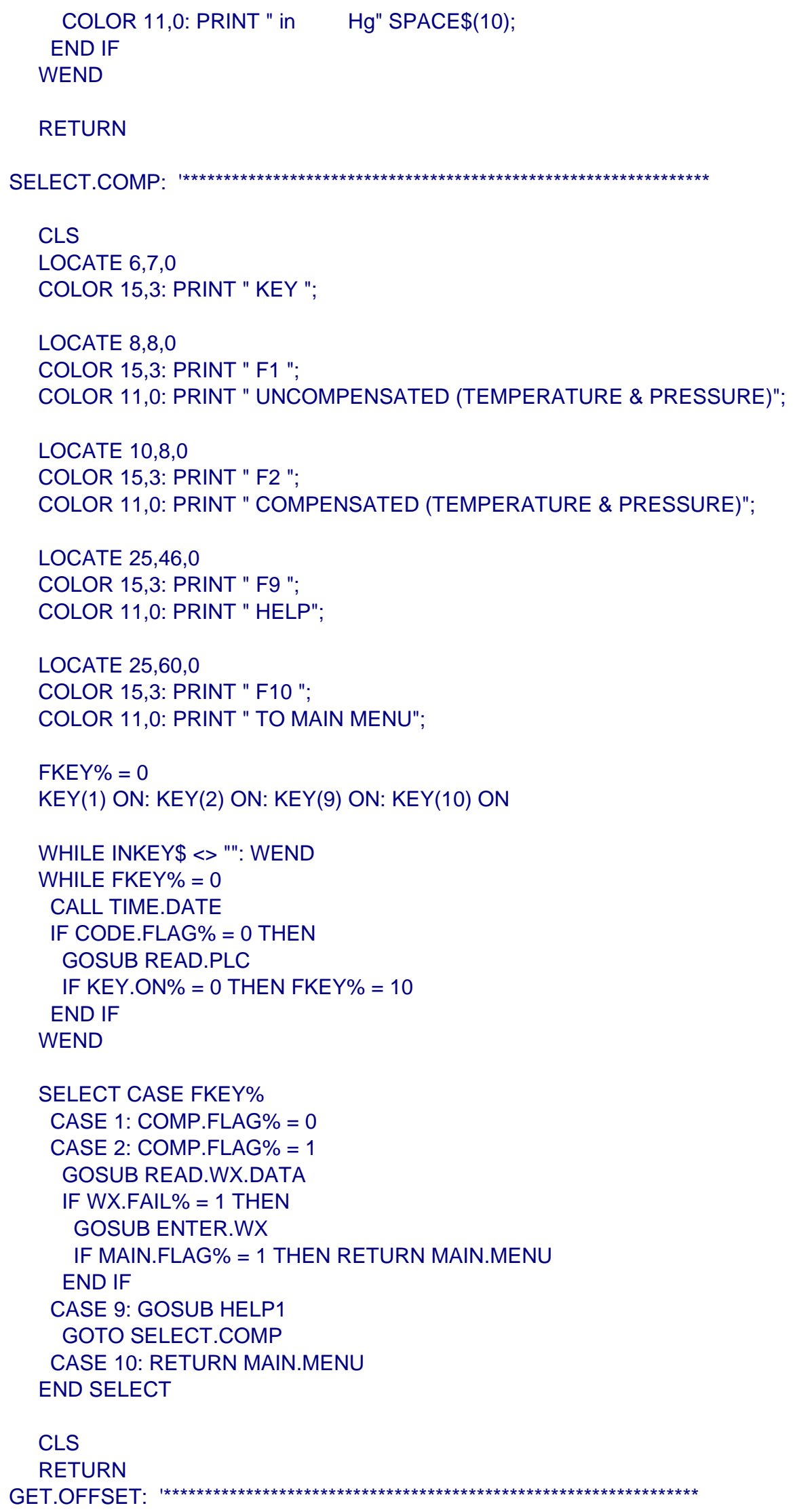




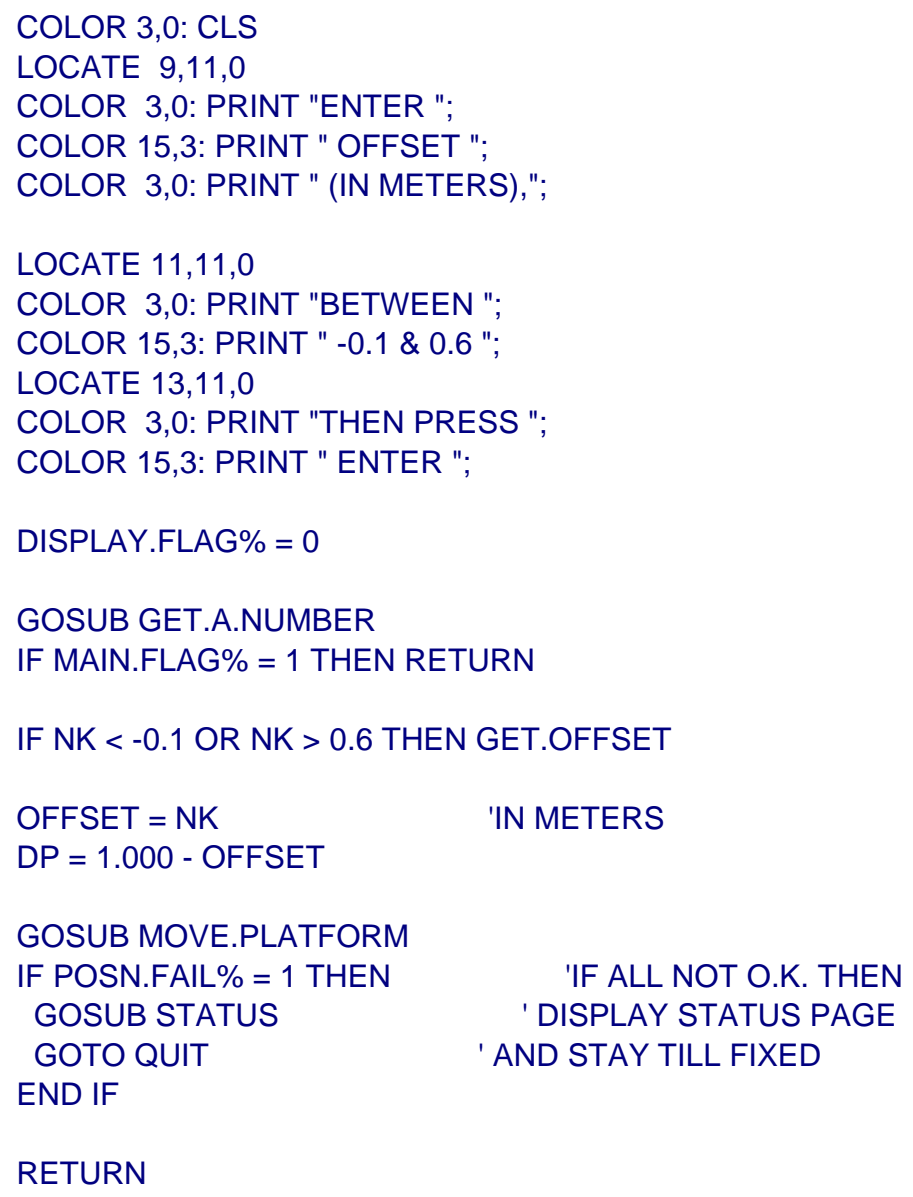




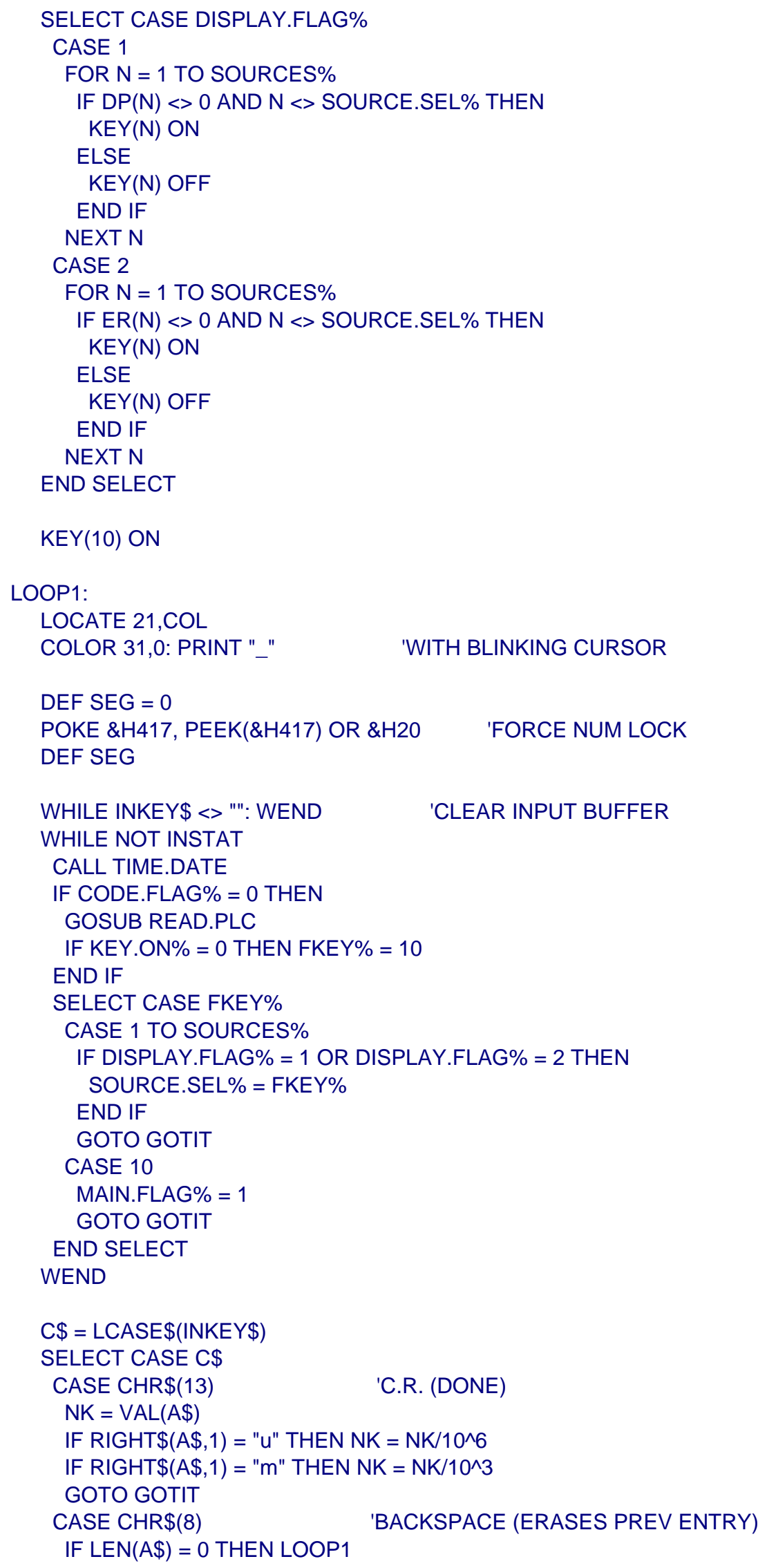




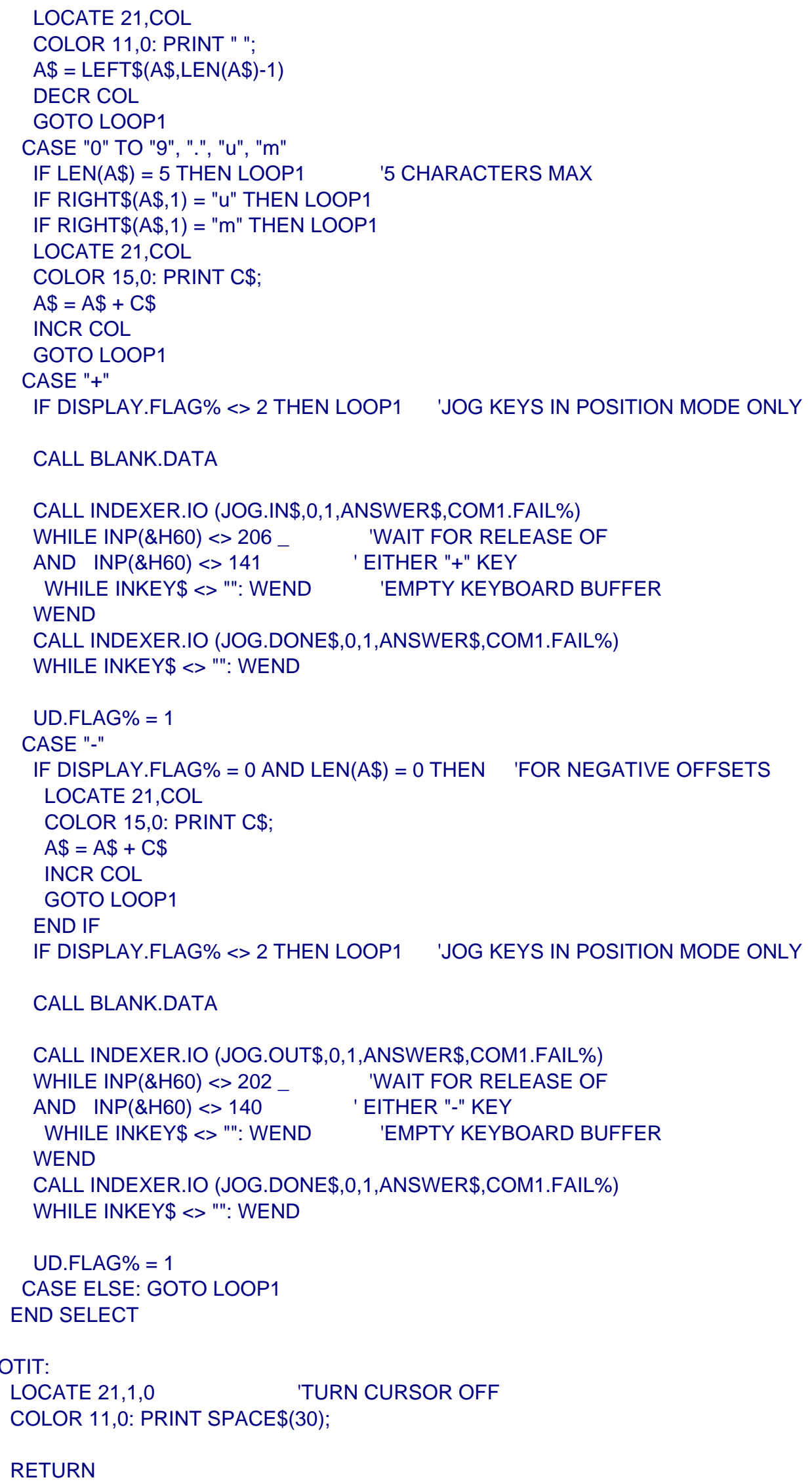




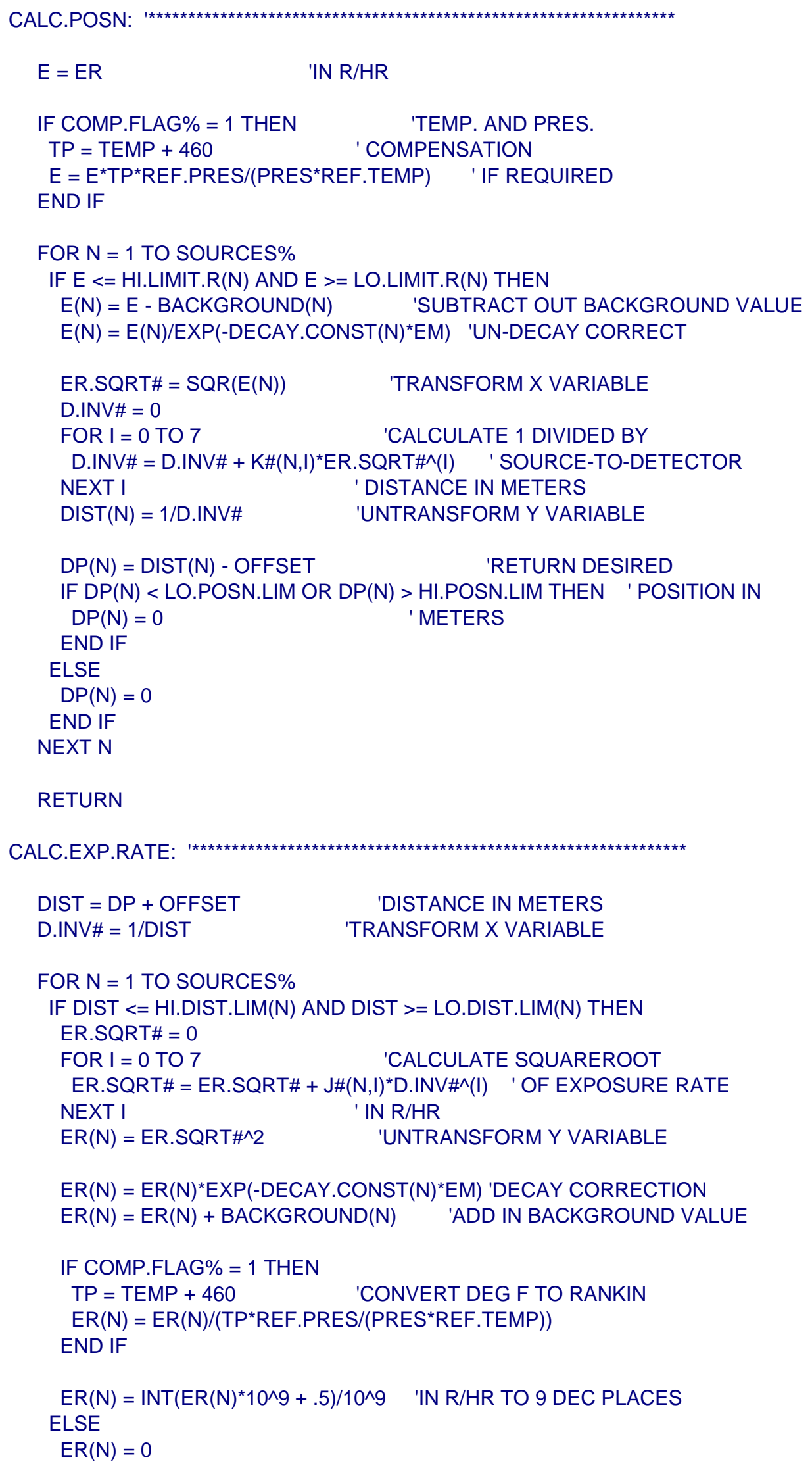




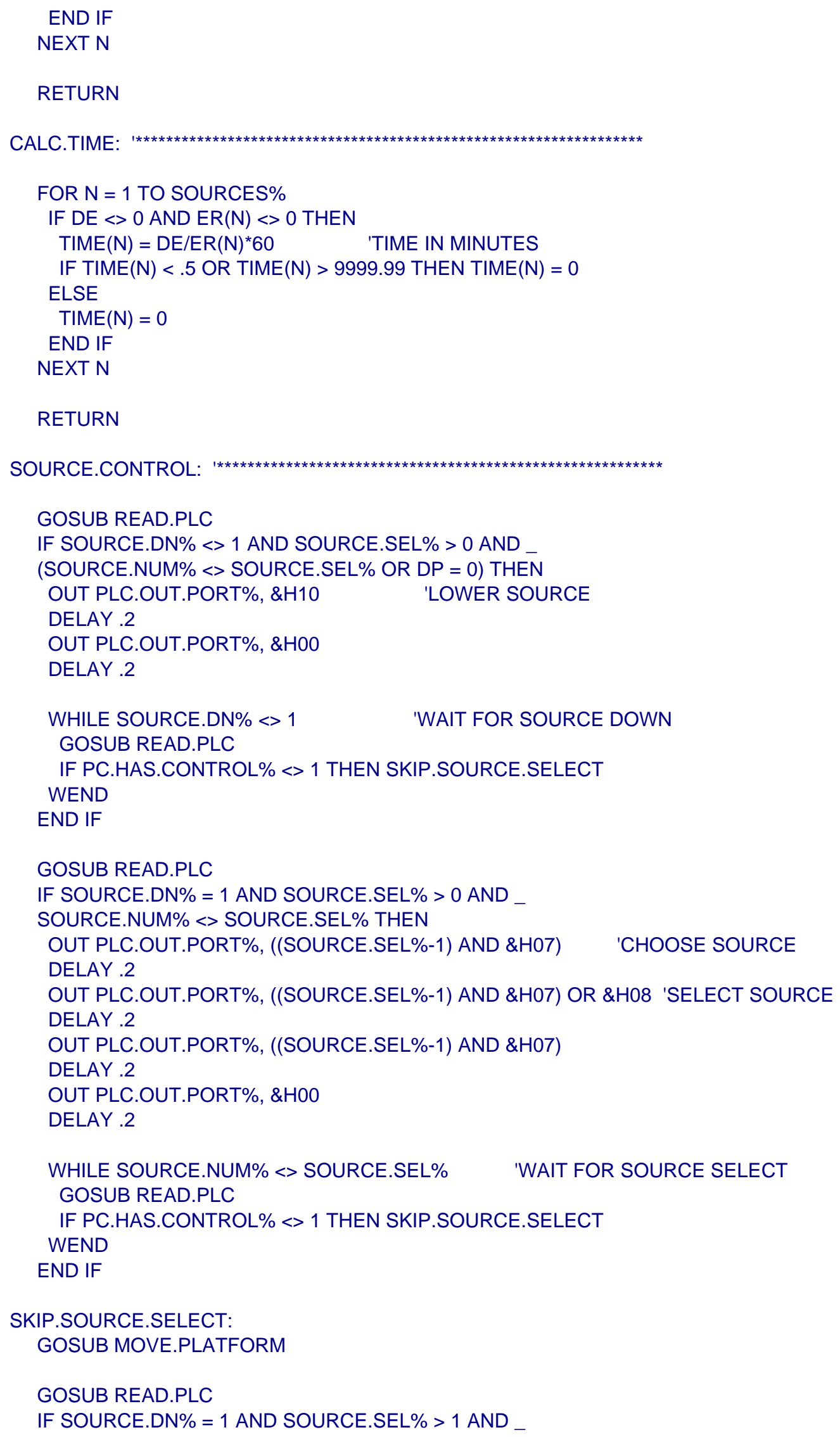




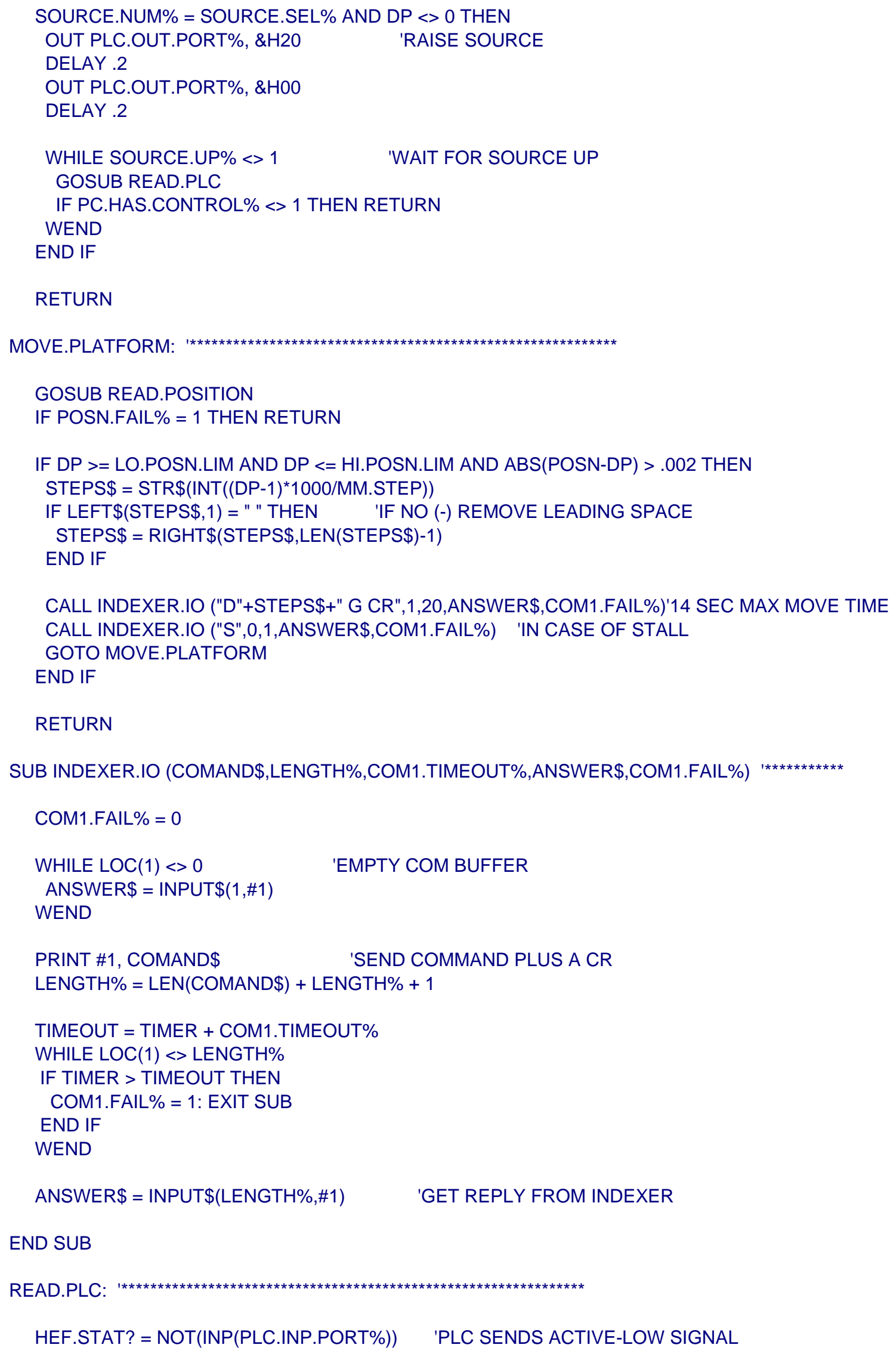




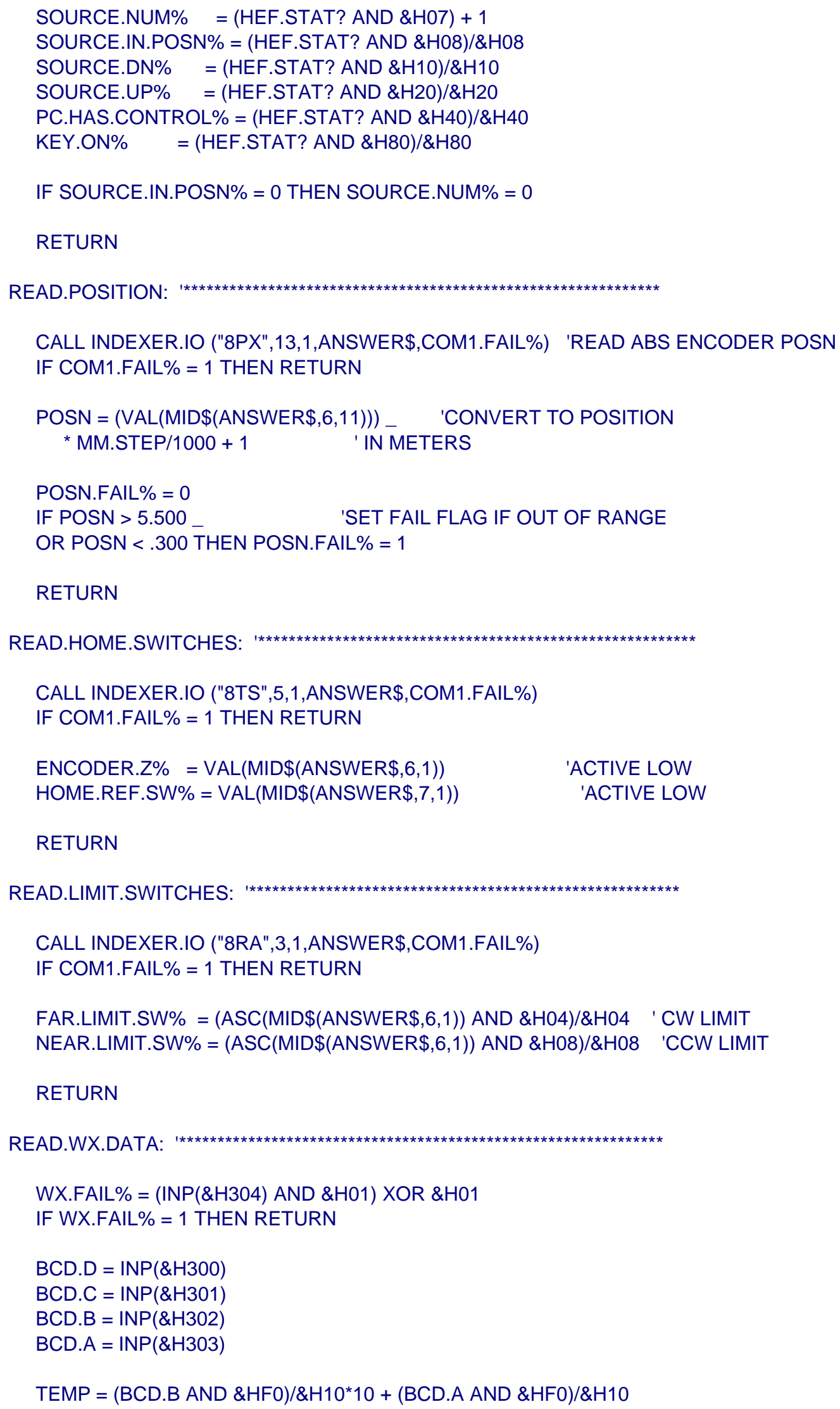




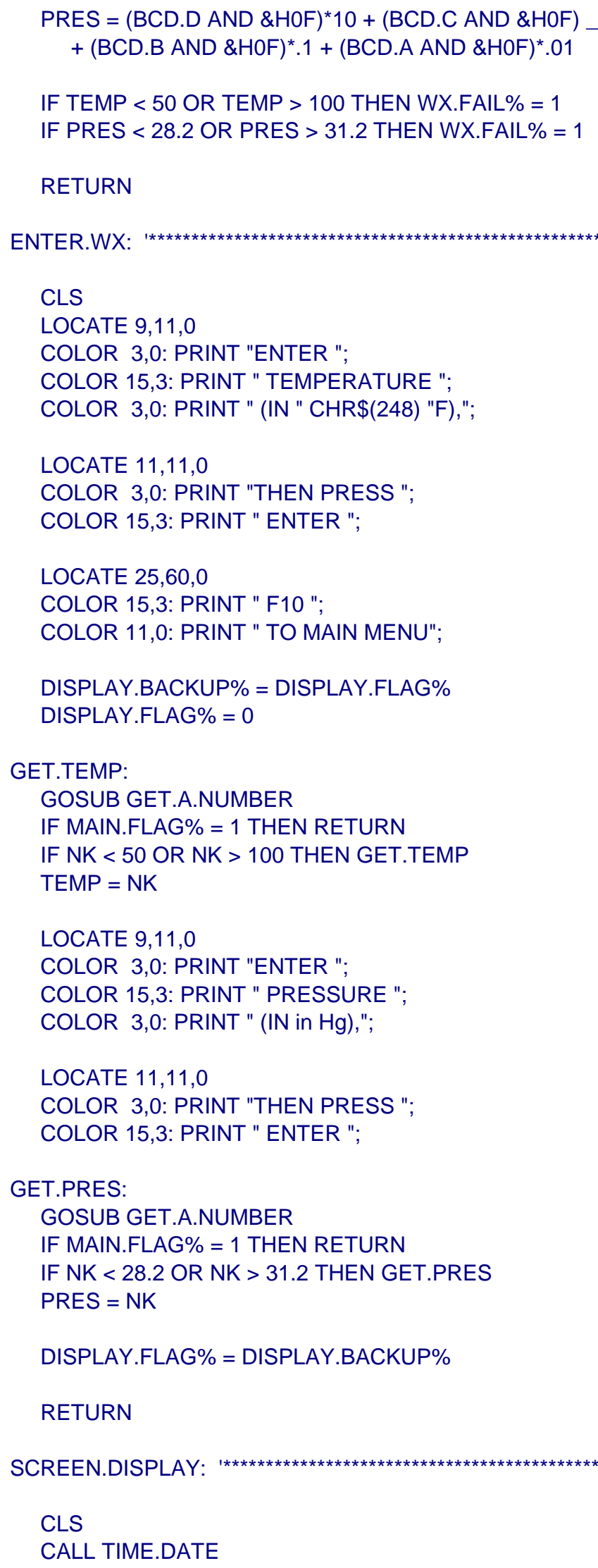




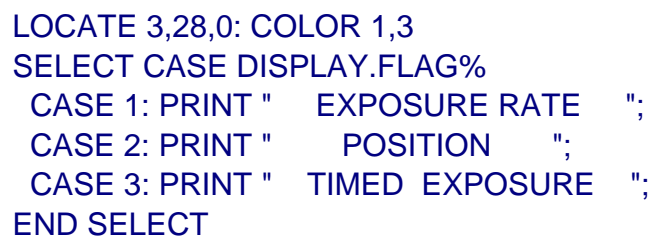




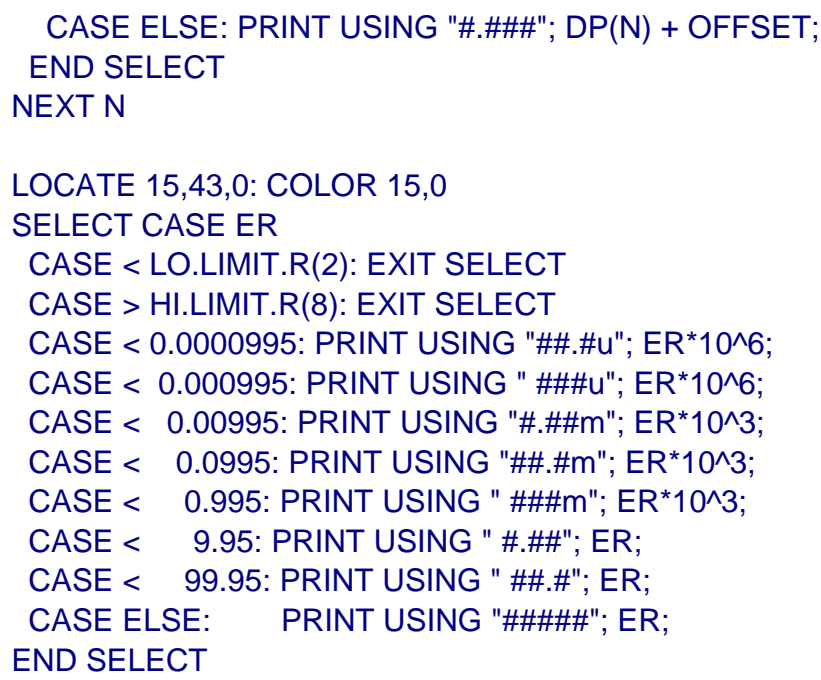




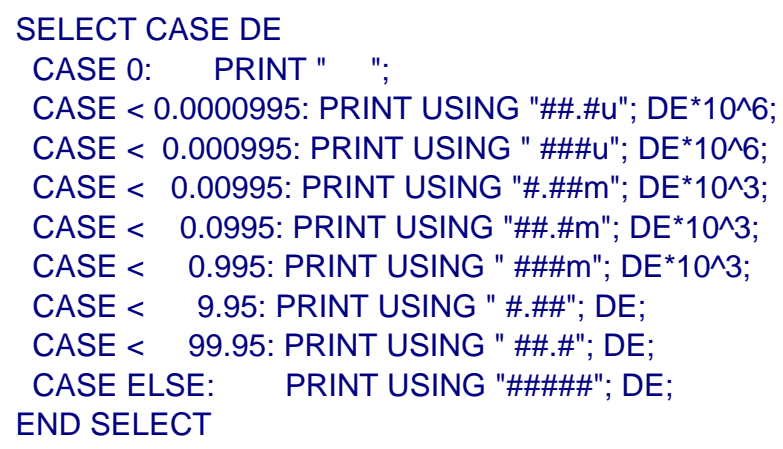


CALL INTERRUPT \&H1A

TIME\$ = HEX\$((REG(3) AND \&HFF00) 1256$)+$ ":" + HEX\$(REG(3) AND \&HFF) + ":" +

HEX\$((REG(4) AND \&HFF00)\256)

END SUB

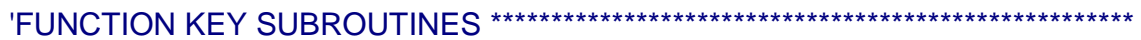

FKEY1:

FKEY\% = 1: GOTO FEXIT

FKEY2:

FKEY\% = 2: GOTO FEXIT

FKEY3:

FKEY\% = 3: GOTO FEXIT

FKEY4:

FKEY\% = 4: GOTO FEXIT

FKEY5:

FKEY\% = 5: GOTO FEXIT

FKEY6:

FKEY\% = 6: GOTO FEXIT

FKEY7:

FKEY\% = 7: GOTO FEXIT

FKEY8:

FKEY\% = 8: GOTO FEXIT

FKEY9:

FKEY\% = 9: GOTO FEXIT

FKEY10:

FKEY\% $=10$

FEXIT: $\quad$ 'TURN OFF ALL KEYS NEXT ROUTINE WILL TURN ON NEEDED KEYS.

KEY(1) OFF: KEY(2) OFF: KEY(3) OFF: KEY(4) OFF: KEY(5) OFF

KEY(6) OFF: KEY(7) OFF: KEY(8) OFF: KEY(9) OFF: KEY(10) OFF

RETURN

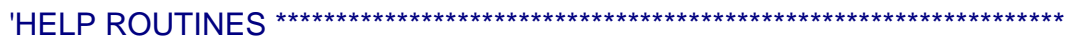

HELPO:

'MAIN MENU

CLS: LOCATE 5,1,0: COLOR 14,0

PRINT "SELECT ";: COLOR 9,7

PRINT " EXPOSURE RATE ";: COLOR 14,0

PRINT " TO MOVE DETECTOR TO DESIRED EXPOSURE RATE FIELD."

PRINT

PRINT "SELECT ";: COLOR 9,7

PRINT " POSITION ";: COLOR 14,0

PRINT " TO MOVE DETECTOR TO DESIRED SOURCE-TO-DETECTOR DISTANCE."

PRINT

PRINT "SELECT ";: COLOR 9,7

PRINT " INSTRUMENTS ";: COLOR 14,0

PRINT " TO MOVE INSTRUMENT TO PREDEFINED CALIBRATION POINTS."

PRINT

PRINT "SELECT ";: COLOR 9,7

PRINT " STATUS ";: COLOR 14,0

PRINT " TO DISPLAY CURRENT FACILITY CONDITIONS." 


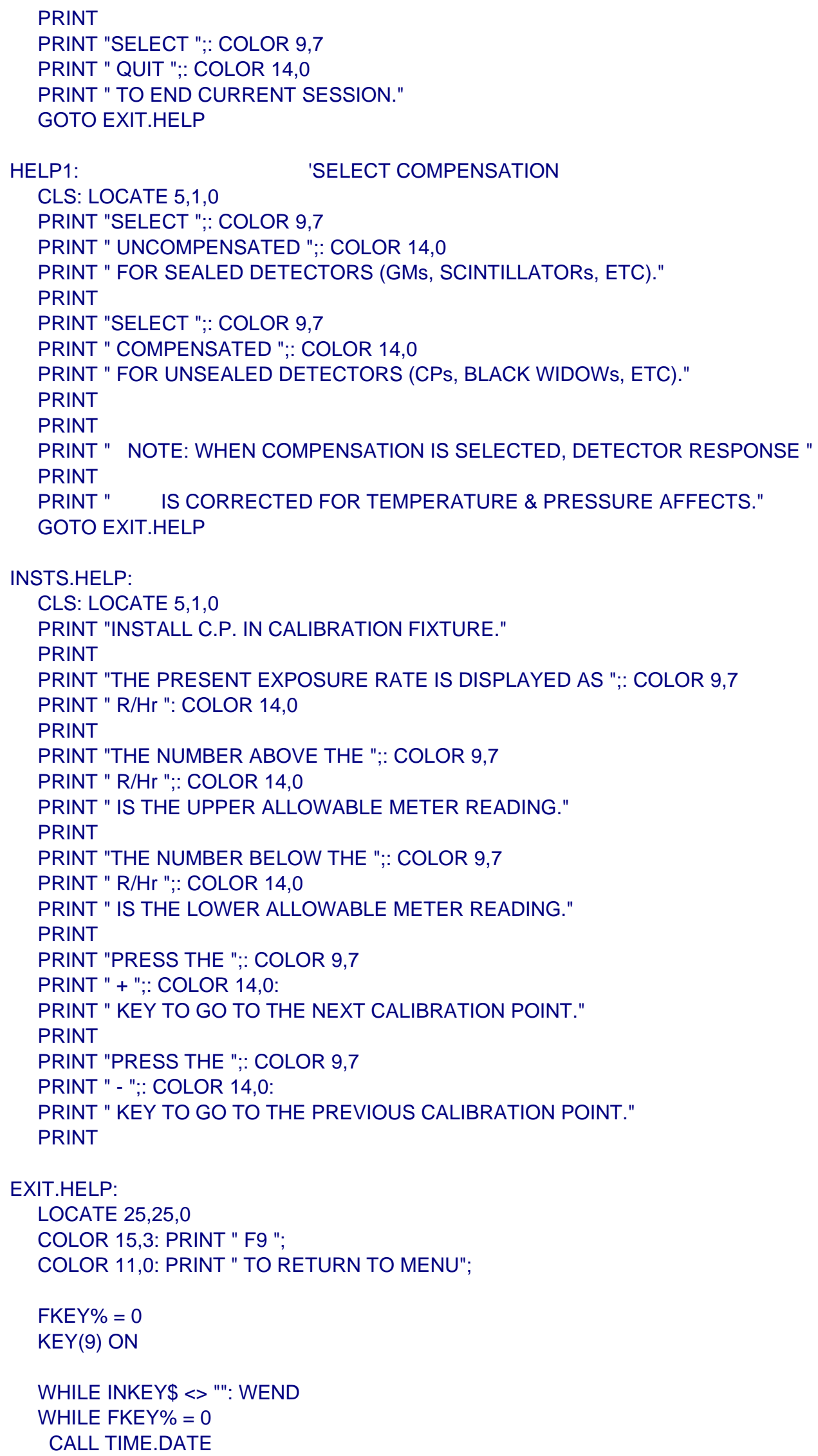




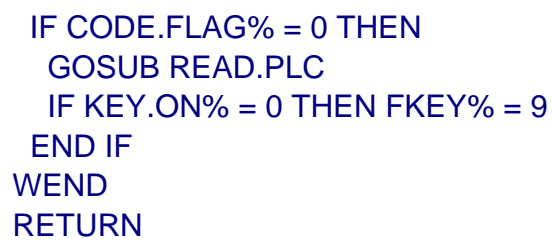

\section{B.2 Data File Entries (Left) and Explanations (Right) for the Control Program}

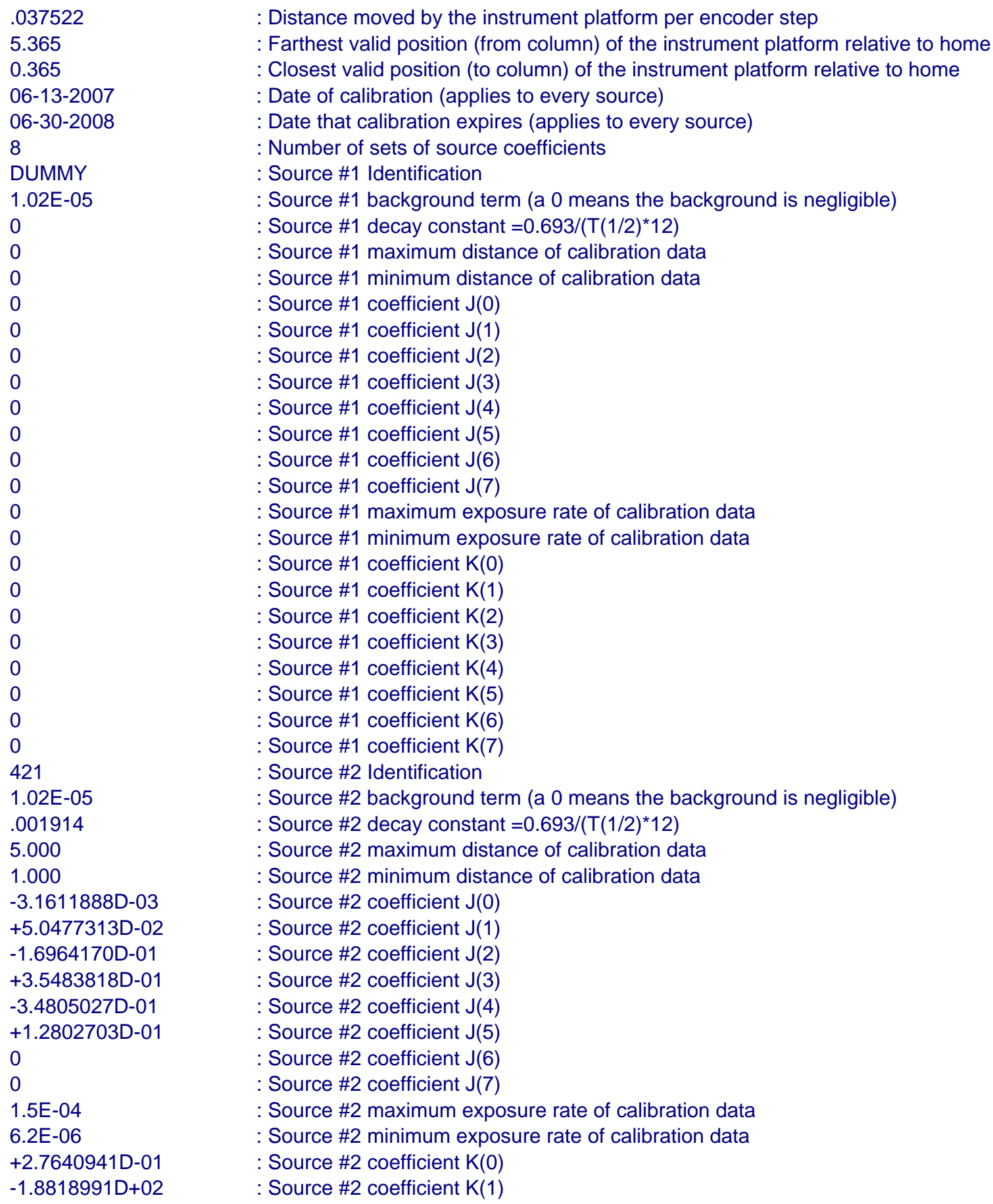

: Distance moved by the instrument platform per encoder step

: Farthest valid position (from column) of the instrument platform relative to home

: Closest valid position (to column) of the instrument platform relative to home

: Date of calibration (applies to every source)

: Date that calibration expires (applies to every source)

: Number of sets of source coefficients

: Source \#1 Identification

: Source \#1 background term (a 0 means the background is negligible)

: Source \#1 decay constant $=0.693 /(T(1 / 2) \star 12)$

: Source \#1 maximum distance of calibration data

: Source \#1 minimum distance of calibration data

: Source \#1 coefficient $\mathrm{J}(0)$

: Source \#1 coefficient J(1)

: Source \#1 coefficient J(2)

: Source \#1 coefficient J(3)

: Source \#1 coefficient J(4)

: Source \#1 coefficient J(5)

: Source \#1 coefficient $\mathrm{J}(6)$

: Source \#1 coefficient J(7)

: Source \#1 maximum exposure rate of calibration data

: Source \#1 minimum exposure rate of calibration data

: Source \#1 coefficient K(0)

: Source \#1 coefficient $K(1)$

: Source \#1 coefficient K(2)

: Source \#1 coefficient K(3)

: Source \#1 coefficient K(4)

: Source \#1 coefficient K(5)

: Source \#1 coefficient K(6)

: Source \#1 coefficient K(7)

: Source \#2 Identification

: Source \#2 background term (a 0 means the background is negligible)

: Source \#2 decay constant $=0.693 /(T(1 / 2) \star 12)$

: Source \#2 maximum distance of calibration data

: Source \#2 minimum distance of calibration data

: Source \#2 coefficient $\mathrm{J}(0)$

: Source \#2 coefficient $\mathrm{J}(1)$

: Source \#2 coefficient J(2)

: Source \#2 coefficient J(3)

: Source \#2 coefficient $\mathrm{J}(4)$

: Source \#2 coefficient J(5)

: Source \#2 coefficient J(6)

: Source \#2 coefficient $\mathrm{J}(7)$

: Source \#2 maximum exposure rate of calibration data

: Source \#2 minimum exposure rate of calibration data

: Source \#2 coefficient $\mathrm{K}(0)$

: Source \#2 coefficient K(1) 


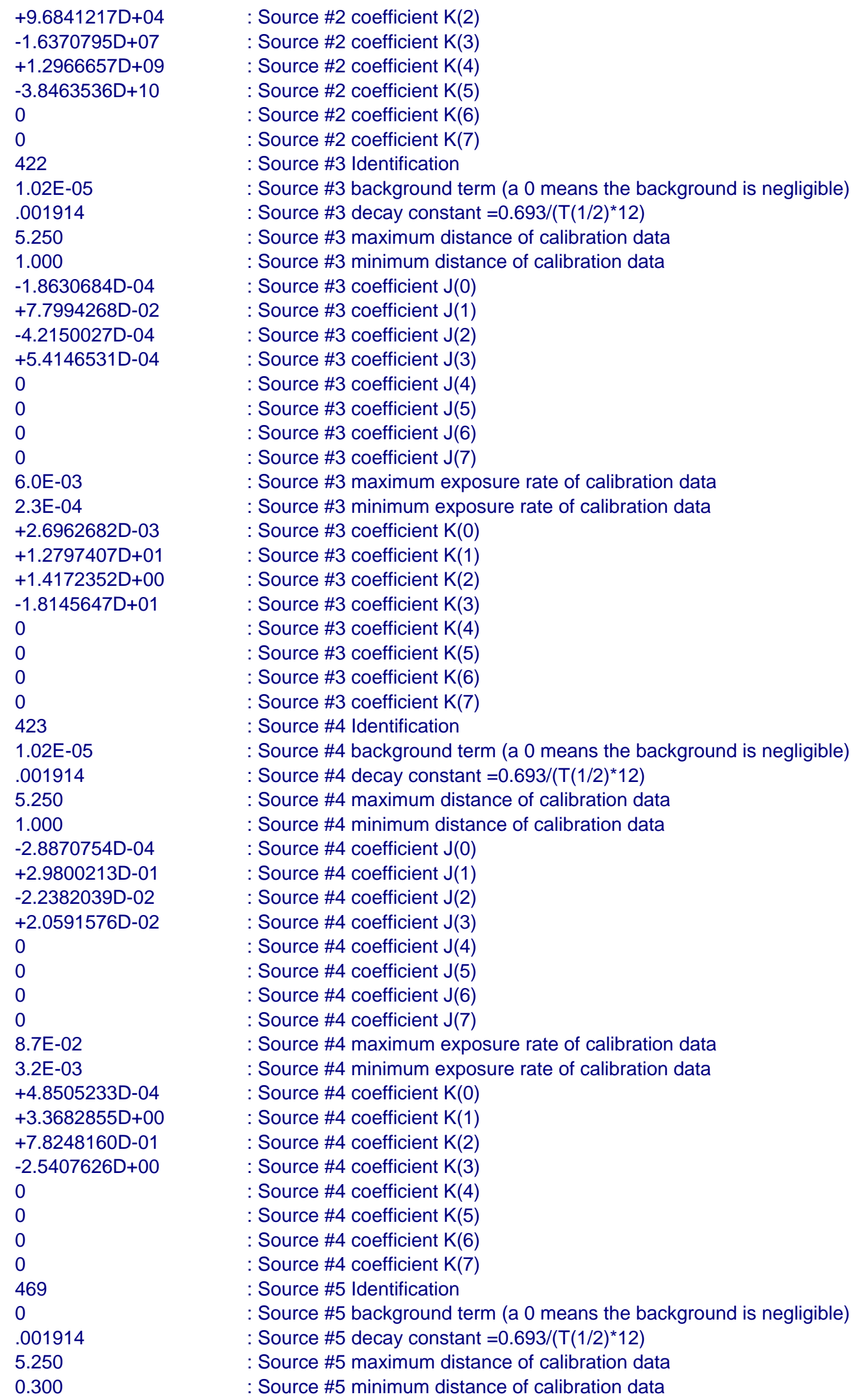




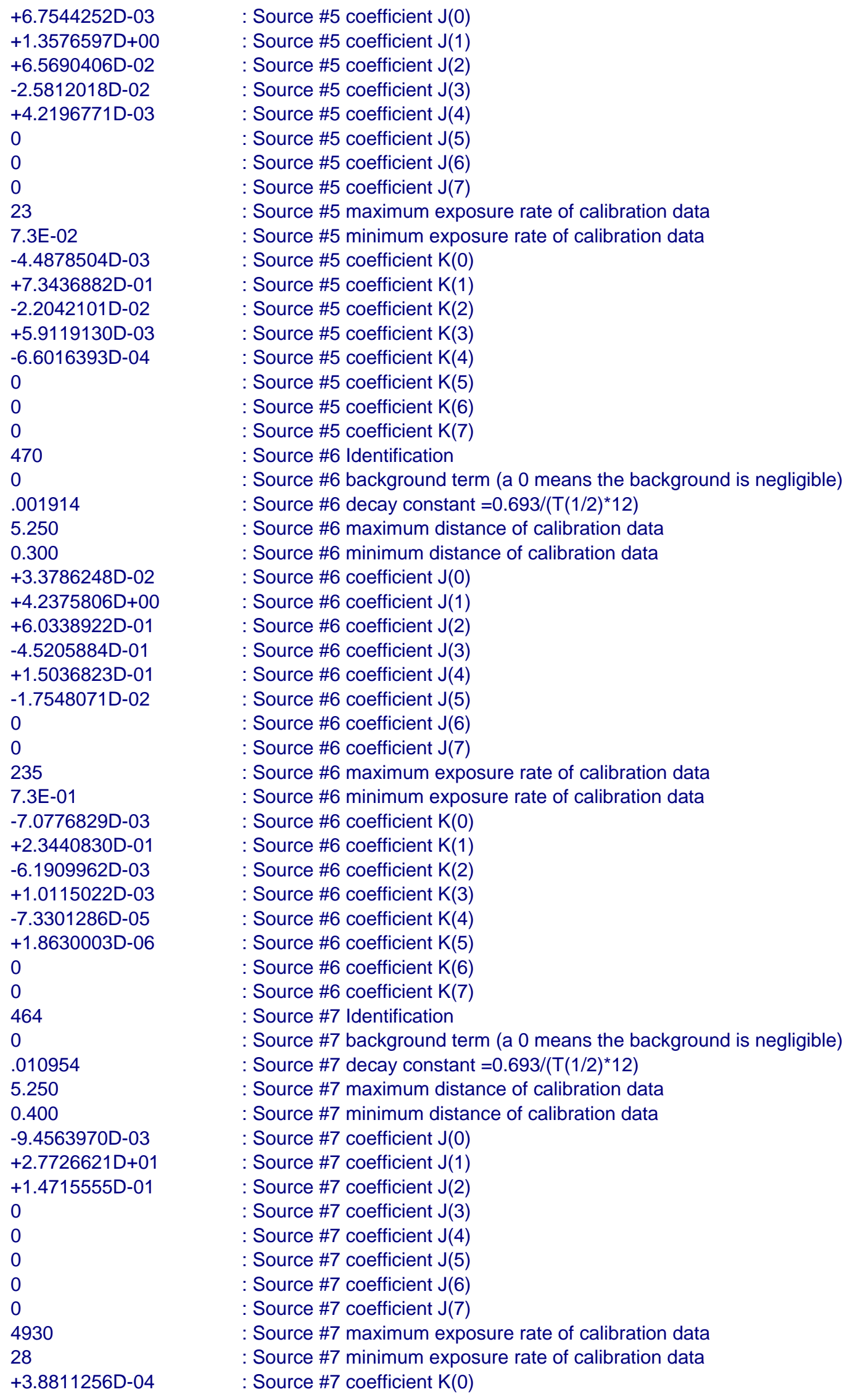




$+3.6058616 \mathrm{D}-02$
$-6.6294390 \mathrm{D}-06$
0
0
0
0
0
420
0
.010954
5.250
0.300
$+1.4473109 \mathrm{D}-01$
$+7.3299013 \mathrm{D}+01$
$+1.2013529 \mathrm{D}+00$
$-3.8515814 \mathrm{D}-01$
$+6.3815235 \mathrm{D}-02$
0
0
0
63200
202
$-1.9010747 \mathrm{D}-03$
$+1.3636703 \mathrm{D}-02$
$-2.8499711 \mathrm{D}-06$
$+1.1974748 \mathrm{D}-08$
$-2.5946869 \mathrm{D}-11$
0
0
0
$B$
0
$0 k$
0
0

Black Widow, 1, XX, 6 7, 40, 44, 36

$1,0,0,0$

7, 100, 110, 90

$7,400,440,360$

7, 1000, OS, OS

$1,0,0,0$ RO-7 (200R/HR), 1, XX,

$7,50.0,55.0,45.0$

$7,150.0,165.0,135.0$

$7,400.0$, OS, OS

$1,0,0,0$ RO-7 (20KR/HR), 1, XX,

$7,50,0.06,0.04$

$1,0,0,0$

$8,500,0.55,0.45$

$8,5000,5.50,4.50$

$8,15000,16.50,13.50$

8, 22000, OS, OS

$1,0,0,0$

RO-20, 1, XX, 3

$7,40,44,36$

7, 100, OS, OS

$1,0,0,0$

WBJ 2000W, 0, XX, 9

$7,80,88,72$

$7,30,33,27$
: Source \#7 coefficient K(1)

: Source \#7 coefficient K(2)

: Source \#7 coefficient K(3)

: Source \#7 coefficient K(4)

: Source \#7 coefficient K(5)

: Source \#7 coefficient K(6)

: Source \#7 coefficient K(7)

: Source \#8 Identification

: Source \#8 background term (a 0 means the background is negligible)

: Source \#8 decay constant $=0.693 /(T(1 / 2) \star 12)$

: Source \#8 maximum distance of calibration data

: Source \#8 minimum distance of calibration data

: Source \#8 coefficient J(0)

: Source \#8 coefficient $\mathrm{J}(1)$

: Source \#8 coefficient $\mathrm{J}(2)$

: Source \#8 coefficient $\mathrm{J}(3)$

: Source \#8 coefficient $\mathrm{J}(4)$

: Source \#8 coefficient J(5)

: Source \#8 coefficient J(6)

: Source \#8 coefficient $\mathrm{J}(7)$

: Source \#8 maximum exposure rate of calibration data

: Source \#8 minimum exposure rate of calibration data

: Source \#8 coefficient K(0)

: Source \#8 coefficient K(1)

: Source \#8 coefficient K(2)

: Source \#8 coefficient $\mathrm{K}(3)$

: Source \#8 coefficient K(4)

: Source \#8 coefficient K(5)

: Source \#8 coefficient K(6)

: Source \#8 coefficient K(7)

: Instrument routine \#1 name, temp \& pres comp flag, dummy, \# of cal points : Instrument routine \#1 source \# (1 = pause), cal point, hi limit, lo limit : Instrument routine \#1 source \# (1 = pause), cal point, hi limit, lo limit : Instrument routine \#1 source \# (1 = pause), cal point, hi limit, lo limit : Instrument routine \#1 source \# (1 = pause), cal point, hi limit, lo limit : Instrument routine \#1 source \# (1 = pause), cal point, hi limit, lo limit : Instrument routine \#1 source \# (1 = pause), cal point, hi limit, lo limit : Instrument routine \#2 name, temp \& pres comp flag, dummy, \# of cal points : Instrument routine \#2 source \# (1 = pause), cal point, hi limit, lo limit : Instrument routine \#2 source \# (1 = pause), cal point, hi limit, lo limit : Instrument routine \#2 source \# (1 = pause), cal point, hi limit, lo limit : Instrument routine \#2 source \# (1 = pause), cal point, hi limit, lo limit

: Instrument routine \#3 name, temp \& pres comp flag, dummy, \# of cal points : Instrument routine \#3 source \# (1 = pause), cal point, hi limit, lo limit : Instrument routine \#3 source \# (1 = pause), cal point, hi limit, lo limit : Instrument routine \#3 source \# (1 = pause), cal point, hi limit, lo limit : Instrument routine \#3 source \# (1 = pause), cal point, hi limit, lo limit : Instrument routine \#3 source \# (1 = pause), cal point, hi limit, lo limit : Instrument routine \#3 source \# (1 = pause), cal point, hi limit, lo limit : Instrument routine \#3 source \# (1 = pause), cal point, hi limit, lo limit : Instrument routine \#4 name, temp \& pres comp flag, dummy, \# of cal points : Instrument routine \#4 source \# (1 = pause), cal point, hi limit, lo limit : Instrument routine \#4 source \# (1 = pause), cal point, hi limit, lo limit : Instrument routine \#4 source \# (1 = pause), cal point, hi limit, lo limit : Instrument routine \#5 name, temp \& pres comp flag, dummy, \# of cal points : Instrument routine \#5 source \# (1 = pause), cal point, hi limit, lo limit : Instrument routine \#5 source \# (1 = pause), cal point, hi limit, lo limit 
$1,0,0,0$

$8,800,880,720$

$1,0,0,0$

$7,200,220,180$

$1,0,0,0$

8, 2000, OS, OS

$1,0,0,0$

$6112 \mathrm{~B}, 0, \mathrm{XX}, 8$

$7,40,44,36$

$1,0,0,0$

$7,200,220,180$

$7,400,440,360$

$7,500,550,450$

$7,750,825,675$

7, 2000, OS, OS

$1,0,0,0$

6150 AD 2, 0, XX, 6

$7,40,44,36$

$7,80,88,72$

$7,400,440,360$

$7,800,880,720$

7,2000, OS, OS

$1,0,0,0$

Xetex 330A, 0, XX, 9

$7,800,880,720$

$1,0,0,0$

$7,30,33,27$

$7,80,88,72$

$1,0,0,0$

7, 200, 220, 180

$1,0,0,0$

8,5000, OS, OS

$1,0,0,0$
: Instrument routine \#5 source \# (1 = pause), cal point, hi limit, lo limit : Instrument routine \#5 source \# (1 = pause), cal point, hi limit, lo limit : Instrument routine \#5 source \# (1 = pause), cal point, hi limit, lo limit : Instrument routine \#5 source \# (1 = pause), cal point, hi limit, lo limit : Instrument routine \#5 source \# (1 = pause), cal point, hi limit, lo limit : Instrument routine \#5 source \# (1 = pause), cal point, hi limit, lo limit : Instrument routine \#5 source \# (1 = pause), cal point, hi limit, lo limit : Instrument routine \#6 name, temp \& pres comp flag, dummy, \# of cal points : Instrument routine \#6 source \# (1 = pause), cal point, hi limit, lo limit : Instrument routine \#6 source \# (1 = pause), cal point, hi limit, lo limit : Instrument routine \#6 source \# (1 = pause), cal point, hi limit, lo limit : Instrument routine \#6 source \# (1 = pause), cal point, hi limit, lo limit : Instrument routine \#6 source \# (1 = pause), cal point, hi limit, lo limit : Instrument routine \#6 source \# (1 = pause), cal point, hi limit, lo limit : Instrument routine \#6 source \# (1 = pause), cal point, hi limit, lo limit : Instrument routine \#6 source \# (1 = pause), cal point, hi limit, lo limit : Instrument routine \#7 name, temp \& pres comp flag, dummy, \# of cal points : Instrument routine \#7 source \# (1 = pause), cal point, hi limit, lo limit : Instrument routine \#7 source \# (1 = pause), cal point, hi limit, lo limit : Instrument routine \#7 source \# (1 = pause), cal point, hi limit, lo limit : Instrument routine \#7 source \# (1 = pause), cal point, hi limit, lo limit : Instrument routine \#7 source \# (1 = pause), cal point, hi limit, lo limit : Instrument routine \#7 source \# (1 = pause), cal point, hi limit, lo limit : Instrument routine \#8 name, temp \& pres comp flag, dummy, \# of cal points : Instrument routine \#8 source \# (1 = pause), cal point, hi limit, lo limit : Instrument routine \#8 source \# (1 = pause), cal point, hi limit, lo limit : Instrument routine \#8 source \# (1 = pause), cal point, hi limit, lo limit : Instrument routine \#8 source \# (1 = pause), cal point, hi limit, lo limit : Instrument routine \#8 source \# (1 = pause), cal point, hi limit, lo limit : Instrument routine \#8 source \# (1 = pause), cal point, hi limit, lo limit : Instrument routine \#8 source \# (1 = pause), cal point, hi limit, lo limit : Instrument routine \#8 source \# (1 = pause), cal point, hi limit, lo limit : Instrument routine \#8 source \# (1 = pause), cal point, hi limit, lo limit 


\section{Appendix C - Diagnostic Software Programs}





\section{Appendix C - Diagnostic Software Programs}

Carousel.exe and Instplat.exe are diagnostic programs that diagnose communication and control problems. These were created by writing a compiler input; PowerBASIC for DOS version 3.5 then generated the executable programs.

\section{C.1 Carousel.exe}

Carousel.exe is a program that allows the facility control computer to eavesdrop on the ASCII strings sent between the carousel drive/indexer and the PLC for diagnosing communication and control problems. It can also be used to send diagnostic commands from the facility control computer to the carousel drive stepper motor drive/indexer, if the communication wiring were reconfigured, by changing the position of a slide switch (Figure C.1) from the PLC to the facility control computer position. In this configuration only the facility control computer can send commands (and not the PLC) to the carousel drive/indexer. This switch can be located by opening the upper right-hand panel on the control panel and finding the switch on the side of the backshell of the DB9 connector pair inline in the cable coming from port 2 of the PLC. To understand which hot keys send which commands, refer to the program listing below. To understand the function of the commands themselves, refer to Compmotor's OEM Series Software Reference Guide Microstepper Products OEM650X/OEM350X/ OEM010 (1993). Remember, however, that to restore the normal operation of the facility, the switch must be returned to the PLC position. If it is not, the PLC will not have control of the carousel and an operator will receive a source select fail alarm.

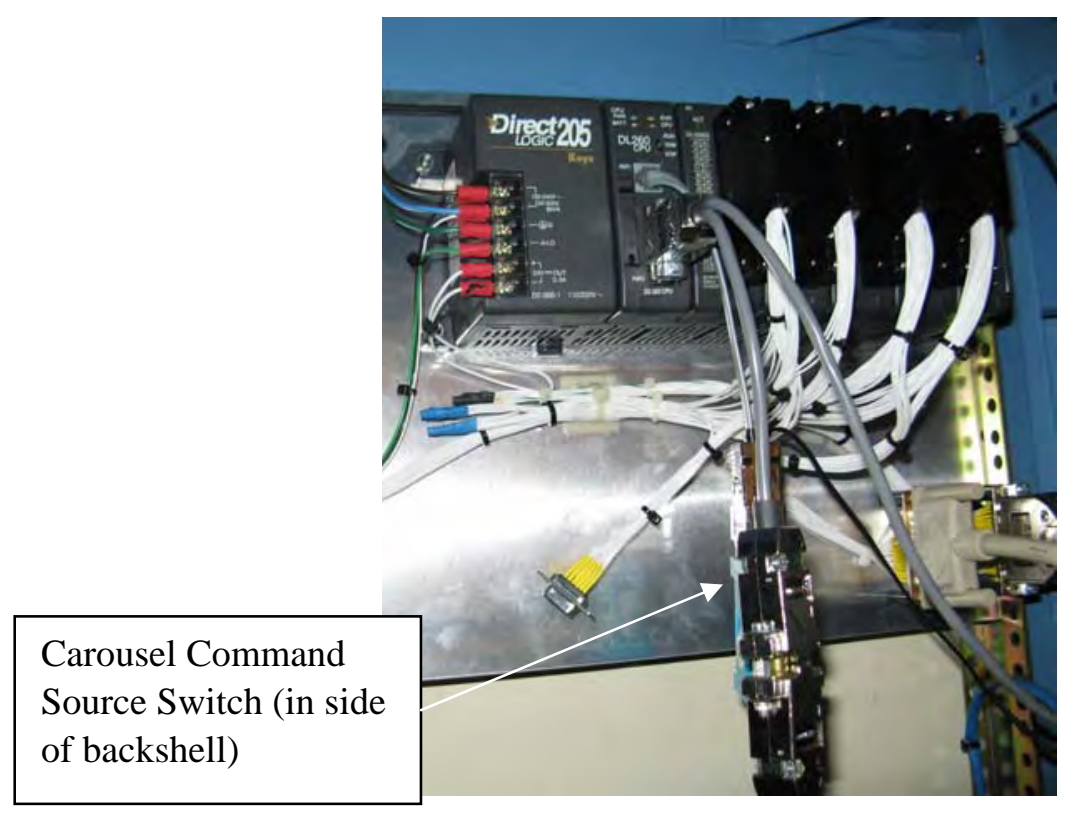

Figure C.1. Location of Carousel Command Source Switch 


\section{C.1.1 Carousel.exe Compiler Input}

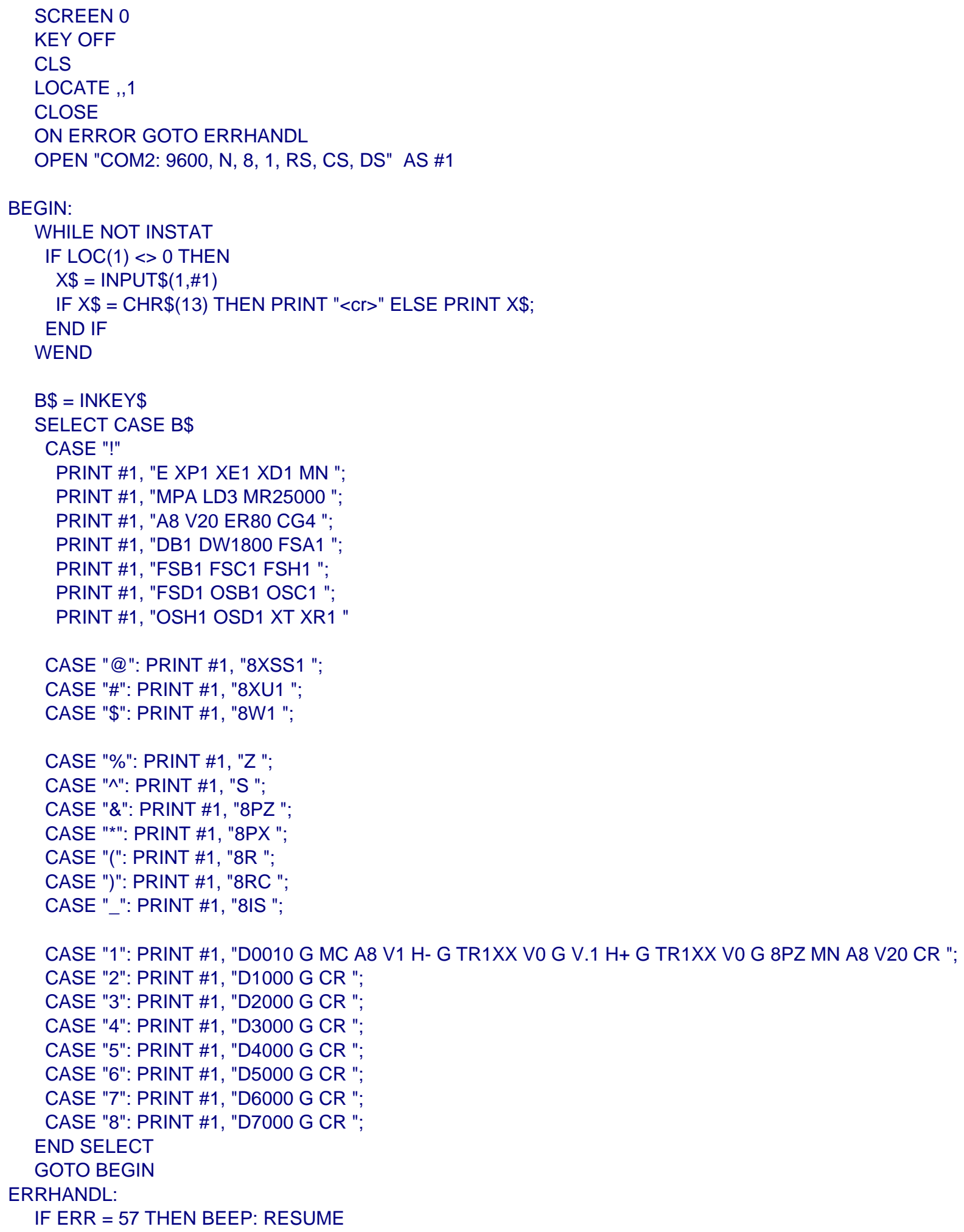




\section{C.2 Insplat.exe}

Instplat.exe is a program that can be used to send commands to the instrument platform drive/indexer and receive replies from it for diagnostic and testing purposes. It is run in the same manner as carousel.exe.

\section{C.2.1 Instplat.exe Compiler Input}

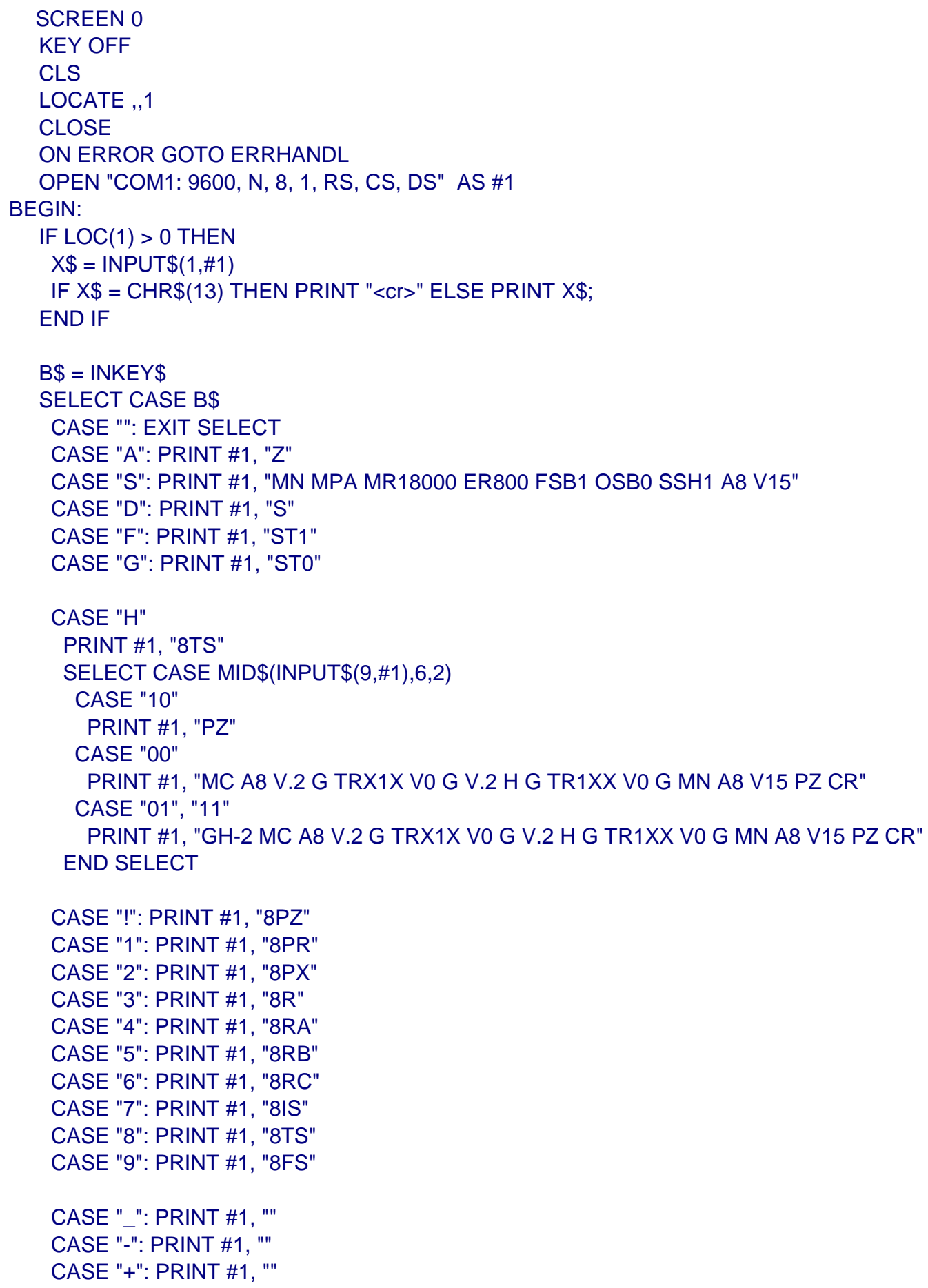




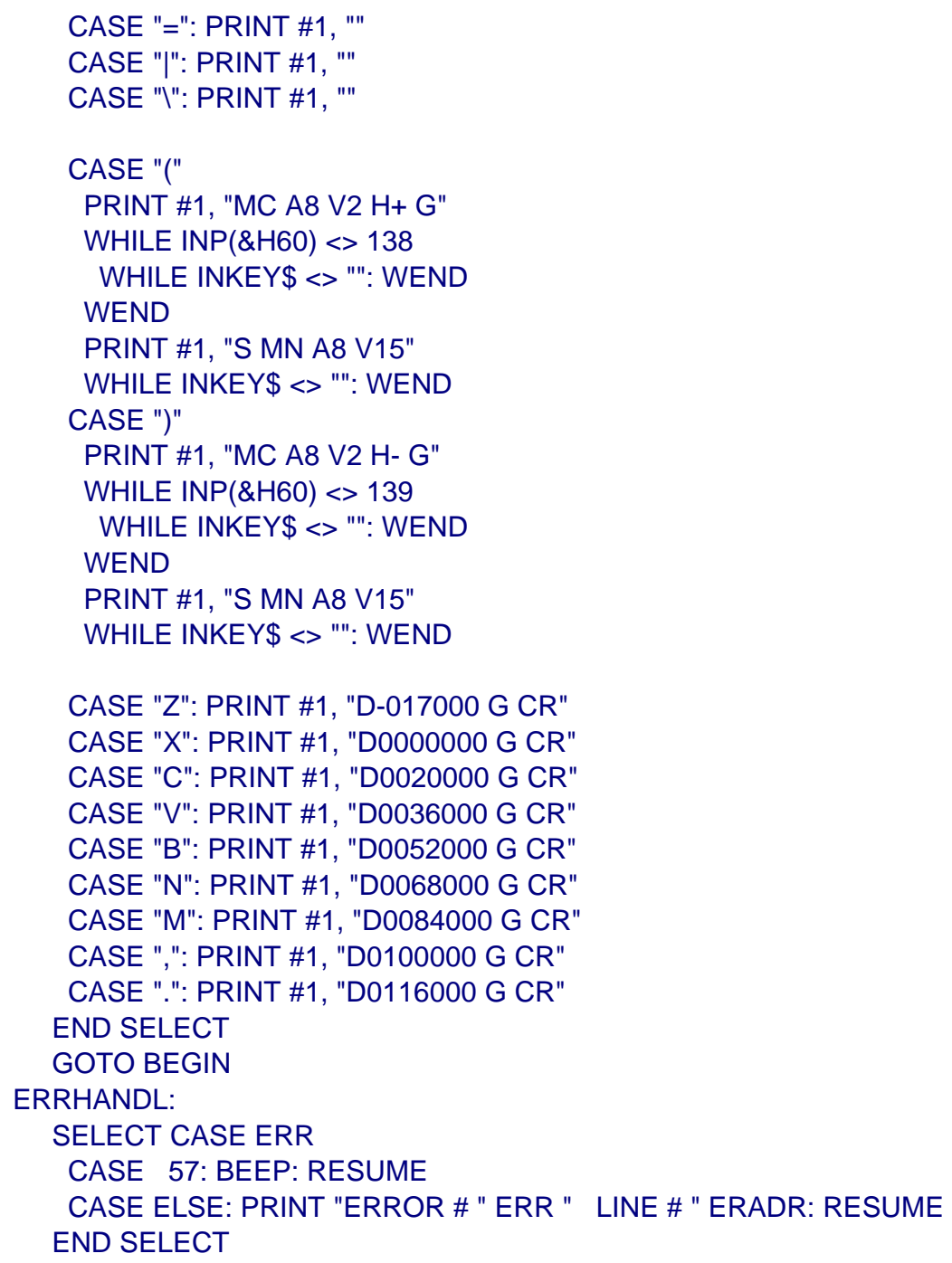

\section{C.3 References}

Compumotor. 1993. OEM Series Software Reference Guide Microstepper Products OEM650X/OEM350X/OEM010. 88-013785-01, Rev A. Rohnert Park, California. 


\section{Distribution}

No. of

$\underline{\text { Copies }}$

\section{OFFSITE}

A. K. Smith

330 Sunset View Lane

Pasco, WA 99301

ONSITE

DOE Pacific Northwest Site Office

R. L. Higgins $\quad$ K9-42

DOE Richland Operations Office

G. Z. Morgan
No. of

$\underline{\text { Copies }}$

15 Pacific Northwest National Laboratory

R. K. Berg (2)

P7-01

G. L. Carter (4) (CD)

P7-01

T. D. Eaton

J2-40

R. J. Ford

J2-40

M. S. Hanson

K9-02

M. L. Johnson

P7-01

M. K. Murphy

P7-01

K. L. Soldat

K3-53

A. R. Stithem

J2-38

Hanford Technical Library (2) 